\title{
Implementação, Adaptação, Combinação e Avaliação de Etiquetadores para o Português do Brasil
}

\author{
Rachel Virginia Xavier Aires
}

Orientadora: Profa. Dra. Sandra Maria Aluísio

Dissertação apresentada ao Instituto de Ciências Matemáticas e de Computação - ICMC-USP, como parte dos requisitos para obtenção do título de Mestre em Ciências - Área: Ciências de Computação e Matemática Computacional.

USP - São Carlos

Setembro de 2000 
Última flor do Lácio, inculta e bela, És, a um tempo, esplendor e sepultura; Ouro nativo, que, na ganga impura, A bruta mina entre os cascalhos vela...

Amo-te assim, desconhecida e obscura, Tuba de alto clangor, lira singela, Que tens o trom e o silvo da procela, E o arrolo da saudade e da ternura!

Amo o teu viço e o teu aroma De virgens selvas e de oceanos largos! Amo-te, ó rude e doloroso idioma,

Em que da voz materna ouvi: "meu filho!" E ern que Camōes chorou, no exilio amargo, $O$ gênio sern ventura e o amor sem brilho!

Língua Portuguesa - Olavo Bilac 
Chos mestres da minha vida - vosinka, wovb Diana, wâ Goq, wâ Qitox, wâ Llaviex, mamàe, papai, nana, tia Boxalia, Dinda, Dada, tis Ditox, tios, tias, priminhos e furminhas -, que a mim dedisaxam tantos alhases. 


\section{AGRADECIMENTOS}

Tentar tornar-se mestre em uma determinada área é uma tarefa sem dúvida alguma cansativa. No entanto, ao longo destes dois anos, com muita ajuda, o que era um simples mestrado em computação, transcendeu esta conotação e se tornou delicioso e enriquecedor. Parecia uma conspiraçăo do Universo para que tudo desse certo. Em 1998 lá estava eu fazendo mestrado na USP, na área dos meus sonhos, já com alguns amigos, é claro que em um vilarejo, mas nada é perfeito, nem mesmo uma conspiração do Universo. É por tudo ter dado tăo certo, quer dizer, quase tudo, que sou grata por tudo que aconteceu e a todos que passaram pela minha vida nestes anos. Em especial agradeço:

(:) a Deus por ter traçado para mim um lindo caminho, colocando a natureza a minha frente quando necessário para me tranquilizar, permitindo que nunca perdesse a esperança;

(:) aos meus pais e à minha maninha pelo colo, pelo carinho que conforta e dá ânimo;

(:) aos amigos de Goiânia que não me esqueceram apesar da distância, em particular a amizade incondicional da Ludi, Ceci, Érika e Túlius;

()) à família do Labic que me acolheu com todo carinho;

(-) ao prazer de ter uma orientadora amiga;

(:) aos amigos de Goiânia que vieram pra cá na mesma época e compartilharam das mesmas saudades - Katinha e Cláudio; 
(-) aos amigos que me apresentaram a USP e a cidade - Nilda, Luiz Carlos, Marco, Ernesto (Tio) e Paulo:

(-) aos amigos bons ouvintes que fiz aqui como o Má, a Ângela e a Dê;

(-) à torcida fofíssima do Alan, da Gio e do Le;

(i) aos amigos do Nilc;

(-) aos demais amigos, mas não menos importantes - Ana Paula, Mariane, Bléia, Chavas, Marquinhos, Daniele, Rosália, Calebe, Xico, Du, Adriano e Leo;

(i) ao apoio moral do Chú;

(:) às fadas e magos do português do Nilc que de alguma forma trabalharam neste projeto - Ana Cláudia, Denise, Gisele, Raquel e Ronaldo;

(:) ao Márcio, um aluno de inciação científica fabuloso, que trabalhou em finais de semana e nas férias com a maior boa vontade (e a Tati por não ter se importado com tanta hora-extra):

(:) ao King Ma por ter fornecido o código do etiquetador neural elástico;

(-) à Eric Brill, Helmut Schimid e a todos da lista corpora@hd.uib.no por terem tirado minhas dúvidas por email

(:) ao superapoio técnico dos amigos: Walter, Robson, Cláudio Hirosi, IA, Ju (dona da BDL) e Renatinho;

(:) à ajuda da Christie, Mônica e Ariane que foram diversas vezes importunadas com perguntas do tipo isso escreve assim, assim fica mais bonito, essa ou essa fonte;

()) à ajuda da Daniela que tirou várias dúvidas mesmo me ouvindo falar tão mal de São Carlos;

(i) à ajuda da mica Andréia com redes neurais;

(-) à ajuda com estatística dos professores Jorge e Creusa;

(-) às conversas com a professora Carolina sobre classificadores e técnicas estatísticas de avaliação;

(-) ao apoio financeiro do CNPQ e da Intelligenesis;

(-) à paciência da Intelligenesis em esperar pelos relatórios;

(:) a todos os outros com quem convivi - o pessoal da seção da pós, porteiros, faxineiras, o pessoal da lanchonete, da biblioteca, etc.;

(:) e à péssima programação da TV que me fez ficar mais tempo no laboratório. 


\section{ÍNDICE}

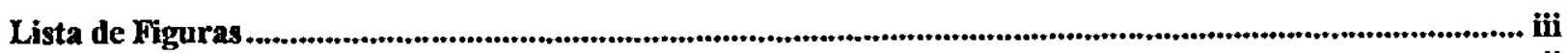

Lista de Tabelas...................................................................................................................................................... vii

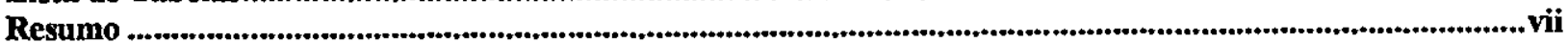

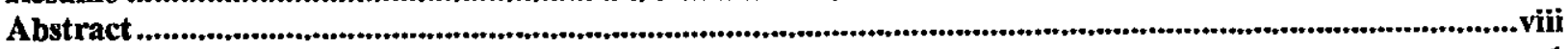

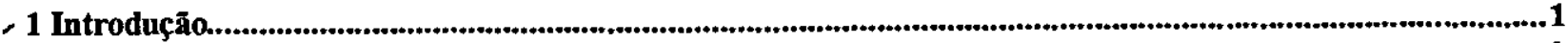

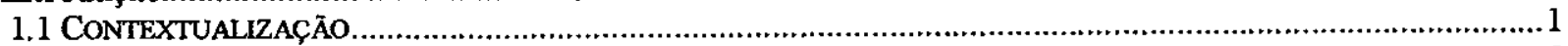

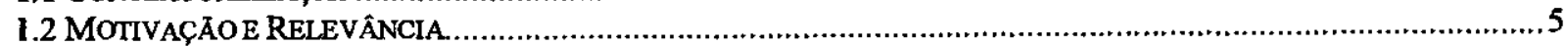

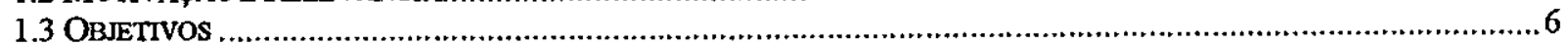

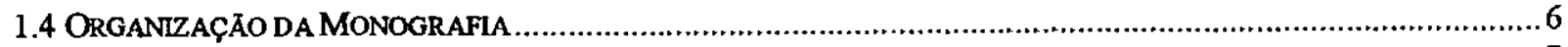

2 Etiquetadores de texto

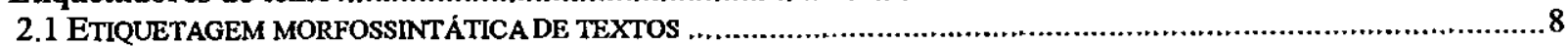

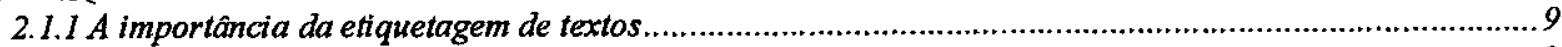

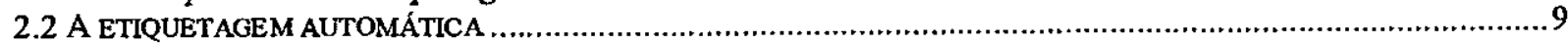

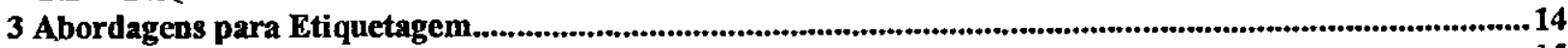

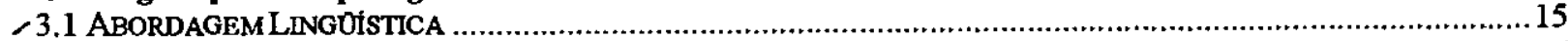

3.1.1 Etiquetador baseado em sintaxe.

3.1.2 Etiquetador baseado em restriçöes ................................................................................................ 18

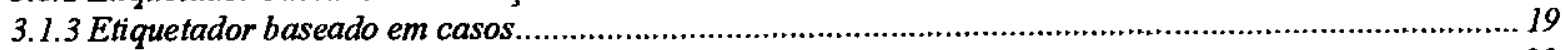

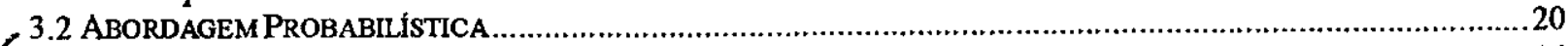

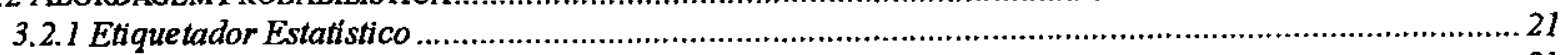

3.2.1.1 Xerox HMM

3.2.1.2 Um Etiquetador estatístico de categorias morfossintáticas para o português .....................................................22

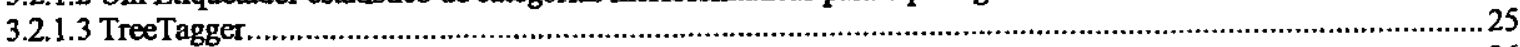

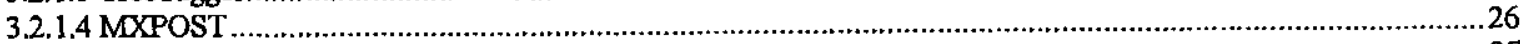

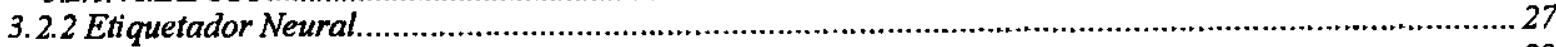

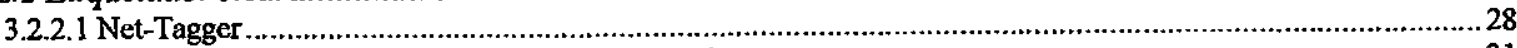

3.2.2.2 Etiquetador Neural da Universidade Nova de Lisboa.................................................................................... 31

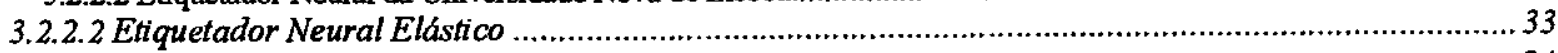

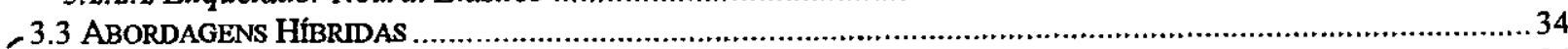

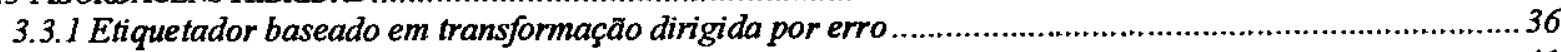

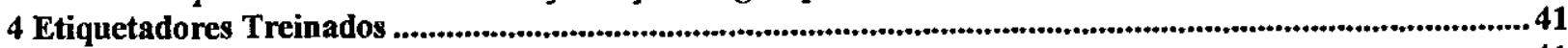

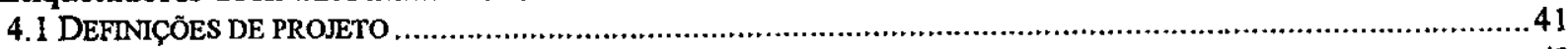

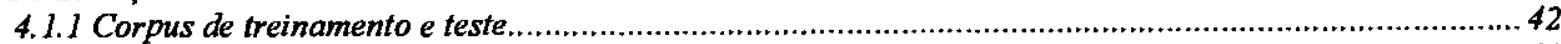

4.1.1.1 Etiquetagem manual de um corpus de treinamento e teste ............................................................................. 44

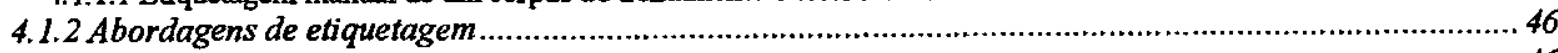

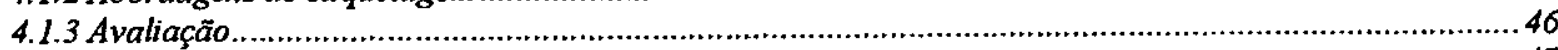

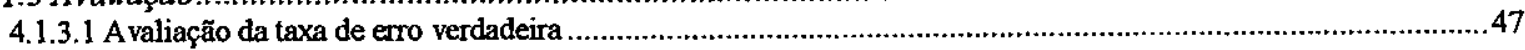




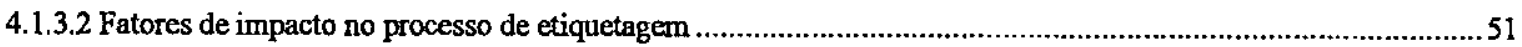

4.2 RESULTADOS DOS EXPERIMENTOS COM OS ETIQUETADORES INDIVIDUAIS..................................................52

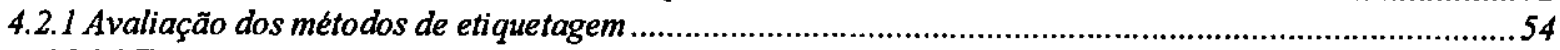

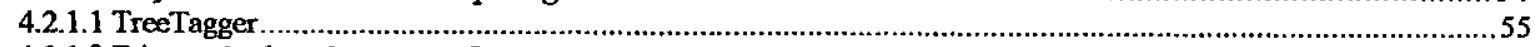

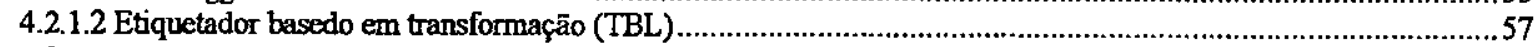

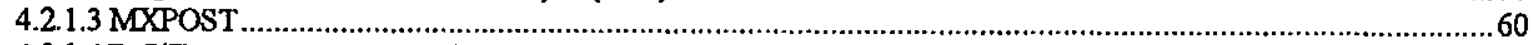

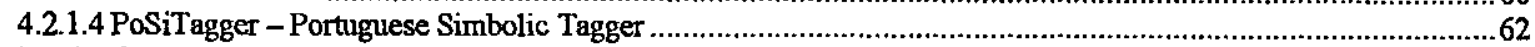

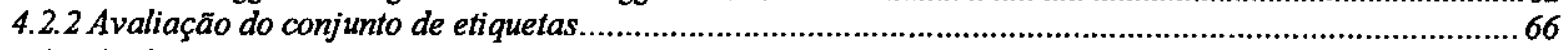

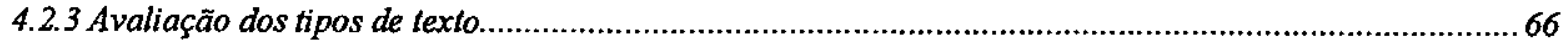

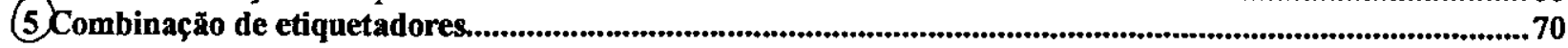

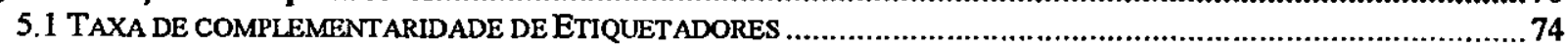

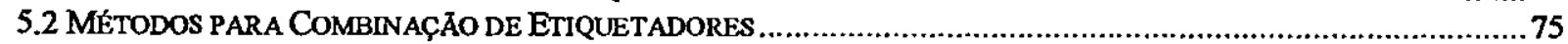

5.2.1 Métodos paralelos baseados em diferentes algoritmos com um único conjunto de dados de treinamento 76

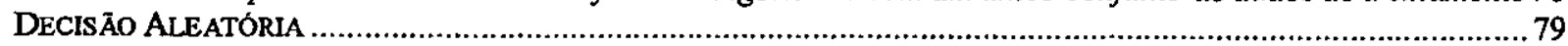

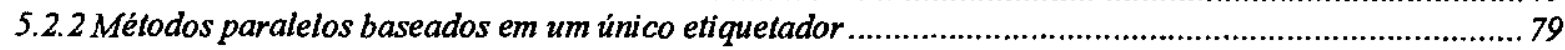

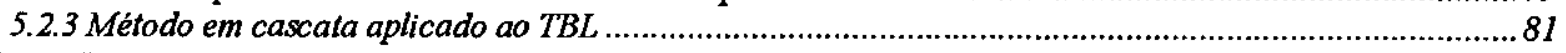

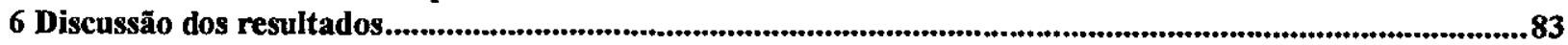

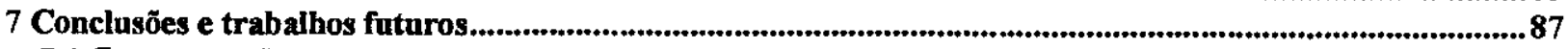

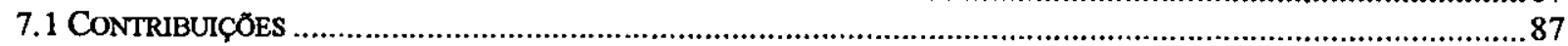

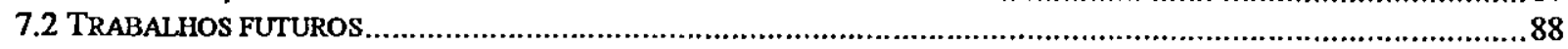

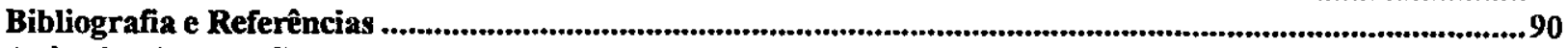

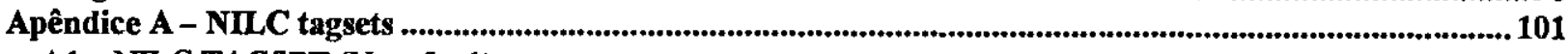

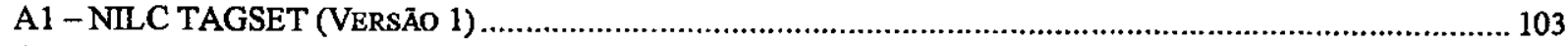

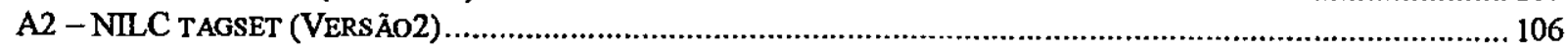

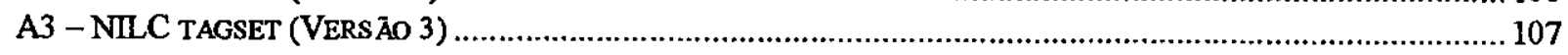

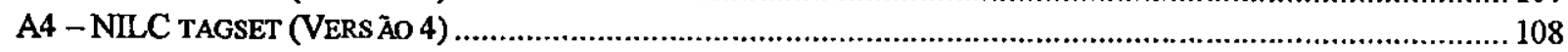

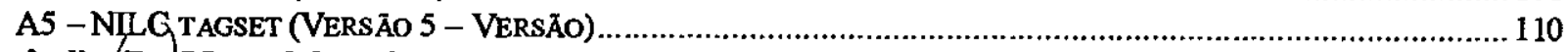

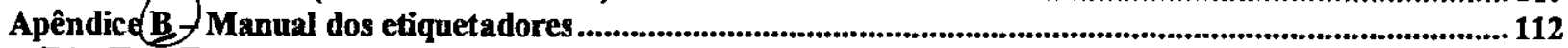

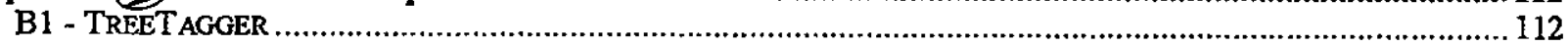

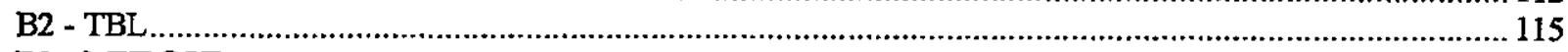

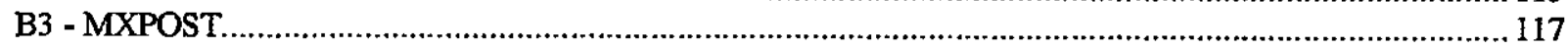

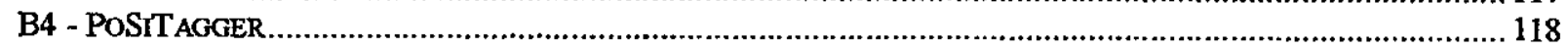

Apêndice C - Regras para desambigüizacão gramatical.........................................................................119

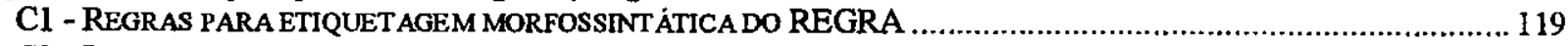

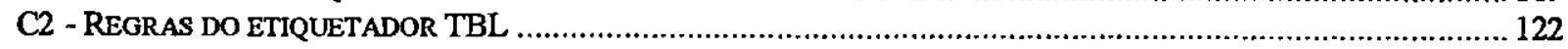

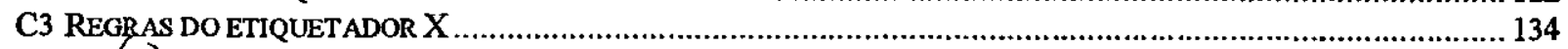

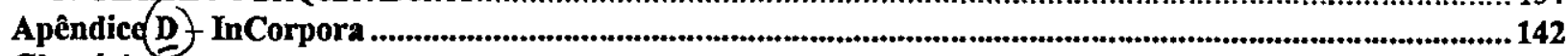

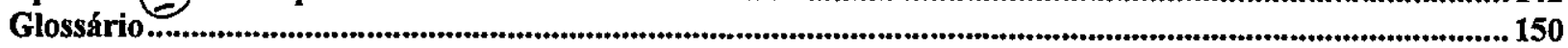




\section{LISTA DE FIGURAS}

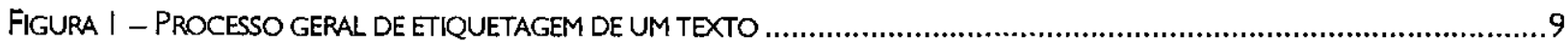

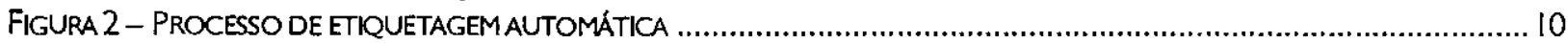

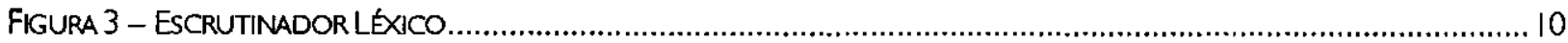

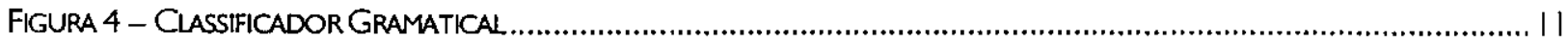

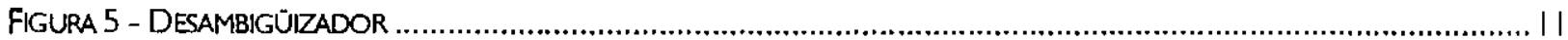

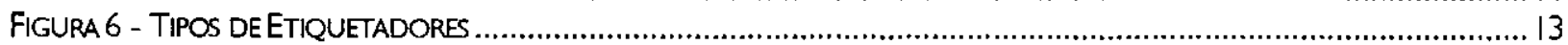

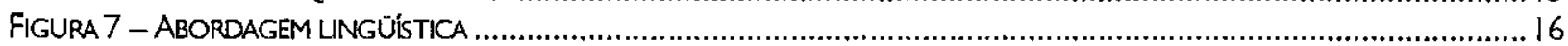

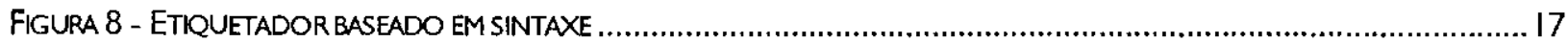

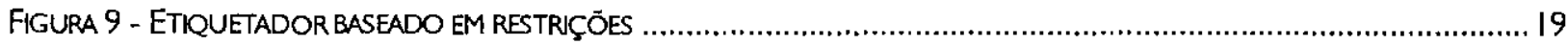

FIGURA 10 - ETIQUETADOR ESTATÍSTICO - MÓDULO DE TREINAMENTO ..................................................................

FIGURA II -ARQUTETURA DO ETIQUETADOR ESTATISTICO DE CATEGORIAS MORFOSSINTÁTICAS PARA O PORTUGUÊS

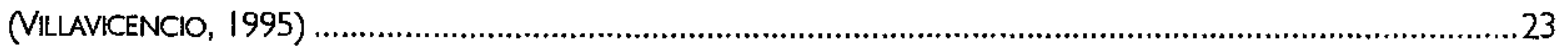

FIGURA I2 -MÓDULO CLASSIFICADOR DO ETIQUETADOR ESTATISTICO DE CATEGORLAS MORFOSSINTÁTICAS PARA O PORTUGUÊS

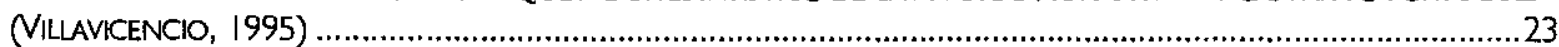

FIGURA 13 - MÓDULO CONSTRUTOR DO ETTQUETADOR ESTATÍSTICO DE CATEGORLAS MORFOSSINTÁTICAS PARA O PORTUGUÉS

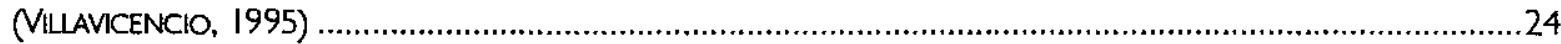

FIGURA 14 - MÓDULO DE VITERBI DO ETRUUETADOR ESTATÍSTICO DE CATEGORIAS MORFOSSINTÁTICAS PARA O PORTUGUÉS

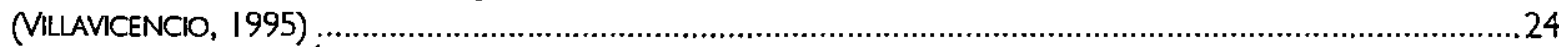

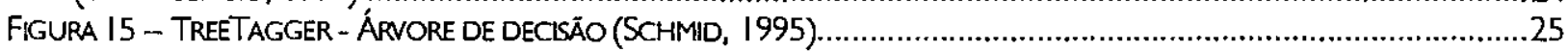

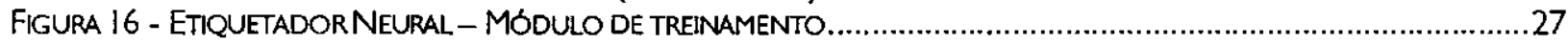

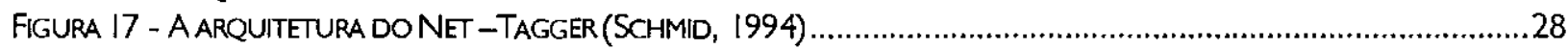

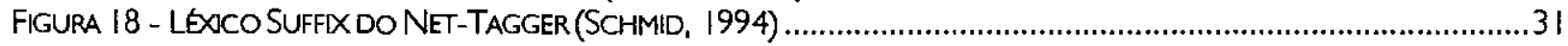

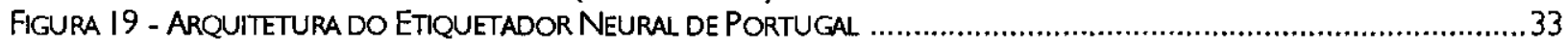

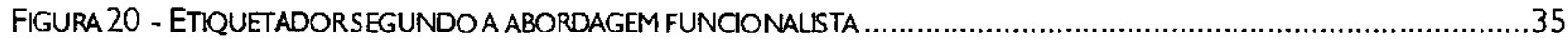

FIGURA 21 - ALGORTMO DE APRENDIZADO BASEADO EM TRANSFORMAÇĀO DIRIGIDA POR ERRO …...................................36

FIGURA 22 - EXEMPLO DE APRENDIZADO BASEADO EM TRANSFORMAÇÄO DIRIGIDA POR ERRO (BRULL, 1994A) .....................38

FiGURA 23 - ETIQUETADOR BASEADO EM TRANSFORMACÃO DIRIGIDA POR ERRO: TREINAMENTO DO ETLUETADOR INICIAL.....38

FIGURA 24 - ETIQUETADOR BASEADO EM TRANSFORMAÇÃO DIPUGIDA POR ERRO: ETIQUETADOR CONTEXTUAL .......................39

FIGURA 26 - PRECISĀO POR ETIQUETAS EM GRUPOS - TREETAGGER .................................................................5

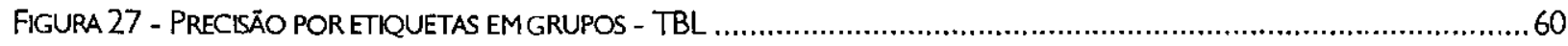

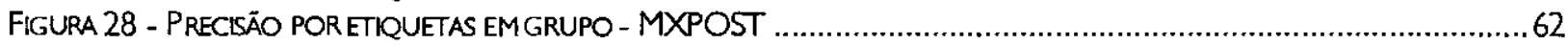

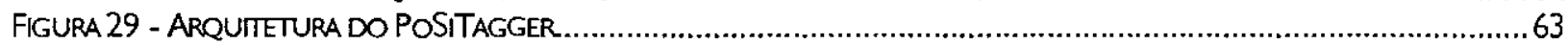

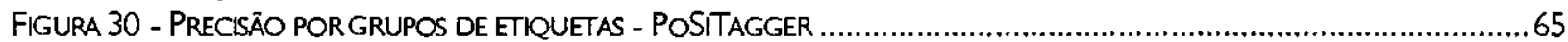


Figura 31 - Precisão por etilueta dos EtiQuetadores TreeTAGger, TBL, MXPOST E PoSitagGer.........................66

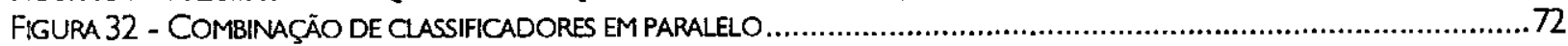

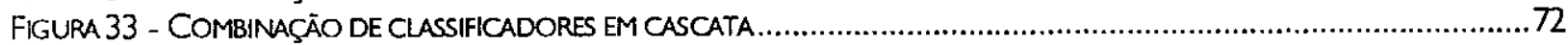

FIGURA 34 - COMBINAÇÄO HIERÁRQUICA DE CLASSIFICADORES .........................................................................72

FIGURA 35 - MÉTODOS PARA COMBINARAS SAIDAS EM UM MODELO PARALELO …........................................................76

FIGURA 36 - ALGORTMOS DE VOTAÇĀO SIMPLES E PONDERADA PARA A ETIQUETAGEM MORFOSSINTÁTICA ...........................77

FIGURA 37 - REGRAS PARA PÓS-PREOCESSAMENTO DE ÉNCLISES E MESÓCLISES ................................................................. 85

FIGURA 38 - FLUXO DE DADOS NO TREINAMENTO E ETIQUETAGEM COM O ETRUETADOR TREETAGGER .......................... 114

FIGURA 39 - FLUXO DE DADOS NO TREINAMENTO COMO ETIQUETADOR TBL ...................................................... 117

FIGURA 40 - FLUXO DE DADOS NO TREINAMENTO E ETIQUETAGEM COMO ETৎUETADOR MXPOST .............................. 118

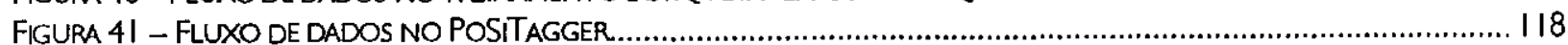




\section{LISTA DE TABELAS}

TABELA 1 - REgRAS DE CONTEXTO Do ETIQUETADOR BASEADO EM TRANSFORMAÇĀo DIRIGIDA POR ERRO ..............39

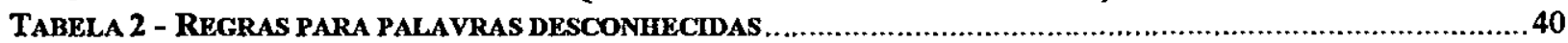

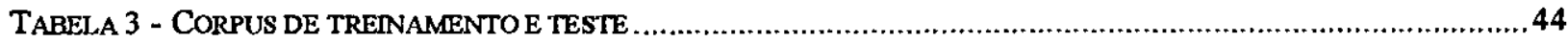

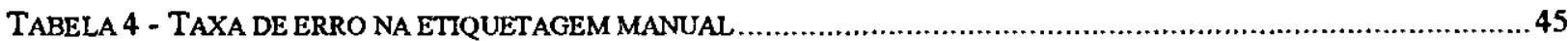

TABELA 5 - COMPARAÇÃO ENTRE HOLDOUT E RANDOM SUBSAMPLING (BATISTA \& MONARD, 1998) .......................49

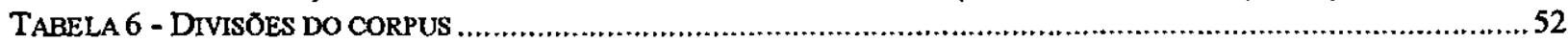

TABELA 7 - TAXAS DE AMBIGOIDADE NAS DIVISOES DO CORPUS ....................................................................5 53

TABELA 8 - PORCENTAGEM DE PALAVRAS DESCONHECIDAS ........................................................................54

TABELA 9 - PRECISĀo GERAL DO ETIQUETADOR TREETAGGER …......................................................................55

TABELA 10 - TEMPOS DE TREINAMENTO ETIQUETAGEM - TREETAGGER................................................................56

TABELA 11 - PRECISÃO POR ETIQUETA NO CORPUS DE TESTE - TREETAGGER COMO TRIGRAMA ................................56

TABELA 12 - TEMPO DE TREINAMENTO E ETIQUETAGEM - TBL …….........................................................58

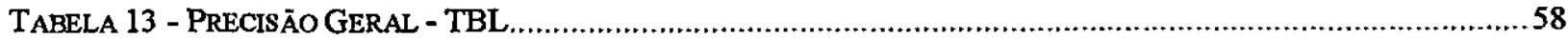

TABELA 14 - PRECISĀO POR ETIQUETAS NO CORPUS DE TESTE- TBL …......................................................59

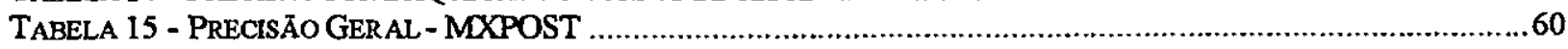

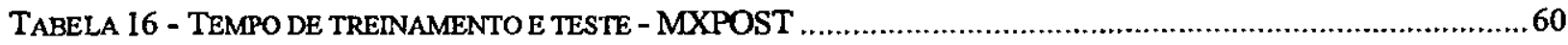

TABELA 17 - PRECISÃO POR ETIQUETAS NO CORPUS DE TESTE - MXPOST ……................................................61

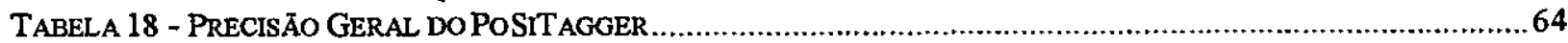

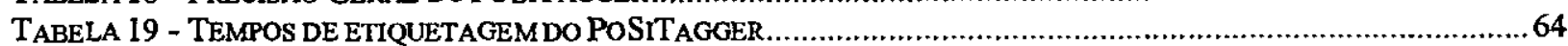

TABELA 20 - PRECISÃo GERAL DO POSITAGGER NOS CORPUS DE TESTE E CALIBRAÇĀo ..............................................64

TABELA 21 - PRECISĀO GERAL DOS ETIQUETADORES PARA TEXTOS DIDÁTICOS....................................................67

TABELA 22 - PRECISĀo GERAL DOS ETIQUETADORES PARA TEXTOS JORNALISTICOS ...................................................67

TABELA 23 - PRECISÃo GERAL DOS ETIQUETADORES PARA TEXTOS LITERÁRIOS .....................................................67

TABELA 24 - ETIQUETADORES DIDÁTICOS FRENTE A TEXTOS JORNALISTICOS E LTTERÁRIOS ......................................69

TABELA 25 - ETIQUETADORES JORNALISTICOS FRENTE A TEXTOS DIDÁTICOS E LTERÁRIOS.........................................69

TABELA 26 - ETIQUETADORES LITERARIOS FRENTE A TEXTOS DIDÁTICOS E JORNAL ISTICOS.....................................69

TABELA 27 - TAXA DE COMPLEMENTARIDADE ENTRE ETIQUETADORES .........................................................74

TABELA 28 - CONCORDÂNCIA ENTRE ETIQUETADORES NO TESTE

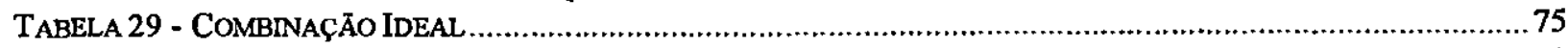

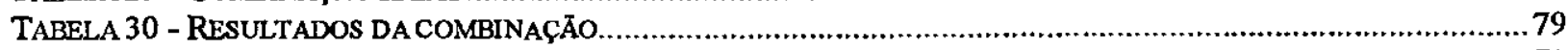

TABELA 31 RESULTADOS DA COMBINAÇÄO UTHLZANDO O MÉTODO TAGPAIR ……............................................... 79

TABELA 32 - PRECISĀO DA COMBINAÇĀO USANDO BAGGING …...................................................................... 81

TABELA 33 - RESULTADOS OBTIDOS NOS MODELOS EM CASCATA …….............................................................. 82

TABELA 34 - OPÇOS DO COMANDO TAGGER ....................................................................................... 117 
RESUMO

A etiquetagem morfossintática é uma tarefa básica, bem conhecida e bastante explorada em diversas aplicaçōes de Processamento de Línguas Naturais (PLN), como análise sintática e extração e recuperação de informaçōes. Os etiquetadores para a língua inglesa atingiram um estado da arte entre $96-99 \%$ de precisão geral. Diferentemente do inglês, para o português do Brasil năo foram ainda exploradas todas as técnicas para a etiquetagem, nem se atingiu a precisão dos melhores etiquetadores para a língua inglesa. Com estas motivações, quatro etiquetadores disponiveis na WWW foram treinados - Unigrama (TreeTagger), Trigrama (TreeTagger), baseado em transformaçoses (TBL) e baseado em máxima entropia (MXPOST) -, e um etiquetador simbólico foi desenvolvido (PoSiTagger). Todos os etiquetadores adaptados foram treinados com um corpus com cerca de 100.000 palavras formado por textos didáticos, jornalísticos e literários, e etiquetado com o Nilc tagset. A maior precisão geral obtida foi a do MXPOST - 89,66\%. Foram também implementados quatorze métodos para a combinação dos etiquetadores, dos quais sete superaram a precisão do MXPOST. A maior precisão obtida com os métodos de combinação foi $90,91 \%$. A precisão geral sofreu a influência do tamanho do corpus manualmente etiquetado disponível para treinamento, do conjunto de etiquetas e dos tipos de texto utilizados. 


\begin{abstract}
POS tagging is a very basic and well known natural language processing task used in several applications such as parsing and information retrieval. The taggers for English achieved a state of the art accuracy of $96-99 \%$. Unlike the case of English, only some approaches to tagging were explored for Brazilian Portuguese and the tagging systems available are still unsatisfactory from the point of view of results based on the state-of-the-art accuracy for English. Four taggers have been trained with the NILC tagset on a mixed 100,000-word corpus of Brazilian Portuguese, namely Unigram (Treetagger), N-gram (Treetagger), transformation-based (TBL) and Maximum-Entropy tagging (MXPOST), and a symbolic tagger, named PoSiTagger, was designed. MXPOST displayed the best accuracy (89.66\%). Fourteen methods of combination were used, seven of which led to an improvement over the MXPOST accuracy. The best result from the combination strategy was $90,91 \%$. The low accuracy is attributed to the reduced size of the training corpus, the tagset used and the mixed corpus employed.
\end{abstract}




\section{INTRODUÇÃO}

The problems are difficult and numerous, and the possibility of achieving a high-quality output has been questioned. Why, then, do researchers persist in their efforts? In on sense this question is similar to asking why people struggle to climb mountains or to get to the moon. The mountain, or the moon, is a challenge, and science grows and makes new discoveries as it attempts to meet challenges. This is certainly true of the research efforts in automated language processing. - Harold Borko

\subsection{Contextualização}

Borko (1968) define processamento de língua natural como sendo a manipulação (codificação) de uma língua com propósitos específicos como comunicaçăo, tradução, armazenamento e recuperação de informaçōes. O processamento automático de línguas seria uma forma de facilitar a manipulação destas utilizando métodos computacionais. Imaginava-se que as tarefas que poderiam ser melhoradas através de sua execução automática seriam: a tradução de uma língua em outra, o armazenamento e recuperação de informaçōes, e o projeto de um automâto inteligente capaz de responder perguntas.

Borko dizia que o processamento automático da língua nunca seria perfeito, mas que poderia ser de alta qualidade. E que apesar da língua ser indisciplinada, ingovernável, havia duas razōes para que os pesquisadores continuassem desenvolvendo trabalhos em processamento automático de línguas:

1) Uma razão relacionada a própria natureza humana - pesquisadores gostam de desafios, têm sede de novas descobertas. 
2) Uma razão prática - caso não consigamos desenvolver métodos mais eficientes de comunicaçäo para compartilhar idéias, o progresso humano seria inibịdo. Dada a importância da troca de informaçōes entre pesquisadores, com a explosão de informaçōes (que começou com a intensificação das pesquisas na guerra fria), gerou-se um grande volume de informaçōes, surgindo a necessidade de se ter métodos que auxiliassem o pesquisador a ter acesso à literatura até mesmo para que não houvesse duplicação de trabalhos.

Nos últimos anos, com o avanço cada vez mais rápido dos computadores e da tecnologia relacionada, esta explosão de informaçōes está cada vez mais intensa. Diariamente, trilhōes de unidades de informaçāo circulam pelo mundo. Graças a este avanço, textos em formato eletrônico săo facilmente obtidos - textos clássicos de grandes escritores, textos de jornais, publicaçōes científicas, etc. - com milhōes de palavras e estruturas lingüísticas das mais variadas.

Esta grande variedade de textos fez com que o interesse por métodos empíricos de análise da língua ressurgisse entre o final da década de 80 e o início da década de 90 , possibilitando o aumento do número de trabalhos na área de lingüística de corpus ${ }^{\prime}$, visto que, para fins de análise lingüística é necessário o uso de textos representativos da língua, dialetos ou subconjuntos da língua. Surgiram, com este renascimento dos métodos empíricos e estatísticos, vários corpora grandes, como, por exemplo, o Birmingham Corpus (Sinclair et al., 1987), resultados de esforços como: Association for Computational Linguistics Data Collection Initiative (ACL/DCI), European Corpus Initiative $(E C l)$, British National Corpus (BNC), Linguistic Data Consortium (LDC) Consortium for Lexical Research (CLR), Electronic Dictionary Research (EDR) e Text Enconding Initiative (TEI).

A pesquisa lingüística abrange uma variedade de níveis de análise. Um exemplo tipíco de ferramenta de análise seria o concordanceador. Um concordanceador é um programa que recupera todas as ocorrências de uma determinada cadeia de caracteres em um corpus e as listam, permitindo inclusive que estas listas sejam manipuladas. Contudo, certos tipos de análise não podem ser obtidos apenas através da grafia das palavras sem a utilização de outras características das palavras em questão, como por exemplo, informaçōes de natureza gramatical.

Porém, para extrair o máximo de informaçōes de um corpus através dessas ferramentas, é necessário fornecer, como entrada para elas, um corpus já etiquetado com marcas chamadas, no inglês, de part-of-speech tags. Tais marcas ou etiquetas são, principalmente, as categorias 
gramaticais (morfossintáticas) das palavras do corpus. Corpora etiquetados são importantes para a construção de modelos estatísticos de gramáticas para a língua escrita formal e coloquial, desenvolvimento de teorias formais sobre as diferentes gramáticas da língua escrita e falada, investigação de fenômenos prosódicos na fala e avaliação de modelos de análise sintática. Existem vários esforços de pesquisas para marcar grandes corpora com informação lingüística, incluindo categorias gramaticais e estruturas sintáticas, por exemplo, o Penn Treebank (Marcus et al., 1993) e o British National Corpus (Leech et al., 1994).

As ferramentas utilizadas na etiquetagem automática de corpus são os etiquetadores (taggers). A etiquetagem automática é uma tarefa básica, bem conhecida e bastante explorada em Processamento de Línguas Naturais (PLN). É muito utilizada em diversas aplicaçōes de PLN, como extração e recuperação de informaçōes, por exemplo, na classificação de documentos em sistes de busca da internet. Os etiquetadores para a lingua inglesa atingiram um estado da arte entre 95 $99 \%$ de precisăo geral, visto que, independente da abordagem para etiquetagem escolhida alguns casos acabam não sendo tratados, por exemplo, por dependerem de informações semânticas, o que impõe um limite à precisão geral. Sempre haverá casos que não serão tratados, mesmo que tenhamos um lingüísta genial para elaborar regras ou um etiquetador perfeito, isto porque não é possível construir um corpus que inclua todas as enunciaçōes de uma língua dada ou subconjunto de uma língua, exceto para algumas línguas mortas, em que a quantidade de textos disponíveis é limitada.

Com a geraçăo de léxicos a partir corpus de treinamento, a etiquetagem de textos do inglês vem se tornando cada vez mais fácil - cerca de $90 \%$ da precisão geral de um etiquetador é efeito do simples uso do léxico na etiquetagem (probabilidades léxicas) e, cerca de $50 \%$ dos $10 \%$ restantes pode ser resolvido por modelos simples de n-gramas. Mas ainda existem $50 \%$ dos $10 \%$ restantes que fazem com que a etiquetagem não seja uma tarefa trivial. Estes $50 \%$ são resultado, por exemplo, dos problemas:

- Ambigüidade léxica que não pode ser resolvida pelo contexto - existe a ambigüidade mas o contexto em que as palavras ambíguas aparecem é o mesmo. Por exemplo:

$\left\{\begin{array}{l}\text { Ele chegou rápido. (advérbio) } \\ \text { Ele.chegou sério. (adjetivo) }\end{array}\right.$

I Os termos que estiverem sublinhados estão definidos no glossário. 
- Tamanho de contexto inadequado - o contexto formado pelo período em que a palavra foco se encontra năo é suficiente para resolver a ambigüidade. Por exemplo:

$\left\{\begin{array}{l}\text { Quando o canto nada importa, a vida é triste. (canto é substantivo) } \\ O \text { hino nacional é fundamental. Quando o canto nada importa. (canto é verbo) }\end{array}\right.$

O primeiro período năo constitui um problema para a etiquetagem, mas sim o terceiro, pois a ambigüidade só pode ser resolvida quando se conhece o segundo período.

- Palavras desconhecidas - palavras que não fazem parte do léxico, ou que não aparecem no léxico com a etiqueta correta para aquele contexto, ou que foram escritas de forma incorreta.

- Estruturas desconhecicas - estruturas que rompem com a estrutura comumente utilizada na formação de períodos e que não tenham aparecido no corpus de treinamento. Aparecem, por exemplo, em textos literários, naqueles que usam ordem indireta ou distanciam o objeto do verbo. Um exemplo que aparece em nosso corpus é o período:

$\left\{\begin{array}{l}\text { Se a poder de estacas e diques o holandês extraiu_VTl de um brejo salgado a Holanda, essa } \\ \text { jóia do esforço, é que ali nada o favorecia. }\end{array}\right.$ Neste exemplo, todos os etiquetadores utilizados neste trabalho etiquetaram a palavra "extraiu" como verbo transitivo indireto, pois o objeto direto "a Holanda" veio depois do objeto indireto, o que usualmente nă̇o aconteceria em outros textos, como os textos jornalísticos. Já quando apresentamos o mesmo período reescrito em uma ordem mais usual - Se o holandés extraiu a Holanda, essa jóia do esforço, de um brejo salgado a poder de estacas e diques, é que ali nada o favorecia. - todos acertaram, etiquetando o verbo "extraiu" como verbo bitransitivo.

- Sentenças Labirinto - períodos para os quais não é possível uma análise morfossintática sequencial. Existem momentos em que se deve voltar e repensar a atribuição inicial das etiquetas, por exemplo:

$\{$ Aluna precisa de matemática vence concurso.

Muito esforço foi feito na tentativa de se obter etiquetadores cada vez mais precisos para o inglês, como a etiquetagem manual de corpus volumoso, correção da etiquetagem automática também objetivando obter corpus de treinamento maior, desenvolvimento de novas técnicas supervisionadas e não supervisionadas e adaptação de técnicas utilizadas em Aprendizado de Máquina. O uso de técnicas de Aprendizado de Máquina se deve ao fato de etiquetadores poderem ser encarados como classificadores. 


\subsection{Motivação e Relevância}

No Brasil, a pesquisa em PLN vem se intensificando há quase duas décadas. Vários sistemas para o português que trabalham em domínios limitados foram construídos no âmbito acadêmico (Beesley \& Grefenstette, 1996; Bick, 1996; Nunes et al., 1996a, 1996b; Paiva et al., 1996). Porém, desde muito cedo se percebeu a complexidade do problema, oriunda tanto de problemas intrinsecamente lingüísticos, quanto das características próprias da língua portuguesa. Durante algum tempo, o entusiasmo pela área de PLN esmoreceu, ainda que vários resultados interessantes e promissores tenham sido alcançados. Atualmente, no entanto, a comunidade de PLN do Brasil vive um novo período de entusiasmo e resultados promissores. Um dos motivos para isso é a possibilidade de contar com ferramentas de tratamento lingǘstico bastante abrangentes e independentes de língua, que facilitam sobremaneira a implementação de aplicativos nessa área. Os processadores de corpus, por exemplo, WordSmith2, LEXA ${ }^{3}$ e MonoConc ${ }^{4}$ são ferramentas de muita utilidade, uma vez que sảo capazes de realizar importantes estatísticas sobre a língua escrita, subsidiando pesquisas sobre a língua e desenvolvimento de processadores automáticos de língua natural.

Dentro do convênio USP-Itautec, firmado em 1993, foi compilado um corpora ${ }^{5}$ de textos originais em português do Brasil, composto de textos jornalísticos, acadêmicos, literários, técnicos, empresariais, da constituição brasileira, etc. O corpora conta hoje com aproximadamente 35 milhōes de palavras e não está etiquetado.

Diferentemente do inglês, para a língua portuguesa não foram ainda exploradas todas as técnicas para a representação de um modelo lingüístico da língua, nem se atingiu a precisão dos melhores etiquetadores para a língua inglesa. Existem três etiquetadores para o Português contemporâneo do Brasil - o etiquetador estatístico desenvolvido na UFRGS (Villavicencio, 1995), apresentando uma precisão de $84,5 \%$, o etiquetador neural desenvolvido na Universidade Nova de Lisboa (Marques \& Lopes, 1996), com a precisão $88.7 \%$, e o etiquetador baseado em regras, desenvolvido por Eckhard Bick (Bick, 1996), que possui uma precisão acima de $99 \%$-, e um etiquetador híbrido para o Português arcaico do Brasil (Finger, 1998; Alves,1999; Alves \& Finger, 1999; Galves \& Britto, 1999).

\footnotetext{
${ }^{2} \mathrm{http} / / \mathrm{hwmw}$.liv.ac.uk/ - ms2928/wordsmit.htm

${ }^{3} \mathrm{ftp}: / / \mathrm{mm}$ w.hd.uib.no/pub/pclexa

${ }^{4} \mathrm{ftp} / / /$ tip.nol.net/pub/users/athel/Win/monoconc/
} 
A etiquetagem automática para Português tem alguns outros pontos diferentes de trabalhos para inglês, como, por exemplo, o tamanho do corpus manualmente etiquetado disponível para treinamento (bem menor). Este e outros pontos serão tratados ao longo deste trabalho.

\subsection{Objetivos}

Este trabalho se propôs a construir um etiquetador simbólico, adaptar para o Português do Brasil três etiquetadores disponíveis via WWW (Schmid, 1995; Brill, 1994a; Ratnaparkhi, 1996), e combinar os etiquetadores adaptados utilizando técnicas da área de Aprendizado de Máquina. Pretendeu-se, assim, desenvolver um trabalho comparativo bastante extenso para a escolha de um etiquetador que etiquete com melhor precisăo uma gama variada de tipos de texto em português do Brasil.

\subsection{Organização da Monografia}

A monografia está dividida em sete capítulos. O Capítulo 2 explica o que é a etiquetagem automática de textos. O Capítulo 3 trata das várias abordagens para etiquetagem encontradas na literatura e descreve as arquiteturas de alguns etiquetadores. O Capítulo 4 apresenta as decisōes de projeto que foram tomadas neste trabaho com relação ao conjunto de etiquetas, corpus de treinamento e teste, abordagens de etiquetagem e métodos de avaliação dos etiquetadores e, traz também os experimentos realizados com cada um dos etiquetadores individualmente. O Capítulo 5 introduz a teoria de combinação de classificadores e traz os experimentos realizados com a combinaçăo dos etiquetadores adaptados. O Capítulo 6 apresenta uma discussão dos experimentos realizados. Por fim, no Capítulo 7 estão as contribuiçōes, limitaçōes e sugestōes de futuros experimentos e aprimoramentos.

\footnotetext{
${ }^{5}$ http://hmw.nilc.icmc.sc.usp.br/tools.html\#CORPUS
} 


\title{
2 ETIQUETADORES DE TEXTO
}

\author{
Quando um rio corta, corta-se de vez \\ o discurso-rio de água que ele fazia; \\ cortado, a água quebra-se em pedaços, \\ em poços de água, em água paralítica. \\ Em situaçāo de poço, a água equivivale \\ a uma palavra em stituação dicionária: \\ isolada, estanque no poço dela mesma, \\ e porque assim estanque, estancada; \\ e mais: porque assim estancada, muda, \\ e muda porque com nenhuma comunica, \\ porque cortou-se a sintaxe desse rio, \\ o fio de água por que ele discorria. \\ 0 discurso de um rio, seu discurso-rio \\ chega raramente a se reatar de vez; \\ um rio precisa de muito fio de água \\ para refazer o fio antigo que o fez. \\ Salvo a grandilloquêência de uma cheia \\ Ihe impondo interina outra linguagem, \\ um rio precisa de muita água em fios \\ para que todos os poços se enfrasem: \\ se reatando, de um para outro poço, \\ em frases curtas, então frase a frase, \\ até a sentença-rio do discurso único \\ em que se tem voz a sede ele combate.
}

João Cabral de Melo Neto

Este capítulo introduz o problema da etiquetagem automática de textos. Começa explicando o que é etiquetar morfossintaticamente um texto, e prossegue demonstrando a importância de se ter textos etiquetados para PLN e apresentando a estrutura de etiquetadores. 


\subsection{Etiquetagem morfossintática de textos}

Marcar, anotar, ou etiquetar morfossintaticamente (tagging) um texto de uma dada língua significa atribuir um rótulo ou etiqueta (tag) de uma palette finita (tagset) a cada palavra da língua, símbolo de pontuação, palavra estrangeira, ou fórmula matemática de acordo com o contexto em que aparecem. Para as palavras da língua utiliza-se uma etiqueta referente a sua categoria morfossintática ou gramatical (adjetivo, verbo, substantivo, etc.); para os símbolos de pontuação aceitos no discurso (por exemplo, vírgula, ponto final, exclamação, interrogação, etc.) geralmente utiliza-se o próprio símbolo. As palavras estrangeiras e fórmulas geralmente são classificadas com um único rótulo, pois, embora, estejam na "borda" da gramática ou léxico da língua em que o texto é escrito, precisam ser etiquetadas (EAGLES, 1996b). Mostramos abaixo um esquema genérico de etiquetas para símbolos de um dado texto de uma língua.

\begin{tabular}{|lll|}
\hline 1. $\mathrm{N}$ (substantivo) & 5. AT (artigo) & 9. NU (numeral) \\
2. V (verbo) & 6. AV (advérbio) & $10 . \mathrm{I}$ (interjeição) \\
3. AJ (adjetivo) & 7. PE (preposição) & $11 . \mathrm{R}$ (residual) \\
4. PO (pronome) & 8. C (conjunção) & $12 . \mathrm{P}$ (pontuação) \\
\hline
\end{tabular}

As etiquetas para cada classe gramatical das palavras de uma língua podem, por sua vez, ser refinadas com atributos referentes a cada classe. Por exemplo, para a língua portuguesa, os substantivos podem ser refinados com o valor para os atributos de tipo (comum, próprio), gênero (masculino, feminino, dois gêneros), número (singular, plural, dois números, invariável), grau (aumentativo, diminutivo, neutro). Pode-se, inclusive, chegar ao extremo de se criar uma etiqueta para uma palavra em particular; um exemplo disso é a etiqueta $V B R$ do conjunto de etiquetas Claws7 (Wynne, 1996) que serve apenas para etiquetar a palavra are. Neste trabalho, estaremos usando o termo etiquetagem com o significado de etiquetagem morfossintática.

O processo de etiquetar consiste, então, em dada uma seqüência de símbolos do texto e um conjunto de etiquetas, associar a cada símbolo a sua respectiva etiqueta. $O$ processo de etiquetagem é mostrado na Figura 1. 


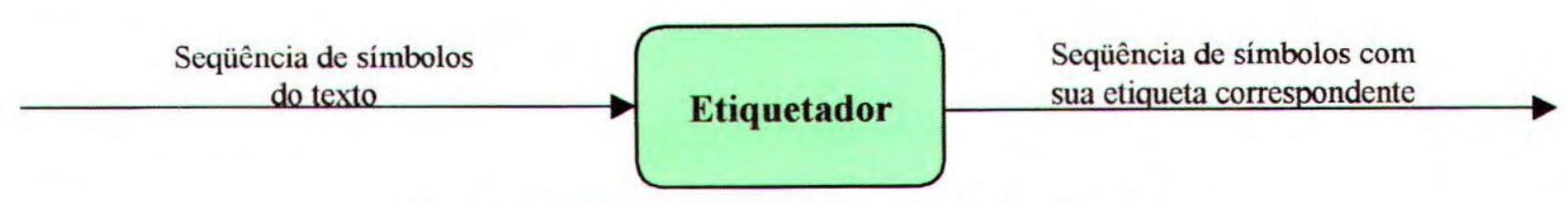

Figura 1 - Processo geral de etiquetagem de um texto

\subsubsection{A importância da etiquetagem de textos}

Estudos e análises de textos baseados em corpora utilizam geralmente corpora etiquetados pois conseguem assim extrair mais informação dos textos. Estes estudos utilizam grandes corpora (da ordem de milhões de palavras) para que as análises reflitam bem a realidade da língua, o que torna impraticável que os textos que estão sendo utilizados sejam etiquetados manualmente. Segundo Villavicencio (1995), a etiquetagem manual de um corpus com 20.982 de palavras feita por um linguista levou cerca de 44 horas, ou seja, para etiquetar manualmente um milhão de palavras nos mesmos moldes levaríamos cerca de 2097 horas. Assim, para etiquetar todo o corpora do Nilc, que possui 35.215.783 de palavras, usando o conjunto de etiquetas utilizado em (Villavicencio, 1995), levaríamos aproximadamente 73849 horas, ou seja, 8 anos 6 meses e 17 dias, isto sem contar férias, feriados, finais de semana, quinze minutos de atraso no expediente, etc. $\mathrm{O}$ alto custo da etiquetagem manual imprime a necessidade da etiquetagem automática.

A etiquetagem automática é uma técnica essencial em PLN. Pode ser aplicada em várias áreas do processamento de informação, incluindo: pré-processamento para sumarização automática, pós-processamento para reconhecimento ótico de caracteres (OCR) e reconhecimento de fala, análise sintática (parsing), tradução automática e recuperação de informações.

\subsection{A etiquetagem automática}

Os programas que fazem a etiquetagem automática são chamados em inglês de part-of-speech tagger ou simplesmente taggers, língua para qual os primeiros deles surgiram. Na tradução para o 
português são utilizados os termos etiquetador e rotulador. Neste trabalho será utilizado o termo etiquetador.

O processo de etiquetagem automática é composto basicamente por 3 tarefas que podem estar dispostas em 3 módulos: escrutinador léxico, classificador gramatical e desambigüizador gramatical, mostrados na Figura 2. No entanto, a maior parte dos etiquetadores pressupõe que os textos que the são fornecidos como entrada estão no formato inicial adequado e por isso não possuem um escrutinador léxico.

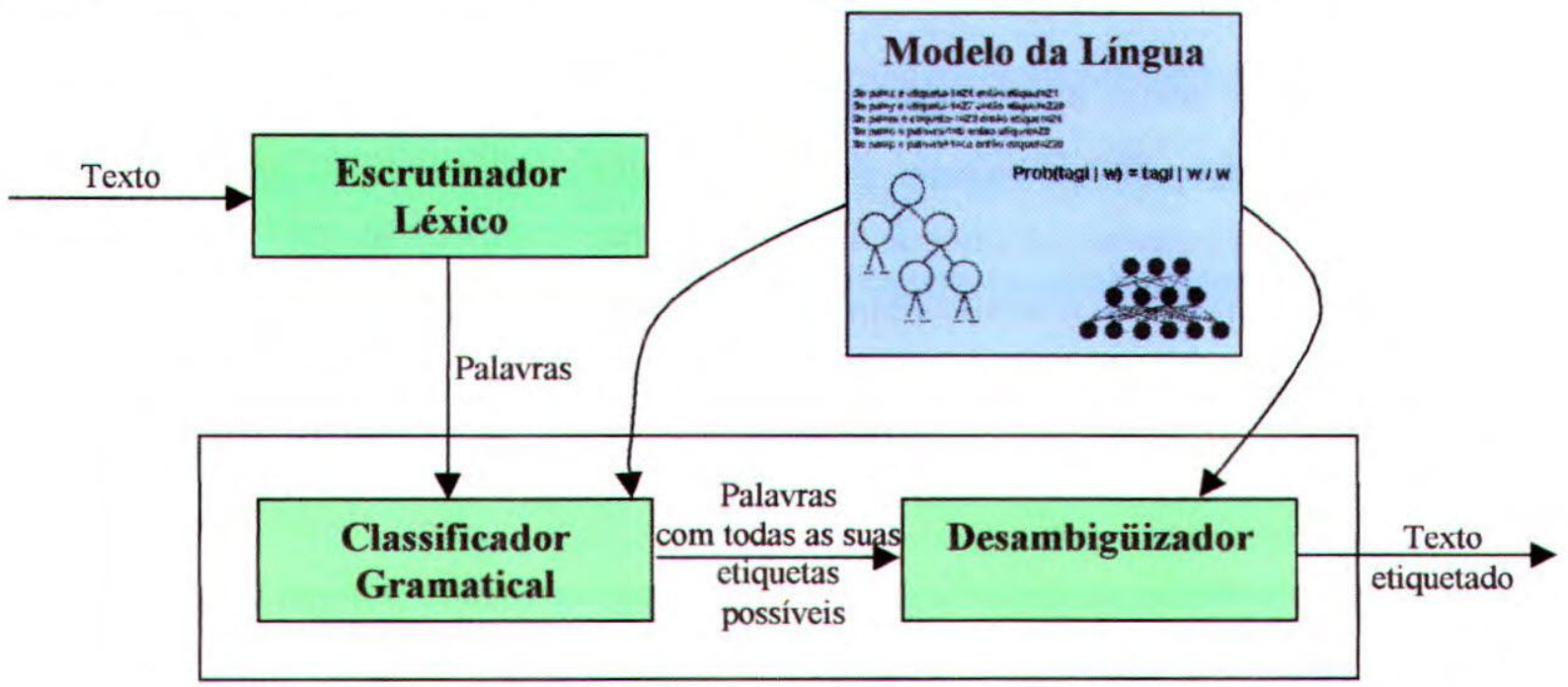

Figura 2 - Processo de etiquetagem automática

O escrutinador léxico identifica os símbolos do texto - pontuação, marcadores de documentos, palavras estrangeiras e as palavras da língua - separando dessa maneira os períodos do texto e, posteriormente, cada palavra de cada oração. A Figura 3 mostra o exemplo de um texto formado por dois períodos sendo submetido ao escrutinador lexical. No caso deste exemplo ${ }^{6}$, o escrutinador apenas acrecentou um espaço em branco antes do ponto final e colocou um período por linha.

Etiquetar é simples. Complicado é etiquetar como queremos.

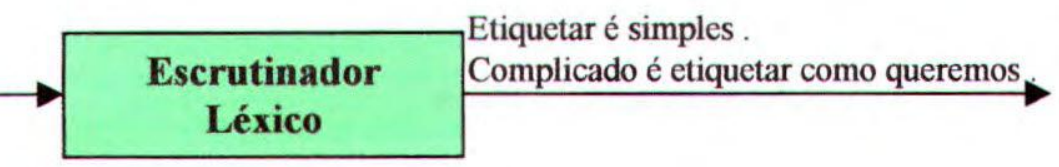

Figura 3 - Escrutinador Léxico

\footnotetext{
${ }^{6} \mathrm{O}$ mesmo exemplo será utilizado nas Figuras 4 e 5 para ilustrar o funcionamento do classificador gramatical e do desambigüizador.
} 
O classificador gramatical atribui classes gramaticais às palavras, utilizando, por exemplo, um léxico e um conjunto de informações para reconhecer as palavras que não pertencem ao léxico (ou por serem palavras estrangeiras, coloquialismos, regionalismos, ou simplesmente por não serem contempladas pelo léxico). Alguns exemplos de informações que podem ser utilizadas para este fim são: o primeiro/último/penúltimo/antepenúltimo caractere da palavra, se a palavra começa com letras maiúsculas, se a palavra tem outras letras maiúsculas além da primeira, se a palavra contém hífen, se contém algum caractere numérico. A Figura 4 ilustra qual seria a saída de um classificador gramatical que usasse o NILC tagset ${ }^{7}$ para o texto da Figura 3.

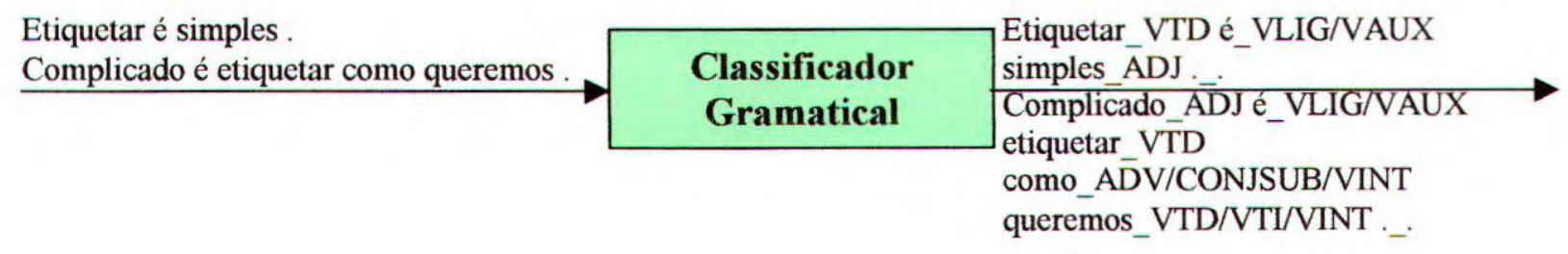

Figura 4 - Classificador Gramatical

Contudo, pode ocorrer o problema de ambigüidade lexical, situação em que temos palavras diferentes com mesma grafia, pertencendo a classes diferentes e que ocorre quando uma palavra é tratada isoladamente. Quando isso acontece, o contexto será analisado para solucionar o problema. Quem faz esta análise é o desambigüizador, que realiza a importante tarefa de atribuir uma, e somente uma, classe à cada palavra do corpus, como é visto no exemplo da Figura 5. A palavra casa, por exemplo, pode ser um substantivo ou um verbo. Essa ambigüidade pode ser resolvida quando se analisa o contexto em que ela se encontra. Por exemplo, na oração "Ela casa hoje", casa é um verbo, enquanto que na oração "Sua casa é bonita", casa é um substantivo.

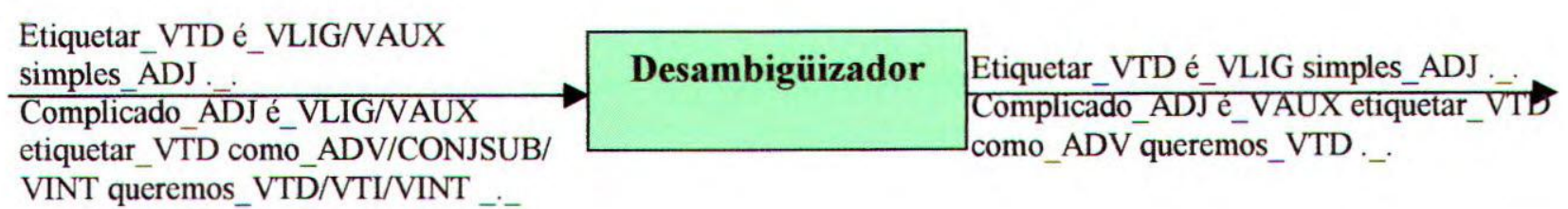

Figura 5 - Desambigüizador

\footnotetext{
${ }^{7}$ Todas as versões do Nilc tagset estão presentes no Apêndice A deste trabalho. $O$ manual referente à versão atual encontra-se disponivel em (Disponivel em http://wnww.nilc.icmc.sc.usp.br/tools.html\#TAGGER
} 
Tanto o léxico, quanto as informaçōes utilizadas para avaliar o contexto, fazem parte do modelo da língua utilizado por cada etiquetador. E é de acordo com a forma que o modelo da língua é construído e representado que classificamos os etiquetadores.

A primeira distinção entre os etiquetadores é feita de acordo com a maneira pela qual o modelo da língua é construído: manualmente, ou seja, elaborado por lingüístas ou automaticamente abstraído de corpus.

Os etiquetadores cujos modelos foram automaticamente abstraídos de um corpus de treinamento podem ainda ser dividos em supervisionados, não supervisionados e totalmente năo supervisionados - segunda distinçăo. Os supervisionados são os etiquetadores que utilizam um coñjünto de étiquetas e corpus de treinamento manualmentē etiquiètado como base para construção do modelo da língua. Já os não-supervisionados precisam apenas de um dicionário para saber qual é o conjunto de etiquetas e quais são as possíveis etiquetas para cada palavra, e de um pequeno corpus manualmente etiquetado para teste. Os totalmente não-supervisionados não dependem de um corpus manualmente etiquetado seja para treinamento, seja para teste, nem de um conjunto de etiquetas, pois fazem uso de métodos computacionais sofisticados para induzir agrupamentos de palavras (conjuntos de etiquetas).

Os etiquetadores supervisionados, não supervisionados e totalmente não-supervisionados podem ser subclassificados de acordo com a abordagem por eles utilizada para representar o modelo da língua: simbólicos (ou lingüísticos), probabilísticos e hibrídos. Como exemplos de etiquetadores supervisionados simbólicos temos etiquetadores baseado em regras, baseado em casos e árvores de decisão não probabilísticas; como exemplos de probabilísticos temos os que fazem uso de Modelo de Markov, máxima entropia, árvores de decisão probabilísticas e redes neurais. De não supervisionados estatísticos temos os que usam o algoritmo Baum-Welch e o aprendizado baseado em transformaçăo dirigida por erro (Brill, 1997b). E de totalmente não supervisionados temos os que usam análise distribuicional de palavras de um texto, algoritmos de clusterizaçăo e redes neurais (Redington et al., 1998). A Figura 6 mostra o esquema da classificação dos etiquetadores. As abordagens para etiquetagem serăo melhor explicadas no Capítulo 3. 


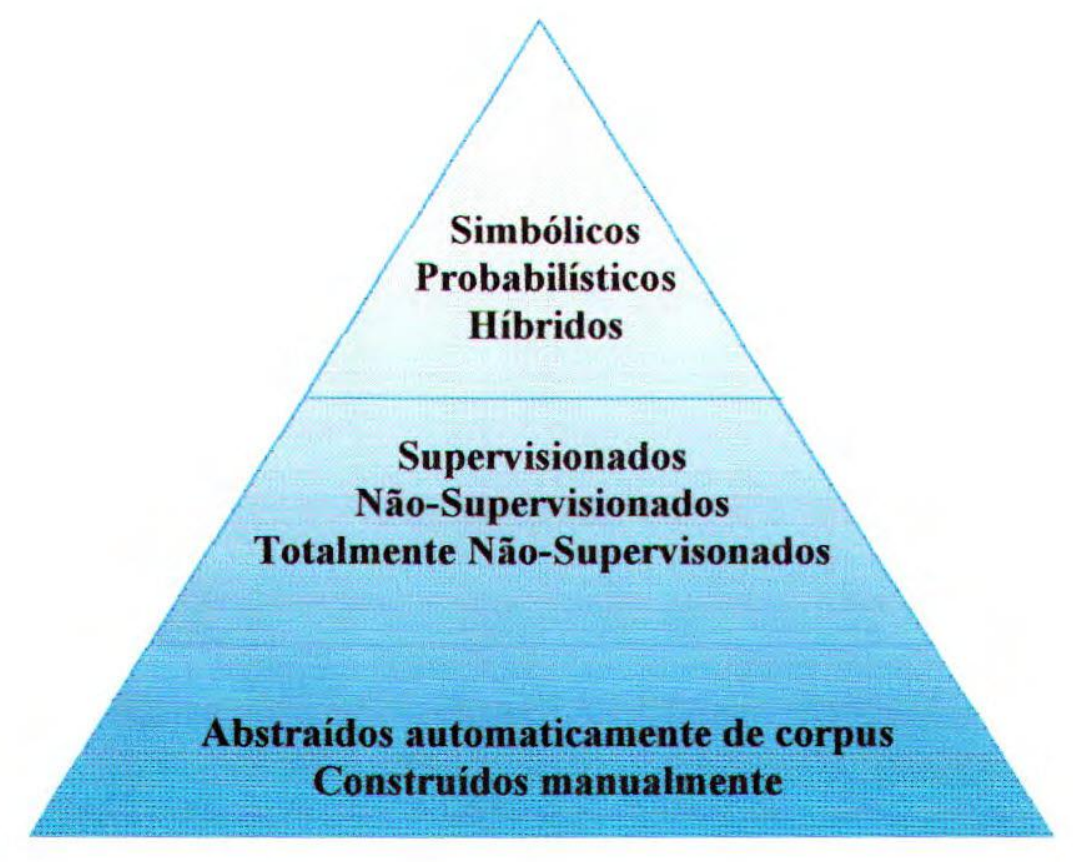

Figura 6 - Tipos de Etiquetadores 


\section{ABORDAGENS PARA ETIQUETAGEM}

The best way to have a good idea is to have a lot of ideas. - Linus Pauling

Os primeiros etiquetadores seguiram a abordagem baseada em regras (Greene \& Rubin, 1971, Klein \& Simmons, 1963) e tiveram muito trabalho de construção manual; tinham léxicos pequenos que cuidavam basicamente de exceçōes às regras. O TAGGIT, de Greene \& Rubin (1971), foi utilizado para fazer a etiquetagem inicial do Brown Corpus (Francis \& Kucera, 1979), que foi depois manualmente revisado. Ele serviu de inspiração para a construção de um etiquetador estatístico, o CLAWS (Wynne, 1995, 1996).

Por volta de 1976, começaram a ser desenvolvidos etiquetadores estatísticos. A idéia de Hidden Markov Models (HMMs) até então utilizada no reconhecimento de fala começou a ser utilizada para etiquetagem automática de textos (Bahl \& Mercer, 1976; Derouault \& Merialdo, 1984; Church, 1988). Antes disso, pensava-se que a desambigüização morfossintática só teria um resultado realmente bom após a análise sintática ter sido realizada; não se acreditava que apenas o etiquetador fosse capaz de um bom trabalho de desambigüização. A partir dos primeiros etiquetadores estatísticos é que ficou comprovado que o etiquetador consegue obter uma boa taxa de acerto na categorização gramatical. No entanto, etiquetadores baseados em regras continuaram a ser desenvolvidos, só que buscando técnicas para ajudar na construção das regras (Karisson, 1990; Voutilainen et al., 1992). Atualmente, os etiquetadores estatísticos são o tipo mais comum de etiquetadores. Basicamente, seu funcionamento consiste da construção de um 
modelo estatístico da língua que é utilizado para desambigüizar uma sequência de palavras. Este modelo, em geral, aparece como um conjunto de frequências de diferentes tipos de fenômenos lingüísticos e é construído em geral através da observação de n-gramas, sendo que o mais comum é a modelagem na forma de unigramas, bigramas e trigramas.

Para melhorar a precisão dos etiquetadores, várias tentativas foram feitas. A partir de 1990 começaram a surgir estudos para a construção de etiquetadores híbridos, como por exemplo o de Brill (Brill, 1993b, 1994a, 1995, 1997b). Dentro da abordagem probabilística, surgiu a idéia do uso de árvores de decisão probabilísticas, de redes neurais artificiais (RN), e do modelo de máxima entropia. Surgiram também os etiquetadores não-supervisionados e totalmente não supervisionados que ajudam nos casos em que não há corpus manualmente etiquetado para uma dada língua ou domínio.

Constantemente, vários etiquetadores têm sido disponibilizados na WWW, tais como: HMM tagger (Cutting et al, 1992), Brill tagger (Brill 1994a, 1997b), TreeTagger (Schmid, 1995), MULTEXT tagger (Armstrong et al., 1995), MXPOST (Ratnaparkhi, 1996) e TnT (Brants, 2000). Têm também sido desenvolvidos para várias línguas que não o inglês, por exemplo o francês (Chanod \& Tapanainen, 1995), alemão (Feldweg, 1995; Schmid, 1995), grego (Dermatas \& Kokkinakis, 1995), italiano (Dermatas \& Kokkinakis, 1995), espanhol (León \& Serrano, 1995; Màrquez et al., 2000), sueco (Brants \& Samuelsson, 1995), turco (Oflazer \& Kuruöz, 1994), holandês (Dermatas \& Kokkinakis, 1995), tailandês (Ma \& Isahara, 1998; Ma et al., 1999a; Ma et al., 1999b; Lu et al., 2000), chinês (Ma et al., 1998), português (Villavicencio, 1995; Marques \& Lopes, 1996; Bick, 1996; Finger, 1998; Alves \& Finger, 1999; Galves \& Britto, 1999).

Este capítulo discute de forma mais detalhada os etiquetadores simbólicos ou lingüísticos na Seção 3.1, os etiquetadores probabilísticos na Seção 3.2, e os híbridos na Seção 3.3, apresentando exemplos de etiquetadores supervisionados e não supervisionados.

\subsection{Abordagem Lingüistica}

Un dos poucos resultados concretos obtidos nos primeiros vinte anos da pesquisa de $I A$. é o fato de que a inteligência requer conhecimento. Para compensar sua característica predomlnante, a indispensabilidade, o conhecimento também possui algumas

propriedades menos desejáveis, incluindo: - É volumoso.

- É difícil de caracterizar com precisão.

Está em constante mutaçāo.

Elaine Rich 
$\mathrm{Na}$ abordagem lingüística, são construídas regras a partir de abstrações lingüísticas sobre paradigmas e sintagmas da linguagem. Tais regras são codificadas manualmente como uma gramática que vai descartar análises ilegítimas. Devido ao fato da gramática ser construída manualmente, esta abordagem acaba exigindo habilidade lingüística, além de muito esforço para ser escrita. $O$ processo de construção deste etiquetador é mostrado na Figura 7.

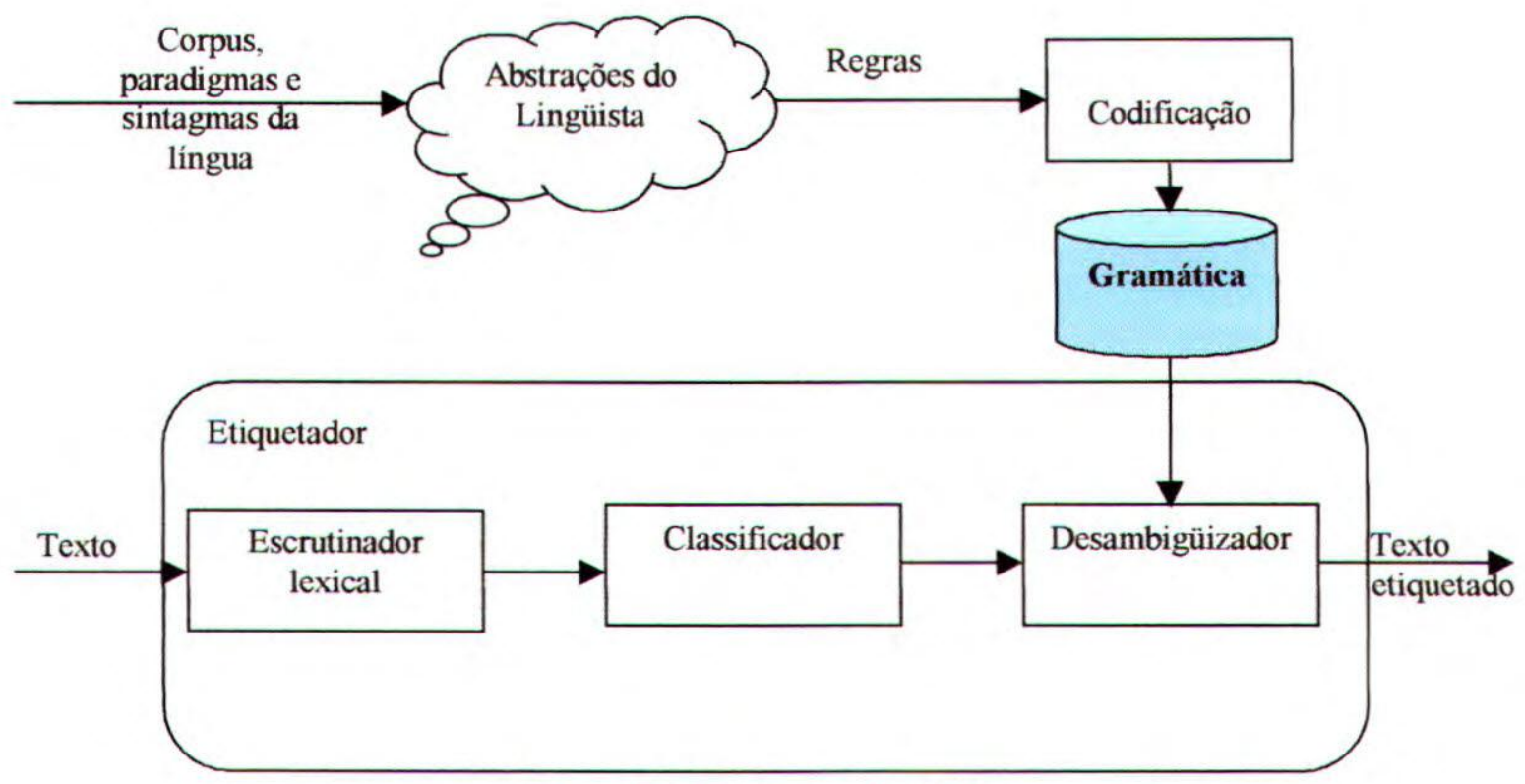

Figura 7 - Abordagem lingüística

A abordagem lingüística foi utilizada nas décadas de 70 e 80 para a análise sintática (Berwick et al., 1992) e baseia-se no pressuposto de que a categoria gramatical de uma palavra é uma característica arbitrária e convencional. Cada palavra é armazenada em um léxico, junto com sua(s) categoria(s) gramatical(ais), e outras informações relevantes para o processamento. Algumas características de um etiquetador lingüístico são:

- facilitar o processamento subseqüente (análise sintática e interpretação semântica) com a riqueza de informações presente sobre cada item lexical;

- refletir o pensamento do lingüista que o construiu, já que este implementa as teorias que deseja usando regras;

- servir normalmente a um domínio específico, já que tanto as teorias quanto as generalizações da língua devem ser explicitamente definidas, portanto para um domínio maior seriam necessárias muitas regras (muito trabalho manual);

- utilizar normalmente programação simbólica. 
Por melhor que seja o léxico sempre haverá falhas, porque o conjunto de palavras em determinado domínio é potencialmente infinito e na prática se modifica regularmente: há neologismos e empréstimos, palavras caem em desuso ou são modificadas (problema de incompletude). Alguns exemplos são os etiquetadores de Chanod \& Tapanainen (1995a, 1995b), Voutilainen (1995), e Bick (1996).

\subsubsection{Etiquetador baseado em sintaxe}

Voutilainen (1995), apresenta um etiquetador que usa propriedades distribucionais gerais de um texto, que são invariantes através de línguas e sublínguas. Ele foi desenvolvido para o inglês e usou um corpus de treinamento com 38.000 palavras. Todas as regras gramaticais são essencialmente sintáticas. Consiste de cinco componentes seqüenciais: escrutinador, classificador, deșambigüizador morfológico ENGCG, etiquetas sintáticas alternativas e desambigüizador sintático de estado finito, mostrados na Figura 8 . Obteve $99,26 \%$ de precisão contra $95 \%-97 \%$ dos etiquetadores estatísticos devido à última fase, o desambigüizador sintático de estado finito.

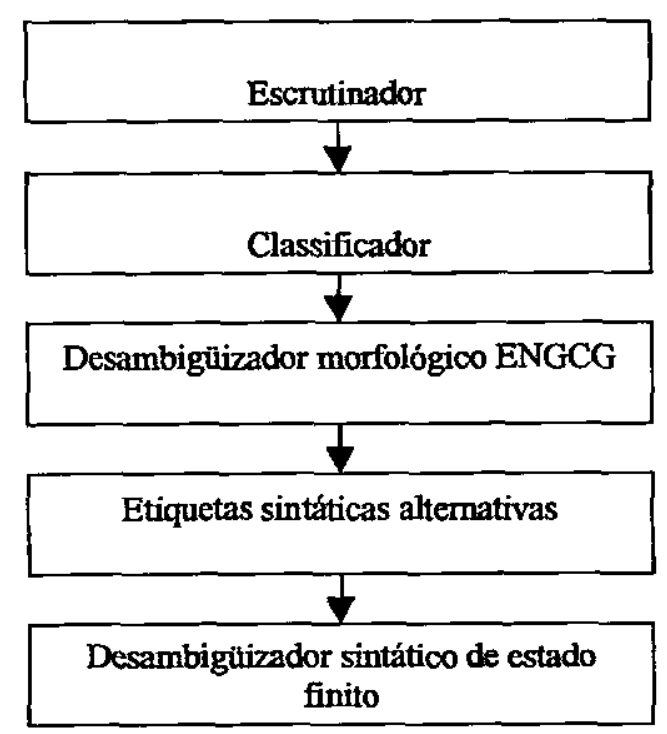

Figura 8 - Etiquetador baseado em sintaxe

No classificador, a descrição morfológica consiste de dois componentes: o léxico e regras heurísticas para tratamento de palavras desconhecidas. O léxico possui 80.000 entradas, cada uma 
representando todas as formas flexionadas e algumas formas derivadas e emprega 139 etiquetas, principalmente para categorias gramaticais.

O classificador produz cerca de 180 classes de ambigüidade. As regras heurísticas têm análise baseada na formação das palavras e se nenhuma das regras é aplicável, a palavra é etiquetada como substantivo.

O desambigüizador morfologico ENGCG faz uso de uma Constraint Grammar. Esta gramática contém 1.185 restriçöes lingüísticas. São 200 as regras heurísticas alternativas (opcionais) e são baseadas em generalizaçỏes lingüísticas.

O desambigüizador sintático de estado finito consiste de uma gramática de Intersecção de estado-finito, um formalismo de análise sintática reducionista descrito detalhadamente em (Koskenniemi, 1990; Koskenniemi et al., 1992; Tapanainen, 1992; Voutilainen \& Tapanainen, 1993; Voutilainen, 1994).

\subsubsection{Etiquetador baseado em restrições}

Chanod e Tapanainen (1995), fizeram um estudo para o francês que consistiu na construção de um etiquetador estatístico adaptado do Xerox HMM (Wilkens \& Kupiec, 1996) e de um simbólico - otiquetador baseado em restriçōes - para o francês. Apesar de o estatístico ter precisão semelhante aos etiquetadores para o inglês - 96,8\% de precisäo - obteve-se melhor resultado com o simbólico, que possui $98,7 \%$ de precisäo.

O Etiquetador baseado em restriçöes foi feito utilizando-se técnicas que foram originalmente desenvolvidas para análise morfologica (Karttunen, 1994). Neste madelo, as regras säo representadas como analisadores de estado-finito. Os analisadores säo campostos com períodos em seqüência. Cada analisador talvez remova au mude uma ou mais etiquetas das palavras. Após todos os analisadores terem sido aplicados, cada palavra tem apenas uma análise.

A Figura 9 mostra o processo de etiquetagem utilizado. Para as formas de ambigüidade mais freqüentes säo utilizadas restriçöes contextuais para resolver a ambigüidade. Através do estudo de um milhão de palauras retiradas de um jornal, Chanod e Tapanainen descobriram que 0 uso de restrições cantextuas seria viável pois perceberam que as 97 palavras mais freqüentes 
eram responsáveis por dois terços da ambigüidade e que dentre estas, apenas 16 (de, la, le, les, des, en, du, un, a, dans, une, pas, est, plus, Le, son) eram as responsóveis por $50 \%$ da ambigüidade ${ }^{8}$. Estas regras não requerem um corpus etiquetado e são independentes do corpus. Säo baseadas em uma pequena lista de palavras comuns (nas 97 mais freqüentes). Caso as regras principais não resolvam a ambigüidade săo utilizadas heurísticas ad-hoc por exemplo: quando a palavra "des" aparece no início de frases ela é preferencialmente um determinador, por exemplo, descrições de combinaçōes de nomes e frases preposicionais. Quando a regra anterior falha são utilizadas regras não contextuais que funcionam como probabilidades léxicas (por exemplo: a etiqueta preposição é preferivel d̀ etiqueta adjetivo, que é preferível da etiqueta pronome, que é preferivel ao particípio passado).

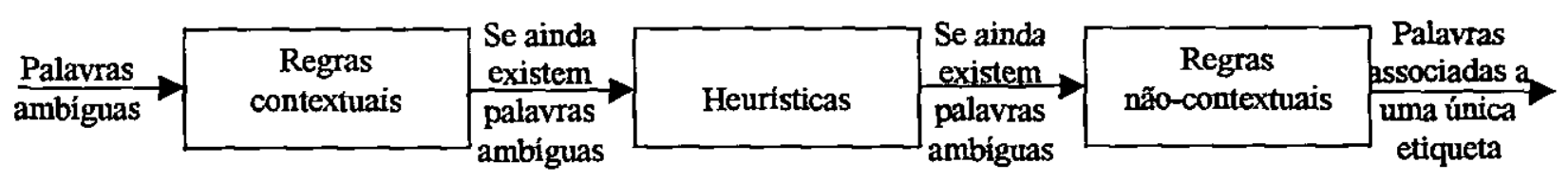

Figura 9 - Etiquetador baseado em restriçōes

Foram feitos dois tipos de teste, um com um corpus de 5752 palavras selecionadas de artigos sobre economia e outro com um corpus de 12000 palavras retiradas de textos de jornal, desta vez incluindo nomes próprios e siglas; a boa precisáo se manteve nos dois tipos de texto. 0 conjunto de etiquetos utilizado possui 88 etiquetas. Contém 75 regras das quais: 39 são regras contextuais, 25 são regras heurísticas e 11 regras nâo-contextuais. Todas as regras são representadas por $1 /$ analisadores de estado finito.

\subsubsection{Etiquetador baseado em casos}

O etiquetador MBT (Memory Based Tagger) foi proposto por (Daelemenans et al., 1996) e se baseia em raciocínio baseado em casos.

\footnotetext{
${ }^{8}$ Um estudo semelhante foi feito para o inglês usando-se o Brown corpus. Descobriu-se que 63 palovros eram responsáveis por $50 \%$ da ambigüidade e que 220 palarras eram responsáveis por $2 / 3$ da ambigüidade.
} 
Durante a fase de treinamento, o corpus de treinamento é transfarmada em duas boses de casos, uma para ser usada nas palavras conhecidas e outra para palavros desconhecidos. Os casos sãa armazenadas em uma IGTree (memória de casas hierárquica (Daelemanset al., 1997)). e durante a etiquetagem novas casos são classificados combinando os novos casos com os casos que estõo na memória indo do atributo mais impartante para o menos importante. A ordem de relevância dos atrbutosé determinada utilizando Information Gain.

Para palavras conhecidas, o etiquetador tem informaçōes sobre a palavra em foca e suas patenciais etiquetos, as etiquetas já desambigüizadas dos duas palavros anteriores e as etiquetas ainda nãa desambigüizadas das duas palavras seguintes. Para palavras desconhecidas, sáo analisadas apenas uma polavra anterior e uma posterior, três letras de sufixo e atributos sobre a presença de letras maiúsculas, hífen e dígitos. A base de casos para palavras desconhecidas é formada apenas por palovras que apareceram no conjunto de treinomento cinco vezes au menas.

\subsection{Abordagem Probabilística}

Há três tipos de situaçōes em que é tentador utilizar o raciocinio probabilístico: o mundo relevante é realmente aleatório; o mundo relevante não é aleatório, dadas as informaçōes suficientes,

mas nosso programa nem sempre terá acesso a todos os dados; o mundo parece ser aleatório porque não o descrevemos ao nivel certo.

Elaine Rich.

Baseia-se no pressuposto de que a categoria gramatical de uma palavra é o conjunto de seus modos de combinação com outras categorias (Harris, 1982). Isto é, em vez de ser umo característica intrínseca à palovra individual, a categoria gramatical representa um padröo de combinaçõo de itens ou um componente de um padrōo sintático.

Pela abordagem probabilística, portanto, näo é necessário um canhecimento prévio dos itens individuais: suas passibilidades de combinação (probabilidade de transição de uma categoria para outra) säo computadas diretamente do corpus. Se intensificou nos anos $80 \mathrm{e}$, tem se manifestado em sistemas que partem de levantamentos estatísticos detalhados em corpora e em sistemas de redes neurais. 


\subsubsection{Etiquetador Estatístico}

Remember the commonsense idea that statistics is not a form of magic. Some sets of data contain too little information to answer our questions. Some questions cannot be answered at all. We cannot change this situation by indications or statistical formulas. But a grasp of statistical methods can increase our ability to learn from experience - sometimes in subtle ways. - Lincoln E. Moses

Na abordagem estatística não é necessário nenhum esforço humano, as abstrações (generalizaçōes) são automaticamente adquiridas a partir do corpus. O único esforço necessário é o de determinar o conjunto de etiquetas adequado e marcar o corpus de treinamento. Porém. quando HMMs são utilizados há necessidade apenas de um léxico.

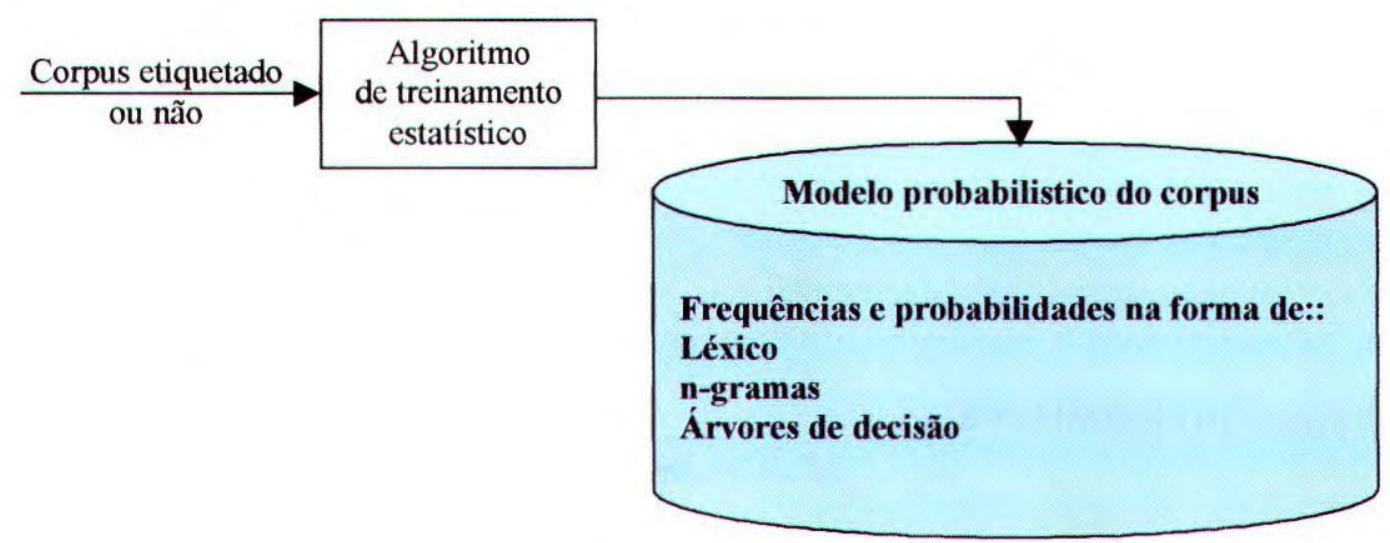

Figura 10 - Etiquetador Estatístico - Módulo de treinamento

Como o processo de inferir regras é totalmente automático, ao contrário da abordagem lingüística, aqui não existe um limite para o domínio, nem para a língua. Existem vários etiquetadores estatísticos que foram construídos a princípio para o inglês, tais como: Xerox HMM tagger (Wilkens \& Kupiec, 1996) e TreeTagger (Schmid, 1995). E existe uma arquitetura que foi construída para o Português do Brasil (Villavicencio, 1995).

\subsubsection{Xerox HMM}

O Xerox HMM (Wilkens \& Kupiec, 1996) é um etiquetador de domínio público baseado em HMM. Ele aplica o algoritmo Forward-Backward para treinamento e o algoritmo de Viterbi para a etiquetagem propriamente dita. 
Para o treinamento, é necessário um escrutinador, um léxico, um corpus grande para treinamento (bons resultados foram obtidos com corpus a partir de 200.000 e os experimentos chegaram até corpus com 2.000.000 palavras) e um corpus manualmente etiquetado para teste. Pode ser treinado com texto etiquetado el ou náo etiquetado. No entanto, os melhores resultados são obtidos quando se é utilizado no treinamento apenas corpora etiquetados.

O tamanho do conjunto de etiquetas varia de uma língua para outra, no caso da adaptação do Xerox HMM para o alemäo, por exemplo, o conjunto continha 42 etiquetas (Feldweg, 1995). Sua precisão gira em torno de $96,67 \%$.

\subsubsection{Um Etiquetador estatístico de categonias morfossintáticas para o português}

Trata-se de um etiquetador probabilístico simples que não contém nenhuma espécie de mecanismo para recalcular probabilidades. Foi desenvolvido pelo grupo de PLN da Universidade Federal do Rio Grande do Sul em conjunto com a Universidade Nova de Lisboa (Portugal) (Villavicencio, 1995) e apesar de ter sido desenvolvido para o português, nada impede que seja usado para outras línguas caso se tenha disponível um corpus para o treinamento.

Foram utilizados dois corpus para o treinamento: o Lusa Corpus (português Continental) e - Radiobrás (português do Brasil). O corpus Radiobrás possui 141.043 palavras, das quais 20.982 foram manualmente etiquetadas. O conjunto de etiquetas utilizado para a língua portuguesa do Brasil contém 33 etiquetas e para a de Portugal 45. Das 20.982 palavras, 20.000 foram utilizadas para treinamento e 982 para teste, obtendo $74,54 \%$ de precisáo com dicionário aberto e corpus acentuado e $87,98 \%$ de precisão com dicionário fechado e corpus acentuado.

O etiquetadar realiza a análise de um corpus de treinamento e modela os padrões lingüísticos nele presentes. Após ter modelado este conhecimento, o etiquetador pode usá-lo para fazer a etiquetagem automática das palovras de um outro corpus qualquer.

É composto de três módulos principais: o módulo construtor de HMMs, o módulo classificador e o módulo de Viterbi como mostra a Figura 11. 


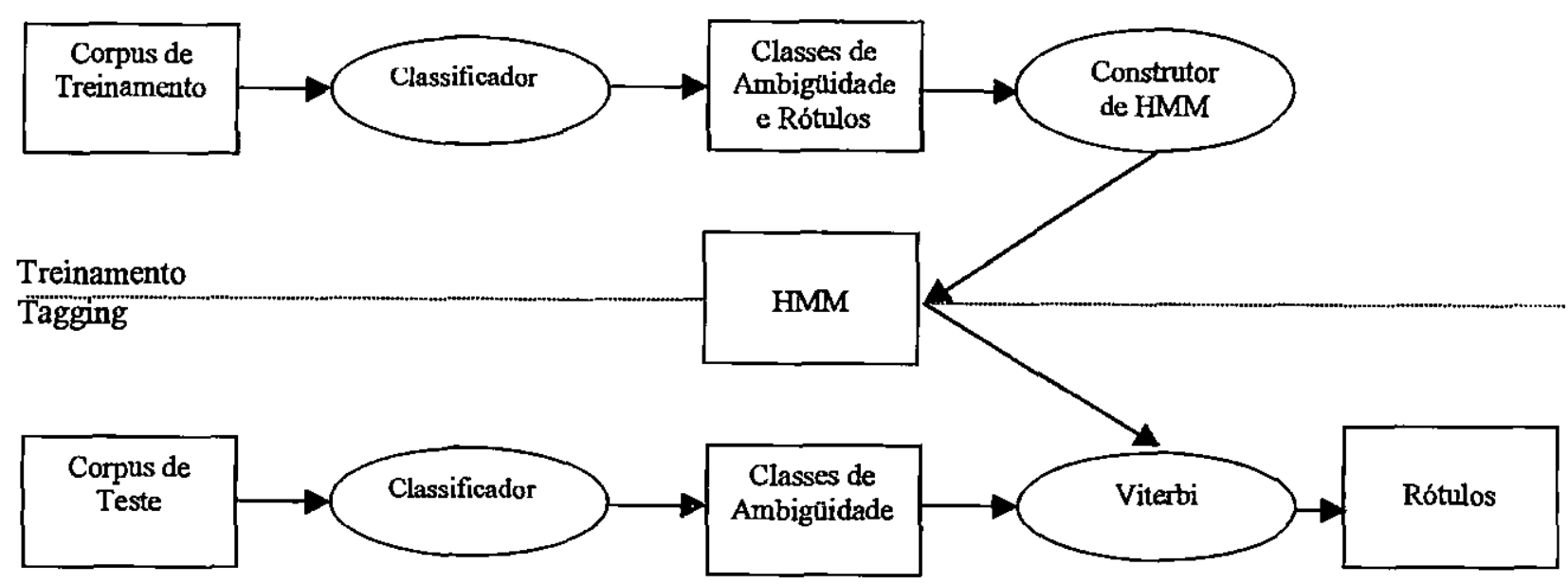

Figura 11 --Arquitetura do etiquetador estatístico de categorias morfossintáticas para o português (Villavicencio, 1995)

No módulo classificador, um corpus de entrada é lido e cada período é decomposto em palavras (Figura 12). Para cada palavra é atribuída uma classe de ambigüidade segundo definido anteriormente no dicionário.

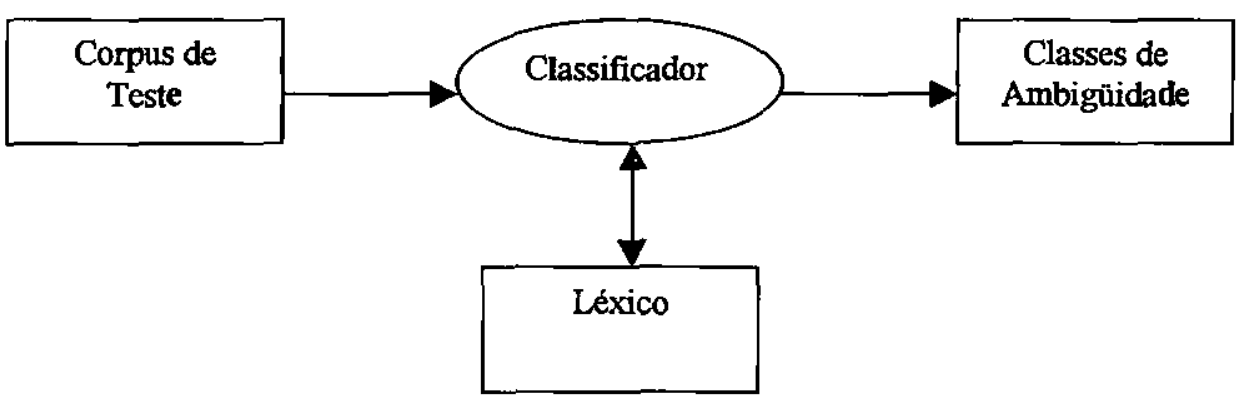

Figura 12 -Módulo classificador do etiquetador estatístico de categorias morfossintáticas para o português (Villavicencio, 1995)

Em seguida, no módulo construtor de HMMs baseado na análise dos padrōes lingüísticos que ocorrem no corpus de treinamento, o construtor produz um HMM (Figura 13). Para modelar as probabilidades contextuais é utilizado o modelo de bigramas e para o cálculo das estimativas destas probabilidades, é utilizado o algoritmo de freqüência relativa. Após a modelagem das probabilidades é feito um refinamento, para evitar que se use probabilidades que tenham sido estimadas a partir de freqüências muito baixas. Para o refinamento é utilizado o algoritmo Deleted 
Interpolation (para maiores detalhes veja (Jelinek \& Mercer, 1980)). Após o modelo ter sido refinado, ele está pronto para utilizar o conhecimento adquirido para marcar outros corpus.

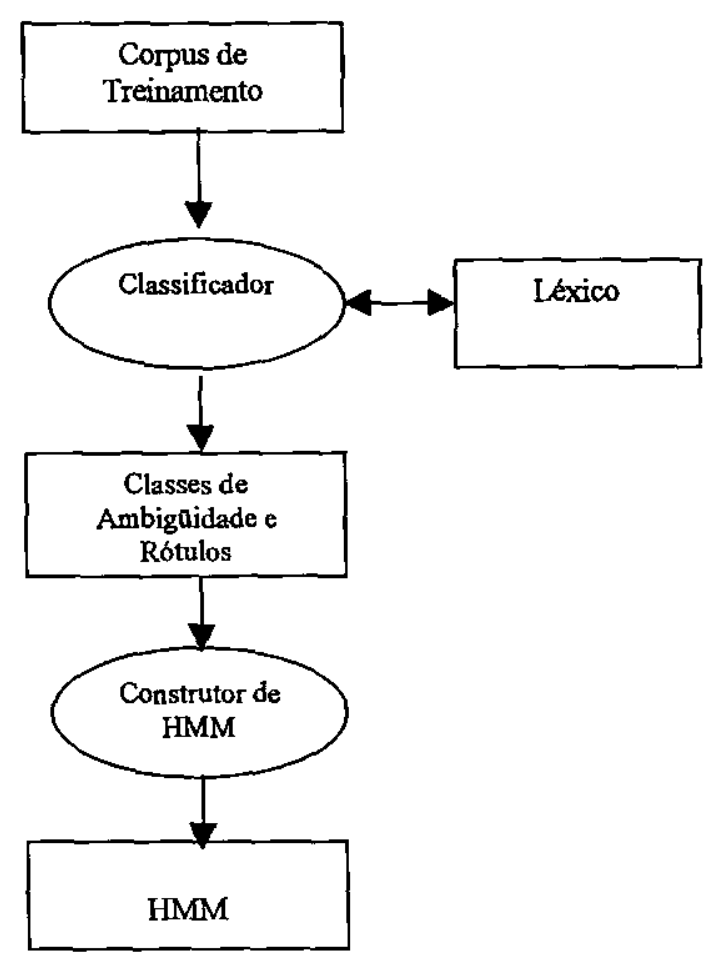

Figura 13 - Módulo Construtor do etiquetador estatístico de categorias morfossintáticas para o português (Villavicencio, 1995)

O último módulo, responsável pela resolução de ambigüidades, é o módulo de Viterbi. Este módulo analisa as classes de ambigüidade encontradas em um corpus (Figura 14). Através da aplicação do algoritmo de Viterbi sobre o HMM treinado, ele descobre qual a seqüência de rótulos mais provável.

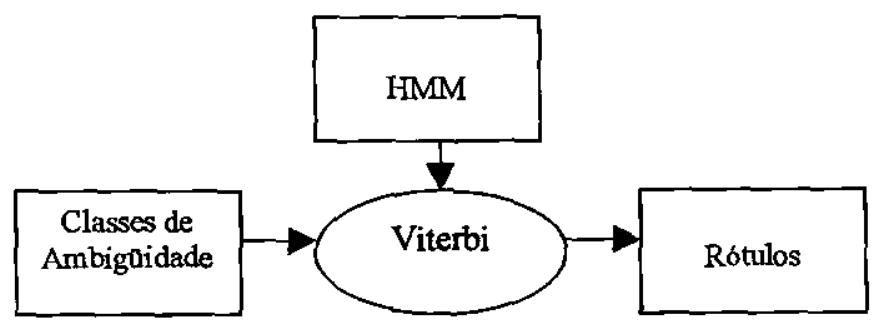

Figura 14 - Módulo de Viterbi do etiquetador estatístico de categorias morfossintáticas para o português (Villavicencio, 1995) 


\subsubsection{TreeTagger}

O Tree Tagger é um etiquetador baseado em árvore de decisāo e modelo de Markov de segunda ordem. Apenas corpora etiquetados săo usados para treinamento. Árvores de decisão são utilizadas para diminuir o problema de dados esparsos, obtendo estimativas confiáveis das probabilidades de transiçâa. É que devido ao grande número de parâmetros (particularmente no caso de trigramas), os métodos estatísticos, em geral, encontram dificuldades na estimativa de probabilidades muito pequenas quando é utilizado um conjunto limitado de dados de treinamento. Essa árvore de decisäo determina automaticamente o tamanho apropriado do contexto utilizado para estimar essas probabilidades (Figura 15).

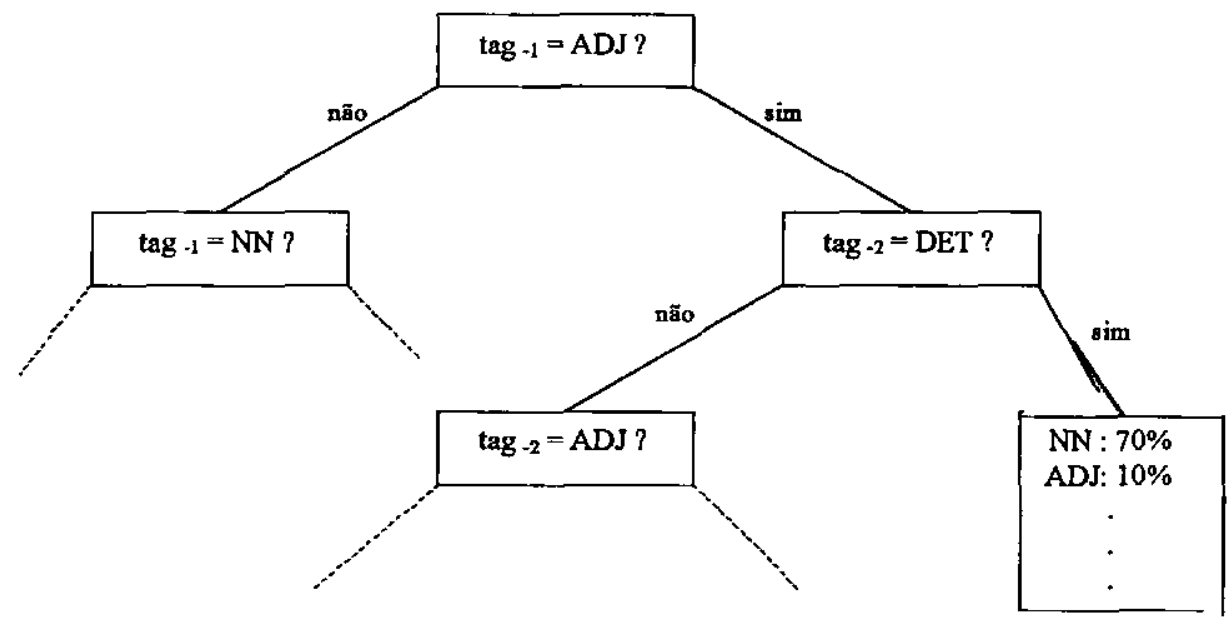

Figura 15 - TreeTagger - Árvore de decisäo (Schmid, 1995)

A probabilidade de um dado trigrama é determinada seguindo o caminho correspondente através da órvore de decisöo até que um nó folha seja encantrado.

As etiquetas para palavras desconhecidas são descobertas através de um léxico com sufixos que é construído automaticamente. Para probabilidades léxicas säo utilizadas classes de ambigüidade.

Para avaliar o desempenho do TreeTagger para a língua inglesa foi utilizando o corpus Penn Treebank (Marcus et al., 1993), que utiliza 36 etiquetas e outras 12 para caracteres de pontuaçäo. Aproximadamente 2 milhōes de palavras foram usadas para treinamento e $100 \mathrm{mil}$ palavras de uma parte diferente do corpus foi usada para teste. 
O TreeTagger foi comparado, com os mesmos dados, com um etiquetador comum baseado em trigramas (Kempe, 1993) que näo utiliza árvore de sufixos. Como resultado, obtevese uma precisão de $96,36 \%$ por parte do TreeTagger, enquanto que o etiquetador estatístico comum alcançou uma precisão de $96,06 \%$. Pode parecer uma diferença muito pequena, mas é considerável quando se trata de um grande volume de dados.

Foi também avaliada a influência do tamanho do corpus de treinamento na precisäo do etiquetador. Ao contrório do etiquetador baseado em trigramas, a precisão do TreeTagger deteriora vagarosamente d̀ medida que 0 corpus de treinamento diminui. Isto mostra que 0 Tree Tagger é robusto com relaçấo ao tamanho do corpus de treinamento em contraste com outros etiquetadores estatísticos.

\subsubsection{MXPOST}

MXPOST é um etiquetador baseado no modelo de Máxima Entropia e foi desenvolvido por Ratnaparkhi (1996). Utiliza várias características da palavra e do contexto de forma similar ao etiquetador MBT.

O modelo final tem um parâmetro de peso para cada valor de atributo que for relevante para estimar a probabilidade $P$ (etiqueta|atributos), e combina as indicações de diversos atributos em um modelo probabilístico explícito. Em contraste com outros etiquetadores, as palavras conhecidas e desconhecidas são processadas pelo mesmo método.

Este etiquetador também não possui um mecânismo para armazenar em separado informações léxicas sobre a palavra em foco. A palavra é apenas mais um atributo no modelo probabilistico. Como resultado disto, não é possível fazer generalizações sobre grupos de palavras para as quais o mesmo conjunto de etiquetas é possível.

Na fase de etiquetagem, o algoritmo de busca beam search é utilizado para encontrar a sequência de etiquetas mais provável para todo o período. 


\subsubsection{Etiquetador Neural}

As pessoas aprendem mudando a estrutura da rede neural que compõe seus cérebros. Por que então não deveríamos construir um programa de aprendizado começando com uma rede simples e fazer conexões nessa rede conforme indicado pelo esforço no ambiente? Elaine Rich

Etiquetadores neurais fazem o "levantamento" do corpus implicitamente, como parte de seu funcionamento (Benello et al., 1989).

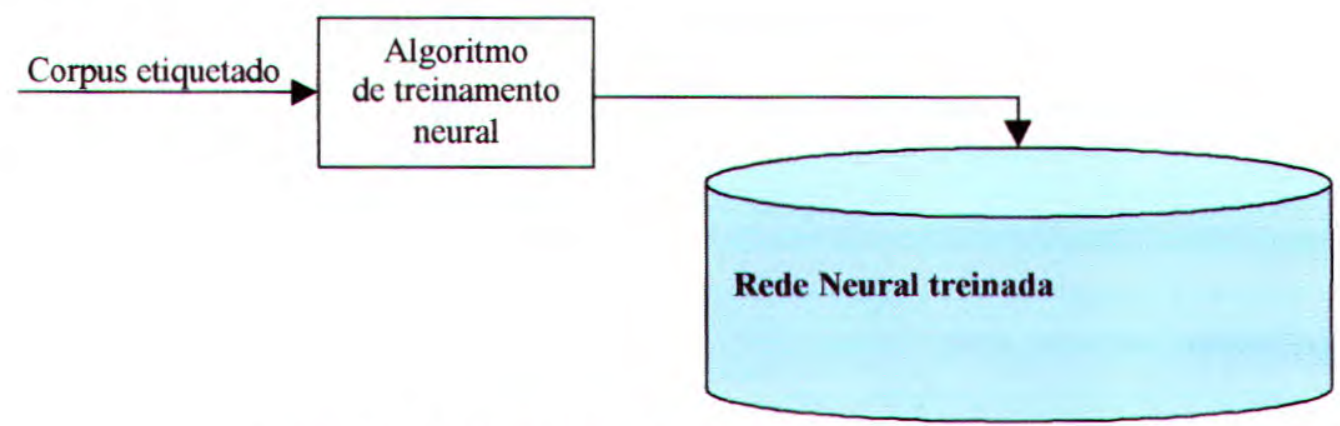

Figura 16 - Etiquetador Neural - Módulo de treinamento

Tem como vantagens as mesmas dos estatísticos: dispensa a elaboração prévia do léxico que é elaborado automaticamente, e é altamente adaptável. No entanto, também apresenta problemas. A fase de treinamento de redes neurais exige cuidado na elaboração de esquemas apropriados de treinamento para evitar superespecialização ou supergeneralização das redes (Benello et al., 1989; Braga et al., 1998).

Um outro fator interessante é que o etiquetador neural não precisa de um corpus etiquetado muito grande, o que facilita no caso da etiquetagem do português já que não existem corpus para o português com I milhão de palavras como existem para o inglês. Baseado nisto, na Universidade Nova de Lisboa, em Portugal, foi desenvolvido um etiquetador neural que foi treinado para o português continental e português do Brasil (Marques \& Lopes, 1996). Um outro exemplo clássico é o Net-Tagger (Schmid, 1994). 


\subsubsection{Net-Tagger}

O Net-Tagger é um etiquetador neural que foi desenvolvido para o inglês por Schmid (1994). Consiste de uma rede neural MLP (Multilayer Perceptron) com uma camada simples feed-forward para a desambigüização e de um léxico (Figura 17). A entrada da rede consiste de vetores de probabilidades léxicas das etiquetas para as palovras na contexto da palavra corrente. A saída da rede é também um vetor de probabilidades que realimenta a rede como vetor de probabilidade do palavra anterior. O etiquetador é treinado com corpus etiquetado usando uma modificação do algoritmo backpropagation. Assim como o TreeTagger, o Net-Tagger também usa um léxico de sufixos para descobrir as possibilidades de etiquetos para uma palavra desconhecida.

Para seu treinamento usou-se 2.000 .000 palavras do Penn Treebank Corpus. Para teste utilizou-se um corpus com 100.000 palovras. 0 contexto limitou-se as três palavras anteriores ( $p$ $=3$ ) e as duas seguintes $(f=2)$.

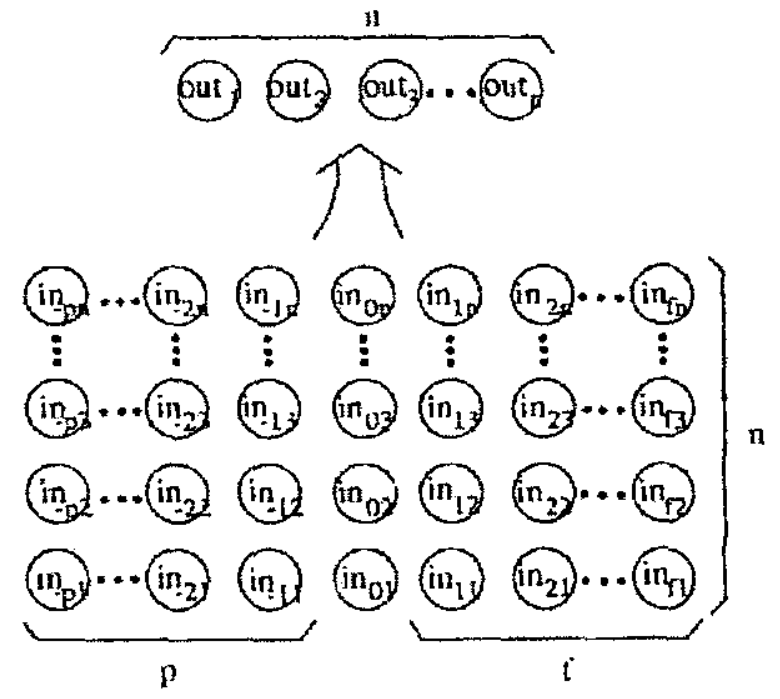

Figura 17 - A arquitetura do Net -Tagger (Schmid, 1994)

A rede neural gastou 4 milhöes de ciclos no treinamento. O treinamento foi feito em uma Sparc 10 e levou um dia. Para a etiquetagem de um corpus com 100.000 palavras levou 12 minutos. O Net-Tagger obteve $96.22 \%$ de precisão, contra 96,06\% do trigram tagger (Kempe, 1993) e $94,44 \%$ do HMM tagger, usando os mesmos dados de treinamento e teste. 


\subsection{A Rede Neural do Net-Tagger}

Na camada de saída da rede MLP, cada unidade corresponde a uma das etiquetas do conjunto de etiquetas. A rede aprende durante o treinamento a ativar a unidade de saída que representa a etiqueta correto e a desativar as demais unidades. Portanta, na rede treinada a unidade de saída com maior ativação indica qual etiqueta deve ser anexada d palavra que está sendo etiquetada naquele instante.

A entrada da rede contém toda a informação que o sistema tem sobre as possíveis classificações da palavra corrente, das $p$ palavras que a antecedem e das $f$ seguintes. Ou seja, para cada etiqueta pos, e cada uma das $p+1+f$ palavras no contexto, há uma unidade de entrada cuja ativaçäo $i_{i j}$ representa a probabilidade da palavra, ter a etiqueta pos.

Da palavra que está sendo etiquetada e das palavras seguintes, a única informação conhecida é a probabilidade léxica $P\left(\right.$ pos $_{j} \mid$ palavra $)$, que nada mais é do que o número de vezes que a palavra aparece com esta etiqueta dividido pelo número de ocorrências da palavra (Maximum Likelihood Principle). Como esta probabilidade, näo leva em conta nenhuma influência contextual, a palavra que está sendo etiquetada e as palavras seguintes possuem a mesma representação de entrada (I):

$$
\mathrm{in}_{\mathrm{ij}}=\mathbf{P}\left(\text { pos }_{\mathrm{j}} \mid \text { palavra } \mathrm{i}_{\mathrm{i}}\right), \text { se } \mathrm{i}>0
$$

Já sobre as palavras anteriores se tem mais informaçäo, visto que já faram etiquetadas. Entâo, ao invés de se utilizar a probabilidade léxica, é utilizado o valor de ativação de saída da unidade do instante do tempo de processamento (2):

$$
\ln _{i j}(t)=\operatorname{outj}(t+i), \text { se } i<0 \text { (2) }
$$

Copiar a ativação de saída da rede na entrada introduz recorrência dentro da rede. Isto complica o processo de treinamento, porque a saída da rede näo está correta quando 0 treinamento é iniciado. Portanto, ao invés disso, é utilizada a "maior média da saída atual" no início do treinamento.

A rede é treinada com um corpus etiquetado. Os valores de ativação são zero para todas as unidades de saída, exceto para a unidade que corresponde a etiqueta correta que recebe 0 valor de ativação l. 
A rede pode usar ou não camadas intermediárias. Com camadas intermediárias o resultado obtido pode ser melhor. No entanto, uma rede com camadas intermediárias precisa de mais treinamento do que uma sem e também corre o risco de ter problemas com a capacidade de generalizaçäo (quando a rede começa a aprender coisas irrelevantes e se torna incapaz de generalizar).

Nos dois tipos de rede, a etiquetagem de uma palavra é feita copiando as etiquetas prováveis da palavra corrente e suas vizinhas nas unidades de entrada, propagando as ativaçöes pela rede até as unidades de saída e vendo qual unidade de saída possui o maior valor de ativaçāo. A etiqueta correspondente a esta unidade de maior valor de ativação será anexada a palavra atual. Se o segundo maior valor de ativaçāo for muito próximo do primeiro, podemos ter uma etiqueta alternativa.

\subsection{O Léxico do Net-Tagger}

O léxico contém as etiquetas prováveis para cada palavra. Tem três partes: fullform, suffix e default.

Quando se vai procurar uma palavra no léxico, a busca é feita primeiro no léxico fullform. Se a palavro for encontrada, é retornado um vetor de etiquetas prováveis, se não, letras maiúsculas são transformadas em minúsculas e a busca é feita novamente. Caso após a segunda busca a palavra nâo tenha sido encontrada, a busca é feita entäo no léxico suffix. Se nenhum destes passos tiver resolvido, a entrada defoult do léxico é retornado.

O léxico fullform é criado a partir do corpus de treinamento. Depois, o número de ocorrências de cada par palavra/etiqueta é contado. Em seguida, todas as etiquetos com probabilidade estimada em menos de $1 \%$ são removidas, isto porque em grande parte dos casos elas säo o resultado de erros no corpus original.

A segunda parte do léxico, o léxico suffix, forma uma árvore. Cada nó da árvore, exceto o raiz é marcado com um caracter. No final, vetores de etiquetos provóveis săo anexados. Durante a busca, a árvore de sufixos é olhada a partir da raiz. A busca se inicia a partir do fim do palavra. 
Por exemplo, a palavra tagging é procurada no léxico suffix mostrado na Figura 18. A busca se inicia no nó raiz e vai para o nó com o caracter $\mathrm{g}$, em seguida se move para o nó n e logo depois para o nó i. O vetor de provóveis etiquetos é então retornado.

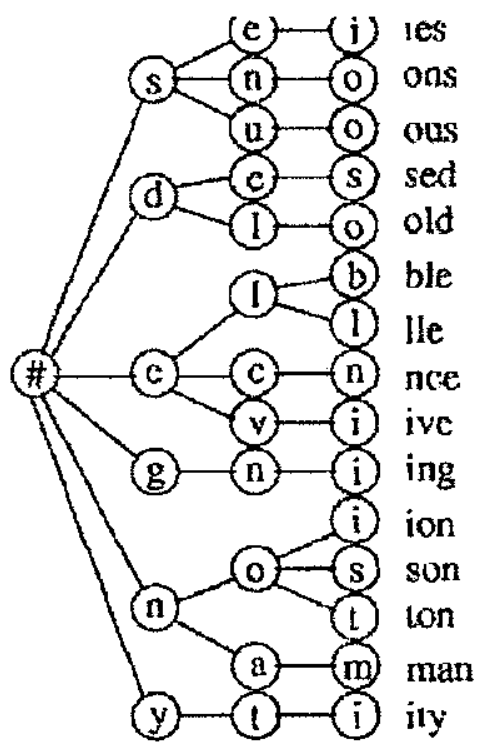

Figura 18 - Léxico Suffix do Net-Tagger (Schmid, 1994)

$O$ léxico suffix é construido outomaticamente a partir do corpus de treinamento. Primeiro, a árvore de sufixos é construída a partir de todas as palovras que tenham pelo menos comprimento cinca e que tenham sido etiquetadas como de classe aberta e então a freqüência das etiquetas é contada para cada um destes sufixos e adicionada a cada nó correspondente.

\subsubsection{Etiquetador Neural da Universidade Nova de Lisboa}

Este etiquetador neural foi desenvolvido por Marques e Lopes (1996) na Universidade Nova de Lisboa em Portugal. Ele será referenciado como Etiquetador de Portugal.

Ao contrório do Net-Tagger, que utilizou um código para a rede neural, as topologias de redes neurais foram testadas e treinadas usando um simulador de redes neurais: o Stuttgart Neural Network Simulator (SNNS). As unidades neurais sẩo de três tipos: entrada, intermediária e saída. 0 
SNNS possui vários algoritmos de aprendizado, mas os únicos utilizados neste trabalho foram o backpropagation e o momentum backpropagation.

Os valores de entrada säo recebidos diretamente de um arquivo chamado pattern. Os valores de saída podem ser passados para um arquivo (quando se está utilizando a rede neural para marcar um texto), ou podem ser recebidos do arquivo pattern (quando se está treinando a rede). O arquivo pattern pode ter vários vetores de entrada com valores de saída associados. Pode-se também ordenar os vetores de entrada em conjuntos com os valores de salda sendo computados para os conjuntos. O trabalho com conjuntos de vetores serve para possibilitar 0 uso do modelo de $n$-gramas. As unidades intermediários podem também receber os valores das unidades anteriores e passar os para as próximas.

Cada unidade no SNNS tem duas funçôes: função de ativação e função de saída. No trabalho de Portugal todas as redes fizeram uso do função de ativação logística.

Após o corpus ter sido processado. o SNNS pode ser utilizado para marcar o texto. Estes procedimentos foram implementados usando comandos de processamento de texto do Unix, a linguagem de programaçāo awk e uma ferramenta desenvolvida previamente chamada classifier. As ferramentas desenvolvidas no UNIX foram:

- classifier_795 - responsável por associar o vetor de probabilidades com cada palavra do corpus é usualmente chamado pelos scripts: evaluate_tagger.x e train_tagger.x;

- build_dic_795.x - constrói o dicionário usando o corpus etiquetado como base;

- rand_split.x - este script divide o corpus randomicamente;

- create_tdnn - transforma arquivos de treinamento ou de teste em arquivos no formato requerido pelo SNNS;

- evaluate_tagger. $x$ - marca o corpus de teste com a rede usada anteriormente e compara o resultado com o corpus etiquetado manualmente, calculando o acerto;

- train_tagger. $x$ - prepara o arquivo de treinamento para treinar a rede;

- unigram_tagger.x - Dá a base-line, através da associaçāo de cada palavra do corpus d̀ etiqueto mais freqü ente para aquela palavro. 
conhecimentos inconsistentes no sistema. Mas, apesar de todos estes problemas, a precisäo dos etiquetadores estatísticos é bastonte alta: 95-97\%, principalmente para o inglês (Voutilainen, 1995).

Com todos estes aspectos, o que se percebe é que se deve pensar cuidadosamente $a$ respeito da abordagem que se vai utilizar. Ou, então, optar por uma abordagem híbrida, que é uma alternativa bastonte interessante porque aumenta as vantagens de cada uma em particular e diminui as desvantagens encontradas na abordagem probabilistica e lingüística.

Eric Brill (1994a), descreve um etiquetador contendo um componente estatístico e outro simbólico. O componente estatístico dá sua contribuiçäo somente durante o treinamento, produzindo regras que são puramente simbólicas. Quando usado põe em ação estas regras que podem ser modificadas. Já o trabalho de Pacheco (Pacheco et al., 199ó) é simbólico ao trator dos itens funcionais, e é probabilístico ao tratar dos itens de classes abertas. No entanto, é feita uma avaliação sobre o que realmente dentre estes itens de classes abertas necessito de uma abordagem probabilística para que não haja desperdício de tempo de processamento. Nesta abordagem, a etiquetagem gramatical tento utilizar ao máximo o potencial das abordagens estatística e simbólica. Baseia-se no fato de que um texto de uma dada língua possui algumas características básicas bem definidas que se repetem freqü entemente nos textos. Quando se faz uso apenos da abordagem probabilística acaba-se desperdiçando recursos e tempo de processamento. A solução dada a este problema foi aproveitar da abordagem simbólico a utilização de informaçōes preestabelecidas somente para os itens funcionais, que aparecem com muita freqüência em textos para todos os assuntos. E da probabilística aproveitar a utilização de procedimentos dependentes de contexto para o estabelecimento da etiquetagem sintática dos elementos das classes gramaticais abertos, que variaróo de um contexto para outro e de assunto para assunto. Um etiquetador sob esta abordagem possuiria um estodo inicial simbólico e um final estatístico (Figura 20), exatamente o inverso do etiquetador de Brill.

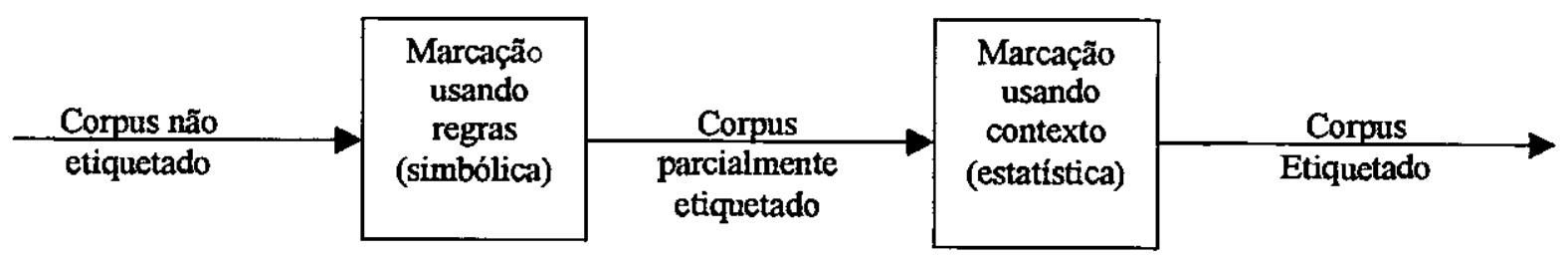

Figura 20 - Etiquetador segundo a abordagem funcionalista 


\subsubsection{Etiquetador baseado em transformação dirigida por erro}

Este etiquetador hibrido baseia-se no algoritmo de Aprendizado Baseado em Transformaçäo Dirigida por Erro (Brill, 1994a, 1995, 1997b) desenvolvido por Brill (Figura 21). Tal algoritmo pode ser aplicado a vários problemas, como, por exemplo, a etiquetagem morfossintática e a análise sintática (Brill, 1994a, 1996a, 1996b).

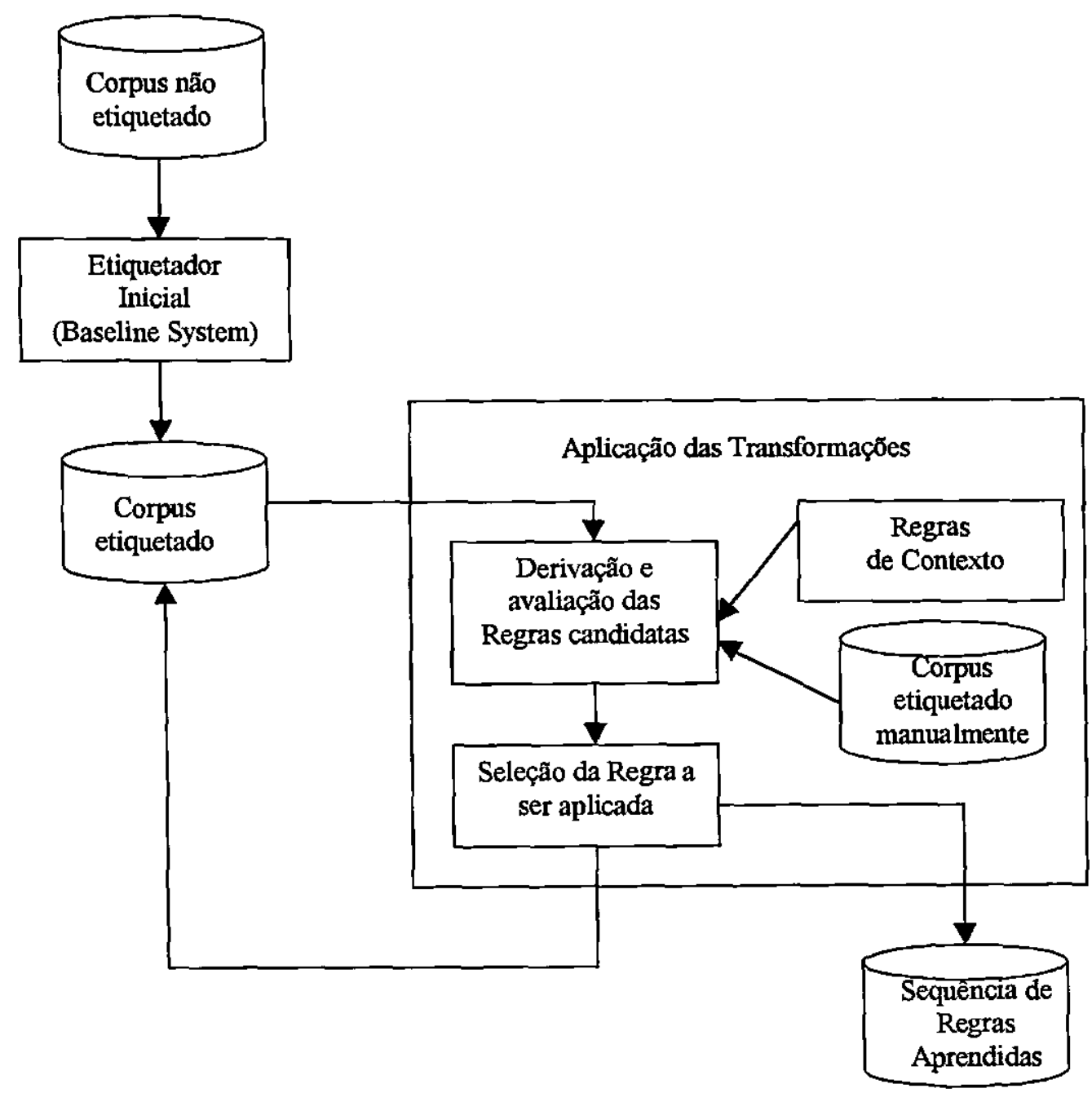

Figura 21 - Algoritmo de Aprendizado baseado em transformação dirigida por erro 


\subsubsection{O Algoritmo}

Como mostrado na Figura 21, o corpus näo-etiquetado passa primeiro por um processo de etiquetagem inicial. Esta é uma fase crucial para o sucesso do algoritmo e pode ser baseada em informaçōes sobre freqüência de categorias para cada palavra de um léxico. Após ter sido etiquetado, o corpus é comparado com a etiquetagem correta (o corpus manualmente etiquetado) e uma lista de transformaçōes é aprendida para ser aplicada à saída do etiquetador inicial. Cada transformação é composta pela regra de reescrita e pelo contexto que vai desencadear esta regra.

A coda interação de aprendizado, a transformaçãa para melhorar a etiquetagem é encontrada de acordo cam uma funçäo objetivo utilizada e entảo adicionada à lista ordenada de transformaçōes. $O$ aprendizado continua até que não sejam mais encontradas transformações que possam melhorar o corpus etiquetado.

A Figura 22 mostra um exemplo de aprendizado de transformaçöes. Neste exemplo assumi-se que existem apenas quatro transformaçỏes possíveis (TI, T2, T3 e T4) e que a funçäo objetivo utilizada seja o número total de erros. O carpus näo etiquetado sofre a etiquetagem inicial, e o resultada é um corpus etiquetado com 5.100 erros. Em seguida, cada uma das transformações sảo aplicadas em ordem. Neste exemplo, nota-se que T2 foi a transformaçảo que possibilitou a maior redução de erros, sendo assim é colocado como a primeira transformação da lista. É então aplicada a todo o corpus e o aprendizado continua. Nota-se que a transformação que mais diminuiu o número de erros foi T3, entảo T3 é aprendida como a segunda transformação. da lista. Após aplicar o etiquetador de estado inicial, T2 e T3 verifica-se que näo há mais reduçöes no número de erros aplicando transformaçōes, entäo o pracesso termina (seqüência mostrada na Figura 22). 


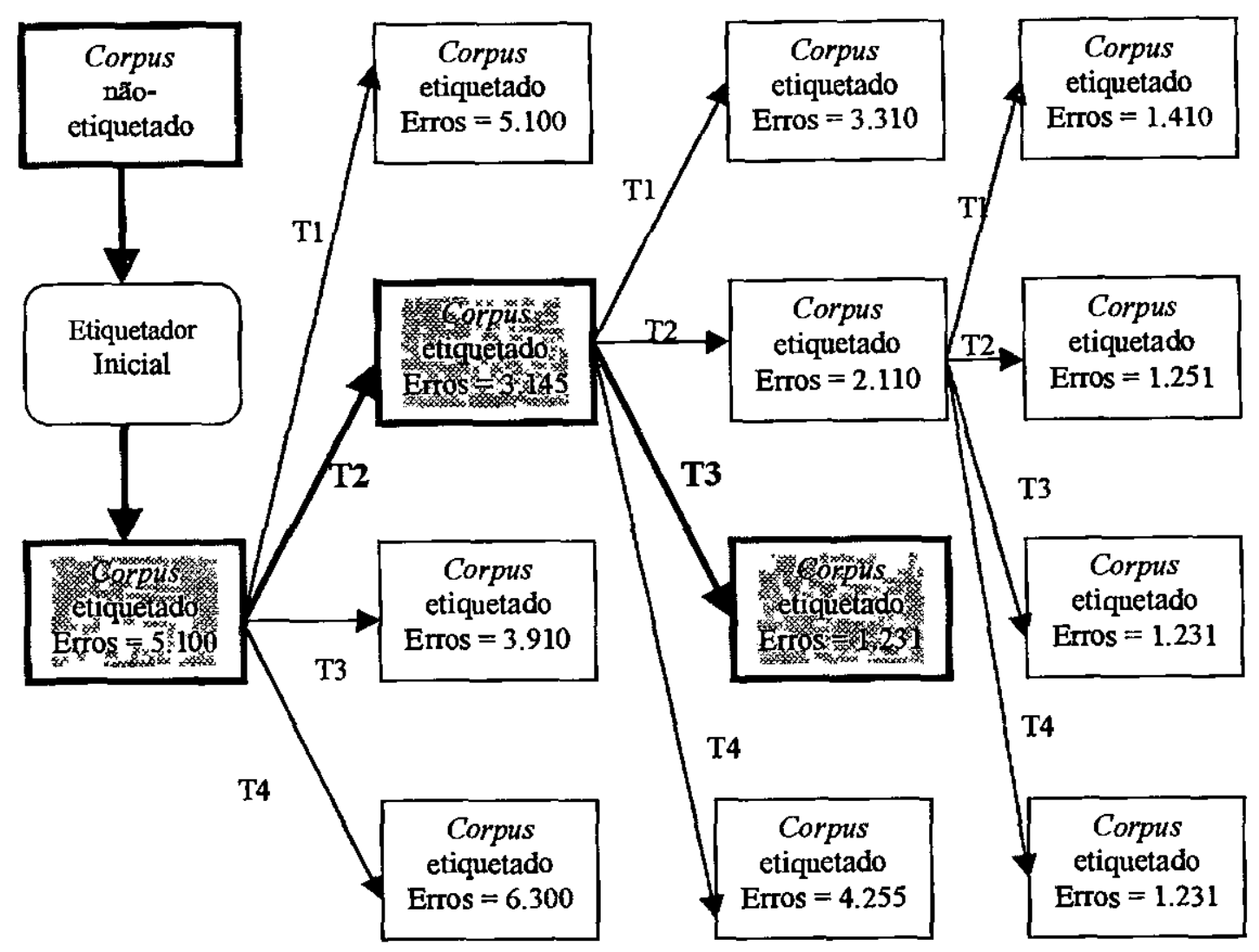

Figura 22 - Exemplo de Aprendizado Baseado em Transformaçāo Dirigida por Erro (Brill,1994a)

\subsubsection{O Etiquetador}

O sistema é composta por dois módulos de etiquetagem: um inicial e um contextual. 0 inicial compila o corpus etiquetado, criando um léxico, em que para cada palavra há apenas sua etiqueta mais comum. Assim, na etiquetagem inicial, ele atribuirá a etiqueta mais provável para a palavra, conforme descrito no léxico (Figuro 23).

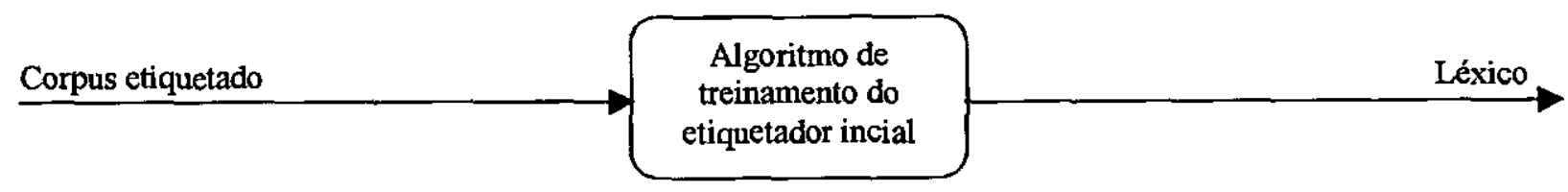

Figura 23 - Etiquetador baseado em Transformaçāo dirigida por erro: Treinamento do etiquetador inicial 
O Etiquetador inicial passui também um pracedimento para a tratamento de palavras desconhecidas. Define que as palavras desconhecidas que iniciam por letra maiúscula tendem a ser substantivas próprios e o que as que se iniciam por letras minúsculas ten dem a ser substantivo comum.

O Etiquetador contextual inferirá automaticamente as regras do contexto, a partir do corpus de treinamento etiquetado. Isto é feito fazendo-se detiquetagem do corpus de treinamento usando a etiquetadar inicial e a seguir camparanda-se outamaticamente as resultados e gerandose a lista de transformaçāes. A partir da aplicação desta lista de transformaçōes no corpus, serâo geradas as regras de cantexto. As aplicações que gerarem o melhor resultado serôo utilizadas como regras de contexto (Figura 24).

Assim, obtém-se um conjunto de regras que analisa a atribuiçāo das etiquetas feita pelo etiquetador inicial e as corrige conforme o contexto no qual as palavras aparecem.

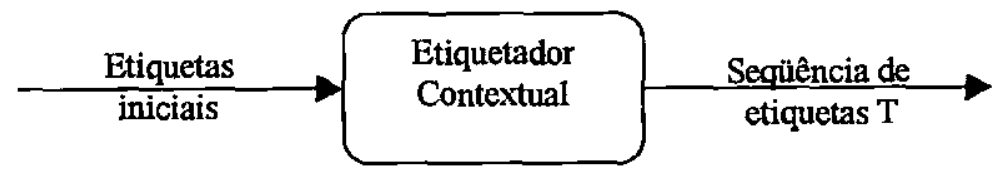

Figura 24 - Etiquetador baseado em transformação dirigida por erro: Etiquetador Contextual

As regras de contexto (transformaçỏes), alteram uma etiqueta de $X$ para $Y$ se:

1) A palavra näo aparece no corpus de treinamento (Tabela 2)

2) A palovra foi etiquetada como Y pelo menos uma vez

As regras padem fazer referência a etiquetas anteriares/posteriores - regras não lexicalizadas ( $\left(\begin{array}{lll}\text { a } & 6\end{array}\right)$ - ou a palavras anteriores/ posteriores - regras lexicalizadas $(7$ a 14 ) como mostrado na Tabela 1.

Tabela 1 - Regras de Conterto do Etiquetador Baseado em Transformação dirigida por erro Mude de tag a para tag b quando:

1) A palavra anterior (posterior) foi etiquetada como $z$

2) A palavra duas posições antes (depois) foi etiquetada como $z$ 


\begin{tabular}{|l|}
\hline 3) Uma das duas palavras anteriores (posteriores) foi etiquetada como $z$ \\
\hline 4) Uma das três palavras anteriores (posteriores) foi etiquetada como $\mathrm{z}$ \\
\hline 5) A palavra anterior foi etiquetada como z e a posterior como w. \\
\hline $\begin{array}{l}\text { 6) A palavra anterior (posterior) foi etiquetada como } \mathrm{z} \text { e a palavra "duas depois (antes)" foi } \\
\text { etiquetada como } \mathrm{w}\end{array}$ \\
\hline 7) A palavra que vem antes (depois) é $\mathrm{w}$ \\
\hline 8) A segunda palavra antes (depois) é w \\
\hline 09) Se uma das duas palavras que vem antes (depois) é w \\
\hline 10) Se a palavra atual é w e a anterior (posterior) é $\mathrm{x}$ \\
\hline 11) Se a palavra atual é w e a palavra anterior (posterior) é classificada $\mathrm{z}$ \\
\hline 12) Se a palavra atual é $\mathrm{w}$ \\
\hline 13) Se a palavra anterior (posterior) é we a classificação anterior (posterior) é t \\
\hline 14) Se a palavra atual é w e a palavra anterior (posterior) é w2 e a classificação anterior \\
(posterior) ét \\
\hline $\begin{array}{l}\text { We } x \text { se referem a todas as palavras no corpus de treinamento, e z se refere a todas as } \\
\text { classes }\end{array}$ \\
\hline
\end{tabular}

Tabela 2 - Regras para palavras desconhecidas

\begin{tabular}{|l|}
\hline Mude a etiqueta de uma palavra desconhecida de $X$ para $Y$ se: \\
\hline $\begin{array}{l}\text { 1. Apagando prefixo(sufixo) } x,|x|<=4 \text {, resulta em uma palavra ( } x \text { é qualquer string de tamanho } \\
\text { 1 a 4) }\end{array}$ \\
\hline 2. O primeiro (último) $(1,2,3,4)$ caracteres da palavra é $x$ \\
\hline 3. Adicionando a string $x$ como prefixo (sufixo) resulta em uma palavra $(|x|<=4)$ \\
\hline 4. A palavra w nunca aparece imediatamente a esquerda(direita) da palavra \\
\hline 5. O caracter $z$ aparece na palavra \\
\hline
\end{tabular}

Através de todo este processo o etiquetador consegue para a língua inglesa uma precisäo de $97 \%$, usando apenas 300 regras que foram automaticamente inferidas. Para tanto se utilizou um corpus de treinamento com I milhäo de palavras (Brill, 1994a). Já o etiquetador simbólico para o inglês de Voutilainen (1995), descrito na Seção 3.1.1, possui 1.185 regras, além de mais 200 regras heurísticas opcionais. 



\section{ETIQUETADORES TREINADOS}

Este capítulo mostra as decisōes de projeto que foram tomadas neste trabalho com relação ao conjunto de etiquetas, corpus de treinamento e teste, abordagens de etiquetagem e métodos de avaliação (Seção 4.1). Traz também os experimentos realizados com cada etiquetador e seus resultados individuais (Seção 4.2).

\subsection{Definiçöes de projeto}

Intellectuals solve problems; geniuses prevent them. - Albert Einstein

Ao se decidir contruir um etiquetador deve-se ter em mente além da língua alvo, quais aplicaçōes farăo uso dos textos etiquetados. O requisito que norteou este projeto foi a construçăo de um etiquetador para o português contemporâneo do Brasil que possa ser utilizado para diversas aplicaçōes, mas que em particular forneça uma boa base para o analisador sintático do ReGra. Baseando-se neste fato definimos o conjunto de etiquetas (Nilc tagset) que se encontra no apêndice $\mathrm{A}$ e os tipos de texto do corpus de treinamento e teste?

Como os etiquetadores são utilizados em ambientes totalmente abertos e repletos de palavras novas e novas possibilidades de etiquetas para algumas palavras, houve uma preocupaçăo 
em encontramos nos artigos da literatura sobre técnicas para estimar a precisão real dos etiquetadores, isto é, como os etiquetadores se comportariam na etiquetagem de textos do mundo real,

\subsubsection{Corpus de treinamento e teste}

The things which hurt, instruct. - Benjamin Franklin

Os trabalhos descritos na literatura de etiquetagem da língua inglesa utilizam para treinamento e teste de um milhão a dois milhōes de palavras, pois existem imensos corpora para esta língua. Existem muitos corpora etiquetados para o inglês, por exemplo: Brown Corpus, BNC, Wall Street Journal (parte do corpora Penn Treebank, contém 1.200.000 palavras). No entanto, para português não existe um corpus manualmente etiquetado desta magnitude e não existiam também corpus formados por diferentes tipos de texto (corpus mistos). O primeiro passo de projeto apbs a definição do conjunto de etiquetas foi a construção de um corpus de treinamento e teste misto que atendesse as necessidades do projeto ReGra, um corretor gramatical de uso geral e as demais aplicações que fazem uso de etiquetadores.

Nosso objetivo inicial era começar com um corpus manualmente etiquetado com cerca de 200.000 palavras cuja etiquetagem manual seria feita com o auxílio de uma ferramenta semiautomática de auxilio à etiquetagem e em cerca de seis meses conseguir um corpus de I milhão de palavras. Dado que a correção da etiquetagem automática mostra ser mais rápida que a etiquetagem manual (Marcus et al., 1993), o processo a ser seguido seria chegar aos I milhão de palavras através de um processo incremental e -cíclico de treinamento - etiquetagem e correção de 200 em 200 mil palavras. Devido à dificuldade do processo, não conseguimos atingir esta marca até o momento de escrita desta dissertação.

Para compor nosso corpus de treinamento e teste selecionamos textos do corpora do Nilc pertecentes a três genêros: didático, jornalístico e literário. Um dos objetivos deste trabalho é avaliar os etiquetadores por gêneros. A escolha destes três genêros foi feita para se abranger em particular:

\footnotetext{
${ }^{9} \mathrm{O}$ corpus de treinamento e teste se encontra disponível em (Disponivel em http://www.nilc.icmc.sc.usp.br/tools.html/TAGCORPUS
} 
1) textos simples, isto é, aqueles que seguem uma estrutura formal fixa, por exemplo a escrita técnica (didáticos);

2) textos mais próximos da linguagem viva (jornalístico);

3) textos com estrutura livre, isto é, com formas menos comuns como ordem inversa por exemplo, (literários).

Barthes (1986) deixa mais clara a diferença entre estes tipos de textos definindo a escritura de grau zero, a escritura neutra e a escritura literária. Segundo Barthes, a escritura de grau zero seria uma escritura indicativa, amodal, em suas palavras uma escritura de jornalista, mas que às vezes faz uso de estruturas optativas. A escritura neutra seria uma espécie de língua básica, distanciada por igual das linguagens vivas e da linguagem literária propriamente dita, ou seja, um texto simples sem coloquialismos, regionalismos e neologismos. A escritura literária seria composta pelos textos literários que conhecemos, uma estrutura livre que abranje desde a prosa clássica a poesia moderna.

Além dos genêros de texto que farão parte do corpus, temos também que decidir se serão ou não mantidos títulos, frases entre parênteses e resumos nos textos. No nosso caso não mantivemos os títulos, mas mantivemos os textos entre parênteses e năo precisamos nos preocupar com resumos, que não apareciam nos textos escolhidos. Já Kim \& Norgard (1998), na preparação do corpus para ser etiquetado para a uso no processo de construção de dicionários de associaçōes baseadas em sintagmas nominais para mapeamento de vocubulário, mantém os títulos e excluem textos entre parênteses dizendo que é muito difícil de tratar todas as variações de textos que podem aparecer entre parênteses, independente do algoritmo utilizado.

Tinhamos, assim, um corpus de treinamento e teste com cerca de 200.000 palavras com um terço de textos didáticos, um terço de textos jornalísticos e um terço de textos literários. No entanto, no final do prazo em que imaginamos que teríamos I milhão de palavras, dezembro de 1999, tinhamos apenas cerca de 100.000 palavras etiquetadas. Fato que ocorreu em parte por termos subestimado a tarefa de etiquetagem, em parte devido às várias alteraçōes do NILC tagset (quatro) que acarretaram em remarcaçōes do corpus e em parte pela falta de uma pessoa qualificada para cuidar unicamente da tarefa de verificação de etiquetagem.

Com todos estes contratempos, em 20 de julho de 2000, obtivemos a última versão do nosso corpus de treinamento e teste contendo 104.963 palavras, que foi utilizada em todos os 
experimentos descritos neste trabalho. Como o corpus manual é menor do que o planejado de 200.000 palavras não mantivemos a proporção desejada de cada um dos tipos de texto no corpus como mostra a Tabela 3.

Tabela 3 - Corpus de treinamento e teste

\begin{tabular}{|l|l|}
\hline Tipo de Corpus & Tamanho do corpus \\
\hline D - Didático & 16.256 palavras \\
\hline J - Jornalístico & 56.653 palavras \\
\hline L - Literário & 32.054 palavras \\
\hline
\end{tabular}

\subsubsection{Etiquetagem manual de um corpus de treinamento e teste}

Quem se mete em atalhos não se livra de trabalhos - Ditado popular

Uma atividade importante quando da contruçăo de um corpus manualmente etiquetado é o acompanhamento durante todo o processo de etiquetagem para que se possa ter estimativas de quăo consistente será o corpus no final do processo, ou seja, qual será a taxa de erro da etiquetagem manual. Outra alternativa é fazer experimentos iniciais e generalizar sobre os valores obtidos.

No projeto do Penn Treebank (Marcus et al., 1993) por exemplo, foram feitos experimentos para se estimar qual seria a consistência do corpus manualmente etiquetado por linguistas e corrigido por linguistas após a etiquetagem automática. Nestes experimentos quatro linguistas estavam envolvidos com a etiquetagem de oito textos com 2.000 palavras cada selecionados do Brown Corpus, sendo que quatro seriam manualmente etiquetados e quatro seriam apenas corrigidos. Fizeram então experimentos para avaliar a taxa de discordância entre cada par de linguistas. A taxa ficou em torno de $7.2 \%$ nos textos manualmente etiquetados e 4. $1 \%$ nos textos corrigidos. E a média de discordåncia entre o que foi feito por cada linguista e os benckmarks (cuidadosamente corrigidos) ficou em torno de $5.7 \%$ na tarefa de etiquetagem e $3.4 \%$ na tarefa de correção.

Neste projeto, não foram feitos os experimentos iniciais para se estimar a consistência dos dois tipos de etiquetagem (etiquetados manualmente e com correção manual), mas estimamos a 
taxa de erro da etiquetagem manual de outra forma. Foi feita uma seleção de trechos dentro de cada tipo para que fossem assim corrigidos cuidadosamente palavra por palavra e pudessemos assim estimar a taxa em todo o corpus. A Tabela 4 mostra as taxa de erro em cada trecho e a estimativa para todo o corpus.

Tabela 4 - Taxa de erro na etiquetagem manual

\begin{tabular}{|l|l|l|l|l|}
\hline & Tamanho & $\begin{array}{l}\text { Número de } \\
\text { erros no trecho }\end{array}$ & $\begin{array}{l}\text { Número de } \\
\text { erros estimado } \\
\text { no corpus }\end{array}$ & $\begin{array}{l}\text { Taxa de erro } \\
\text { estimada no } \\
\text { corpus }\end{array}$ \\
\hline $\begin{array}{l}\text { Trecho formado por períodos de } \\
\text { tertos didáticos }\end{array}$ & 322 palavras & $5^{10}$ & 252 & $1,55 \%$ \\
\hline $\begin{array}{l}\text { Trecho formado por períodos de } \\
\text { tertos jornalísticos }\end{array}$ & 927 palavras & $30^{11}$ & $1833 \%$ & $3,23 \%$ \\
\hline $\begin{array}{l}\text { Trecho formado por períodos de } \\
\text { textos literários }\end{array}$ & 486 palavras & $14^{12}$ & $923 \%$ & $2,88 \%$ \\
\hline \begin{tabular}{l} 
Todo o corpus \\
\hline
\end{tabular} & 3008 & $2,86 \%$ & \\
\hline
\end{tabular}

\footnotetext{
${ }^{10}$ Das 5 palavras com etiquetagem errada duas estāo como CONJCOORD (existem 8 destas no trecho e 456 em todos os textos didáticos), uma está como PD (existem 6 destas no trecho e 130 em todos os textos didáticos), uma está como PPS (existem 6 destas no trecho e 56 em todos os textos didáticos) e uma está como VTD (existem 24 destas no trecho e 705 em todos os textos didáticos).

"Das 30 palavras com etiquetagem errada uma está como VNT (existem 6 destas no trecho e 562 em todos os textos jornalísticos), duas estão como LCONJ (existem 8 destas no trecho e 247 em todos os textos jornalísticos), duas estão como ART (existem 77 destas no trecho e 4398 ern todos os textos jornalísticos), três estäo como CONJSUB (existem 8 destas no trecho e 580 em todos os textos jornalísticos), três estäo como ADV (existem 31 no trecho, 1869 ern todos os textos jornalísticos), uma está como VAUX (existern 8 no trecho e 779 ern todos os textos jornalísticos), cinco estão como VTD (existem 60 no trecho e 3523 em todos os textos jornalísticos), duas estäo como VTI (existem 6 no trecho e 779 em todos os textos jomalisticos), uma está como PREP+ART (existem 60 no trecho e 3715 em todos os textos jornalísticos), três estāo como CONJCOORD (existem 40 no trecho e 1532 ern todos os textos jornalísticos), uma está como PR (existem 102 no trecho e 598 em todos os textos jomalísticos), duas estão como N (existem 214 no trecho e 12100 em todos os textos jornalísticos), uma está como ADJ (existem 69 no trecho e 3596 em todos os textos jomalísticos), duas estão como PREP (existem 91 no trecho e 5082 em todos os textos jomalísticos) e uma está como PAPASS (existem 2 no trecho e 29 em todos os textos jomalisticos).

${ }^{12}$ Das 14 palavras com etiquetagem errada uma está como PREP+ART (existem 27 no trecho e 1784 em todos os textos literários em todos os textos literários), duas estão como VNT (existern 6 no trecho e 767 em todos os textos literários), tres estäo como PREP (existem 33 no trecho e 2293 em todos os textos literários), uma está como ADJ (existem 40 no trecho e 2406 em todos os textos líterários), uma está como VTI (existem 3 no trecho e 431 em todos os textos literánios), uma está como VAUX (existem 5 no trecho e 261 em todos os textos literánios), uma está como ADV (existem 28 no trecho e 1426 ern todos os textos literários), duas estão como VTD (existem 27 no trecho e 1727 em todos os textos literários), uma está como N (existem 100 no trecho e 6214 em todos os textos literánios) e uma está como VBI (existem 3 no trecho e 173 em todos os textos líterários).
} 


\subsubsection{Abordagens de etiquetagem}

0 ideal deve, como a árvore, ter suas raizes na terra - Graf

Para o português contemporâneo do Brasil o primeiro passo foi fazer um estudo comparativo que reunisse pelo menos um bom etiquetador por abordagem: um estatístico, um neural e um híbrido. Escolhemos os etiquetadores dentre os que são independentes da língua e que estavam disponíveis na WWW. Tentando obter dentre as possibilidades em cada abordagem o que tivesse maior precisão geral para o inglês e/ou tivesse sido utilizado em vários experimentos para outras línguas.

De acordo com este critério, escolhemos para representar a abordagem estatística os etiquetadores TreeTagger (Schmid, 1995) e MXPOST (Ratnaparkhi, 1996), para representar a abordagem neural o etiquetador elástico ( $M a$ et al., 1999) e para representar a abordagem híbrida o etiquetador TBL. (Brill 1994a). Outra meta de pesquisa foi elaborar um etiquetador simbólico descrito em detalhes na Seção 4.2.1.4.

\subsubsection{Avaliação}

0 maior objetivo de um classificador é ser capaz de predizer com sucesso a respeito de novos casos.

$\mathrm{Na}$ literatura de etiquetagem morfossintática quando se questiona a qualidade de um etiquetador os critérios levantados são:

- sua precisão geral (accuracy), que é dada pelo número de palavras classificadas corretamente dividido pelo número de palavras do seu arquivo de teste;

- se o etiquetador é independente da língua, ou seja, se pode ou não ser treinado para outras línguas;

- seu tempo de etiquetagem e tempo de treinamento;

- qual o formato de entrada exigido;

- se existem restrições quanto ao tamanho do conjunto de etiquetas, tanto para a precisão quanto para a complexidade do algoritmo de treinamento;

- se existe a possibilidade de incrementar o léxico,isto é, fazer um treinamento incremental.

Dentre estas seis questōes, apenas as questóes l e 3 exigem experimentos. A questão l é a de resposta mais difícil já que é desejado que o etiquetador tenha bons resultados em dados 
reais - e não apenas no corpus de teste. Apesar disso, em nossa revisão da literatura de etiquetagem morfossintática năo encontramos artigos que mostrassem técnicas para estimar qual seria o desempenho do etiquetador frente a dados reais. Na seção 4.1.3.1 discutiremos algumas técnicas baseadas na teoria estatística de resampling que foram utilizadas para estimar a taxa de erro verdadeira de classificadores. Em geral, no entanto, nosso objetivo não é apenas avaliar a qualidade de um etiquetadores, mas também avaliar as influências de diferentes fatores em seu desempenho - quão diferentes são os resultados de etiquetadores que utilizam diferentes abordagens de etiquetagem (Seção 4.2.1), qual a influência do conjunto de etiquetas (Seção 4.2.2), e como diferentes tipos de texto podem influenciar um etiquetador (Seção 4.2.3) - para este tipo de avaliação nos baseamos nas recomendações do EAGLES (1996). Este tipo de avaliação está descrito na Seção 4.1.3.2.

\subsubsection{Avaliação da taxa de erro verdadeira}

A taxa de erro, que é a forma mais utilizada para medir o desempenho de um classificador, pode ser calculada através da equação:

$$
\text { Taxa de erro }=\frac{\text { númerodeerros }}{\text { númerodecasos }}
$$

E pode ser de dois tipos:

1) Taxa de erro aparente: é calculada utilizando-se somente os exemplos de treinamento, ou seja, inicialmente o sistema é treinado com um conjunto de exemplos e depois é verificado quantos erros o classificador cometeu classificando exemplos que fazem parte dos mesmos do treinamento.

2) Taxa de erro verdadeira: é a taxa de erro obtida sobre um número muito grande de novos casos, selecionados independentemente dos casos usados para treinar o classificador.

A taxa de erro verdadeira é uma excelente medida para a taxa de erro de um classificador, no entanto, para muitas aplicações não se tem um número grande de exemplos, o que inviabliza 
seu cálculo. Mas através de técnicas estatísticas que apresentam de diferentes formas os exemplos ao classificador é possível obter aproximações da taxa de erro verdadeira bem mais confiáveis que a taxa de erro aparente (Dietterich, 1997).

Um dos requisitos para se estimar a taxa de erro verdadeira é manter a amostra de exemplos em ordem aleatória, ou seja, a amostra de exemplos não deve ser pre-selecionada, de forma a evitar que seja feita qualquer suposição sobre a qualidade dos exemplos. Partindo deste princípio, temos duas técnicas para estimar a taxa de erro verdadeira: Probably Approximately Correct (PAC), estimação da taxa de erro através do paradigma treinar-e-testar.

Nos cașos em que estão disponíveis um número ilimitado de casos para testar e treinar, a taxa de erro aparente é a taxa de erro verdadeira. Mas, como em geral existe um número de casos limitado, 'questionou-se quantos casos seriam necessários para que a taxa de erro aparente se tornasse efetivamente a taxa de erro verdadeira dadas uma amostra e uma taxa de erro relativamente baixa. Resultados teóricos mostraram que, tipicamente, a taxa de erro em novos casos não supera em duas vezes a taxa de erro para os exemplos da amostra. A análise Probably Approximately 'Correct (Kearns, 1994) surge dessa idéia. É uma análise de pior caso, e os resultados mostram que é necessário um grande número de casos para garantir o desempenho, já que é uma técnica para estimar a taxa de erro geral e não para uma população em particular.

No nosso caso, por não termos um conjunto grande de exemplos temos de recorrer a técnicas que dada uma amostra estimem a taxa de erro para uma população e não para todas as possíveis populaçōes, o que requer muito menos casos já que uma única distribuição da população é considerada. Uma opção é o paradigma treinar-e-testar, em que os casos săo particionados em dois grupos, um para treinar e outro para testar. Esta técnica de análise não dá garantias para todas as possíveis distribuiçōes, mas fornece uma estimativa da taxa de erro verdadeira para a população considerada. O princípio básico do paradigma treinar-e-testar é dividir a amostra de exemplos em dois grupos mutuamente exclusivos - conjunto de treinamento (utilizado exclusivamente para treinar) e conjunto de teste (utilizado exclusivamente para testar). Os dois conjuntos de casos devem ser amostras aleatórias de alguma população e devem ser independentes. Dizer que devem ser independentes significa que a única relação entre eles é o fato de pertencerem a uma mesma população. Para isso devem ser coletados em datas diferentes, ou por pesquisadores diferentes. Resultados práticos da literatura mostram que esta independência gera excelentes aproximaçōes da taxa de erro mesmo quando as amostras de 
exemplos são pequenas. Esta técnica tem cerca de $95 \%$ de confiabilidade, ou seja, não há mais de $5 \%$ de probabilidade de que a taxa de erro exceda os valores apresentados - estes valores são de consideraçōes básicas de probabilidade e estatística (Batista \& Monard, 1998).

Existem várias formas de dividir a amostra em conjunto de treinamento e teste. Uma delas é o método Holdout ou método $H$ que divide a amostra em $2 / 3$ para treinamento e $1 / 3$ para teste e quando o número de casos é maior que 1.000 casos costuma aumentar a fração de treinamento. Este método apresenta uma boa estimativa dadas amostras grandes, entretanto para amostras pequenas apresenta aproximaçōes pessimistas. Para os casos em que o conjunto de exemplos não é grande são utilizadas variaçōes de treinar-e-testar conhecidas como métodos de resampling.

Os métodos de resampling consistem em realizar vários experimentos de treinar-e-testar com diferentes partições de exemplos. Alguns exemplos destes métodos são: Random Subsampling, Cross-validation e Bootstraping.

O método Random Subsampling faz vários experimentos treinar-e-testar gerando várias partiçŏes de treinamento e teste, solucionando assim o problema de selecionar um conjunto de teste que não seja representativo o que podia acontecer no Holdout. isto é feito gerando um número de partições menor ou igual ao número de casos, em que o conjunto de teste é composto do que năo foi utilizado na formaçăo do conjunto de treinamento, como mostra a Tabela 5.

Tabela 5 - Comparação entre Holdout e Random Subsampling (Batista \& Monard, 1998)

\begin{tabular}{|l|l|l|}
\hline & Holdout & Random subsampling \\
\hline Casos de Treinamento & $\mathrm{j}$ & $\mathrm{j}$ \\
\hline Casos de Teste & $\mathrm{n}-\mathrm{j}$ & $\mathrm{n}-\mathrm{j}$ \\
\hline Iterações & 1 & Número de interações $<<\mathrm{n}$ \\
\hline
\end{tabular}

O método Cross-validation é também conhecido como k-fold Cross-validation, sendo ko número de partiçöes geradas aleatóriamente a partir da amostra de exemplos para treinar-e-testar o sistema, sendo que a amostra de exemplos é dividida em $k$ partiçōes mutuamente exclusivas. A cada iteraçäo uma partiçâo diferente é utilizada para testar o sistema e todas as outras k-1 
iterações sảo utilizadas para treinar o sistema. A taxa de erro é a média das taxas de erro calculadas dadas as diversas partições.

Um tipo especial de Cross-validation é o Leaving-one-out em que para uma amostra de $n$ exemplos são feitas $n$ iteraçōes, sendo que em cada iteração um exemplo é retirado para testar e os demais $n$ - I são utilizados para treinar. A taxa de erro é calculada dividindo-se o número de erros observados por $n$. A estimativa da taxa de erro verdadeira do Leaving-one-out é praticamente não tendenciosa e com vários conjuntos de exemplos tende a taxa de erro verdadeira, porém é um algoritmo muito caro. Por ser um algoritmo caro costuma ser utilizado apenas para amostras realmente pequenas e em casos de amostras maiores geralmente é utilizado o K-fold Cross-valiation com k igual a 10.

Apesar de quase não ser tendencioso, o Leaving-one-out possui alta variância, portanto, para amostras pequenas em que a variância tende a dominar, métodos com baixa variância tendem a apresentar melhores resultados. Um destes métodos que tem sido bastante estudado na área de estatística aplicada é o Bootstraping, sendo que dentre os estimadores Botstraping existentes dois se destacam: o eO Bootstrapinge 0.632 Bootstraping. No caso do estimador e0, 0 conjunto de treinamento consiste de n casos copiados aleatoriamente da amostra inicial - ou seja, continuam a fazer parte da amostra inicial de forma que o conjunto de treinamento poderá conter casos repetidos. E o conjuto de teste é formado por todos os casos que não fizerem parte do conjunto de treinamento. Em geral são feitas cerca de 200 interações. A aproximação da taxa de erro verdadeira é a média das taxas calculadas. Esta técnica possui uma fração média de casos não repetidos no conjunto de treinamento que é de .0632 , e uma fração média de casos não repetidos no conjunto de teste de 0.368 . O estimador .632 Bootstraping faz uso desta informação e sua estimativa da taxa de erro verdadeira é:

\section{.368 * taxa de erro aparente para todos os casos de treinamento e teste +.632 * $\mathrm{e} 0$.}

Neste trabalho foi utilizado apenas o estimador e0 Bootstraping para estimar a taxa de erro verdadeira do etiquetador TreeTagger. Quando vários experiementos de treinar-e-testar são realizados, um novo classificador é projetado com cada conjunto de treinamento, esta foi a razáo de termos escolhido o TreeTagger para este experimento, dado que é o etiquetador de treinamento mais rápido. Todos os algoritmos implementados neste trabalho para auxiliar no processo de etiquetagem, na avaliação de etiquetadoes, na combinação de etiquetadores 
(Capítulo 5) e na avaliação da combinação fazem parte de um software, chamado inCorpora descrito no Apêndice $D$.

\subsubsection{Fatores de impacto no processo de etiquetagem}

Os fatores de impacto no processo de etiquetagem são três: a abordagem de etiquetagem, o conjunto de etiquetas e os tipos de textos utilizados no treinamento e teste (EAGLES, 1996). Desta forma é essencial para um bom estudo avaliar o impacto de:

1) Diferentes métodos de etiquetagem nos resultados, comparando os resultados de diferentes etiquetadores - as diferenças na precisăo e os erros cometidos por cada método. Esta avaliação serve para indicar também quais são as etiquetas mais problemáticas para cada etiquetador, quais são as etiquetas que são confundidas da mesma forma em todos os etiquetadores testados e quais são os contextos problemáticos para todos os etiquetadores.

2) Diferentes conjuntos de etiquetas nos resultados da etiquetagem, objetivando encontrar uma forma de modificar o conjunto de etiquetas para atingir melhores resultados, e através da análise dos resultados encontrar dicas para possíveis casos difícieis de tratar na contrução do conjunto de etiquetas.

3) Diferentes tipos de textos com o objetivo de encontrar formas de medir o impacto de diferenças que possam ocorrer entre textos de treinamento e teste, já que alguns tipos de texto (por exemplo: jornalísticos, jurídicos e técnicos) diferem entre si na distribuição das construçōes sintáticas e isso pode conduzir a ligeiras diferenças entre os modelos estatísticos de cada tipo.

Neste trabalho a avaliação 2 foi feita apenas para verificar o peso de termos em nosso conjunto de etiquetas aquelas que consideram a transitividade, e não com o objetivo de econtrar um conjunto de etiquetas ideal. 


\subsection{Resultados dos experimentos com os etiquetadores individuais}

Personally, I'm aways ready to learn, although I do not always like being taught. - Winston Churchill

O corpus de treinamento e teste manualmente etiquetado foi dividido de diferentes formas pois realizamos diferentes experimentos que são apresentados nesta seção e no Capítulo 5. A divisão padrão do corpus foi de $80 \%$ para treinamento $(\mathrm{C} 3, \mathrm{C} 4, \mathrm{C} 5$ e $\mathrm{C} 6), 10 \%$ para o aprendizado dos algoritmos de combinação (C3l, C4!, C51, C61 e C7) - chamado de corpus de calibração e $10 \%$ para testes de precisão de cada etiquetador e dos algoritmos de combinação (C32, C42, C52, C62 e C8) - chamado corpus de teste. O corpus de treinamento é formado por $80 \%$ dos textos de cada genêro (C3) ou $80 \%$ dos textos de um genêro quando da avaliação dos tipos de texto $(\mathrm{C} 4, \mathrm{C} 4$ e $\mathrm{C} 6)$. Para verificar o efeito que o uso de um corpus maior no treinamento tem na precisão foi feita também uma divisão do corpus manualmente etiquetado em $90 \%$ para treinamento (C2) e 10\% para teste (C21). Para avaliar o efeito das palavras desconhecidas na preciāo foi feita também a divisão em $100 \%$ para treinamento $(\mathrm{Cl})$ e $10 \%$ para teste (C2I). Foram construídos também seis conjuntos de calibraçăo e seis de teste através dos conjuntos C41, C51 e C61 e, C42, C52 e C62 respectivamente, tomados dois a dois. Cada um destes conjuntos tem seu tamanho proporcional ao conjunto de textos de treinamento do tipo de texto que foi deixado de fora em sua formação, e tais conjuntos servirāo para verificarmos os efeitos de termos tipos de texto diferentes formando o corpus de treinamento e teste. A Tabela 6 mostra a divisão do corpus em Kb, número de períodos e palavras.

Tabela 6 - Divisóes do corpus

\begin{tabular}{|c|c|}
\hline Corpus & Tamanho \\
\hline C1 - Corpus total & $960 \mathrm{~Kb}-4957$ períodos -104.963 palavras \\
\hline $\begin{array}{l}\text { C2 - Corpus de treinamento (90\%) } \\
\text { C21 - Corpus de teste }(90 \%)\end{array}$ & $\begin{array}{l}863 \mathrm{~Kb}-4478 \text { periodos }-94.472 \text { palavras } \\
98 \mathrm{~Kb}-479 \text { periodos }-10.491 \text { palavras }\end{array}$ \\
\hline $\begin{array}{l}\text { C3 - Corpus de treinamento (80\%) } \\
\text { C31 -Corpus de calibração (80\%) } \\
\text { C32 - Corpus de teste (80\%) }\end{array}$ & $\begin{array}{l}768 \mathrm{~Kb}-4001 \text { períodos }-83.972 \text { palavras } \\
95 \mathrm{~Kb}-477 \text { períodos }-10.500 \text { palavras } \\
98 \mathrm{~Kb}-480 \text { periodos }-10.491 \text { palavras }\end{array}$ \\
\hline $\begin{array}{l}\text { C4 - Conjunto de textos didáticos de treinamento } \\
\text { C41 - Conjunto de textos didáticos de calibração } \\
\text { C42 - Conjunto de textos didáticos de teste }\end{array}$ & $\begin{array}{l}124 \mathrm{~Kb}-589 \text { períodos }-13.004 \text { palavras } \\
16 \mathrm{~Kb}-68 \text { periodos }-1.635 \text { palavras } \\
16 \mathrm{~Kb}-64 \text { períodos }-1.617 \text { palavras }\end{array}$ \\
\hline $\begin{array}{l}\text { C5 - Conjunto de textos jornalísticos de treinamento } \\
\text { C51 - Conjunto de textos jomalísticos de calibração } \\
\text { C52 - Conjunto de textos jomalísticos de teste }\end{array}$ & $\begin{array}{l}413 \mathrm{~Kb}-2040 \text { períodos }-45.327 \text { palavras } \\
52 \mathrm{~Kb}-229 \text { periodos }-5.661 \text { palavras } \\
53 \mathrm{~Kb}-241 \text { períodos }-5.665 \text { palavras } \\
\end{array}$ \\
\hline $\begin{array}{l}\text { C6 - Conjunto de textos literários de treinamento } \\
\text { C61 - Conjunto de textos literários de calibração } \\
\text { C62 - Conjunto de textos literários de teste }\end{array}$ & $\begin{array}{l}232 \mathrm{~Kb}-1322 \text { periodos }-25.641 \text { palavras } \\
29 \mathrm{~Kb}-180 \text { periodos }-3.204 \text { palavras } \\
31 \mathrm{~Kb}-175 \text { periodos }-3.209 \text { palavras }\end{array}$ \\
\hline C7 - Conjuntos de textos de 2 genêros de calibração JL & $15 \mathrm{~Kb}-71$ periodos -1.611 palavras \\
\hline
\end{tabular}


C8 - Conjuntos de textos de 2 genêros de teste JL

C9 - Conjuntos de textos de 2 genêros de calibração DL

C10 - Conjuntos de textos de 2 genêros de teste DL

C11 - Conjuntos de textos de 2 genêros de calibração DJ

$\mathrm{C} 12$ - Conjuntos de textos de 2 genêros de teste DJ
$15 \mathrm{~Kb}-75$ periodos - 1.606palavras

$44 \mathrm{~Kb}-248$ períodos -4.839 palavras $46 \mathrm{~Kb}-239$ períodos -4.826 palavras

$30 \mathrm{~Kb}-116$ períodos -3.222 palavras

$30 \mathrm{~Kb}-130$ períodos -3.193 palavras

Nosso corpus possui uma taxa de ambigüidade em torno de $54,32 \%$, sendo que o conjunto de textos didáticos contém $14,77 \%$ das palavras ambíguas, o conjunto de textos jornalísticos $53,69 \%$ e o conjunto de textos literários 31,54\%, como mostrado na Figura 25. A Tabela 7 mostra a taxa de ambigüidade em cada uma das divisões do corpus. Para verificar se esta taxa alta de ambigüidade não acontecia apenas nos textos utilizados neste trabalho, gerou-se uma lista de palavras ambíguas a partir da Base de dados lexicais do Nilc (BDL) ( I.5 I5.500 palavras), o que resultou em uma lista com 19.817 palavras ambíguas. Esta lista serviu para realizar uma busca em parte do corpora do NILC (8.844.492 de palavras), na qual apareceram 13.950 das palavras da lista, que resultam em uma taxa de ambigüidade neste corpora de $44,49 \%$

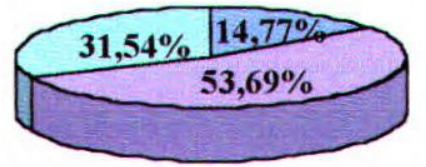

\begin{tabular}{|l|}
\hline$\square$ Didático \\
$\square$ Jornalistico \\
$\square$ Lite rário \\
\hline
\end{tabular}

Figura 25 - Porcentagem da taxa de ambigüidade do corpus por conjunto de textos

Tabela 7 - Taxas de ambigüidade nas divisões do corpus

\begin{tabular}{|l|l|}
\hline Corpus & Taxa de ambigüidade \\
\hline C1 - Corpus total & $54,32 \%$ \\
\hline C2 - Corpus de treinamento & $54,33 \%$ \\
C21 - Corpus de teste & $54,30 \%$ \\
\hline C3 - Corpus de treinamento & $54,44 \%$ \\
C31 - Corpus de calibração & $53,42 \%$ \\
C32 - Corpus de teste & $54,30 \%$ \\
\hline C4 - Conjunto de textos didáticos de treinamento & $51,47 \%$ \\
C41 - Conjunto de textos didáticos de calibração & $51,38 \%$ \\
C42 - Conjunto de textos didáticos de teste & $54,98 \%$ \\
\hline C5 - Conjunto de textos jornalísticos de treinamento & $53,79 \%$ \\
C51 - Conjunto de textos jornalísticos de calibração & $55,04 \%$ \\
C52 - Conjunto de textos jornalísticos de teste & $55,02 \%$ \\
\hline C6 - Conjunto de textos literários de treinamento & $\mathbf{5 7 , 1} \%$ \\
C61 - Conjunto de textos literários de calibração & $51,59 \%$ \\
C62 - Conjunto de textos literários de teste & $52,69 \%$ \\
\hline C7 - Conjuntos de textos de 2 genêros de calibração JL & $52,45 \%$ \\
C8 - Conjuntos de textos de 2 genêros de teste JL & $56,23 \%$ \\
\hline C9 - Conjuntos de textos de 2 genêros de calibração DL & $51,52 \%$ \\
C10 - Conjuntos de textos de 2 genêros de teste DL & $53,46 \%$ \\
\hline C11 - Conjuntos de textos de 2 genêros de calibração DJ & $54,06 \%$ \\
C12 - Conjuntos de textos de 2 genêros de teste DJ & $56,22 \%$ \\
\hline
\end{tabular}


Outra estatística importante é saber qual a porcentagem de palavras desconhecidas nos corpus de calibração e corpus de teste com relação ao corpus de treinamento, ou seja, as palavras que apareceram nestes corpora que não faziam parte do treinamento ( 1 ) ou que faziam mas com outras etiquetas (2). Estes dados são mostrados na Tabela 8.

Tabela 8 - Porcentagem de palavras desconhecidas

\begin{tabular}{|l|l|l|}
\hline Corpus & $\begin{array}{l}\text { Porcentagem de palavras } \\
\text { desconhecidas (1) }\end{array}$ & $\begin{array}{l}\text { Porcentagem de palavras } \\
\text { desconhecidas (2) }\end{array}$ \\
\hline C21 - Corpus de teste & $14,20 \%$ com relação a C2 & $0,18 \%$ com relação a C2 \\
\hline C31 - Corpus de calibração & $15,23 \%$ com relação a C3 & $0,26 \%$ com relação a C3 \\
C32 - Corpus de teste & $15,21 \%$ com relação a C3 & $0,20 \%$ com relação a C3 \\
\hline C41 - Conjunto de textos didáticos de calibração & $13,45 \%$ com relação a C4 & $0,49 \%$ com relação a C4 \\
C42 - Conjunto de textos didáticos de teste & $14,04 \%$ com relação a C4 & $0,37 \%$ com relação a C4 \\
\hline C51 - Conjunto de textos jornalísticos de calibração & $15,95 \%$ com relação a C5 & $0,32 \%$ com relação a C5 \\
C52 - Conjunto de textos jomalísticos de teste & $14,88 \%$ com relação a C5 & $0,26 \%$ com relação a C5 \\
\hline C61 - Conjunto de textos literários de calibração & $26,99 \%$ com relação a C6 & $0,25 \%$ com relação a C6 \\
C62 - Conjunto de textos literários de teste & $28,51 \%$ com relação a C6 & $0,25 \%$ com relação a C6 \\
\hline C7 - Conjuntos de textos de 2 genêros de calibração JL & $35,19 \%$ com relação a C4 & $0,37 \%$ com relação a C4 \\
C8 - Conjuntos de textos de 2 genêros de teste JL & $31,75 \%$ com relação a C4 & $0,37 \%$ com relação a C4 \\
\hline C9 - Conjuntos de textos de 2 genêros de calibração DL & $22,96 \%$ com relação a C5 & $0,33 \%$ com relação a C5 \\
C10 - Conjuntos de textos de 2 genéros de teste DL & $24,22 \%$ com relação a C5 & $0,29 \%$ com relação a C5 \\
\hline C11 - Conjuntos de textos de 2 genêros de calibração DJ & $27,13 \%$ com relação a C6 & $0,43 \%$ com relação a C6 \\
C12 - Conjuntos de textos de 2 genêros de teste DJ & $24,15 \%$ com relação a C6 & $0,41 \%$ com relação a C6 \\
\hline
\end{tabular}

\subsubsection{Avaliação dos métodos de etiquetagem}

Pelos frutos se conhece a árvore. - Provérbio

A avaliação dos métodos de etiquetagem pode ser dividida em metas mais precisas. Escolhemos oito metas mostradas abaixo, cujos resultados aparecem nas próximas subseçōes:

- Verificar o tempo gasto por cada etiquetador com treinamento e etiquetagem

- Calcular a precisão geral de cada etiquetador

- Utilizar o algoritmo eO Bootstraping para estimar a taxa de erro do etiquetador de treinamento mais rápido

- Verificar quais eram as etiquetas mais problemáticas para cada etiquetador

- Averiguar se existia um etiquetador que apresentasse uma melhor precisão dado o nosso corpus e conjunto de etiquetas

- Averiguar se existiam etiquetas que eram problemáticas para todos os etiquetadores 
- Checar se haveria um acréscimo na precisão do etiquetador de maior precisâo com o aumento do corpus de treinamento através do treinando deste com $90 \%$ do corpus.

- Verificar a importância das palavras desconhecidas verificando se a precisão geral do etiquetador de maior precisão sofreria acréscimo quando com treinamento fechado, ou seja, quando $100 \%$ do corpus fosse utilizado para treinamento de forma que o teste năo conteria palavras desconhecidas

\subsubsection{TreeTagger}

O Tree Tagger permite a parametrização do contexto, tendo sido bastante utilizado na literatura como trigrama. Assim, nossos primeiros experimentos com o Tree Tagger foram feitos usando um contexto de tamanho três. Como o manual do sistema sugeria que para conjuntos de etiquetas grandes ou corpus de treinamento pequeno a precisão geral poderia melhorar com a alteração do contexto para um bigrama este foi nosso segundo experimento. Entretanto, como mostra a Tabela 9 isto não aconteceu. O meihor resultado foi o do etiquetador como trigrama: $88,47 \%$. Utilizamos o TreeTagger como unigrama para servir de base para comparaçōes. O TreeTagger, tanto como bigrama quanto como trigrama, foi o etiquetador que apresentou menor tempo de treinamento e etiquetagem rodando em uma Sun Uitra $1 \mathrm{com} 128 \mathrm{Mb}$ de RAM. Os tempos gastos por ele no treinamento e etiquetagem săo mostrados na Tabela 10. O treinamento do TreeTagger como trigrama resultou em um modelo com 2163 nós e uma altura máxima da árvore igual a 73 .

Utilizando o algoritmo de el Boostraping com 200 iteraf̧ōes, a taxa de erro verdadeira estimada para o etiquetador TreeTagger como trigrama foi de $88,95 \%$. O processo de estimar a taxa de erro verdadeira para o TreeTagger - 200 treinamentos e etiquetagens - durou 3 horas e 10 minutos.

Tabela 9 - Precisão Geral do etiquetador TreeTagger

\begin{tabular}{|l|l|}
\hline & Resultados da precisăo \\
\hline TreeTagger-Unigrama (C3) & \\
Corpus de calibração (C31) & $79.62 \%$ \\
Corpus de teste (C32) & $80.01 \%$ \\
\hline TreeTagger-Bigrama (C3) & \\
Corpus de calibração (C31) & $87.77 \%$ \\
Corpus de teste (C32) & $88.41 \%$ \\
\hline TreeTagger-Trigrama (C3) & \\
\hline
\end{tabular}


Tabela 10 - Tempos de treinamento e etiquetagem - TreeTagger

\begin{tabular}{|c|c|c|}
\hline & Tempo de treinamento & Tempo de etiquetagem \\
\hline $\begin{array}{l}\text { TreeTagger-Unigrama (C3) } \\
\text { Corpus de calibração (C31) } \\
\text { Corpus de teste (C32) }\end{array}$ & $\begin{array}{r}- \\
- \\
- \\
\end{array}$ & $\begin{array}{l}- \\
\text { menos de } 1 \text { segundo } \\
\text { menos de } 1 \text { segundo }\end{array}$ \\
\hline $\begin{array}{l}\text { TreeTagger-Bigrama (C3) } \\
\text { Corpus de calibraçäo (C31) } \\
\text { Corpus de teste (C32) }\end{array}$ & 6 segundos & $\begin{array}{l}\text { menos de } 1 \text { segundo } \\
\text { menos de } 1 \text { segundo }\end{array}$ \\
\hline $\begin{array}{l}\text { TreeTagger-Trigrama (C3) } \\
\text { Corpus de calibração (C31) } \\
\text { Corpus de teste (C32) }\end{array}$ & 51 segundos & $\begin{array}{l}\text { - } \\
\text { menos de } 1 \text { segundo } \\
\text { menos de } 1 \text { segundo }\end{array}$ \\
\hline
\end{tabular}

Analisando a precisão por etiquetas nota-se que as etiquetas problemáticas ${ }^{13}$ para 0 TreeTagger correspondem a 33,33\% das etiquetas como mostra a Tabela II, em que as etiquetas problemáticas aparecem em vermelho. A Figura 26 mostra de forma mais clara as precisōes, agrupando algumas delas ${ }^{14}$.

Tabela 11 - Precisão por etiqueta no corpus de teste - TreeTagger como trigrama

\begin{tabular}{|l|l|l|l|}
\hline Etiquetas & Precisão & Etiquetas & Precisão \\
\hline ADJ & 82,608 & PREP+P POA & -15 \\
\hline ADV & 81,078 & PREP+ADV & 1008 \\
\hline ART & 97,758 & PPOA+PPOA & - \\
\hline NC & 93,238 & ADV+PPR & - \\
\hline ORD & 81,258 & ADV+PPOA & $0 \%$ \\
\hline NO & 08 & ADJ+PPOA & - \\
\hline N & & VTD+PPOA & $6,49 \%$ \\
\hline NP & 93,398 & VTD+PAPASS & $0 \%$ \\
\hline CONJCOORD & 87,918 & VAUX+PPOA & 1008 \\
\hline CONJSUB & VBI+PPOA & $0 \%$ \\
\hline PD & 94,508 & VLIG+PPOA & $0 \%$ \\
\hline
\end{tabular}

${ }^{13}$ Consideramos como problemáticas as etiquetas para as quais a precisão é menor que $80 \%$.

${ }^{14} \mathrm{Num}$ - são as etiquetas referentes aos numerais - NC, ORD e NO

$\mathrm{Sub}$ - são as etiquetas referentes a substantivo - N e NP

Conj - são as etiquetas referentes as conjunçōes - CONJCOORD e CONJSUB

Pron - são as etiquetas referentes aos pronomes - PD, PIND, PPOA, PPR, PPS, PR, PPOT,PINT, PAPASS, PREAL e PTRA

V - são as etiquetas referentes aos verbos - VAUX, VIG, VNT, VTD, VTI e VBI

Loc - são as etiquetas referentes as locuçöes - LADV, LCONJ, LDEN, LPREP e LP

Cont - sāo as etiquetas referentes as contraçōes - PREP + ART, PREP +PREP, PREP +PD, PREP + PPR, PREP + PPOT,

$P R E P+A D$ ], $P R E P+N, P R E P+P P O A, P R E P+A D V, P P O A+P P O A, A D V+P P R, A D V+P P O A$ e $A D J+P P O A$

Encl - são as etiquetas referentes as ênclises - VTD +PPOA,VTD +PAPASS, VAUX+PPOA, VBI +PPOA,

VLIG +PPOA,VTI+PPOA,VTI + PREAL, VBI + PPOA, VNT + PREAL, VNT + PPOA, VNT + PAPASS, VBI +PPR,

VTD +PPR, VTD +PREAL E VBI+PAPASS

Res - são as etiquetas - RES e IL

Pon - são as etiquetas referentes as pontuaçōes

${ }^{15}$ Etiqueta que não apareceu no corpus de teste. 


\begin{tabular}{|c|c|c|c|}
\hline PIND & 83,878 & VTI+PPOA & $0=8$ \\
\hline PPOA & 81,398 & VTI+PREAL & - \\
\hline PPR & $93,75 \%$ & VINT+PREAL & - \\
\hline PPS & 98,278 & VINT+PPOA & 08 \\
\hline $\mathrm{PR}$ & 81,348 & VINT+PAPASS & $0=$ \\
\hline PPOT & 1008 & VBI+PPR & - \\
\hline PINT & 08 & VTD+PPR & - \\
\hline PAPASS & 08 & VTD +PREAI & $0=$ \\
\hline BREAL & 0 & VBI+PAPASS & - \\
\hline PTRA & - & VAUX! PPOA & - \\
\hline PREP & 92,618 & VTD!PPOA & - \\
\hline VAUX & 79,668 & RES & $15=$ \\
\hline VLIG & 84,718 & IL & - \\
\hline VINT & $57,39=$ & . & 1008 \\
\hline VTD & 76,408 & $:$ & 1008 \\
\hline VTI & 34,430 & ; & $100 \%$ \\
\hline VBI & 23,258 & - & 1008 \\
\hline I & - & 1 & 1008 \\
\hline LADV & $53,66=$ & $!$ & - \\
\hline LCONJ & 59,09 & ? & 1008 \\
\hline LRRER & $70,83=$ & $\ldots$ & 1008 \\
\hline LP & $50=-5$ & 1 & $100 \%$ \\
\hline LDEN & 66,672 & $"$ & 1008 \\
\hline PDEN & - & {[} & $100 \frac{8}{8}$ \\
\hline PREP+ART & 96,59 웅 & ] & $100 \frac{8}{8}$ \\
\hline PREP+PREP & - & 1 & - \\
\hline PREP+PD & 96,088 & \} & - \\
\hline PREP+PPR & $85,71 \frac{8}{8}$ & , & $100 \%$ \\
\hline PREP+PPOT & - & 1 & - \\
\hline PREP +ADJ & $0=$ & & \\
\hline $\mathrm{PREP}+\mathrm{N}$ & $100 \frac{8}{8}$ & & \\
\hline
\end{tabular}

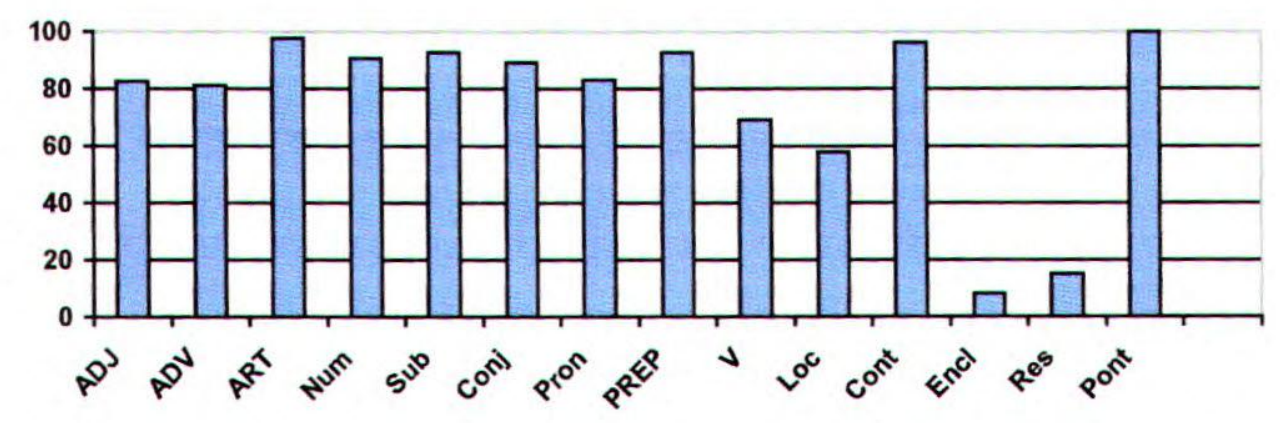

Figura 26 - Precisão por etiquetas em grupos - TreeTagger

\subsubsection{Etiquetador basedo em transformação (TBL)}

Nos experimentos com o etiquetador TBL foram mantidos todos os parâmetros default: 
- Para o aprendizado das regras para palavras desconhecidas foi mantido o valor 300 - apenas bigramas em que pelo menos uma das palavras for uma das 300 mais frequentes serão utilizados na construção das regras.

- O programa de aprendizado de regras para palavras desconhecidas parará de rodar quando a pontuação da melhor regra encontrada cair abaixo do limiar igual a 3, valor default e que é indicado por Brill para textos com menos de 50K.

- A primeira decisão do etiquetador inicial será marcar as palavras que começam com letras maiúsculas como substantivo próprio e as que começam com minúsculas como substantivo comum, assim onde havia no código $N N P^{16}$ foi alterado para NP e onde havia NN para N.

- O programa de aprendizado de regras contextuais parará de rodar quando a pontuação da melhor regra encontrada cair abaixo de um limiar igual a 2, valor default e que também é indicado por Brill para textos com menos de $50 \mathrm{~K}$.

O treinamento em uma Sun Ultra Interprise $3000 \mathrm{com} 2 \mathrm{~Gb}$ de RAM foi bem mais lento do que o do TreeTagger como pode ser visto na Tabela 12. O modelo gerado por este treinamento é composto de $X$ regras para tratar palavras desconhecidas e $Y$ regras contextuais. $A$ precisão geral deste etiquetador é um pouco melhor que a do etiquetador TreeTagger $88,76 \%$ (Tabela 13).

Tabela 12 - Tempo de treinamento e etiquetagem - TBL

\begin{tabular}{|l|l|l|l|}
\hline & $\begin{array}{l}\text { Tempo de treinamento - } \\
\text { regras para palavras } \\
\text { desconhecidas }\end{array}$ & $\begin{array}{l}\text { Tempo de treinamento - } \\
\text { regras contextuais }\end{array}$ & Tempo de etiquetagem \\
\hline TBL (C3) & $\begin{array}{l}15 \text { horas, 54 minutos e 33 } \\
\text { segundos }\end{array}$ & $\begin{array}{l}\text { 6 horas, 14 minutos e 14 } \\
\text { segundos }\end{array}$ & $\begin{array}{l}7 \text { segundos } \\
6 \text { segundos }\end{array}$ \\
$\begin{array}{l}\text { Corpus de calibraçä (C31) } \\
\text { Corpus de teste (C32) }\end{array}$ & - & - & - \\
\hline
\end{tabular}

Tabela 13 - Precisão Geral - TBL

\begin{tabular}{|l|l|}
\hline & Preecisão Geral \\
\hline TBL (C3) & \\
Corpus de calibração (C31) & $88.09 \%$ \\
Corpus de teste (C32) & $88.76 \%$ \\
\hline
\end{tabular}

A Tabela 14 mostra as precisões por etiqueta do etiquetador TBL. A porcentagem de etiquetas problemáticas para o TBL é $33,34 \%$, sendo que as etiquetas que são problemáticas para 
o etiquetador TBL e TreeTagger estão em vermelho, enquanto as que são problemáticas apenas para ○ TBL estão em verde. Nota-se que uma das etiquetas - ORD - que não eram problemáticas para o TreeTagger é problemática para o TBL e que uma - VTD+PPOA - que era problemática para o TreeTagger não é para o TBL. A Figura 27 resume a Tabela 14.

Tabela 14 - Precisão por etiquetas no corpus de teste- TBL

\begin{tabular}{|c|c|c|c|}
\hline Etiquetas & Precisão & Etiquetas & Precisão \\
\hline $\mathrm{ADJ}$ & 83,038 & PREP+PPOA & - \\
\hline ADV & $88,80 \%$ & PREP+ADV & $100 \%$ \\
\hline ART & 98,638 & $\mathrm{PPOA}+\mathrm{PPOA}$ & - \\
\hline $\mathrm{NC}$ & $96,99 \%$ & $\mathrm{ADV}+\mathrm{PPR}$ & - \\
\hline ORD & 68,755 & ADV+PPOA & 03 \\
\hline NO & $50 \times$ & $\mathrm{ADJ}+\mathrm{PPOA}$ & - \\
\hline $\mathrm{N}$ & 91,928 & \begin{tabular}{|l}
$\mathrm{VTD}+\mathrm{PPOA}$ \\
\end{tabular} & 83,12 \\
\hline $\mathrm{NP}$ & $95,97 \%$ & VTD+PAPASS & $07 \quad-5$ \\
\hline CONJCOORD & 94,788 & VAUX+PPOA & $100 \frac{8}{8}$ \\
\hline CONJSUB & $73,58=$ & VBI +PPOA & $35,71=$ \\
\hline $\mathrm{PD}$ & 92,318 & VLIG+PPOA & $50=$ \\
\hline PIND & $90,32 \%$ & VTI+PPOA & $0+$ \\
\hline PPOA & 81,398 & V'TI+PREAL & - \\
\hline PPR & $100 \frac{8}{8}$ & VINT+PREAL & - \\
\hline PPS & 96,558 & VINT+PPOA & 0 \\
\hline PR & $80,6 \frac{8}{8}$ & \begin{tabular}{|l} 
VINT + PAPASS \\
\end{tabular} & $0=$ \\
\hline PPOT & 1008 & VBI+PPR & - \\
\hline PINT & $0=2$ & VTD+PPR & - \\
\hline PAPASS & $0=$ & \begin{tabular}{|l} 
VTD + PREAL \\
\end{tabular} & 05 \\
\hline PREAL & $0=$ & VBI+PAPASS & - \\
\hline PTRA & - & VAUX! PPOA & - \\
\hline PREP & 93,648 & VTD!PPOA & - \\
\hline VAUX & $67,8=$ & RES & 408 \\
\hline VLIG & 84,088 & IL & - \\
\hline VINT & $47,83^{2}$ &. & $100 \%$ \\
\hline VTD & $70,45=$ & $:$ & $100 \%$ \\
\hline VTI & 23,77 & ; & 1008 \\
\hline VBI & 6,98 & - & 1008 \\
\hline I & - & 1 & 1008 \\
\hline L.A.DV & $43,90 \times$ & $!$ & - \\
\hline LCONJ & 45,458 & $?$ & 1008 \\
\hline LPREP & $58,33=$ & $\ldots$ & 1008 \\
\hline LP & $0=29$ & 1 & 1008 \\
\hline LDEN & $50=$ & $"$ & $100 \%$ \\
\hline PDEN & - & {[} & 1008 \\
\hline PREP+ART & $97,73 \%$ & 1 & $100 \%$ \\
\hline PREP+PREP & - & \{ & - \\
\hline $\mathrm{PREP}+\mathrm{PD}$ & $94,12 \frac{8}{8}$ & \} & - \\
\hline PREP+PPR & 1008 & , & 1008 \\
\hline PREP+PPOT & - & 1 & - \\
\hline PREP+A.DJ & $0=$ & & \\
\hline $\mathrm{PREP}+\mathrm{N}$ & $100 \%$ & & \\
\hline
\end{tabular}

\footnotetext{
${ }^{16}$ No conjunto de etiquetas utilizado por Brill, NNP é a etiqueta para substantivo próprio e NN a etiqueta para
} 


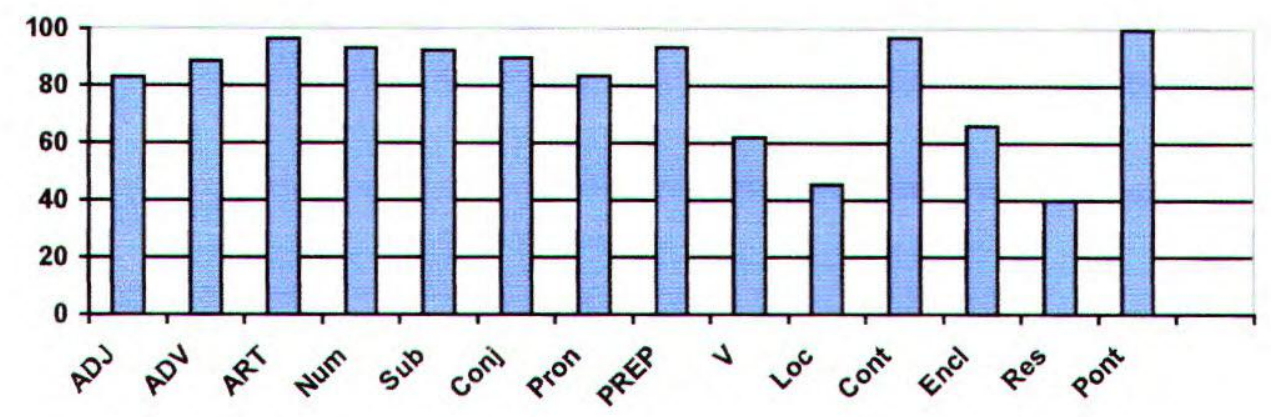

Figura 27 - Precisão por etiquetas em grupos - TBL

\subsubsection{MXPOST}

etiquetador MXPOST não possui parâmetros para serem alterados. Foi o etiquetador que obteve maior precisão geral $-89,66 \%$ - como pode ser visto na Tabela 15. Os tempos de treinamento e teste são mostrados na Tabela 16.

Tabela 15 - Precisão Geral - MXPOST

\begin{tabular}{|l|l|}
\hline & Preecisão Geral \\
\hline MXPOST (C3) & $88.70 \%$ \\
Corpus de calibração (C31) & $89,66 \%$ \\
Corpus de teste (C32) & \\
\hline
\end{tabular}

Tabela 16 - Tempo de treinamento e teste - MXPOST

\begin{tabular}{|l|l|l|}
\hline & Tempo de treinamento & Tempo de etiquetagem \\
\hline MXPOST (C3) & 1 hora 28 minutos e 27 segundos & - \\
Corpus de calibração (C31) & - & 3 minutos e 12 segundos \\
Corpus de teste (C32) & - & 3 minutos e 14 segundos \\
\hline
\end{tabular}

A porcentagem de etiquetas problemáticas para O MXPOST é $38,46 \%$. A Tabela 17 mostra as precisões por etiquetas, mostrando que todas as etiquetas que eram problemáticas para - TreeTagger e para O TBL são também problemáticas (em vermelho) para o MXPOST e que a que era apenas para o TBL também é para O MXPOST (em verde) e que uma das classes problemáticas para $\circ$ TreeTagger que não era problemática para ○ TBL é para ○ MXPOST 
(VTD + PPOA) e que as classes - PPOA, PR e PREP+ADV que não eram problemáticas nem para - TreeTagger nem para o TBL são para o MXPOST (azul). Comparando as Figuras 28, 27 e 26 nota-se que os grupos de etiquetas problemáticas são os mesmos para os três etiquetadores, variando apenas a proporção.

Tabela 17 - Precisão por etiquetas no corpus de teste - MXPOST

\begin{tabular}{|c|c|c|c|}
\hline Etiquetas & Precisão & Etiquetas & Precisão \\
\hline ADJ & 83,888 & PREP+PPOA & - \\
\hline ADV & 86,48 & EREP+A.DV & 508 \\
\hline ART & $98,88 \%$ & PPOA+PPOA & - \\
\hline $\mathrm{NC}$ & 95,498 & ADV+PPR & - \\
\hline ORD & $508=8$ & $\mathrm{ADV}+\mathrm{PPOA}$ & $0=$ \\
\hline NO & Os & $\mathrm{ADJ}+\mathrm{PPOA}$ & - \\
\hline $\mathrm{N}$ & $94,61 \%$ & VTD +PPOA & 72,738 \\
\hline NP & $96,7 \%$ & VTD+PAPASS & $66,67=$ \\
\hline CONJCOORD & 93,968 & VAUX+PPOA & 1008 \\
\hline CONJSUB & $74,53=$ & VBI +PPOA & $28,57=$ \\
\hline PD & $92,31 \%$ & \begin{tabular}{|l} 
VLIG+PPOA \\
\end{tabular} & $50=$ \\
\hline PIND & 80,648 & VTI +PPOA & 08 \\
\hline PPOA & 74,428 & VTI+PREAL & - \\
\hline PPR & 1008 & VINT+PREAL & - \\
\hline PPS & $96,55 \%$ & \begin{tabular}{|l} 
VINT +PPOA \\
\end{tabular} & $0=$ \\
\hline PR & 77,618 & VINT+PAPASS & $0=$ \\
\hline PPOT & 1008 & VBI+PPR & - \\
\hline PINT & D & VTD +PPR & - \\
\hline PAPASS & $7,14=$ & VTD+PREAL & 08 \\
\hline PREAL & $0=$ & VBI+PAPASS & - \\
\hline PTRA & - & VAUX! PPOA & - \\
\hline PREP & $93,43 \%$ & VTD!PPOA & 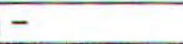 \\
\hline VAUX & $66,95=$ & RES & $45=$ \\
\hline VLIG & $84,08 \%$ & IL & - \\
\hline VINT & $53,04=$ & . & 1008 \\
\hline VTD & 72,61 & $:$ & 1008 \\
\hline VTI & $39,34=$ & $i$ & $100 \%$ \\
\hline VBI & $32,56$. & - & 1008 \\
\hline I & - & 1 & 1008 \\
\hline LADV & $43,9 \times$ & $!$ & - \\
\hline LCONJ & $77,27=$ & $?$ & 1008 \\
\hline LPREP & 58,33 & $\ldots$ & $100 \frac{2}{8}$ \\
\hline LP & $0=2 \cdot 2$ & 1 & $100 \%$ \\
\hline LDEN & $33,33=$ & $"$ & 1008 \\
\hline PDEN & - & {[} & 1008 \\
\hline PREP+ART & $97,59 \%$ & ] & 1008 \\
\hline PREP+PREP & - & 1 & - \\
\hline PREP+PD & $90,2 \frac{9}{8}$ & \} & - \\
\hline PREP+PPR & 1008 & , & 1008 \\
\hline PREP+PPOT & - & ' & - \\
\hline PREP + ADJ & 0 & & \\
\hline $\mathrm{PREP}+\mathrm{N}$ & 1008 & & \\
\hline
\end{tabular}




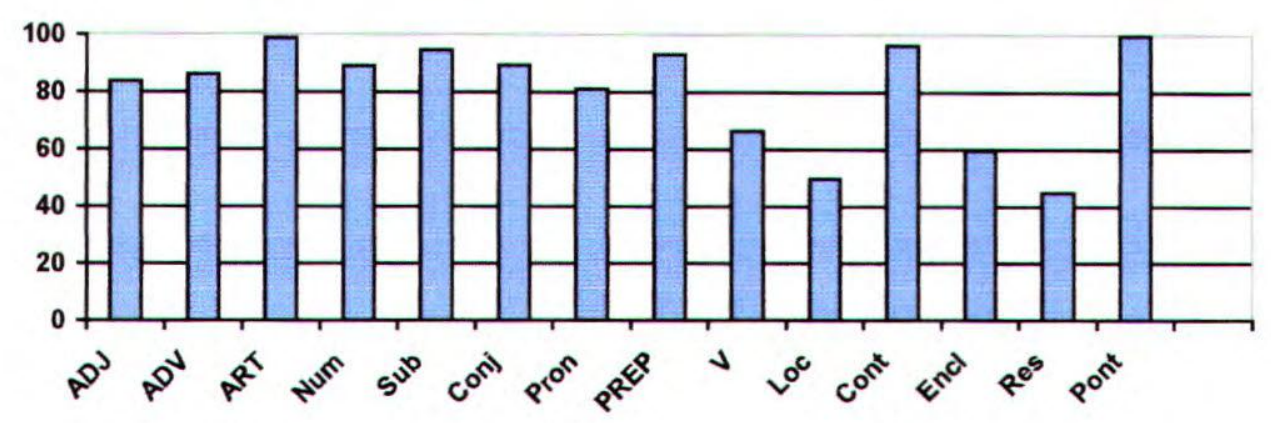

Figura 28 - Precisão por etiquetas em grupo - MXPOST

Por ser o etiquetador de maior precisão geral foi o etiquetador escolhido para verificarmos o impacto de um corpus de treinamento maior na precisão geral e também o impacto das palavras desconhecidas. Treinando o etiquetador com $90 \%$ do corpus ( $80 \%$ de treinamento + $10 \%$ de calibração) e testando com os $10 \%$ de teste foi encontrada uma precisão geral de $90,25 \%$, ou seja, com $10 \%$ a mais de corpus de treinamento a precisão geral aumentou $0,59 \%$. Treinando o etiquetador com 100\% do corpus de treinamento e testando com os 10\% do teste, ou seja, não existem palavras desconhecidas - foi obtida uma precisão de $93.65 \%$.

\subsubsection{PoSiTagger - Portuguese Simbolic Tagger}

Sou definitivamente contra o definido, porque o definido é o bastante e o bastante não basta. - Fernando Pessoa

O etiquetador PoSiTagger é um etiquetador simbólico construído no Nilc, que teve suas regras construídas por uma lingüísta, em vinte dias. As regras foram elaboradas tomando por base as regras de desambigüização morfossintática do ReGra (Apêndice $\mathrm{Cl}$ ) e as regras contextuais do etiquetador TBL (Apêndice C2). A elaboração de tais regras foi feita seguindo dicionários, dicionário inverso, gramáticas e vocabulário ortográfico da língua portuguesa (Pinheiro, 1990; Luft, 1993; Biderman, 1992; Lima, 1992; Kury, 1993; André, 1990; Fernandes, 1995; d’Andrade, 1993; Ibaixe, 1994; Cunha \& Cintra, 1985; Faraco \& Moura, 1994; Academia Brasileira de Letras, 1998). 
A etiquetagem se dá em duas etapas: inicial e contextual. A etiquetagem incial é feita em duas fases: primeiro, o texto é etiquetado segundo uma lista de regras lexicalizadas preestabelida e depois, as palavras que näo tiverem sido etiquetadas segundo estas regras e se estiverem presentes no léxico săo etiquetadas com a etiqueta a elas associdas no léxico, caso não sejam palavras contempladas pelo léxico é utilizado o léxico de sufixos e prefixos ${ }^{17}$. Se ainda assim a palavra não for etiquetada é atribuída a ela a etiqueta RES caso inicie com letra minúscula, pressupondo-se que esta palavra se trata de uma palavra estrangeira, um coloquialismo, ou regionalismo, e caso tenha inicial maiúcula é etiquetada como substantivo próprio.

$\mathrm{Na}$ etiquetagem contextual, as etiquetas são alteradas de acordo com um contexto variável que pode ser formado por: palavras anteriores àquela que está sendo etiquetada, posteriores, etiquetas anteriores e posteriores; e pelos atributos: a existência ou não de uma dada palavra ou etiqueta no período, o fato de a palavra ser a primeira do período ou não, qual é a primeira palavra do período, qual é a última palavra do período ou qualquer combinaçāo destas características utilizando-se de operadores e, ou e não. A Figura 29 mostra a arquitetura deste etiquetador.

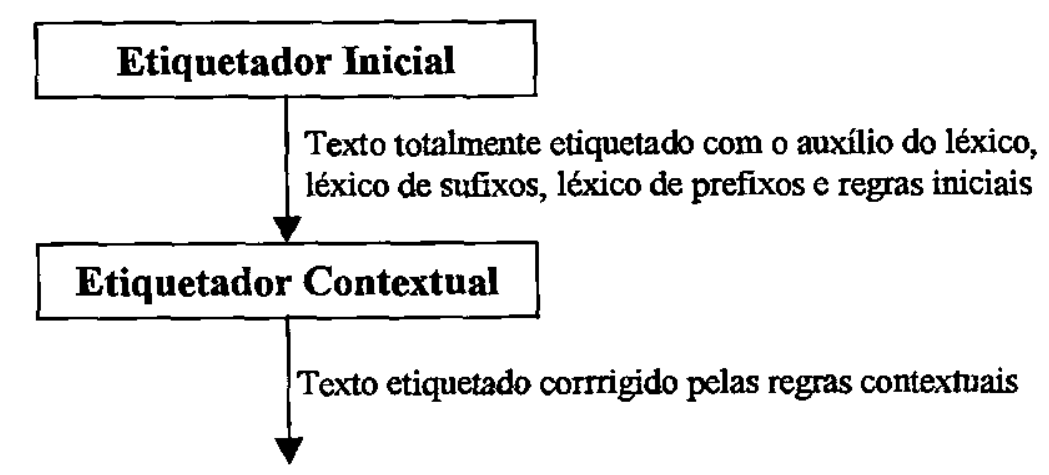

Figura 29 - Arquitetura do PoSiTagger

Apenas dois ítens säo obrigatórios nas regras: a palavra e/ou etiqueta que deve ser alterada e a nova etiqueta que deve ser utilizada. As regras iniciais e as regras contextuais năo estão no código do etiquetador mas em arquivos a parte para facilitar futuras alteraçōes. Nestes experimentos o contexto utilizado foi de até sete palavras/etiquetas a esquerda/direita da palavra em foco, mas pode ser alterado para qualquer valor desejado. As regras utilizadas neste experimento estão no Apêndice C3.

\footnotetext{
${ }^{17}$ Prefixos e sufixos são adicionados e retirados da palavra tentando encontrar uma palavra conhecida pelo léxico.
} 
A precisão geral é mostrada na Tabela 18. Os tempos gastos na etiquetagem são mostrados na Tabela 19. A tabela 20 mostra as precisões por etiqueta e a Figura 31 mostra as informações da Tabela 20 agrupando as etiquetas.

Tabela 18 - Precisão Geral do PoSiTagger

\begin{tabular}{|l|l|}
\hline PoSiTagger & Preecisão Geral \\
\hline Corpus de calibração (C31) & $83,57 \%$ \\
Corpus de teste (C32) & $82,65 \%$ \\
\hline
\end{tabular}

\section{Tabela 19 - Tempos de etiquetagem do PoSiTagger}

\begin{tabular}{|l|c|}
\hline PoSiTagger & Tempo de etiquetagem \\
\hline Corpus de calibração (C31) & 25 minutos e 41 segundos \\
Corpus de teste (C32) & 28 minutos e três segundos \\
\hline
\end{tabular}

Tabela 20 - Precisão Geral do PoSiTagger nos corpus de teste e calibração

\begin{tabular}{|c|c|c|c|}
\hline Etiquetas & Precisão & Etiquetas & Precisão \\
\hline $\mathrm{ADJ}$ & $88,26 \%$ & $\mathrm{PREP}+\mathrm{PPOA}$ & - \\
\hline$\overline{A D V}$ & $44 \div 2$ & PREP +ADV & $50 \%$ \\
\hline ART & $97,25 \%$ & $\mathrm{PPOA}+\mathrm{PPOA}$ & - \\
\hline $\mathrm{NC}$ & 1008 & $\mathrm{ADV}+\mathrm{PPR}$ & - \\
\hline ORD & $68,75 \%$ & $\mathrm{ADV}+\mathrm{PPOA}$ & 07 \\
\hline NO & 1008 & $\mathrm{ADJ}+\mathrm{PPOA}$ & - \\
\hline $\mathrm{N}$ & $85,02 \frac{8}{8}$ & VTD +PPOA & 37,668 \\
\hline NP & $73,26:$ & VTD+PAPASS & 1008 \\
\hline CONJCOORD & $90,38 \%$ & VAUX+PPOA & 0 용 \\
\hline CONJSUB & $56,60=$ & $\mathrm{VBI}+\mathrm{PPOA}$ & $7,14=$ \\
\hline PD & $38,46=$ & VLIG+PPOA & $0=2$ \\
\hline PIND & $61,29=$ & VTI+PPOA & $14,28=$ \\
\hline PPOA & 27,908 & VTI+PREAL & - \\
\hline PPR & 93,758 & VINT+PREAL & - \\
\hline PES & 18,96 & VINT +PPOA & 08 \\
\hline PR & 72,398 & VINT+PAPASS & $0=$ \\
\hline PPOT & $100 \%$ & $\mathrm{VBI}+\mathrm{PPR}$ & - \\
\hline PINT & $100 \%$ & VTD+PPR & - \\
\hline EAPASS & $0 \%$ & VTD+PREAL & 03 \\
\hline PREAI & $0=$ & VBI+PAPASS & - \\
\hline PTRA & - & VAUX!PPOA & - \\
\hline PREP & 87,498 & VTD!PPOA & - \\
\hline VAUX & $38,98=$ & RES & $97,5 \%$ \\
\hline VLIG & 91,08 & IL & - \\
\hline VINT & $60=1$ & . & $100 \%$ \\
\hline VITD & 62,168 & $:$ & $100 \%$ \\
\hline VTI & $52,46=$ & ; & 1008 \\
\hline
\end{tabular}




\begin{tabular}{|l|l|l|l|}
\hline VBI & 44,19 & - & $100 \%$ \\
\hline I & - & & \\
\hline LADV & 65,85 & $!$ & - \\
\hline LCONJ & 68,18 & $?$ & 1008 \\
\hline LPREP & 83,338 & $\ldots$ & 1008 \\
\hline LP & 1008 & 1 & 1008 \\
\hline LDEN & 50 & $n$ & 1008 \\
\hline PDEN & - & {[} & 1008 \\
\hline PREP+ART & 93,198 & ] & $100 \%$ \\
\hline PREP+PREP & - & 1 & - \\
\hline PREP+PD & 56,86 & - & - \\
\hline PREP+PPR & 1008 & 1 & $99,76 \%$ \\
\hline PREP+PPOT & - & 1 & - \\
\hline PREP+ADJ & 1008 & & \\
\hline PREP+N & 1008 & & \\
\hline
\end{tabular}

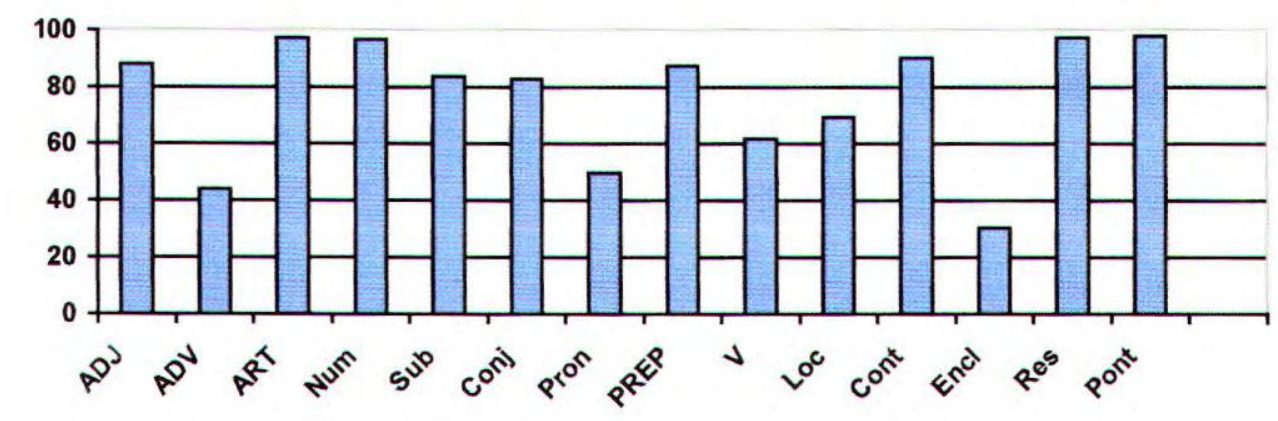

Figura 30 - Precisão por grupos de etiquetas - PoSiTagger

A Tabela 20 mostra que oito das etiquetas (em cor-de-rosa) que não eram problemáticas para nenhum dos três etiquetadores das seções anteriores são para o PoSiTagger. Em contrapartida mostra que sete das etiquetas que são problemáticas - NO, PINT, LPREP, LP, PREP + ADJ, VTD + PAPASS e RES - para os três etiquetadores não são pra ele e que para quatro destas ele tem $100 \%$ de precisão. Fora estas sete etiquetas todas as outras que eram problemáticas para um dos etiquetadores ou para todos eles, o são também para o PoSiTagger. A Figura 3 I contrapõe os resultados dos quatro etiquetadores por grupos de etiquetas.

\footnotetext{
${ }^{18} \mathrm{O}$ erro na etiquetagem deste símbolo foi causado por não ter sido colocado na lista de símbolos de pontuação, tendo sido etiquetado pelo PoSiTagger como residual.
} 


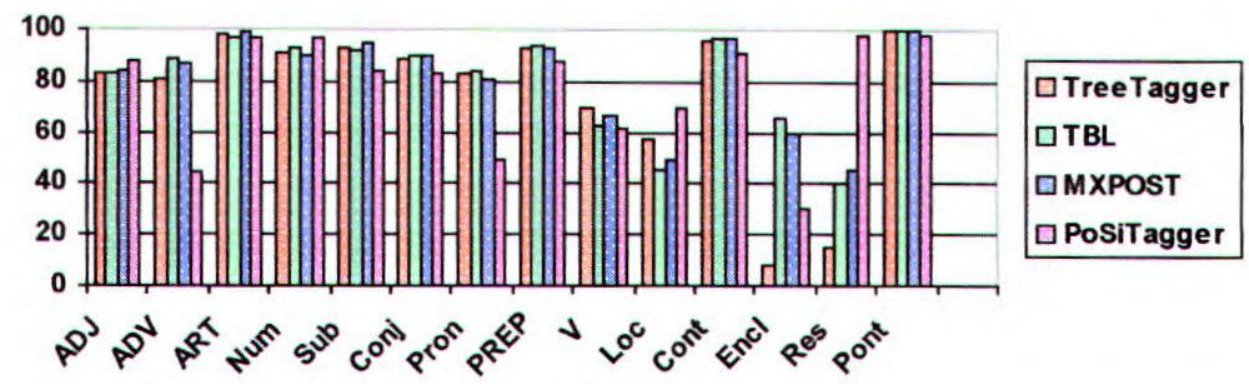

Figura 31 - Precisão por etiqueta dos etiquetadores TreeTagger, TBL, MXPOST e PoSiTagger

\subsubsection{Avaliação do conjunto de etiquetas}

Aprenda cada qual a caminhar pela estrada que mais the convenha - Propércio

Para avaliar qual o grau de dificuldade imposto por termos em nosso conjunto de etiquetas as que consideram a transitividade, treinamos o etiquetador de maior precisão - MXPOST - com um conjunto de etiquetas em que a única diferença com relação ao NILC tagset é que verbos não são subcategorizados. A precisão obtida treinando o etiquetador com os mesmos $80 \%$ dos dados utilizados anteriormente foi $92,51 \%, 2,85 \%$ menos erros no teste.

\subsubsection{Avaliação dos tipos de texto}

Quanto aos tipos de texto utilizados no treinamento e teste, havia duas perguntas a serem respondidas:

I) Se existem métodos de etiquetagem que tem uma maior precisão com um certo tipo de texto

2) Qual o impacto do uso de tipos de texto no teste que são diferentes do treinamento

Para responder a primeira pergunta foram feitos 3 treinamentos com os etiquetadores TreeTagger como trigrama e unigrama, TBL e MXPOST, utilizando em cada um deles um dos três conjuntos de textos - didático, literário e jornalístico ( $\mathrm{C} 4, \mathrm{C} 5$ e $\mathrm{C} 6$ ) e etiquetagens com os conjuntos de texto de calibração e teste - didático, literário e jornalístico (C41, C42, C51, C52, 
C61 e C62). Também foram etiquetados os corpus C4I, C42, C51, C52, C61 e C62 com o

PoSiTagger. A Tabela 21 mostra as precisōes de cada um dos etiquetadores para textos didáticos,

a Tabela 22 para jornalísticos e a Tabela 23 para literários.

Tabela 21 - Precisão geral dos etiquetadores para textos didáticos

\begin{tabular}{|l|l|}
\hline Etiquetadores & Precisão Geral \\
\hline TreeTagger - Unigrama (C4) & \\
Conjunto de textos didáticos de calibração (C41) & 83,308 \\
Conjunto de textos didáticos de teste (C42) & 82,508 \\
\hline TreeTagger - Trigrama (C4) & \\
Conjunto de textos didáticos de calibração (C41) & 89,118 \\
Conjunto de textos didáticos de teste (C42) & 86,648 \\
\hline TBL (C4) & 87.898 \\
Conjunto de textos didáticos de calibração (C41) & $\begin{array}{l}88.19 \% \\
\text { Conjunto de textos didáticos de teste (C42) }\end{array}$ \\
\hline MXPOST (C4) & 89.058 \\
Conjunto de textos didáticos de calibração (C41) & $88 \%$ \\
\hline Conjunto de textos didáticos de teste (C42) & \\
\hline PoSiTagger (C4) & 81,65 \\
Conjunto de textos didáticos de calibração (C41) & $83,24 \%$ \\
Conjunto de textos didáticos de teste (C42) &
\end{tabular}

Tabela 22 - Precisão geral dos etiquetadores para tertos jornalísticos

\begin{tabular}{|l|l|}
\hline Etiquetadores & Precisão Geral \\
\hline TreeTagger - Unigrama (C5) & \\
Conjunto de textos jornalísticos de calibração (C51) & $79,33 \%$ \\
Conjunto de textos jornalisticos de teste (C52) & $79,73 \%$ \\
\hline TreeTagger - Trigrama (C5) & \\
Conjunto de textos jornalisticos de calibração (C51) & 88,32 \\
Conjunto de textos jornalisticos de teste (C52) & $\mathbf{8 8 , 9}$ \\
\hline TBL (C5) & \\
Conjunto de textos jornalísticos de calibração (C51) & 88,57 \\
Conjunto de textos jornalísticos de teste (C52) & 88,53 \\
\hline MXPOST (C5) & \\
Conjunto de textos jornalisticos de calibração (C51) & 88,68 \\
Conjunto de textos jornalisticos de teste (C52) & 88,67 \\
\hline PoSiTagger (C5) & 83,51 \\
Conjunto de textos jomalísticos de calibração (C51) & 81,59 \\
Conjunto de textos jornalísticos de teste (C52) &
\end{tabular}

Tabela 23 - Precisão geral dos etiquetadores para textos literários

\begin{tabular}{|l|l|}
\hline Etiquetadores & Precisão Geral \\
\hline TreeTagger - Unigrama (C6) & \\
Conjunto de textos literários de calibração (C6I) & $73,53 \%$ \\
Conjunto de textos literários de teste (C62) & $74,32 \%$ \\
\hline TreeTagger - Trigrama (C6) & \\
Conjunto de textos literários de calibração (C61) & 82,46 \\
Conjunto de textos literários de teste (C62) & 84,08 \\
\hline TBL (C6) & \\
\hline
\end{tabular}


Analisando as Tabelas 21 , 22 e 23 poderia se concluir com os resultados para o conjunto de textos de teste que o etiquetador TBL é melhor para textos didáticos, que o etiquetador TreeTagger como trigrama é melhor para textos jornalísticos e que o etiquetador MXPOST é o melhor para textos literários. No entanto, no conjunto de textos de calibração o etiquetador TreeTagger é o melhor para textos didáticos, o MXPOST para textos jornalísticos e o TBL para textos literários. O que mostra que não existe uma relação entre tipo de texto e etiquetador ou, o mais provável, que apenas um teste năo é capaz de verificar e determinar a relaçăo existente entre estes textos, ou ainda indicar que existem problemas em nossos dados de treinamento e que alguns dos etiquetadores conseguem obter melhores resultados que outros frente a dados com alguma inconsistência. Este teste serviu também para comprovar o grau de dificuldade imposto por cada tipo de texto. Note que a pior média dos resultados é a dos dos etiquetadores literários, melhor um pouco se saem os jornalísticos e a melhor, apesar de serem os de menor corpus de treinamento, é a dos didáticos.

Para responder a segunda pergunta testamos cada um dos etiquetadores treinados para um único tipo de texto com um conjunto de teste formado pela união proporcional dos conjuntos de teste dos outros dois tipos. As Tabelas 24,25 e 26 mostram que uma vez treinado com um tipo de texto um etiquetador não se sai bem quando testado com outros tipos de texto. O que indica que existem duas op̧̧ões para etiquetar textos dos três graus de escrita, citados na Seção 4.1.1:

- ter um corpus de treinamento equilibrado com os diversos tipos de texto de interesse, contendo um grande número de exemplos para que o etiquetador generalize corretamente;

- ter um conjunto de etiquetadores especialistas, treinados cada um com um único tipo de texto de forma que um conjunto de exemplos pequeno e cheio de exceçōes năo prejudique o aprendizado do etiquetador. 
Tabela 24 - Etiquetadores didáticos frente a textos jornalísticos e literários

\begin{tabular}{|l|l|}
\hline Etiquetadores & Precisão Geral \\
\hline TreeTagger - Unigrama (C4) & \\
Conjuntos de textos de 2 genêros de calibração JL (C7) & $64,93 \%$ \\
Conjuntos de textos de 2 genêros de teste JL (C8) & $68,80 \%$ \\
\hline TreeTagger - Trigrama (C4) & \\
Conjuntos de textos de 2 genêros de calibração JL (C7) & $\mathbf{7 4 , 7 4 \%}$ \\
Conjuntos de textos de 2 generos de teste JL (C8) & $\mathbf{8 1 , 6 3 \%}$ \\
\hline TBL (C4) & \\
Conjuntos de textos de 2 genêros de calibração JL (C7) & $77,84 \%$ \\
Conjuntos de textos de 2 genêros de teste JL (C8) & $81,07 \%$ \\
\hline$M X X O S T$ (C4) & \\
Conjuntos de textos de 2 genêros de calibração JL (C7) & $77,65 \%$ \\
Conjuntos de textos de 2 genêros de teste JL (C8) & $79,39 \%$ \\
\hline
\end{tabular}

Tabela 25 - Etiquetadores jornalísticos frente a textos didáticos e literários

\begin{tabular}{|l|l|}
\hline Etiquetadores & Precisão Geral \\
\hline TreeTagger - Unigrama (C4) & \\
Conjuntos de textos de 2 genêros de calibração DL (C9) & $73,98 \%$ \\
Conjuntos de textos de 2 genêros de teste DL (C10) & $73,54 \%$ \\
\hline TreeTagger - Trigrama (C4) & \\
Conjuntos de textos de 2 genêros de calibração DL (C9) & $82,12 \%$ \\
Conjuntos de textos de 2 genêros de teste DL (C10) & $82,1 \%$ \\
\hline TBL (C4) & \\
Conjuntos de textos de 2 genêros de calibração DL (C9) & $82,66 \%$ \\
Conjuntos de textos de 2 genêros de teste DL (C10) & $84,02 \%$ \\
\hline$M X P O S T(C 4)$ & \\
Conjuntos de textos de 2 genêros de calibração DL (C9) & $82,58 \%$ \\
Conjuntos de textos de 2 genêros de teste DL (C10) & $\mathbf{8 4 , 6 4 \%}$ \\
\hline
\end{tabular}

Tabela 26 - Etiquetadores literários frente a textos didáticos e jornalísticos

\begin{tabular}{|l|l|}
\hline Etiquetadores & Precisão Geral \\
\hline TreeTagger - Unigrama (C4) & \\
Conjuntos de textos de 2 genêros de calibração DJ (C11) & $73.28 \%$ \\
Conjuntos de textos de 2 genêros de teste DJ (C12) & $73.38 \%$ \\
\hline TreeTagger - Trigrama (C4) & \\
Conjuntos de textos de 2 genêros de calibração DJ (C11) & $81.56 \%$ \\
Conjuntos de textos de 2 genêros de teste DJ (C12) & $80.49 \%$ \\
\hline TBL (C4) & \\
Conjuntos de textos de 2 genêros de calibração DJ (C11) & $81.72 \%$ \\
Conjuntos de textos de 2 genêros de teste DJ (C12) & $81.49 \%$ \\
\hline MXPOST (C4) & \\
Conjuntos de textos de 2 genêros de calibração DJ (C11) & $83.02 \%$ \\
Conjuntos de textos de 2 genêros de teste DJ (C12) & $\mathbf{8 1 . 8 7 \%}$ \\
\hline
\end{tabular}




\section{COMBINAÇÃO DE ETIQUETADORES}

maior objetivo de um classificador é predizer com sucesso novos casos apresentados. No entanto, para a maioria dos problemas tratados a quantidade de dados disponíveis é limitada e muitas vezes traz informações superficiais. Este limite quanto ao volume e qualidade dos dados torna bem mais difícil a tarefa de classificar corretamente um dado não visto no treinamento e foi para superá-lo que surgiu em Aprendizado de Máquina (AM) a idéia de combinar classificadores.

Se diferentes classificadores erram de forma diferente, ou por serem baseados em diferentes formalismos ou por conterem conhecimento diferente, então combinar um conjunto de classificadores (ensemble) é uma forma de minimizar os erros (aumentar a precisão geral), explorando as situações em que um classificador erra e outro acerta. A combinação de classificadores surge como uma técnica para ser utilizada para resolver problemas mais gerais que envolvem diferentes tipos de dados ou para ser aplicada em problemas que não foram resolvidos satisfatoriamente por um único classificador e/ou em problemas cujo desempenho deve ser estável, isto é, termos um classificador robusto (para uma revisão da área veja (Dietterich, 1997; Chan et al., (999)).

A combinação de classificadores tem sido utilizada em diversas áreas em Inteligência Artificial, como Redes Neurais (Sharkey, 1999), Aprendizado Simbólico de Máquina (Barnett, 1981), Engenharia de Software (Knight, 1986) e mais recentemente em PLN em tarefas como 
dizambigüização semântica (Rigau et al., 1997), avaliação de heurísticas (Agirre et al., 1998) e etiquetagem morfossintática (van Halteren et al., 1998; Brill \& Wu, 1998), mostrando resultados melhores que o do melhor dos classificadores individuais quando os erros dos classificadores não estão relacionados.

O método de combinação escolhido deveria, então, aproveitar os pontos fortes de classificadores individuais, evitar os seus pontos fracos, melhoranđo a precisão da classificação. Entretanto, é dificíl combinar as saídas de tal forma que as falhas de alguns não interfiram nas saídas corretas de outros. Esta é uma situaçăo ideal, porém não existe nenhum método que a garanta. Segundo Sharkey (1996), o método de combinação envolveria três aspectos:

- A escolha de quantos classificadores serão combinados.

- A criação ou seleção do conjunto de classificadores para serem combinados.

- O método pelo qual as saídas dos classificadores escolhidos serão combinadas.

A escolha de quantos classificadores serão utilizados depende do problema em questão e do número de classes utilizadas. Há apenas uma sugestão comum na literatura quanto a este critério, que é a sugestão intuitiva de usar um número de classificadores ímpar, de preferência um número primo, para que fique mais difícil a ocorrência de conflitos, em que duas classes distintas possuem o mesmo número de votos para serem selecionadas como a classe associada a um novo padrão.

conjunto de classificadores pode ser formado treinando diferentes algoritmos com um único conjunto de dados de treinamento, ou treinando o mesmo algoritmo com diferentes conjuntos de dados de treinamento ou com diferentes partes de um mesmo conjunto de dados. Dentre os classificadores formados devem ser utilizados os que não produzem muitos erros semelhantes. Neste trabalho, para selecionar quais etiquetadores seriarn combinados utilizamos a mesma medida utilizada por Brill \& Wu (Brill \& Wu, 1998) que será mostrada na Seção 5.1 .

As saídas dos classificadores podem ser combinadas de três formas: em paralelo, em cascata e de forma hierárquica. No modelo em paralelo (ou cooperativo), os classificadores possuem o mesmo conjunto de entradas e produzem saídas pertencentes ao mesmo conjunto de possíveis classes, cooperando para classificar um padrão de entrada (Figura 32). No modelo em cascata (ou sucessivo), a saída de um classificador serve como entrada para outro classificador (Figura 33). Já o modelo hierárquico mistura os modelos paralelo e cascata, em que os classificadores trabalham cooperativamente, mas há um classificador trabalhando em cascata, 


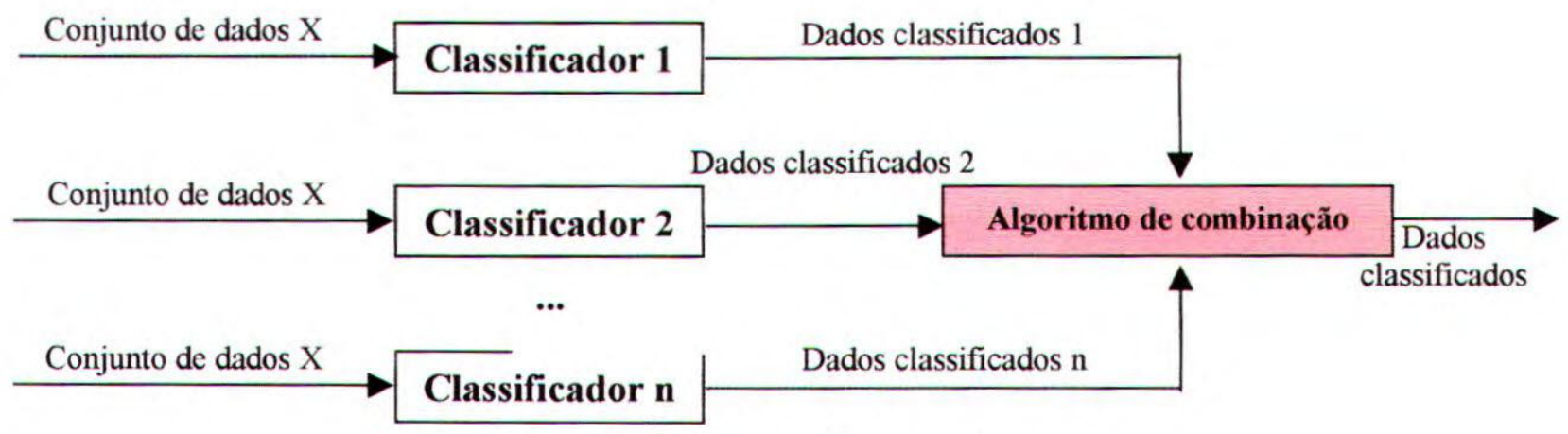

Figura 32 - Combinação de classificadores em paralelo

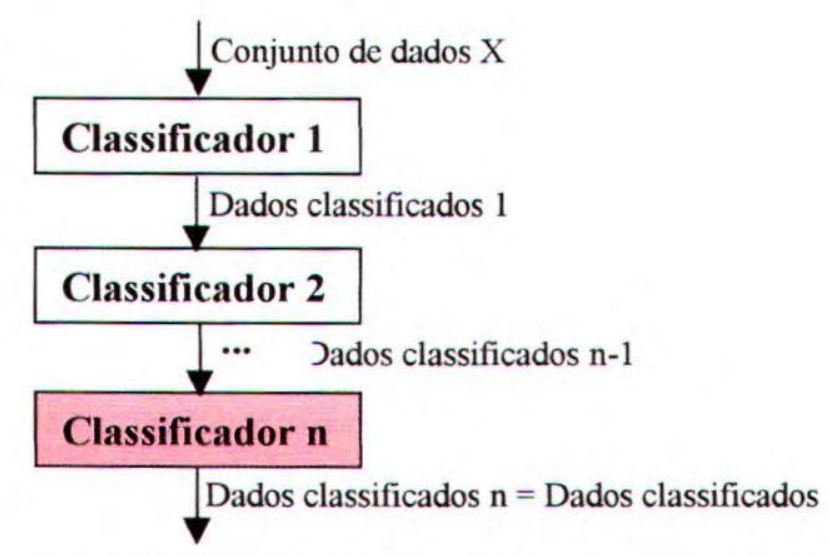

Figura 33 - Combinação de classificadores em cascata

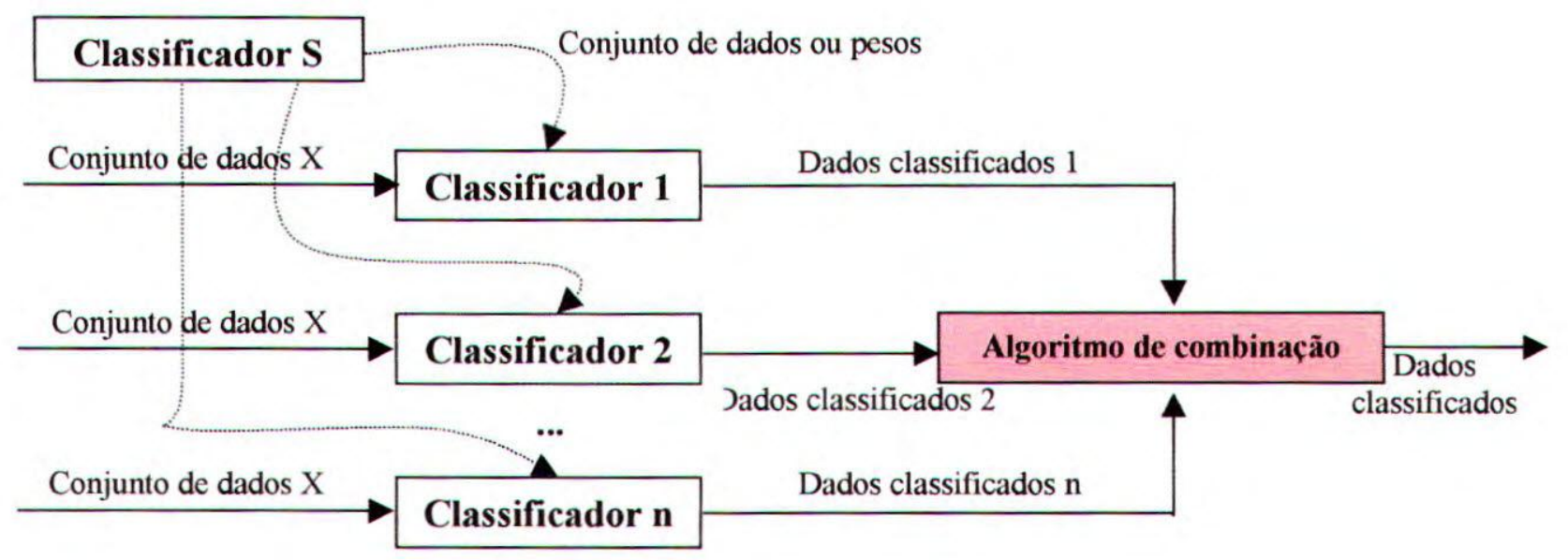

Figura 34 - Combinação hierárquica de classificadores 
Fazendo uma analogia entre as formas de combinar os classificadores e um jogo de futebol, o modelo em cascata seria o processo de marcar um gol, o modelo em paralelo seriam os comentaristas decidirem se uma jogada foi ou não falta e o modelo hierárquico seria a estratégia dos jogadores em campo. Para o exemplo do modelo em cascata, o time de futebol seria o conjunto de classificadores com os classificadores especialistas - goleiro, zagueiros, laterais, meio-campo, pontas-de-lança e atacantes -, e o objetivo seria marcar gols. Cada jogador faria o seu papel de especialista, o goleiro defenderia e faria um arremesso, o meiocampo passaria a bola para o ponta-de-lança que driblaria um jogador do time adversário e faria um lançamento para um atacante que marcaria o gol. A bola seria como o dado a ser classificado e cada ação de cada jogador por onde ela passou seria como a sua classificação para a entrada bola. A classificação definitiva seria a dada pelo último classificador da sequência, o atacante. Para 0 modelo em paralelo, o conjunto de classificadores seriam os comentaristas, o dado seria a jogada e cada um deles, dado seu ângulo, ponto de vista, e conhecimento dariam seu voto dizendo se foi ou não falta, o sistema de decisão seria o narrador que diria se realmente foi ou não falta, dados o número de votos a favor e contra e/ou a confiança que ele tem em cada um dos comentaristas. No modelo hierárquico, o time seria mais uma vez o conjunto de classificadores, cada jogador decide qual a estratégia seguir durante o jogo, mas há uma interferência de um supervisor na decisão de um ou mais jogadores. Este supervisor poderia ter conhecimento prévio das principais especialidades de cada jogador (técnico) ou poderia ser um dos classificadores e estar avaliando isto durante o jogo (capitão do time). Neste modelo, a decisão final sai das decisões de todos os jogadores, mas o processo é influenciado pelo supervisor.

A escolha de qual forma utilizar depende do problema, não havendo recomendações para tal escolha, de forma que deve-se estudar mais de um método e escolher o mais rápido e eficiente para o problema em questão.

Neste trabalho, foram utilizados o modelo em cascata e o modelo em paralelo. As formas utilizadas em nossos experimentos e os resultados são mostrados na Seção 5.2. 


\subsection{Taxa de complementaridade de Etiquetadores}

Como falado anteriormente, a combinação de classificadores é viável quando existe um número razoável de situaçōes em que um classificador erra e outro acerta, isto é, se são complementares. Para verificar quais os etiquetadores tratados neste trabalho eram complementares foi utilizada a mesma medida usada por Brill \& Wu (1998) para analisar quão diferentes são os erros dos etiquetadores. A taxa de complementaridade dos etiquetadores $\mathrm{X}$ e $\mathrm{Y}$ é definida como:

\section{$\operatorname{Comp}(X, X)=(1-(\# \text { de erros comuns/\# número de erros somente de } X))^{*} 100$}

e mede a porcentagem de vezes em que $X$ está errado e $Y$ correto. Como mostra a Tabela 27, as taxas são altas. Por exemplo, quando o MXPOST está errado, o TreeTagger como Trigrama está certo em $35,24 \%$ das vezes, e quando o TreeTagger como Trigrama está errado, MXPOST está certo em $38,99 \%$ das vezes.

Tabela 27 - Taxa de Complementaridade entre Etiquetadores

\begin{tabular}{|l|c|c|c|c|}
\hline $\mathbf{X}$ & $\begin{array}{c}\text { TreeTagger } \\
\text { como Unigrama }\end{array}$ & $\begin{array}{c}\text { TreeTagger } \\
\text { como Trigrama }\end{array}$ & TBL & MXPOST \\
\hline $\begin{array}{l}\text { TreeTagger } \\
\text { como Unigrama }\end{array}$ & - & $53.78 \%$ & 60.84 & 64.48 \\
\hline $\begin{array}{l}\text { TreeTagger } \\
\text { como Trigrama }\end{array}$ & $21.44 \%$ & - & 37.01 & 38.99 \\
\hline TBL & 32.96 & 36.56 & - & 34.32 \\
\hline MXXOST & 35.92 & 35.24 & 30.77 & - \\
\hline
\end{tabular}

Para a combinaçăo gerar bons resultados, os etiquetadores escolhidos precisam cometer erros diferentes. A Tabela 28 mostra que, para $95,68 \%$ das palavras do corpus de teste, ao menos um dos quatro etiquetadores acerta ao etiquetar a palavra. Quando utilizamos apenas três 
etiquetadores (não utilizamos o TreeTagger como unigrama), para $94,8 \%$ das palavras pelo menos um dos etiquetadores acertou (terceira coluna).

Tabela 28 - Concordância entre etiquetadores no teste

\begin{tabular}{|l|c|c|}
\hline & Todos os etiquetadores & $\begin{array}{c}\text { Etiquetadores sem o Tree Tagger como } \\
\text { unigrama }\end{array}$ \\
\hline Todos os etiquetadores estāo corretos & $73,32 \%$ & 0,03 \\
\hline Maioria correto & 14,55 & 8,29 \\
\hline Correto presente sem maioria & 4,25 & 83,20 \\
\hline Minoria correta & 3,56 & 3,27 \\
\hline Todos os etiquetadores estāo errados & $4,32 \%$ & 5,20 \\
\hline
\end{tabular}

Em outras palavras, se tivéssemos um oráculo que pudesse sempre pegar a etiqueta correta das diferentes saídas, poderíamos ter um resultado melhor do que o resultado do melhor etiquetador. A Tabela 29 mostra que as taxas de erro diminuem à medida que acrescentamos mais etiquetadores na combinação. Os resultados da Tabela 29 sảo referentes ao maior acréscimo possível em relação à precisão do MXPOST. Por exemplo, quando o oráculo usa os quatro etiquetadores treinados, a taxa de erro é $4,32 \%$ o que significa uma redução de $58,22 \%$ sobre a taxa de erro do MXPOST. Podemos esperar melhorias aditivas apesar de não sabermos quando a saturação será alcançada.

Tabela 29 - Combinaçāo Ideal

\begin{tabular}{|l|c|c|c|c|}
\hline & MXPOST & $\begin{array}{l}+ \\
\text { Trigrama }\end{array}$ & + TBL & + Unigrama \\
\hline$\%$ de vezes em que todos estão errados & $10,34 \%$ & $6,80 \%$ & $5,20 \%$ & $4,32 \%$ \\
\hline$\%$ melhoria do oráculo & - & $34,23 \%$ & $49,71 \%$ & $58,22 \%$ \\
\hline
\end{tabular}

\subsection{Métodos para Combinação de Etiquetadores}

Da discussão nasce a luz. - Provérbio

Neste trabalho, foram utilizadas três estratégias para combinar os etiquetadores baseadas nas variaçōes do número de etiquetadores, da forma de gerar o conjunto de etiquetadores e do modelo de combinação das saídas dos etiquetadores para combinar os etiquetadores que são mostradas em detalhes nas próximas subseçōes. 


\subsubsection{Métodos paralelos baseados em diferentes algoritmos com um único conjunto de dados de treinamento}

No modelo em paralelo, sảo três os principais métodos que podem ser utilizados para combinar as saídas: votação pela maioria simples (simple voting), votação ponderada (weighted voting) e stacking. No método votaçăo pela maioria simples, cada classificador vota e o voto da maioria é a classe escolhida. Já no método votação ponderada o voto de cada classificador é pesado por sua precisão (Golding \& Roth, 1999) ou usando métodos mais sofistificados, como por exemplo o uso do algoritmo Naive Bayes para aprender pesos para os classificadores (Ali \& Pazzani, 1996). Em stacking,um classificador (nível 1) é treinado para predizer a classe correta quando é fornecido como entrada as saídas de outros classificadores e informaçōes adicionais (retiradas do corpus de calibração). Stacking não necessariamente seleciona uma das classes sugeridas pelos classificadores de nível 0 . Neste trabalho, o classificador de nível I é baseado em casos. A Figura 35 mostra as três principais formas de combinar as saídas e as técnicas implementadas por van Halteren et al. $(H)$ e por Brill \& Wu (B) para combinação de etiquetadores em paralelo.

\begin{tabular}{|l|l|}
\hline Decisão Aleatória ${ }^{19}$ & \\
\hline Votação pela Maioria & $\begin{array}{l}\text { Majority1(H) } \\
\text { Majority2(B) }\end{array}$ \\
\hline Votação Ponderada & Tot Precision (H) \\
& Tag Precision (H) \\
& Precision-Recall (H) \\
\hline Stacking & TagPair (H) \\
& Tags (H) \\
& Tags+Word (H) \\
& Tags+Context (H) \\
& Pick Tag (B) \\
& Pick Tagger (B) \\
\hline
\end{tabular}

Figura 35 - Métodos para combinar as saídas em um modelo paralelo

Na Decisão Aleatória, dadas as saídas de todos os classificadores, a saída de um deles é escolhida aleatoriamente. Em Majorityl, cada etiquetador vota e a etiqueta com maior número de votos é a escolhida e, em caso de empate, escolhe-se aleatoriamente entre as etiquetas vencedoras.

\footnotetext{
${ }^{19}$ A decisāo aleatória é utilizada apenas como base para comparaçāo dos resultados.
} 
Em Majority2, a etiqueta com maior número de votos é a escolhida e, em caso de empate, a etiqueta do etiquetador de maior precisão é a escolhida. Nós implementamos outra estratégia de votação pela maioria (Majority3), na qual a maioria é somente considerada quando pelo menos $51 \%$ dos etiquetadores votam na mesma etiqueta, e em caso de empate, a etiqueta do etiquetador de maior precisão é a escolhida.

Em Tot Precision, cada etiquetador vota sua precisão sobre a etiqueta sugerida, sendo adicionados os votos para a mesma classe, e o resultado final é a classe com mais votos. Em caso de empate, escolhe-se aleatoriamente entre as etiquetas vencedoras. Tag Precision segue a mesma idéia de Tot Precision, mas cada etiquetador vota sua precisão para a classe sugerida (Precision). Precision-Recall é semelhante ao último, mas cada etiquetador vota a sua precisão para a classe sugerida mais 1 menos o recall dos oponentes para a etiqueta que ele sugeriu. Os métodos de votação simples e ponderada são melhor detalhados na Figura 36.

Dado que $E_{i}$ são os etiquetadores a ser combinados, que $e_{i}(p s)$ é a etiqueta mais votada ${ }^{20}$ para uma palavra/símbolo $p s$ como sugerido por $E_{i}$ e que a qualidade de um etiquetador é medida por:

- Precisão de $E_{i}$ para a etiqueta $e t: \operatorname{Prec}\left(E_{i}\right.$ et)

- Recall de $E_{i}$ para a etiqueta $e t: \operatorname{Rec}(E i, e t)$

- Precisão geral de Ei: Prec(Ei)

Então o voto $V(e t, p s)$ para a etiquetar a palavra/símbolo ps com a etiqueta et é dado por:

- Majority1:

$$
\sum_{i} \operatorname{Se} e i(\mathrm{ps})=\text { et ENTÃO et SENÃO } 0
$$

- Majority2:

- Majority3:

$$
\sum_{i} \operatorname{Se~ei(ps)~=~et~ENTÃO~et~SENÃO~Prec(Ei)~}
$$

$$
\sum_{i} \operatorname{Se} \text { ei(ps) }=\text { et ENTÃO et SENÃO Prec(Ei) }
$$

- Tot Precision:

$$
\sum_{i} \operatorname{Se} e i(p s)=\text { et ENTÃO Prec(Ei) SENÃO } 0^{21}
$$

- Tag Precision:

$$
\sum_{i} \operatorname{Se} e i(p s)=\text { et ENTÃO Prec(Ei, et) SENÃO } 0
$$

- Precision-Recall:

$$
\sum_{i} \operatorname{Se} e i(p s)=\text { et ENTÃO Prec(Ei, et) SENÃO 1-Rec(ei, et) }
$$

Figura 36 - Algoritmos de votação simples e ponderada para a etiquetagem morfossintática

\footnotetext{
${ }^{20}$ Para Majority 3 a etiqueta mais votada é a que obteve mais de $50 \%$ dos votos.
} 
TagPair permjte que uma etiqueța sugerida pela minoria (ou nenhum) dos etiquetadores tenha chance de vences usando informações dos etiquetadores em pares. Ele considera situações nas quais um etiquetador sugere $T_{1}$ e outro $T_{2}$, e estima a probabilidade de nesta situaçăo a etiqueta ser realmente $T_{x}$. Na combinaçăo, cada par é selecionado e vota (com as propabilidadẹs para a etiqueta apropriada) para cada etiquețta possível, năo apenas as sugeridas pelos etiquetadores. Por expmplo, para os casos listados abaixo, a escolha seria $T_{x 2}$.

$\begin{array}{llll}\mathrm{T}_{1} & \mathrm{~T}_{2} & \mathrm{~T}_{\mathrm{x}} & \text { Probabiliqades } \\ \mathrm{T}_{1} & \mathrm{~T}_{2} & \mathrm{~T}_{\mathrm{x} 1} & (2 / 12) \% \\ \mathrm{~T}_{+} & \mathrm{T}_{2} & \mathrm{~T}_{2} & (5 / 12) \% \\ \mathrm{~T}_{1} & \mathrm{~T}_{2} & \mathrm{~T}_{\mathrm{x}} & (3 / 12) \% \\ \mathrm{~T}_{1} & \mathrm{~T}_{2} & \mathrm{~T}_{\mathrm{x} 4} & (2 / 12) \%\end{array}$

Entretanto, sf um par de etiquetas $\left(T_{1}-T_{2}\right)$ não foi observado no corpus de calibração, é usada informação de çada etiquetador em particular (a probabilidade de cada etiqueta $T_{x}$ dado que o etiquetador sugeriu $T_{i}$ ).

Em Tags, kadagaso tonșiste das etiquetas sugeridas por cada um tos etiquetadores e da etiqueta correta, enquanto que em Tags +Word a palavra em foco também é considerada. Durante a etiquetaçăo a medida de "similaridade usada é a freqüência da etiqueta. Em Tags+Context ${ }^{22}$, caşa caso consiste da informação usada em Tags +Word mais as etiquetas sugeridas pelos demais etiquetadores para as palavras anterior e posterior. Em Pick Tag e Pick Tagger cada caso consiste de toda a informaçáo de Tags + Context mais as palavras anterior e posterior. O primeiro usa este contexto para especificár que etiqueta escolher enquanto que $o$ segundo usa papa espeqfificar em que etiquetador confiar.

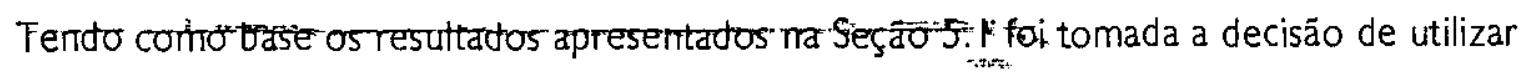
os quatro etiquptadgres - TreeTagger como ynigrama e como trigrama, TBL e MXPOST, treinados com a corqus de treinamento (C3) - na combinação em paralelo com as técnicas mostradas na Figura 35. Analisando a Tabela 30, vê-se que seis métodos superaram o melhor dos algoritmos individualmente e que a técnica de melhor resultado foi a TagPair com $90.91 \%$ de precisão. A Tabẹ|a 3?, mostra em mais detalhes os resultados da técnica TagPair.

\footnotetext{
${ }^{21}$ SENĀO 0 significa que em caso de empate a etiqueta é escolhida aleatóreamente entre as etiquetas votadas

${ }^{22} \mathrm{Nāo}$ foi implementado neste trabalho.
} 
Tabela 30 - Resultados da combinaçăo

\begin{tabular}{|l|l|}
\hline Métodos & Precisão \\
\hline Decisão Aleatória & $86.43 \%$ \\
\hline Majority1 & $89.16 \%$ \\
\hline Majority2 & $89.20 \%$ \\
\hline Majority3 & $90.41 \%$ \\
\hline Tot Precision & $90.70 \%$ \\
\hline Tag Precision & $90.72 \%$ \\
\hline Precision-Recall & $90.3 \%$ \\
\hline TagPair & $90.91 \%$ \\
\hline Tags & $89.66 \%$ \\
\hline Tags+Word & $90.04 \%$ \\
\hline Pick Tag & $88.51 \%$ \\
\hline Pick Tagger & $87.83 \%$ \\
\hline
\end{tabular}

Tabela 31 Resultados da combinação utilizando o método TagPair

\begin{tabular}{|l|l|c|c|}
\hline Etquetadores & $\begin{array}{l}\text { \% no corpus } \\
\text { de teste }\end{array}$ & $\begin{array}{l}\text { Média da \% individual dos } \\
\text { etiquetadores +\% de melhora }\end{array}$ & $\begin{array}{l}\text { Redução do erro quando comparando } \\
\text { com o melhor }\end{array}$ \\
\hline $\mathbf{U}^{23}$ & 80,018 & - & - \\
\hline T & 88,478 & - & - \\
\hline B & 88,768 & - & - \\
\hline M & 89,668 & - & - \\
\hline UT & 88,748 & $84,24+4,5$ & $\star$ \\
\hline UB & 89,498 & $84,38+5,11$ & \\
\hline UM & 90,048 & $84,83+5,21$ & \\
\hline TB & 89,578 & $88,61+0,96$ & 3,678 \\
\hline TM & 89,518 & $89,06+0,45$ & \\
\hline BM & 89,808 & $89,21+0,59$ & \\
\hline UTB & 89,638 & $85,75+3,88$ & 1,358 \\
\hline UTM & 89,738 & $86,05+3,68$ & \\
\hline UBM & 90,618 & $86,14+4,47$ & 0,688 \\
\hline TBM & 90,918 & $88,96+1,95$ & 6,478 \\
\hline UTBM & 90,538 & $86,72+3,81$ & 12,098 \\
\hline
\end{tabular}

\subsubsection{Métodos paralelos baseados em um único etiquetador}

Nós somos aquilo que fazemos repetidamente. Excelência, então, não é um modo de agir, mas um hábito. -Aristóteles

Uma alternativa aos métodos apresentados na Seção 5.2.I é fazer o treinamento com um único algoritmo, utilizando n partes do corpus de treinamento como entrada do algoritmo. Isto pode ser feito de duas maneiras:

${ }^{23}$ A letra "U" é utilizada para representar o TreeTagger como unigrama, a letra "T" para representar o TreeTagger como trigrama, a letra "B" é utilizada para representar o etiquetador TBL e a letra " $M$ " para representar o etiquetador MXPOST. ${ }^{24}$ * Quando não houve reduçāo de erro 
1) Dividindo-se o corpus de treinamento de acordo com os diversos tipos de informação nele contido - por exemplo, para o nosso caso, em textos didáticos, jornalísticos e literários. Em que para cada divisão é feito um treinamento.

2) Gerando n corpus de treinamento a partir do corpus de treinamento original e fazendo um treinamento com cada uma dessas $n$ novas formas do corpus, seguida da combinação das saídas utilizando votação - esta classe de métodos é chamada de arcing (a daptive resampling and combining).

Os métodos arcing utilizados são bagging (de bootstrap aggregating) e boosting. Em bagging são formados vários corpus de treinamento do mesmo tamanho do corpus original. Cada corpus é formado selecionando-se randomicamente exemplos do corpus de treinamento original. Com isso algumas dos períodos que apareciam no corpus original podem não aparecer no novo corpus e outras podem aparecer duplicadas. $E$, então, é feito um treinamento com cada um dos corpus gerados e um único algoritmo de etiquetagem. Cada etiquetador gerado dá seu voto e o voto da maioria ganha. Apesar dos vários modelos serem gerados a partir do mesmo conjunto de treinamento, ao contrário do que se espera, os modelos originados usualmente não são praticamente idênticos e não classificam as novas instâncias da mesma forma, principalmente se o conjunto de treinamento é pequeno. Com isso, bagging, geralmente, gera um modelo significamente melhor do que um modelo de um classificador simples (sem combinação) e nunca gera um modelo substancialmente pior (Witten \& Frank, 2000). Bagging explora a instabilidade inerente em algoritmos de aprendizado, o que faz com que năo funcione com algoritmos de classificação estáveis, que não são sensíveis a pequenas mudanças na entrada, isto porque nestes casos pequenas mudanças nos dados de treinamento não causam mudanças nos modelos. A combinação funciona justamente por explorar as diferenças entre estes modelos que fazem com que um modelo complemente o outro.

Boosting também gera vários corpus de treinamento do corpus original. A diferença é que eles não são feitos em separado como em bagging. Aqui cada corpus de treinamento é influenciado pelo desempenho do modelo originado com o treinamento do corpus anterior. Boosting tenta encorajar os novos modelos a serem especialistas nas etiquetas escolhidas erroneamente pelos modelos anteriores. No primeiro corpus todos os períodos começam com um mesmo peso, o etiquetador é então treinado com este corpus e o novo corpus será gerado diminuindo o peso das etiquetas que foram classificadas corretamente e aumentando o peso das 
etiquetas que foram classificadas erradamente. Os votos de cada modelo não tem o mesmo peso, tem seu peso estabelecido por seu desempenho.

Neste trabalho, foi implementado apenas bagging utilizando o TreeTagger como trigrama. A escolha do TreeTagger foi devido ao fato deste algoritmo ser baseado em árvore (e portanto ser instável) e ter um custo de treinamento baixo. Não foi encontrado na literatura de combinação de classificadores um número padrăo que devesse ser utilizado como número de conjuntos a serem gerados a partir do conjunto de treinamento inicial e sim apenas os valores utilizados por cada autor em seu trabalho. Quinlan (1996) gera 10 conjuntos, Bauer \& Kohavi (1999) 25, Breiman (1996b) 50 e Freund \& Schapire (1996) 100. Resolvemos então realizar experimentos com três destes quatro valores - 10,25e 50 - verificando assim qual é o melhor para a nossa tarefa, a etiquetagem morfossintática. A precisăo obtida em cada um dos experimentos é mostrada na Tabela 32.

Tabela 32 - Precisão da combinação usando bagging

\begin{tabular}{|l|c|}
\hline Número de corpus gerados a partir do corpus de treinamento original (C2) & Precisão \\
\hline 10 & $89,32 \%$ \\
\hline 25 & $89,40 \%$ \\
\hline 50 & $89,65 \%$ \\
\hline
\end{tabular}

\subsubsection{Método em cascata aplicado ao TBL}

Não encontramos sugestões detalhadas na literatura para o modelo em cascata. Fala-se apenas que os dados classificados por um classificador $X$ servirão como entrada para um classificador $Y$. Mas não há sugestōes, por exemplo, de quantos classificadores encadear.

Uma forma possível no caso da etiquetagem morfossintática seria, por exemplo, utilizar a etiqueta dada como resposta pelo etiquetador inicial para casos em que o etiquetador seguinte não consiga etiquetar aquela palavra. Pode-se pensar também em um etiquetador que admita ter como entrada um texto já com uma etiquetagem inicial e que dado este texto tente melhorar a etiquetagem. 
A opção utilizada neste trabalho foi a última acima. O etiquedor TBL admite também a opção de que não seja utilizado seu etiquetador inicial, podendo fornecer a ele um texto já etiquetado para ser passado pelo seu etiquetador final, o etiquetador contextual (que foi explicado no Capítulo 3, na Seção 3.3.1.2). Foram feitos três experimentos:

I) $\mathrm{O}$ corpus de teste (C3!) foi etiquetado pelo etiquetador TreeTagger como unigrama (treinado com C3) e depois fornecido como entrada para o etiquetador TBL

2) O corpus de teste $(\mathrm{C} 3 \mathrm{l})$ foi etiquetado pelo etiquetador TreeTagger como trigrama (treinado com C3) e depois fornecido como entrada para o etiquetador TBL

3) O corpus de teste ( $\mathrm{C} 3 \mathrm{I}$ ) foi etiquetado pelo etiquetador MXPOST (treinado com C3) e depois fornecido como entrada para o etiquetador TBL

Nos experimentos I e 2 a precisão foi maior do que havia sido obtida pelo TreeTagger, mas não superou a precisão do etiquetador TBL. Apenas no experimento 3 a precisão superou a precisão obtida pelo etiquetadore TBL e a obtida pelo etiquetador inicial - MXPOST. A Tabela 33 mostra os resultados obtidos com os experimentos.

Tabela 33 - Resultados obtidos nos modelos em cascata

\begin{tabular}{|l|c|c|}
\hline Etiquetadores & Precisão & Precisão do modelo em cascata \\
\hline TBL & $88,76 \%$ & - \\
\hline TreeTagger como unigrama & $80,01 \%$ & $80,79 \%$ \\
\hline TreeTagger como trigrama & $88,47 \%$ & $88,70 \%$ \\
\hline MXPOST & $89,66 \%$ & $89,68 \%$ \\
\hline
\end{tabular}





\section{DISCUSSÃO DOS RESULTADOS}

Primeiro obtenha os fatos; depois pode torcê-los tanto quanto quiser. - Mark Twain

Como mostrado no Capítulo 4 a melhor precisão geral individual é de $89,66 \%$ (melhor etiquetador no corpus de teste), que é um valor insatisfatório, não só por não alcançar os valores obtidos pelos mesmos etiquetadores quando treinados para o inglês, mas principalmente pelo que uma taxa de erro de aproximadamente 10\% significa. Dizer que um etiquetador tem $90 \%$ de precisão geral é o mesmo que dizer que ele comete em média três erros por período, considerando que um período tenha cerca de 30 palavras. Dado que a etiquetagem morfossintática é uma tarefa básica para a maioria dos aplicativos de PLN, começar com esta taxa de erro em cada período pode ser uma forte desvantagem, especialmente se considerarmos que alguns destes erros podem crescer mais que linearmente. Alguns fatores poderiam ser os responsáveis por esta baixa precisão:

- qualidade da etiquetagem manual do corpus de treinamento;

- tamanho do corpus de treinamento;

- o conjunto de etiquetas;

- os tipos de texto utilizados;

- as abordagens de etiquetagem.

Fora os experimentos citados até aqui, vários outros foram feitos a cada nova versão corrigida do corpus manualmente etiquetado. Após o treinamento e teste dos etiquetadores, uma 
lista com as situaçöes em que todos eles davam a mesma resposta e estavam errados era gerada junto com a resposta da etiquetagem manual para que pudessemos assim encontrar possíveis erros de etiquetagem manual. Assim, ao longo dos experimentos foram revisadas as palavras "que", "se", "como", "outro", "algum", "todo", "qualquer", "cada", "vários", "muitos" e "poucos", as conjunçōes, locuçōes e verbos. As correçōes dos problemas de padronização na etiquetagem manual ocasionaram um aumento de $0,93 \%$ na precisão geral da penúltima para a última versão do corpus etiquetado manualmente.

O tamanho do corpus de treinamento foi um dos fatores de maior influência para a baixa precisão encontrada. Como mostrado na Seção 4.2.1.3, incrementando o corpus de treinamento com 10.500 palavras a precisão saltou de $89,66 \%$ para $90,25 \%$, ou seja, houve um aumento de $0,59 \%$. O que faz do tamanho do corpus um fator tão importante, é o fato que quanto maior o corpus menor o número de palavras e de contextos desconhecidos. Ainda na Seção 4.2.1.3 foi mostrada a influência das palavras desconhecidas, e viu-se que quando não existiam palavras desconhecidas a precisåo geral foi de $93,65 \%$, um aumento de $3,99 \%$. Esta relação entre tamanho do corpus versus número de palavras desconhecidas pode ser vista na Tabela 8 da Seção 4.2. O que mostra que quando se muda a divisão do corpus de $90-10$ para 80-10-10 o número de palavras desconhecidas aumenta em cerca de $1 \%$. É importante ressaltar também que nos experimentos para o inglês feitos em (van Haltaren et al., 1998), a porcentagem de palavras novas é de $2,5 \%$ e a porcentagem de palavras com etiquetas novas é de 0,2\%. Já em nossos experimentos, a porcentagem de palavras desconhecidas no corpus de teste é de $15,21 \%$ e a porcentagem de palavras com etiquetas novas é 0,2 .

O Nilc Tagset com certeza é outro causador da baixa precisão. Na Seção 4.2.2 quando treinamos o etiquetador MXPOST com o mesmo corpus de treinamento, porém sem considerar a transitividade, a precisão aumentou para $92,51 \%$ - um aumento de 2,85\% na precisão geral. Nas Seçōes 4.2.1.1, 4.2.1.2 e 4.2.1.3, fica claro também que as etiquetas referentes às locuçóes, palavra denotativa, ênclises e mesóclises são as mais problemáticas, mas não são as grandes vilãs, primeiro por causarem uma pequena parte dos erros (aparcem muito pouco nos textos), segundo por serem casos fáceis de resolver, não justificando uma alteração no conjunto de etiquetas. $O$ problema com as locuções pode ser resolvido com o pós-processsamento através de uma lista fechada. A classe das palavras denotativas exige bastante cuidado devido à ambigüidade com adjetivos, advérbios, locuçōes, preposiçōes e conjunçōes. Porém, segundo Celso Cunha (1979) as 
palavras denotativas não devem ser incluídas entre os advérbios, posto que não modificam o verbo, nem o adjetivo, nem outro advérbio. Resolve-se assim a classe de ambigüidade formada por palavra denotativa-advérbio. Há a exceção das palavras "cá" e "lá", que exercem a função de advérbio e que têm uso raro como palavras denotativas no português do Brasil, por exemplo: "Tenho cá minha opinião". No entanto, mesmo em nosso corpus manualmente etiquetado, esta năo foi a metodologia utilizada para etiquetar as palavras denotativas. Já os erros relativos às mesóclises e ênclises estão relacionados ao número reduzido de vezes em que aparecem em nosso corpus, o que impossibilitou que os etiquetadores aprendessem regras simples ${ }^{25}$ para tratar parte destes casos como, por exemplo, as mostradas na Figura 37.

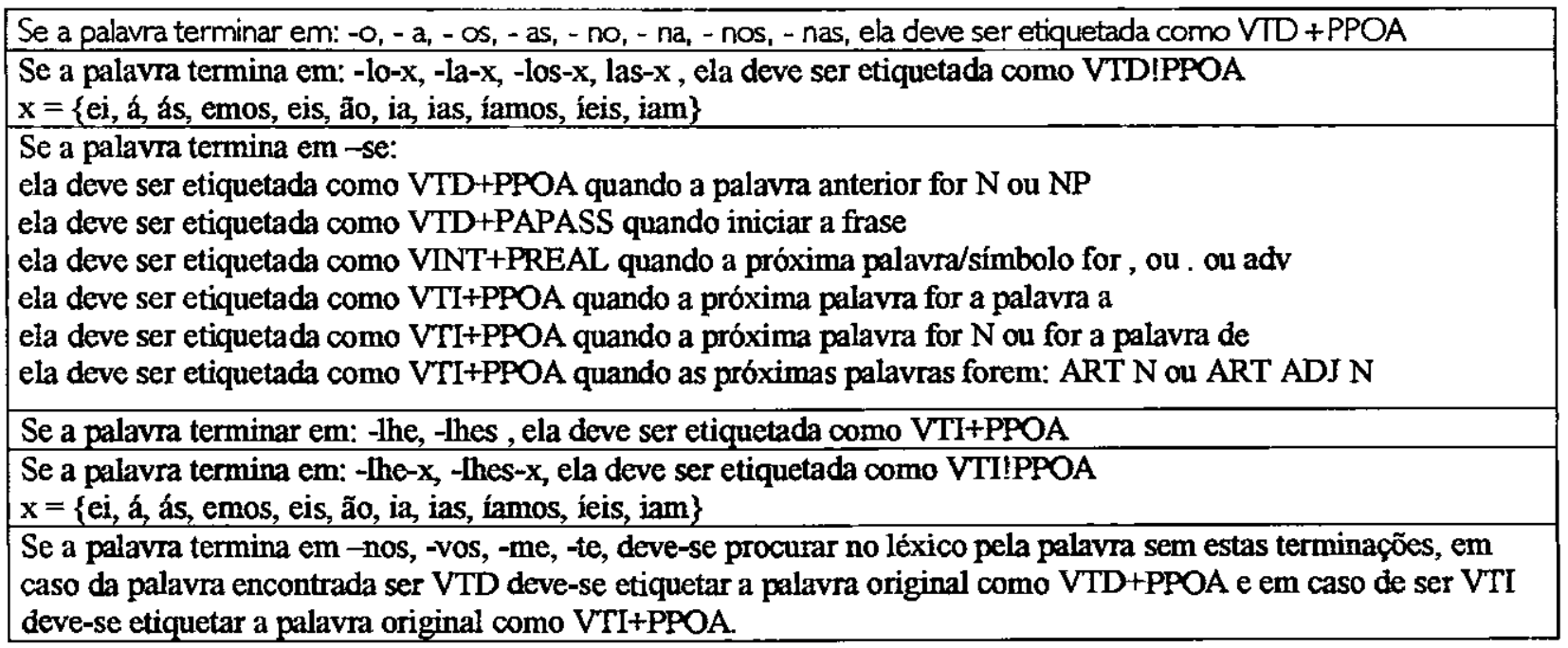

Figura 37 - Regras para pós-preocessamento de ênclises e mesóclises

Quais textos utilizar foi outra escolha problemática que certamente influenciou na precisão geral obtida nos experimentos. Os experimentos para inglês reportados na literatura geralmente fazem uso de corpus formados por textos jornalísticos. Já nosso corpus contém aproximadamente $30,54 \%$ de textos literários, que, como mostrado na Tabela 7 da Seçăo 4.2, é o tipo de texto com proporcionalmente a maior taxa de ambigüidade.

Como os etiquetadores utilizados neste trabalho săo reconhecidos pela literatura como estado-da-arte, o problema é mais uma vez o tamanho do corpus, já que estes etiquetadores precisam de corpus grandes (entre 1.000 .000 e 2.000 .000 de palavras) para obterem bons

${ }^{25}$ Estas regras fazem parte das regras elaboradas por uma lingüista para o PoSTTagger. 
resultados. Uma solução seria utilizar uma abordagem que trabalhasse bem com corpus pequenos, como é o caso dos etiquetadores neurais. Outra seria aumentar progressivamente o tamanho do corpus - treinando, etiquetando automaticamente, corrigindo manualmente e retreinando, até que se obtivesse um corpus etiquetado com 1 milhão de palavras. Ou ainda combinar os etiquetadores como foi feito no Capítulo 6.

O etiquetador simbólico PoSiTagger também năo atingiu a precisăo imaginada, já que para outras línguas este é o tipo de etiquetador que atinge a maior precisão geral, pelo menos quando restritos a um domínio. Atribuímos esta baixa precisão ao tempo destinado para elaboração das regras - 20 dias - e ao fato destas ainda não terem sido reavaliadas e refinadas através de testes.

A combinação de etiquetadores é uma solução bem interessante para se obter etiquetadores estáveis. No entanto, apenas seis dos métodos de combinação mostrados na Seção 5.2. I ultrapassaram a precisăo geral do melhor dos etiquetadores com um acréscimo máximo de 1,25\% sobre a precisão geral do melhor deles, enquanto que para o inglês todos os métodos de combinaçăo superaram a precisăo geral do melhor etiquetador. Em todos os experimentos de combinação em que se utilizou bagging os resultados foram melhores que 0 do etiquetador inidividual (TreeTagger como trigrama), com um acréscimo de até 1,18\% na precisão, no entanto, não houve melhora com relação ao melhor dos etiquetadores. $E_{1}$ com o modelo em cascata o acréscimo na precisão foi mínimo - 0,02\%. 


\section{CONCLUSÕES E TRABALHOS FUTUROS}

Experiência é o nome que cada qual dá a seus próprios erros. - Oscar Wilde

Com todos os experimentos realizados fica evidente a importância de um bom corpus de treinamento - um corpus grande e com uma taxa de erro de etiquetagem manual mínima. Entretando, a construção de um corpus etiquetado é uma tarefa que exige tempo e cuidados. Neste trabalho, a etiquetagem manual foi feita em paralelo com a construção dos etiquetadores. Em Alves (1999) há uma analogia que descreve muito bem o processo de construir um etiquetador enquanto se constrói um corpus etiquetado, comparando este processo a "tentar navegar em um navio enquanto é construído". Apesar disso, este trabalho gerou várias contribuições (Seção 7.1). A Seção 7.2 traz algumas sugestōes de trabalhos futuros.

\subsection{Contribuições}

Apesar da baixa precisão geral, este trabalho contribuiu para a etiquetagem automática comprovando que:

- É possível utilizar um conjunto de etiquetas que contenha também outras características além das morfossintáticas, como é o caso do Nilc tagset que trata também a transitividade de verbos. Apesar da literatura dizer que as etiquetas podem ser de outra natureza que não a 
morfossintática, não encontramos na literatura conjuntos de etiquetas que considerassem características morfossintáticas e de outro tipo ao mesmo tempo.

- A combinação de etiquetadores melhora a precisão mesmo com corpus pequenos.

- O uso de diferentes tipos de texto no treinamento e etiquetagem influencia consideravelmente na precisão geral. Não encontramos trabalhos que tivessem feito este teste mesmo que fazendo parte das recomendaçöes do EAGLES (1996b). Encontramos apenas um trabalho que identificou a influência causada na precisão por textos escritos em épocas diferentes (Alves, 1999).

- É importante o uso de técnicas estatísticas se para estimar a taxa de erro verdadeira de etiquetadores. Notou-se que a precisão já variava entre os arquivos de teste e calibração. E o experimento utilizando bootstrap mostrado na Seção 4.2.1.1 mostrou a diferença entre a precisão encontrada no teste e a estimada como sendo a real $(88,47 \%-88,95 \%$, respectivamente).

\subsection{Trabalhos futuros}

São vários os trabalhos que podem surgir deste projeto de mestrado. Listamos alguns abaixo que são caracterizados como extensōes e como superação das limitações encontradas.

- Treinar o etiquetador neural elático (Ma et al., 1999) com 90\% do corpus manualmente etiquetado. Foi implementada uma ferramenta para que o corpus fosse colocado no formato exigido por este etiquetador (Apêndice D).

- Treinar o etiquetador TnT (Brants, 2000) com 90\% do corpus manualmente etiquetado.

- Treinar os etiquetadores TreeTagger, TBL e MXPOST com 90\% do corpus.

- Analisar as regras para palavras iniciais e as regras para palavras contextuais do etiquetador TBL, na tentativa de melhorar sua precisăo.

- Refinar as regras do etiquetador PoSiTagger - testando, avaliando e reescrevendo as regras problemáticas.

- Verificar se o PoSiTagger trata as classes de ambigüidade das palavras que forem as maiores responsáveis pela taxa de ambigüidade.

- Utilizar o etiquetador PoSiTagger nos experimentos de combinação. 
- Refazer os experimentos com combinação do Capítulo 6 utilizando mais etiquetadores (treinados com $90 \%$ do corpus manualmente etiquetado) e no caso dos algoritmos da Seção 5.2.I utilizar o corpus de treinamento como corpus de calibraçäo.

- Utilizar boosting para combinação.

- Treinar o etiquetador TBL (Brill, 1994a) não-supervisionado com $90 \%$ do corpus manualmente etiquetado.

- Fazer experimentos com etiquetadores totalmente não supervisonados.

- Aumentar o corpus de treinamento de 100.000 em 100.000 até alcançar um corpus de 1 milhão de palavras - etiquetando textos com 100.000 palavras com o melhor dos algoritmos de combinação, corrigindo estes textos e retreinando todos os etiquetadores com o novo corpus.

- Implementar outras das técnicas estatísticas para estimar a taxa de erro verdadeira mostradas na Seção.

- Etiquetar períodos escritos de forma incorreta para verificar o quanto estes erros influenciam no trabalho do etiquetador.

- Como os textos que são etiquetados dificilmente estão livres de erros, verificar se o aprendizado na presença de erros como é feito em Aprendizado de Máquina (Kearns, 1990) melhorará a precisão geral.

- Verificar se alguns problemas do ReGra são resolvidos quando são utilizados textos etiquetados. 



\section{BIBLIOGRAFIA E REFERẾNCIAS}

(Abney et al., 1999) Abney, S.; Shapire, R. E.; Singer, Y. Boosting Applied to Tagging and PP Attachment. In Proceedings of the 1999 joint S/GDAT Conference on Empinical Methods in Natural Language Processing and Very Large Coppora, 1999. p. 38-4I.

(Abney, 1997) Abney, S. Part-of-Speech Tagging and Partial Parsing. Corpus-Based Methods in Language and Speech Processing. Editado por Steve Young e Gerrit Bloothooft. Kluwer Academic Publishers, 1997. p. 118-136.

(Academia Brasileira de letras, 1998) Academia Brasileira de Letras. Vocabulário Ortográfico da Língua Portuguesa. $2^{\text {a }}$ edição. Imprensa Nacional. 1998.

(Agirre et al., 1998) Agirre, E.; Gojenola, K.; Sarasola, K.; Voutilainen, A. Towards a Single Proposal in Spelling Correction. In COLING-AQ' '98, p. 22-28.

(Ali \& Pazzani, 1996) Ali, K. M.; Pazzani, M. J. Error Reduction through Learning Multiple Descriptions. Machine Leaming, 24(3): 173-202.

(Alpaydin, 1998) Alpaydin, E. Techniques for Combining Multiple Learners. In Proceedings of Engineering of Intelligent Systems, p. 6-12.

(Alves \& Finger, 1999) Alves, Carlos D. e Finger, Marcelo. Etiquetagem do Português Clássico Baseada em Córpora. In: Anais do /I Encontro para Processamento Computacional do Portugues Escrito e Falado. Évora, 1999. p. 17-31.

(Alves, 1999) Alves, Carlos Daniel Chacur. Etiquetagem do Portugués Clássico Baseada em Conpus. São Paulo, 1999. Dissertação (Mestrado) - IME - Universidade de São Paulo.

(André, 1990) André, Hildebrando A. de. Gramática llustrada. Editora Moderna. 4a edição. 1990.

(Armstrong et al., 1995) Armstrong, S.; Russel, G.; Petitpierre, D.; Robert, G. An Open Architecture for Multilingual Text Processing. In: SIGDAT-95 (EACL-95 Workshop), Dublin, 1995. p. 30-34.

(Augusto et al, 1998) Augusto, M.; Britto, H.; Scher, A. P. Morphological tagging for different periods of 
statistical and a constraint-based method. 1995. (Disponivel em http://xxx.lanl.gov/cmp-lg/9503003).

(Charniak \& Wilks, 1976) Charniak, E.; Wilks, Y. Fundamental Studies in Computer Science 4: Computationa/ Semantics. North-Holland Publishing Company, 1976. p. 89-100, 155-184.

(Charniak et al., 1993) Charniak, E.; Hendrickson, C.; Jacobson, N.; Perkowitz, M. Equations for part-of-speech tagging. In: Proceedings of the Eleventh National Conference on Artificial Intelligence, 1993. p. 784-789.

(Charniak et al., 1994) Charniak, E.; Carroll, G.; Adcock, J.; Cassandra, A.; Gotoh, Y.; Katz, J.; Littman, M.; MCCANN, J. Taggers for Parsers. Technical Report CS-94-06, Brown University, 1994.

(Charniak, 1995) Charniak, E. Statistical language learning. 1995. (Disponível em http://xxx.lanl.gov/cmp-lg/9506019)

(Chen et al., 1999) Chen, J.; Bangalore, S.; Vijay-Shanker, K. New Models for Improving Supertag Disambíguation. In Proceedings of the 1999 joint SIGDAT Conference on Empinical Methods in Natural Language Processing and Very Large Copora, p. 188-195.

(Chomsky, 1995) Chomsky, N. The minimalist program. Cambridge, Mass., The MIT Press, 1995.

(Church \& Gale, 1991) Church, K. W.; Gale, W.A. A comparison of the Enhanced Good-Turing and Deleted Estimation Methods for Estimating Probabilities of English Bigrams. Computer Speech and Language, n.5, p. 19-54, 1991.

(Church \& Gale, 1991) Church, k.; Gale, W. Concordances for parallel text. In Proceedings, Seventh Annual Conference of the UW Centre for the New Oxford English Dictionary and Text Research. 1991.

(Church, 1988) Church, K. A Stochastic Parts Program and Noun Phrase Parser for Unrestrict Text. In: Proceedings ANLP 88, Austin, TX, 1988.

(Cole, 1996) Cole, R. (Ed.) Suney of the State of the Art in Human Language Technology. Center for Spoken Language Understanding, Oregon Graduate Institute, 1996. (Disponível em http://unw.cse.ogi.edu/cslu/HLTsurvey]

(Cunha \& Cintra, 1985) Cunha, C. e Cintra, L. Nova Gramática do Português Contemporâneo. Rio de Janeiro: Nova Fronteira, 1985.

(Cunha, 1979) Cunha, C. Ferreira da. Gramática da Língua Portuguesa. Rio de Janeiro, Fename, 1979. $5^{\mathrm{a}}$ ediçăo.

(Cutting et al., 1992) Cutting, D., Kupiec, J., Pedersen, J.,; Sibun, P. A Practical Part-of-Speech Tagger. In: Third Conference on Applied Natural Language Processing (ANLP-92). Trento, 1992. p. 133-140.

(d'Andrade, 1993) d’Andrade, Ernesto. Dicionánio Inverso do português. Ediçöes Cosmos. 1993. 1 aediçăo.

(Daelemans et al, 1996) Daelemans, W.; Zavrel, J,; Berck, P.; Gillis, S. MTB: A Memory-Based Part of Speech Tagger-Generator. In: Proceedings of Fourth WMC. Copenhagen, 1996. P. 14-27.

(Daelemans et al, 1997) Daelemans, W.; Bosch, a Van den; Weijters, A. IGTree: using trees for compression and classification in lazy learning algorithrns. Artificial Intelligence Review, 11:407-423. 1997.

(Dermatas \& Kokkinaks, 1995) Dermatas, E.; Kokkinakis, G. Automatic Stochastic Tagging of Natural Language Texts. Computationa/ Linguistics, 21(2):137-164. 1995. 
(Brill, 1992) Brill, E. A Simple Rule-Based Part of Speech Tagger. In: Proceedings of the Third Conference on Applied Natural Language Processing (AQ). Trento, Italy, 1992. P. I 52- 155.

(Brill, 1993a) Brill, E. Automatic Grammar Induction and Parsing Free-Text: A Transformation-Based Approach. In: Proceedings of Association For Computacional Linguistics Annual Meeting (AC-93) 31 ., Columbus.OH, 1993. (Disponível em http://nww.cs.jhu.edu/ brill/papers.html)

(Brill, 1993b) Brill, E. A Coppus-Based Approach to Language Leaming. Philadelphia, 1993. Dissertation (PhD) - University of Perınsylvania.

(Brill, 1994a) Brill, E. Some Advances in Transformation-Based Part-of-Speech Tagging. I/r. Proceedings of National Conference On Avtificial Ntelligence (AAAl-94), 12., Seattle, 1994. (Disponivel em http://uww.cs.jhu.edu/-brill/papers.html)

(Brill, 1994ab) Brill, E. A Rule-Based Approach to Prepositional Phrase Attachment Disambíguation. In: Proceedings of COLING 1994. (Disponivel em http://uww.cs.jhu.edu/ -brill/papers.html)

(Brill, 1995) Brill, E. Transformation-based error-driven learning of ratural language: A case study in part of speech tagging. Computational Linguistics, v. 21, r.4, p. 543-565, 1995. (Disponivel em http://uww.cs.jhu.edu/ brill/papers.html)

(Brill, 1996a) Brill, E. Efficient Transformation-Based Parsing. In: Proceedings of ACL 1996. (Disponivel em http://unw.cs.jhu.edu/ brill/papers.html)

(Brill, 1996b) Brill, E. Learning to Parse With Transformations. In: Recent Advances in Parsing Technology , Kluner Academic Publishers. 1996. (Disponível em http://unw.cs.jhu.edu/ - brili/papers.html)

(Brill, 1997a) Brill, E. Automatic Rule Acquisition for Spelling Correction. In: Proceedings of /CML 97, 1997. (Disponivel em http://uww.cs.jhu.edu/_brill/papers.html)

(Brill, 1997b) Brill, E. Unsupervised Learning of Disambíguation Rules for Part of Speech Tagging. In: Natural Language Processing Using Very Large Corpora. Klwwer Academic Press, 1997. (Disponível em http://www.cs.jhu.edu/ brill/papers.html)

(Briscoe et al., 1994) Briscoe, Ted; GREFENSTETTE, Greg; PADRÓ, Luís; SERAIL, I. Hybrid techniques for training HMM part-of-speech taggers. Acquilex // working paper 45, 1994.

(Britto et al.) Britto, $\mathrm{H}$. et al. Morphological annotation system for automated tagging of electronic textual corpora: from English to romance languages. (Disponível em http://unw.ime.usp.br/ -tycho/papers/index.html).

(Calzolari \& Monachini, 1994) Calzolari, N.; Monachiri, M. MULTEXT: Lexical specifications: application to Italian. Pisa, ILC. (Disponível em http://mww.lpl.univaix.fr/projects/multext/LEX/LEX.LangSpec.it.html).

(Chan et al., 1999) Chan, P. K.; Stolfo, S. J.: Wolpert, D. Guest Editors'Introduction. Special Issue on Integrating Multiple Learned Models for Improving and Scaling Machine Leaming Algorithms. Machine Leaming, 36(1-2):5-7.

(Chanod \& Tapanainen, 1995a) Chanod, J.p.i Tapanainen, P. Creating a tagset, lexicon and guesser for a French tagger. 1995. (Disporível em (Disponível em http://xxx.lanl.gov/cmp-lg/9503004 v2).

(Chanod \& Tapanainen, 1995b) Chanod, J.p.; Tapanainen. P. Tagging French - comparing a 
(Harris, 1982) Harriz, Z. A grammar of English on mathermatical principles. New York: Wiley, 1982.

(Hays, 1966) Hays, D. G. Readings in automatic language processing. American Elsevier Publishing Company inc, 1966. p. 73-82.

(Hearst, 1991) Hearst, M. Toward noun homonym disambíguation using local context in large text corpora. In Proceedings, Seventh Annual Conference of the UW Centre for the New OED and Text Research. University of Waterloo, Waterloo, Ontario, p. 1-22. 1991.

(Ho et al., 1994) Ho, T. K.; Hull, J. J.; Srihari, S. N. Decision Combination in Multiple Classifier Systems, in IEEE Transactions on Pattem Analysis and Machine Intelligence, vol. 16, No. 1, p. 66-75.

(Hutchinson, 1994) Hutchinson, Alan. Algorithmic Learning. Clarendon Press, 1994.

(Ibaixe, 1994) Ibaixe, Ana Maria. Tópicos de Linguagem - Gramática. As palavras Que, Se e Como - Teoria e Prática. Atual Editora. 6edição. 1994.

(Jelinek \& Mercer, 1980) Jelinek, F; Mercer, F. L. Interpolated estimation of Markov source parameters from sparse data. In Proceedings of the Workshop on Pattem Recognition in Practice, 381-397. 1980.

(Jelinek et al., 1991) Jelinek, F.; Mercer, R.; Roukos, S. Principles of lexical language modeling for speech recognition. In Advances in Speech Signal Processing. Marcel Dekker, p. 651-700. 1991.

(Jelinek, 1985a) JELINEK, F. Robust part of speech tagging using a hidden markov model. 1985. Technical Report, IBM, T.J. Watson Research Center.

(Jelinek, 19985b) Jelinek, F. Self-organized language modeling for speech recognition. IBM Report. Reprinted in W\&L, 450-506.

(Karlsson, 1990) Karlsson, F. Constraint Grammar as a Framework for Parsing Running Text. In COUNG-90. Helsinki, 1990. p. 168-173.

(Karttunen, 1994) Karttunen, L. Constructing Lexical Transducers. In: Proceedings of Coling-94. The firteenth Intemational Conference on Computational Linguistics. Vol I, p. 406-411. Kyoto, 1994.

(Kearns, 1990) Kearns, Michael J. The Computational Complexity of Machine Learning. MIT Press, 1990.

(Kearns, 1994) Kearns, Michael J. An Introduction to Computational Learning Theory. MIT press, 1994.

(Kelly, 1992) Kelly, M. Using sound to solve syntactic problems: the role of phonology in gramatical category assigments. Psychological Review, v 99, n 2, p. 349-364. 1192.

(Kempe, 1993) Kernpe, André. Stochastic Tagger and an Analysis of Tagging Errors. Stuttgart: University of Stuttgart, 1994. Technical Report.

(Kempe, 1994) Kempe, André. Probabilistic Tagging with Feature Structures. In: Proceedings of the International Conference on Cornputational Linguistics - COLING. 1994

(Kim \& Norgard, 1998) Kim, Youngin; Norgard, Barbara. Adding Natural Language Processing Techniques to the Entry Vocabulary Module Building Process. 1998.

(Disponível em http://metaphor.sims.berkeley.edu/papers/nlptech.html

(Klavans \& Tzoukermann, 1990) Klavans, J.; Tzoukermann, E. Linking bilingual corpora and machine readable dictionaries with the BICORD system. In Proceedings, Sixth Annual Conference of the UW 
(Deroault \& Merialdo, 1984) Deroault, A. M.; Menialdo, B. Language modelling at the syntactic level. In: Proceedings 7th International Conference on Pattern Recognition, 1984.

(Derose, 1988) Derose, S. Grammatical category disambíguation by statistical optimisation. Computational Linguistics, Cambridge, v. 14, n. I, p. 31-39, 1988.

(Dietterich, 1997) Dietterich, T. G. Machine Learning Research: Four Current Directions. $A$ Magazine, 18(4):97-136.

(EAGLES, 1996a) EAGLES - Expert Advisory Group on Language Engineering Standards. Study of the relation between Tagsets and Taggers. 1996. (Disponivel em http://Mww.ilc.pi.cnr.it/EAGLES96/browse.html).

(EAGLES, 1996b) EAGLES - Expert Advisory Group on Language Engineening Standards. Recomendations for the Mophosytactic Annotation of Conpora. 1996. (Disponivel em http://www.ilc.pi.cnr.it/EAGLES96/browse.html).

(Faraco \& Moura, 1994) Faraco, Carlos E. e Moura, Francisco M. de M. Gramática- Faraco \& Moura. Editora Ática. 1994. $13^{a}$ edição.

(Feldweg, 1995) Feldweg, H. Implementation and evaluation of a Geman HMM for POS disambiguation. 1995. (Disponivel em http://xox.lanl.gov/cmp-lg/9502038).

(Fernandes, 1995) Fernandes, Francisco. Dicionário de Vertos e Regimes. $40^{a}$ edição. Editora Globo. 1995.

(Finger, 1998) Finger, M. Tagging a Morphologically Rich Language: The Construction of the Tycho Brahe Parsed Corpus of Historical Portuguese. IME, Universidade de São Paulo. (Disponivel em http://wnw.ime.usp.br/ -tycho).

(Francis \& Kucera, 1979) Francis, W. N.; Kucera, H. Brown Corpus Manual. Providence, Rhode Island, Department of Linguistics, Brown University, 1979. (Disponível em http://uww.hit.uib.no/icame/brown/bcm.html )

(Freund \& Schapire, 1996) Freund, Y. \& Schapire, R. E. Experiments with a new boosting algorithm. In L. Saitta (Ed.), Machine Learning. Proceedings of the Thirteenth National Conference (p. 148156). Morgan Kaufmann. 1996.

(Galves \& Britto, 1999) Galves, Charlotte. e Britto, Helena. A construção do Corpus Anotado do Português Histórico Tycho Brahe: o sistema de anotação. In: Anais do /I Encontro para Processamento Computacional do Portugués Escrito e Falado. Évora, 1999. p. 81-92.

(Garside) Garside, R Using CAWS to annotate the British National Copus. Department of Computing, University of Lancaster. (Disponível em http://info.ox.ac.uk/bnc/what/garside_allc.html)

(Golding \& Roth, 1999) Golding, A. R; Roth, D. A Winnow-Based Approach to Context-Sensitive Spelling Correction. Machine Leaming, 34(I-3): 107-130.

(Greene \& Rubin, 197I) Greene, B. B.; Rubin, G. M. Automated Grammatical Tagging of English. Department of Linguistics, Brown University.

(Hagège \& Bès, 1998) Hagège, C. e Bès, G. G. Da observação de propriedades lingüísticas a sua formalização numa gramática do processamento da língua. In: Anais do III Encontro para o Processamento Computacional de Portugués Escrito e Falado (PROPOR'98). Porto Alegre, 1998. p. 23-31. 
(Disponível em http://umw.ldc.upenn.edu/doc/treebank2/d93.html )

(Marques \& Lopes, 1996) Marques, N. C.; Lopes, G. Pereira. A Neural Network Approach to Partof-Speech Tagging. In: Anais do // Encontro para Processamento Computacional do Portugues Escrito e Falado. Curitiba, 1996. p. 1 -9.

(Marques, 1995) Marques, N. C. YATH - Yet another HMM Tagger - Modelos de Markov Escondidos Aplicados à Classificação de Largos Corpora de Textos. Technical Report, Universidade Nova de Lisboa, 1995.

(Màrquez et al., 2000) Márquez, Lluís; Padró, Lluís; Rodríguez, Horacio. A Machine Learning Approach to POS Tagging. Machine Learning, 39, 59-91, 2000. Kuwer Academic Publishers.

(Mendes \& Eizirik, 1989) Mendes, S.Bandeira Teixeira e Eizirik, L.m. Ripoll. Um modelo neuronal probabilístico para solução da ambigüidade do português. Revista brasileira de computação, Rio de Janeiro, v. 5, n. l, p. 45-51, Jul./Set. 1989.

(Merialdo, 1994) Merialdo, B. Tagging English Text with a Probabilistic Model. Computational Linguistics, Cambridge, v.20, n.2, p.I55-177, 1994.

(Mikheev, 1996) Mikheev, A. Unsupervised Leaming of Word-Category Guessing Rules, 1996. (Disponível em http://xox.lanl.gov/cmp-lg/9604022)

(Moses, 1986) Moses, Lincoln E. Think and Explain with Statistics. Addison-Wesley Publishing Company, 1986.

(Nakamura \& Shicano, 1989) Nakamura, M.; Shicano, K. A study of English word prediction based on neural network. In: Proceedings of /CASSP. Glasgow, 1989. p.731-734.

(Nakamura et al.) Nakamura, M. et al. Neural Network Approach to word Category Prediction for English Texts. In: Proceedings of COL/NG-90, 1990, Helsinki University. p. 213-218.

(NILC, 1999) NILC_Núcleo Interinstitucional de Lingüística Computacional. O projeto ReGra. In: Introdução ao processämento das IInguas naturais. ICMC-USP, São Carlos, Marçol 999. p. 77-80.

(NLP) NLP - Group of the School of Computer Studies at Leeds University. Automatic Mapping Among Lexico-Grammatical Annotation Models (AMALGAM). (Disponivel em (Disponivel em http://www.scs.leeds.ac.uk/amalgam/amalgam/amalghome.htm)

(Nunes et al., 1996a) Nunes, Maria das Graças V.; Vieira, F. M. C.; Zavaglia, C.; Sossolote, C. R. C. e Hemandez, J. A corıstrução de um léxico para o Português do Brasil: Liçōes aprendidas e perspectivas. In: Anais do // Encontro para Processamento Computacional do Portugués Escrito e Falado. Curitiba, 1996. p. 61-70.

(Nunes et al., 1996b) Nunes, Maria das Graças V.; Ghiraldelo, C. M.; Montilha, G.; Turine, M. A. S.; Oliveira, M. C. F.; Hasegawa, R.; Martins, R. T. e Oliveira Jr, O. N. Desenvolvimento de um Sistema de Revisão Gramatical Automática para o Português do Brasil. In: Anais do // Encontro para Processamento Computacional do Portugués Escrito e Falado. Curitiba, 1996. p. 71-80.

(Nunes et al., 1996c) Nunes, Maria das Graças V. A Construçăo de um kexico para suporte à revisăo autornática do Portugués do Brasil. Relatório Técnico do ICMC-USP, nro 42, 1996, 37p.

(Oflazer \& Kuruöz, 1994) Oflazer, K.; Kuruöz, l. Tagging and Morphological Disambíguation of Turkish Text. In: Fourth Conference on Applied Natural Language Processing (AWLP-94). Stuttgart, 1994. p.144-149.

(Oksefjell \& Santos, 1998) Oksefjell, S. e Santos, D. Breve Panorâmica dos Recursos de Português 
Centre for the New Oxford English Dictionary and Text Research, p. 19-30. 1990.

(Klein \& Simmons, 1963) Klein, S.; Simmons, R. A Computational Approach to Grammatical Coding of English Words. JACM, 10:334-337.

(Koskenniemi et al., 1992) Koskenniemi, K; Tapanainen, P.; Voutilainen, A. Compiling and using finite-state syntactic rules. In: Proceedings of the fifteenth Intermational Conference on Computational Linguistics. COUNG-92. Vol. 1, p. 156-162, Nantes, France.

(Koskenniemi, 1990) Koskenniemi, K. Finite-state parsing and disambíguation. Proceedings of the fourteenth international Conference on Computational Linguistics. COLING-90. Helsinki, Finland, 1990.

(Kupiec, 1992) Kupiec, J. Robust part-of-speech tagging using a hidden markov model. Computer Speech and Language, 6:225-242.

(Kury, 1993) Kury, Adriano da Gama. Novas Liçōes de Análise Sintática. Editora Ática. $6^{a}$ edição. 1993.

(Leech et al., 1994) Leech, G.; Garside, R.; Bryant,M. Claws4: The tagging of the British National Corpus. In: Proceedings of the 15th International Conference on Computational Linguistics, (COING94), 1994. p. 622-628.

(Léon \& Serrano, 1995) Léon, F. S.; Serrano, A. F. N. Development of a Spanish Version of the Xerox Tagger. (Disponível em (Disponível em http://xx.lanl.gov/cmp-lg/9505035).

(Liberman \& Church, 1991) Liberman, M.; Church, K. Text analysis and word pronunciation in textto-speech synthesis. In Advances in Speech Signal Processing, edited by S. Furui ans M. Mohan. Marcel Dekker, p. 791-832.

(Lima, 1992) Lima, Rocha. Gramática Normativa da Língua Portuguesa. 1992. José Olympio Editora. $31^{\mathrm{a}}$ ediç̧ão.

(Lu et al., 2000) Lu, Bao-Liang; Ma, Q.; Ichikawa, M.; Isahara, H. Massively Parallel Part of Speech Tagging Using Min-Max Modular Neural Networks.

(Luft, 1993) Luft, Celso Pedro. Dicionário Prático de Regência Verbal. Editora Ática. 1993.

(Ma \& isahara, 1998) Ma, Q.; Isahara, H. A multi-neuro tagger using variable lenghts of contexts. In Proceedings of COLING-ACL'98, Montreal, p. 802-806, 1998.

(Ma et al., 1998) Ma, Q.; Sun, M.; Isahara, H. A multi-neuro tagger applied in Chinese texts. In Proceedings of 1998 Int Conf. Chinese Info. Processing, Beijing, Nov. 18-20, p. 200-207, 1998.

(Ma et al., 1999a) Ma, Q.; Uchimoto, K.; Murata, M.; Isahara, H. Elastic Neural Networks for part of speech tagging. In: Proceedings of JCNN'99, Washington DC., July, 1999.

(Ma et al., 1999b) Ma, Q; Lu, B. L.; Isahara, H. Part of speech tagging with min-max neural networks. In Proceedings of IEEE SMC'99, Tokyo, Oct. 12-15, vol 5, p. 356-360, 1999.

(Magerman, 1995a) Magerman, D. Statistical Language Leaming - Review. 1995. (Disponível em http://xox.lanl.gov/cmp-ig/)

(Magerman, 1995b) Magerman, D. Statistical Decision-Tree Models for Parsing. 1995. (Disponível em http://xx.lani.gov/cmp-lg/9504030)

(Marcus et al., 1993) Marcus, Michell P.; Santorini, Beatrice; Marcinkiewicz, Mary Ann. Building a large annotated corpus of English: the Penn Treebank -. 1993. Computationa/ Linguistics, 19(2). 
Resolução da Ambigüidade Léxica no Processamento da Linguagem Natural. In: Anais do /l Encontro para Processamento Computacional do Portugues Escrito e Falado. Cunitiba, 1996. P. 149-158.

(Tapanainen, 1992) Tapanainen, P. "Äärellisiin automaatteihin perustuva luonnollisen kielen jäsennin" (A finite state parser of natural language). Licentiate (pre-doctoral) thesis. Department of Computer Science, University of Helsinki.

(Taylor \& Kroch, 1994) Taylor, A.; Kroch, A. The Penn-Helsinki Parsed Corpus of Middle English. 1994. (Disponível em http://www.ling.upenn.edu/mideng)

(van Halteren, 1998) van Halteren, H.; Zavrel, J.; Daelemans, W. Improving Data Driven Wordclass Tagging by System Combination. COUNG-ACL 1998. Montreal, Canada, 1998. P. 491-497

(Vapnik, 1995) Vapnik, Vladimir N. The Nature of Statistical Leaming Theory. Springer, 1995.

(Villavicencio et al., 1995) Villavicencio, A. et al. Part-of-Speech Tagging for Portuguese Texts. In: Anais do Simpósio Brasileiro de Inteligência Artificial (SBIA'95). 1995.

Villavicencio et al., 1996) Villavicencio, A. et al. Evaluating Part-of-Speech Taggers for the Portuguese Language. In: Anais do // Encontro para Processamento Computacional do Portuguess Escrito e Falado. Curitiba, 1996. p. 159-168.

Villavicencio, 1995) Villavicencio, A. Avaliando um rotulador estatístico de categorias morfo-sintáticas para o português. Rio Grande do Sul, 1995. Dissertação (Mestrado) - Universidade Federal do Rio Grande do Sul.

(Viterbi, 1967) Viterbi, A. J. Error bounds for convolutional codes and an asymptotically optimal decoding algorithm. IEEE Transactions on Information Theory, p 260-269. 1967.

Voutilainen \& Tapanainen, 1993) Voutilainen, A. And Tapanainen, P. Ambiguity Resolution in a Reductionistic Parser. Proceedings of the Sixth Conference of the European Chapter of the Association for Computational Linguistics. Association for Computational Linguistics. Utrecht. 394403.

Voutilainen et al., 1992) Voutilainen, A., Heikkila, J. And Antilla, A. Constraint Grammar of English: A Perfomance-Oriented Introduction. Technical Report Publication No. 21, University of Helsinki, Department of General Linguistics, Helsinki. 1992.

(Voutilainen, 1994) Voutilainen, A. Three studies of grammar-based surface parsing of unrestricted English text. (Doctoral dissertation.). Publications 24, Department of General Linguistics, University of Helsinki.

Voutilainen, 1995) Voutilainen, A. A syntax-based part-of-speech analyser. 1995. (Disponivel em http://xox.lanl.gov/cmp-lg/9502012)

(Wilkens \& Kupiec, 1996) Wilkens, M. And Kupiec, J. Training Hidden Markov Models for Part of Speech Tagging-Revision 4. 1996.

(Disponivel em http://www.rxrc.xerox.com/grenoble/mltt/sNLP/train.html)

(Witten \& Frank, 2000) Witten, I. H.; Frank, Eibe. Data mining: practical machine leaming tools and techniques with Java implementations. Academic Press, 2000.

(Wynne, 1995) Wynne, Martin. A post-editor's guide to Claws 5 Tagging. UCREL. University of Lancaster, 1995. (Disponivel em http://www.comp.lancs.ac.uk/computing/users/paul/ucrel/claws/)

Wynne, 1996) Wynne, Martin. A post-editor's guide to Claws 7 Tagging. UCREL. University of 
Mencionados na WEB. In: Anais do III Encontro para o Processamento Computacional de Portugue. Escrito e Falado (PROPOR'98). Porto Alegre, 1998. p. 38-47.

(Pacheco et al, 1996) Pacheco, H.c. da Fonseca. et al. Uma nova abordagem para análise sintática do português. In: Anais do // Encontro para Processamento Computacional do Portugués Escrito e Falado. Curitiba, 1996. p. 51-60.

(Paiva et al., 1996) Paiva, Daniel da S. de.; Carvalho, Adriane M. B. R e Wainer, Jacques. Um sistema para Processamento Distribuído de Linguagem Natural. In: Anais do // Encontro para Processamento Computacional do Português Escrito e Falado. Curitiba, 1996. p. 81-90.

(Pinheiro, 1990) Pinheiro, João Batista Gonçalves Pinheiro. Tópicos de Linguagem - Gramática Análise Sintática -Teoria e Prática. Atual Editora. 1990. $9^{\mathrm{a}}$ ediçăo.

(Quinlan, 1996) Bagging, boosting, and c4.5. Proceedings of the Thirteenth National Conference on Avtificial Intelligence (p. 725-730). AAAl Press and the MIT Press. 1996.

(Ramshaw \& Marcus, 1994) Ramshaw, L; Marcus, M. Exploring the Statistical Derivation of Transfomational Rule Sequences for Part-of-Speech Tagging. 1994. (Disponivel em (Disponivel em http://xox.lanl.gov/cmp-lg/cmp-lg 940601 I)

(Ratraparkhi, 1996) Ratnaparkhi, A. A Maximum Entropy Part-of-Speech Tagger. Proceedings of the First Empincal Methods in Natural Language Processing Conference. Philadelphia, Pa. 1996.

(Redington et al., 1998) Redington, Martin; Chater, Nick; Finch, Steven. Distributional Information: A Powerful Cue for Acquiring Syntactic Categories. Cognitive Science, vol 22 (4), p. 425-469. 1999.

(Rigau et al., 1997) Rigau, G.; Atserias, J.; Agirre, E. Combining Unsupervised Lexical Knowledge Methods for Word Sense Disambíguation. In Proceedings of AQ EAC '97, p. 48-55.

(Rocha \& Dillinger, 1996) Rocha, N.and Dillinger, M. Interpretação de estruturas sintáticas do português. In: Anais da V Semana de Iniciação Cientifica. Belo Horizonte: Universidade Federal de Minas Gerais, 1996.

(Roth, 1998) Roth, D. Learning to Resolve Natural Language Ambiguities: A Unified Approach. In Proceedings of $A A 4 V^{\prime}$ '98. p. 806-813.

(Salton et al., 1990) Salton, G.; Zhao, Z.; Buckley, C. A simple syntactic approach for the generation of indexing phrases. Technical Report 90-1137, Department of Computer Science, Cornell University. 1990.

(Santorini, 1990) Santorini, B. Part of Speech Tagging Guidelines for the Penn Treebank Project. 1990. (Disponivel em http://wmw.cis.upenn.edu/treebank/home.html)

(Schmid, 1994) Schmid, H. Part-of-Speech Tagging with Neural Networks. 1994. (Disponivel em http://xox.lanl.gov/cmp-lg/)

(Schmid, 1995) Schmid, H. Probabilistic Part-of-Speech Tagging Using Decision Trees. 1995. (Disponivel em ttp://umw.ims.unituttgart.de/Tools/DecisionTreeTagger.html)

(Schutze, 1995) Schütze, H. Distributional Part-of-Speech Tagging. 1995. (Disponível em http://xc.lanl.gov/cmp-lg/9503009)

(Sharkey, 1999) Sharkey, A.J.C. Combining Artificial Neural Nets: Ensemble and Modular Multi-Net Systems, London: Springer. 1999

(Silva \& Lima, 1996) Silva, J.L. Tavares da. e Lima, V.I. S. de. Algumas Consideraçöes sobre 
Lancaster, 1996. (Disponivel em http://www.comp.lancs.ac.uk/computing/users/paul/ucrel/claws/)

(Young \& Bloothooft, 1997) Young, S.; Bloothooft, G. Corpus-Based Methods in Language and Speech Processing. Kluwer Academic Publishers, 1997. 


\section{APÊNDICE A - NILC TAGSETS}

A definição do conjunto de etiquetos que será utilizado na etiquetogem de um corpus é uma tarefa um tanto complexa, pois envolve conhecimento lingüístico e conhecimento sobre os fatores que influenciom no desempenho de um dado etiquetador. Alguns dos itens que devem ser considerados são: (a) o tamanho do conjunto de etiquetos e (b) a quantidade de informação lingüística necessário para realizar uma determinada tarefa, por exemplo a inclusäa ou näo de informaçōes de número e gênero (EAGLES, 19960).

No entanto, mesmo com uma elaboraçäo cuidadosa do conjunto de etiquetas, pode haver a necessidade de redefini-lo dado uma etiqueta que faltou, uma etiqueta desnecessária, etc. detalhes que só são observados durante a etiquetogem manual do corpus. Foi o que aconteceu neste trabalho em que o conjunto de etiquetas foi reformulado quatro vezes, em uma primeira instância para sanar problemas de eficiência de treinamento do etiquetador TBL, em outra para cobrir novos casos que foram observados na etiquetagem manual do corpus.

O primeiro NILC tagset foi criado de acordo com as recomendaçóes contidas em (EAGLES, 1996) para se incluir atributos e valores para as 14 categorias principais do conjunto de etiquetos: 


\begin{tabular}{|l|l|l|}
\hline S (substantivo) & PP (preposição) & E (residual-palavras estrangeiras) \\
V (verbo) & $\mathrm{C}$ (conjunção) & SE (residual-símbolos especiais) \\
AJ (adjetivo) & $\mathrm{N}$ (numeral) & FM (residual-fórmulas matemáticas) \\
PR (pronome) & AR (artigo) & símbolo (pontuação) \\
AV (advérbio) & I (interjeição) & SI (siglas) \\
& & AB (abreviaturas) \\
\hline
\end{tabular}

As recomendaçóes levaram a cada etiqueta de uma palavra ser formada pelos valores, em seqüência, de cada atributo relativo a cada categorio do conjunto de etiquetas. Note que, separando cada valor usa-se um ponto, por exemplo, "mesa" seria macada com S.C.F.S.N; "carrinhos" com S.C.M.P.D; e "personagem" com S.C.2G.S.N. dados os atributos e valores do categoria substantivo:

\begin{tabular}{|l|l|l|l|l|}
\hline Tipo & Comum (C) & Próprio (P) & \\
\hline Gênero & Masculino (M) & Feminino (F) & $2 \mathrm{G} \mathrm{(2G)}$ & \\
\hline Número & Singular (S) & Plural (P) & $2 \mathrm{~N}(2 \mathrm{~N})$ & Invariável (I) \\
\hline Grau & Aumentativo (A) & Diminutivo (D) & Neutro (N) & \\
\hline
\end{tabular}

Na segunda versāo do NILC tagset, o conjunto de etiquetas foi reduzido, pois não havio necessidade do aprendizodo de muitos dos atributos dos categorias principais. Uma vez que 0 etiquetador consegue descobrir a categoria, o texto poderia ser pós-processado com a ajuda do léxico do NILC, preenchendo-se os valores paro os atributos restantes. Foi aindo na segunda versáo que as etiquetas para siglas e abrevioturas desapareceram como categorias principais sendo renomeadas com a categoria de substantivo; que criamos etiquetas para os verbos "ter" e "ser"; e que começamos a usor símbolos para marcar contrações, ênclieses e mesóclises. Esta segunda versão parece-se muito com o conjunto de etiquetas utilizado por Marques \& Lopes (1996) na etiquetogem de textos em português continental. Na terceira versão do Nilc Tagset houve mudança nas etiquetas para pronomes; os verbos começaram a ser avaliados conforme a transitividade; e além das duas etiquetas para os verbos "ter" e "ser", passamos a ter também etiquetas para os verbos "ir". "estor" e "haver", e também uma etiqueta pora palavras residuais. Na quarta versäo excluimos as etiquetas para os verbos "ter", "ser", "ir", "estar" e "haver" e 
criamos uma etiqueta para verbos auxiliares. E, finalmente, na quinta versão (atual) foram criadas as etiquetas para locuçóes e para palavra denotativa, item de lista e os coloquialismos e regionalismos passaram a fazer parte da etiqueta residual. Este apêndice traz as cinco versōes do NILC tagset.

\section{A1 - NILC TAGSET (Versão 1)}

\section{SUBSTANTIVO (S)}

\section{Atributos e Valores}

\begin{tabular}{|l|l|l|l|l|}
\hline Tipo & Comum (C) & Próprio (P) & & \\
\hline Gênero & Masculino (M) & Feminino (F) & 2G(2G) & \\
\hline Número & Singular (S) & Plural (P) & 2N (2N) & Invariável (I) \\
\hline Grau & Aumentativo (A) & Diminutivo(D) & Neutro (N) & \\
\hline
\end{tabular}

Exemplos: mesa /SCFSN

carrinhos /SCMPD

personagem /SC2GSN

lápis /SCMIN

Brasil /SPMSN

\section{ADJETIVO (AJ)}

\begin{tabular}{|c|c|c|c|c|}
\hline Gênero & Masculino (M) & Feminino $(\mathrm{F})$ & $2 G(2 G)$ & \\
\hline Número & Singular $(\mathrm{S})$ & Plural (P) & $2 \mathrm{~N}(2 \mathrm{~N})$ & \\
\hline Grau & Aumentativo (A) & Diminutivo (D) & Neutro(N) & Superlativo (S) \\
\hline
\end{tabular}

Exemplos: belo /AJMSN

amicíssimas /AJFPS

\section{ARTIGO (AR)}

\begin{tabular}{|l|l|l|}
\hline Tipo & Definido (D) & Indefinido (I) \\
\hline Gênero & Masculino (M) & Feminino (F) \\
\hline Número & Singular (S) & Plural (P) \\
\hline
\end{tabular}

Exemplos: os /ARDMP uma /ARIFS

\section{PREPOSICৃÃO (PP)}

Exemplos: desse /PP; de /PP; ao /PP 


\section{CONJUNÇÃO (C)}

\begin{tabular}{|l|l|l|}
\hline Tipo & Coordenativa & Subordinativa \\
\hline Complemento & Adit (AT) & Integ (I) \\
& Adv (AV) & Caus (CA) \\
& Alter (AL) & Comp (CM) \\
& Concl (CL) & Conc (CC) \\
& Expl (E) & Cond (CD) \\
& Cons (CS) \\
& Fin (F) \\
& Temp (T) \\
& Propor (P) \\
& Confor (CF) \\
\hline
\end{tabular}

Exemplos: e /C $[\mathrm{AT} \mid \mathrm{AV}]$

que /C[[AT|AL][[I|CA|CM|F|CC]]

\section{NUMERAL $(\mathrm{N})$}

\begin{tabular}{|l|l|l|l|l|l|}
\hline Tipo & Cardinal (C) & Ordinal (O) & Multiplicativo (M) & Fracionário(F) & Frac-Ord. (FO) \\
\hline Gênero & Masculino (M) & Feminino (F) & $2 \mathrm{G}(2 \mathrm{G})$ & Invariável (I) \\
\hline Número & Singular (S) & Plural (P) & $2 \mathrm{~N}(2 \mathrm{~N})$ & Invariável (I) \\
\hline Função & Pronome (P) & Adjetivo (A) & & \\
\hline
\end{tabular}

Exemplos: o quarto /NFOMSA poder duplo /NMMS A sentido o primeiro /NOMSP foi meu pai, o segundo....

\section{INTERJEIÇÃO (I)}

Exemplo: Ei, Oh, Ah, Ui

\section{PRONOME (PR)}

\begin{tabular}{|c|c|c|c|c|c|c|c|c|c|c|}
\hline Tipo & $\begin{array}{l}\text { Reto } \\
\text { (RT) }\end{array}$ & $\begin{array}{l}\text { Obl.Áto } \\
\text { no } \\
\text { (OA) }\end{array}$ & $\begin{array}{l}\text { Obl.Tôn } \\
\text { ico } \\
\text { (OT) }\end{array}$ & $\begin{array}{l}\text { Possessi } \\
\text { vo } \\
\text { (P) }\end{array}$ & $\begin{array}{l}\text { Indefini } \\
\text { do } \\
\text { (ID) }\end{array}$ & $\begin{array}{l}\text { Interrog } \\
\text { at. } \\
\text { (IT) }\end{array}$ & $\begin{array}{l}\text { Relativo } \\
\text { (RL) }\end{array}$ & $\begin{array}{l}\text { Reflexiv } \\
0 \\
\text { (RF) }\end{array}$ & $\begin{array}{l}\text { Tratame } \\
\text { nto } \\
\text { (T) }\end{array}$ & $\begin{array}{l}\text { Demonstr } \\
\text { (D) }\end{array}$ \\
\hline Gênero & $\begin{array}{l}\text { Mascu } \\
\text { lino } \\
(M)\end{array}$ & $\begin{array}{l}\text { Feminin } \\
0 \\
\text { (F) }\end{array}$ & $\begin{array}{l}2 \mathrm{G} \\
(2 \mathrm{G})\end{array}$ & \multicolumn{7}{|l|}{$\begin{array}{l}\text { Invarióvel } \\
\text { (I) }\end{array}$} \\
\hline Número & $\begin{array}{l}\text { Singul } \\
\text { ar } \\
\text { (S) } \\
\end{array}$ & $\begin{array}{l}\text { Plural } \\
\text { (P) }\end{array}$ & $\begin{array}{l}2 \mathrm{~N} \\
(2 \mathrm{~N})\end{array}$ & \multicolumn{7}{|c|}{$\begin{array}{l}\text { Invariável } \\
\text { (I) }\end{array}$} \\
\hline Pessoa & $\begin{array}{l}1^{\mathrm{E}} \cdot \operatorname{Sin} \\
\mathrm{g} . \\
\text { (1S) }\end{array}$ & $\begin{array}{l}2^{\mathrm{a}} \text {.Sing. } \\
(2 \mathrm{~S})\end{array}$ & $\begin{array}{l}3^{a} . \text { Sing. } \\
(3 \mathrm{~S})\end{array}$ & $\begin{array}{l}\text { la }^{a} \text {.Plural } \\
\text { (1P) }\end{array}$ & \begin{tabular}{|l|}
$2^{\mathrm{a}}$.Plural \\
(2P)
\end{tabular} & $\begin{array}{l}3^{a} \text {.Sing } \\
\text { Plu } \\
\text { (3SP) }\end{array}$ & $\begin{array}{l}\text { Neutro } \\
\text { (N) }\end{array}$ & & & \\
\hline
\end{tabular}

Exemplos: desse /PRDMS2S os /PR[D|OA]MP3P livros estão aqui

o /PRDMSN que eu gostaria de dizer, já o /PRDMSN disse. 


\section{VERBO (V)}

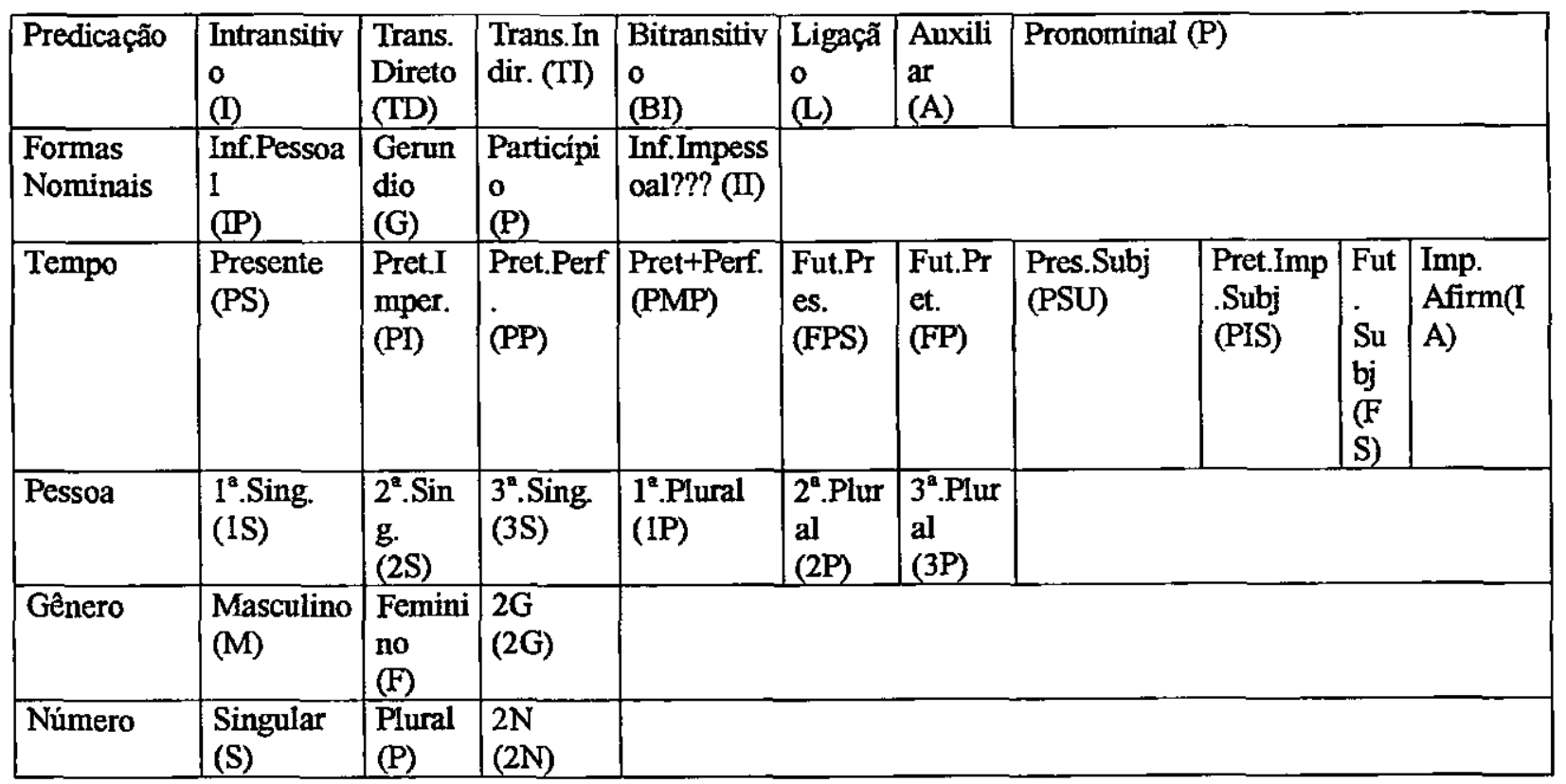

Exemplos:

10. ADVÉRBIO (AV)

\begin{tabular}{|l|l|l|l|l|l|l|l|l|l|l|l|}
\hline Tipo & $\begin{array}{l}\text { Circ- } \\
\text { Lugar } \\
\text { (CL) }\end{array}$ & $\begin{array}{l}\text { Circ- } \\
\text { Tempo } \\
\text { (C) }\end{array}$ & $\begin{array}{l}\text { Circ- } \\
\text { Modo } \\
\text { (CM) }\end{array}$ & $\begin{array}{l}\text { Negaçã } \\
\text { (C) } \\
\text { (N) }\end{array}$ & $\begin{array}{l}\text { Dúvida } \\
\text { (D) }\end{array}$ & $\begin{array}{l}\text { Interrog } \\
\text { ativo } \\
\text { (I) }\end{array}$ & $\begin{array}{l}\text { Afirmat } \\
\text { ivo } \\
\text { (A) }\end{array}$ & $\begin{array}{l}\text { lnt- } \\
\text { Lugar } \\
\text { (IL) }\end{array}$ & $\begin{array}{l}\text { Int- } \\
\text { Tempo } \\
\text { (IT) }\end{array}$ & $\begin{array}{l}\text { Int- } \\
\text { Modo } \\
\text { (IM) }\end{array}$ & $\begin{array}{l}\text { Int- } \\
\text { Causa } \\
\text { (IC) }\end{array}$ \\
\hline Grau & Aumentativo (A) & Diminutivo (D) & Superlativo (S) & Neutro (N) \\
\hline
\end{tabular}

11. SIGLAS (SI)

Ex. IBM CACM ICAI ICMC USP

\section{ABREVIATURAS (AB)}

EX. ex. i.e. exmo. Ilmo. Sra.

13. PONTUAÇÃO (o próprio símbolo é o tag)

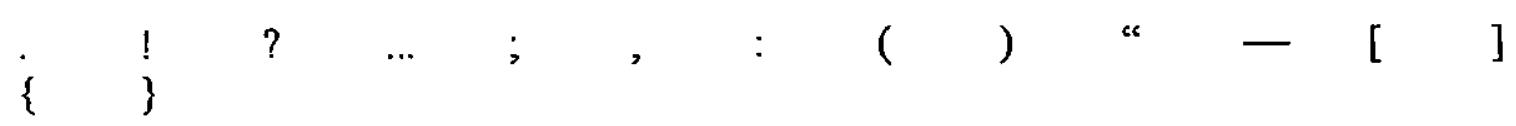

\section{RESIDUAL}

É atribuída a palavras que estão fora das classes tradicionais, embora ocorram com frequência.

Ex: palavras estrangeiras, fórmulas matemáticas (quando aparecem sem espaço em branco, como em $X / 21,2+3=5$ ), símbolos especiais, como @, $\mathrm{R} \$, \$, \%, \#,+,-,=, \wedge, \sim,<,>, 1,1$ 
É dividida em 3 subcategorias:

\section{(a) PALAVRAS ESTRANGEIRAS (E)}

Não se trata de estrangeirismos (ex. flat, shopping, abajour, pizza), ou seja, não são palavras já incorporadas ao Português.

Ex. home

Love

(b) SÍMBOLOS ESPECIAIS (SE)

São os símbolos com exceção daqueles da classe 14. Pontuação:

@, $\mathrm{R} \$, \$, \%, \#,+,-,=, \wedge, \sim,<,>, /, \backslash$ e todos os demais que podem ser inseridos dos alfabetos especiais (Symbol, etc.)

(c) FÓRMULAS MATEMÁTICAS (FM)

São expressões, sem espaço entre os símbolos, que não constituem palavras do português.

Ex. $f(x)$

$\mathrm{x}+\mathrm{y}$ (observe que $\mathrm{x}+\mathrm{y}$ - com espaço - seria classificado como $\mathrm{x} / \mathrm{S}+/ \mathrm{SE} \mathrm{y} / \mathrm{S}$

$35 / 4$

$10 \%$

\section{A2 - NILC tagset (Versão2)}

É composto por 49 etiquetas sem contar as etiquetas compostas pela utilização dos operadores de contrações, mesóclises e ênclises, sendo que destas 15 são utilizadas para pontuação.

São utilizados dois operadores ${ }^{26}$, um para contrações (da, desses, destes, daquela) e ênclises (darlhe, dei-lhe, dei-o) - +, e outro para mesóclises (dar-lhe-ei, tirá-lo-ei) - !. Utilizando estes operadores, alguns exemplos de etiquetagem seriam: "do" = PREP+ART, "dar-lhe" = VINF+ART e, "dar-lhe-ei" = VINF!PPOA.

\begin{tabular}{|l|l|}
\hline Categoria morfossintática & Etiqueta \\
\hline Adjetivo & ADJ \\
\hline Advérbio & ADV \\
\hline Artigo & ART \\
\hline Numeral Cardinal & NC \\
\hline Numeral Ordinal & ORD \\
\hline Outros Numerais & NO \\
\hline Substantivo Comum & N \\
\hline Nome Próprio + Siglas & NP \\
\hline Conjunção Coordenativa & CONJCOORD \\
\hline
\end{tabular}

${ }^{26}$ Estes operadores são utilizados nas versỏes 2, 3, 4 e 5 do NILC tagset. 


\begin{tabular}{|c|c|}
\hline Conjunção Subordinativa & CONISUB \\
\hline Pronome Demonstrativo & PD \\
\hline Pronome Indefinido & PIND \\
\hline Pronome Oblíquo Átono & PPOA \\
\hline Pronome Pessoal Caso Reto & PPR \\
\hline Pronome Possessivo & PPS \\
\hline Pronome Relativo & PR \\
\hline Pronome Oblíquo Tônico & PPOT \\
\hline Pronome Interrogativo & PINT \\
\hline Pronome Reflexivo & PREF \\
\hline Pronome Tratamento & PTRA \\
\hline Preposição & PREP \\
\hline Verbo no Gerúndio & $\begin{array}{l}\text { VGER } \\
\end{array}$ \\
\hline Verbo no Infinitivo & VINF \\
\hline Verbo no Participio Passado & VPP \\
\hline Verbo Ser no Gerúndio & VGERSER \\
\hline Verbo Ser no Infinitivo & VINFSER \\
\hline Verbo Ser no Particípio Passado & VPPSER \\
\hline Verbo Ter no Gerúndio & VGERTER \\
\hline Verbo Ter no Infinitivo & VINFTER \\
\hline Verbo Ter no Particípio Passado & VPPTER \\
\hline Verbo Ser (outras formas) & VSER \\
\hline Verbo Ter (outras formas) & VTER \\
\hline Verbo (outras formas) & $\mathrm{V}$ \\
\hline Interjeição & $\mathbf{I}$ \\
\hline. & . \\
\hline$\vdots$ & $:$ \\
\hline$=$ & 二 \\
\hline( & ( \\
\hline 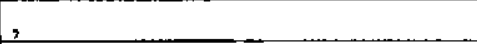 & , \\
\hline$!$ & $!$ \\
\hline$?$ & $?$ \\
\hline$\ldots$ & $\ldots$ \\
\hline ) & ) \\
\hline “ & « \\
\hline [ & {[} \\
\hline ] & ] \\
\hline\{ & $f$ \\
\hline$\}$ & 3 \\
\hline$\div$ & \\
\hline
\end{tabular}

\section{A3 - NHC tagset (Versão 3)}

Mesmo com as alterações, o número de etiquetas permanece estável, isto é, 49 etiquetas sem contar as etiquetas compostas pela utilização dos operadores de contrações, mesóclises e ênclises, sendo que destas 15 são utilizadas para pontuação.

\begin{tabular}{|l|l|}
\hline Categoria morfossintática & Etiqueta \\
\hline Adjetivo & ADJ \\
\hline Advérbio & ADV \\
\hline Artigo & ART \\
\hline Numeral Cardinal & NC \\
\hline
\end{tabular}




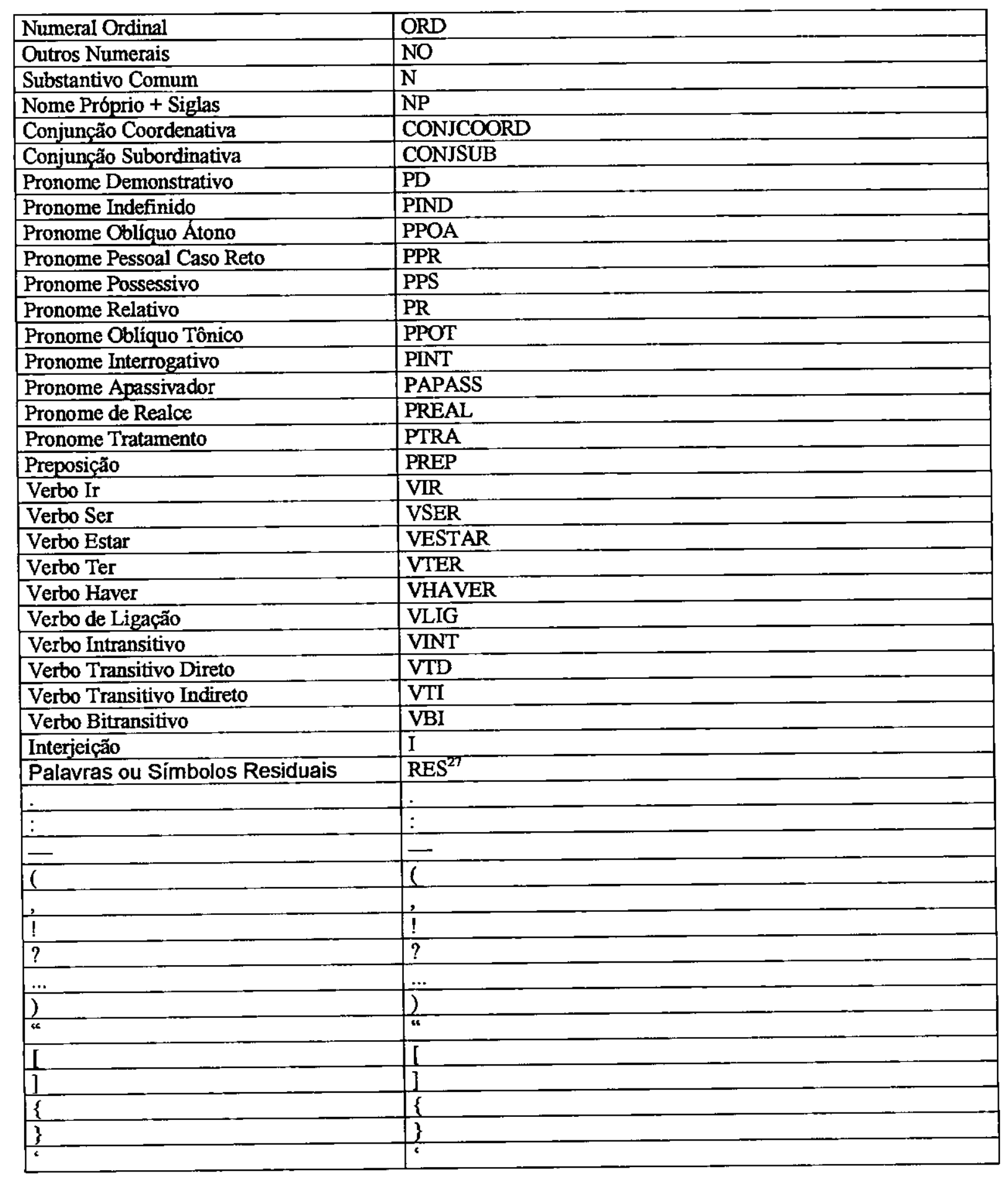

\section{A4 - NILC tagset (Versão 4)} ${ }^{27}$ A etiqueta para palovras e símbolos residuais - RES - volta a ser utilizoda e é compostos pelas mesmas partes que a
compunham na primeira versốo do NILC tagset e permanece com a mesma estrutura até a versäo 4 do NILC tagset. 
Nesta versão do NILC tagset o número de etiquetas cai para 45 etiquetas, sem contar as etiquetas compostas pela utilização dos operadores de contrações, mesóclises e ênclises, sendo que destas 15 são de pontuação.

\begin{tabular}{|c|c|}
\hline Categoria morfossintática & Etiqueta \\
\hline Adjetivo & $\mathrm{ADJ}$ \\
\hline Advérbio & $\mathrm{ADV}$ \\
\hline Artigo & ART \\
\hline Numeral Cardinal & $\mathrm{NC}$ \\
\hline Numeral Ordinal & $\mathrm{ORD}$ \\
\hline Outros Numerais & NO \\
\hline Substantivo Comum & $\mathrm{N}$ \\
\hline Nome Próprio + Siglas & NP \\
\hline Conjunção Coordenativa & CONJCOORD \\
\hline Conjunção Subordinativa & CONISUB \\
\hline Pronome Demonstrativo & PD \\
\hline Pronome Indefinido & PIND \\
\hline Pronome Oblíquo Átono & PPOA \\
\hline Pronome Pessoal Caso Reto & PPR \\
\hline Pronome Possessivo & PPS \\
\hline Pronome Relativo & PR \\
\hline Pronome Oblíquo Tônico & PPOT \\
\hline Pronome Interrogativo & PINT \\
\hline Pronome Apassivador & PAPASS \\
\hline Pronome de Reaice & PREAL \\
\hline Pronome Tratamento & PTRA \\
\hline Preposição & PREP \\
\hline Verbo Auxiliar & VAUX \\
\hline Verbo de Ligação & VLIG \\
\hline Verbo Intransitivo & VINT \\
\hline Verbo Transitivo Direto & VTD \\
\hline Verbo Transitivo Indireto & VII \\
\hline Verbo Bitransitivo & VBI \\
\hline Interjeição & 1 \\
\hline Palavras ou Simbolos Residuais & RES \\
\hline 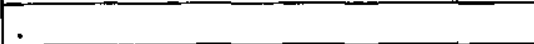 & . \\
\hline$\dot{\vdots}$ & $\therefore$ \\
\hline- & - \\
\hline( & 1 \\
\hline$!$ & $!$ \\
\hline$?$ & $?$ \\
\hline$\ldots$ & $\ldots$ \\
\hline$)$ & 2 \\
\hline$n$ & " \\
\hline [ & $I$ \\
\hline 1 & 1 \\
\hline\{ & I \\
\hline 3 & \} \\
\hline 1 & $\div$ \\
\hline & \\
\hline
\end{tabular}




\section{A5 - NILC tagset (Versão 5 - Versão)}

A versão atual do NULC tagset é um pouco maior que a versão 4, tem 51 etiquetas sem contar as etiquetas compostas pela utilização dos operadores de contrações, mesóclises e ênclises, sendo que 15 são de pontuação. Nela, a etiqueta para palavras e símbolos residuais - RES - passa a ser dividida em 4 subcategorias, as três das versões 1, 3 e 4 mais uma categoria para coloquialismos e regionalismos. Coloquialismos são expressões de estilo de linguagem informal (Por exemplo: Cê vai aonde?). Já os regionalismos são expressões próprias de uma região e regiões (Por exemplo: $O$ bichinho venha aqui).

\begin{tabular}{|c|c|}
\hline Categoria morfossintática & Etiqueta \\
\hline Adjetivo & $\mathrm{ADJ}$ \\
\hline Advérbio & $\mathrm{ADV}$ \\
\hline Artigo & $\mathrm{ART}$ \\
\hline Numeral Cardinal & $\mathrm{NC}$ \\
\hline Numeral Ordinal & ORD \\
\hline Outros Numerais & NO \\
\hline Substantivo Comum & $\mathrm{N}$ \\
\hline Nome Próprio + Siglas & $\mathrm{NP}$ \\
\hline Conjunção Coordenativa & CONJCOORD \\
\hline Conjunção Subordinativa & CONJSUB \\
\hline Pronome Demonstrativo & $\mathrm{PD}$ \\
\hline Pronome Indefinido & PIND \\
\hline Pronome Oblíquo Átono & PPOA \\
\hline Pronome Pessoal Caso Reto & PPR \\
\hline Pronome Possessivo & PPS \\
\hline Pronome Relativo & $\mathrm{PR}$ \\
\hline Pronome Oblíquo Tônico & PPOT \\
\hline Pronome Interrogativo & PINT \\
\hline Pronome Apassivador & PAPASS \\
\hline Pronome de Realce & PREAI \\
\hline Pronome Tratamento & PTRA \\
\hline Preposição & PREP \\
\hline Verbo Auxiliar & VAUX \\
\hline Verbo de Ligaçâo & VLIG \\
\hline Verbo Intransitivo & VINT \\
\hline Verbo Transitivo Direto & VTD \\
\hline Verbo Transitivo Indireto & VTI \\
\hline Verbo Bitransitivo & VBI \\
\hline Interjeição & I \\
\hline Locuçáo Adverbial & LADV \\
\hline Locução Conjuncional & LCONJ \\
\hline Locução Prepositiva & LPREP \\
\hline Locução Pronominal & $\overrightarrow{\mathrm{LP}}$ \\
\hline Locuçáo Denotativa & LDEN \\
\hline Palavra Denotativa & PDEN \\
\hline Palavras ou Símbolos Residuais & RES \\
\hline Ítem de lista & $\overline{\mathrm{IL}}$ \\
\hline
\end{tabular}




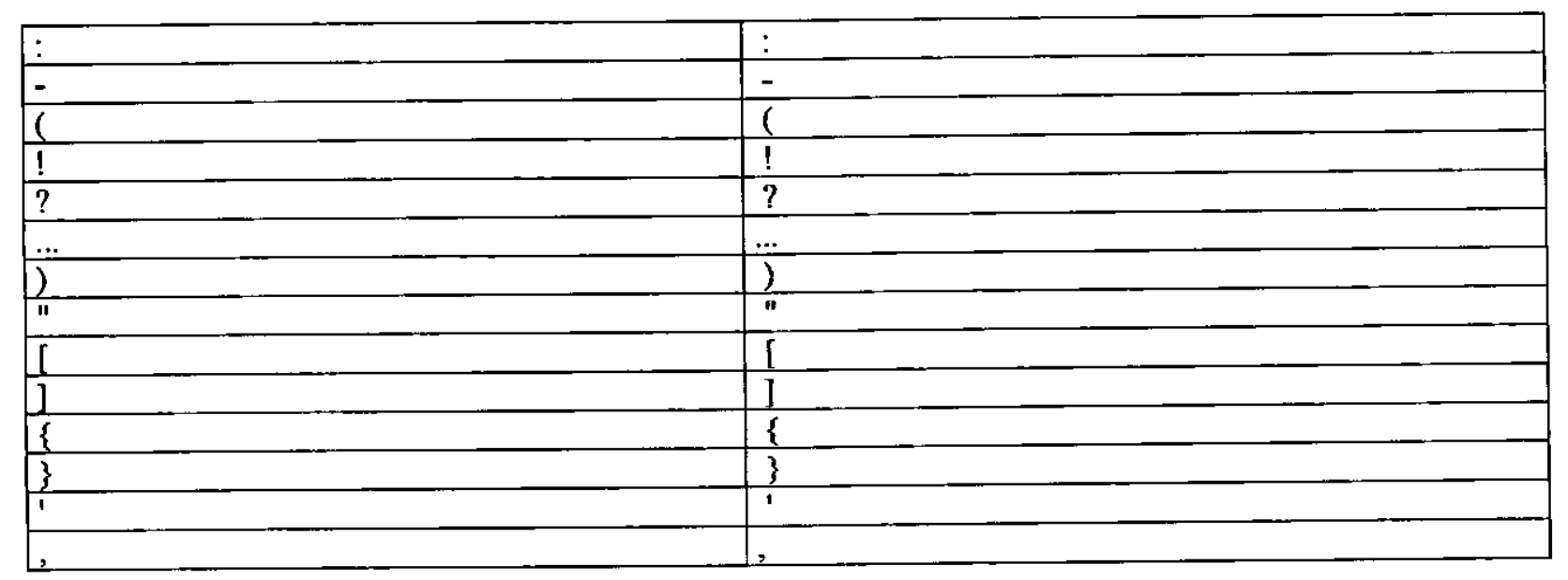





\section{APÊNDICE B - MANUAL dOS ETIQUETADORES}

Este apêndice mostra quais säo as ferramentas utilizadas e arquivos utilizados/gerados no treinamento e etiquetagem feitos pelos etiquetadores: Tree Tagger, TBL, MXPOST e X.

\section{B1 - TreeTagger}

Para treinar o Tree Tagger para uma nova língua, deve-se utilizar o comando:

train-tree-tagger [-st] [-cl] [-dtg] [-ecw] [-atg] <léxico><classes abertas><arquivo de treinamento><arquivo modelo>

Em que:

léxico é o arquivo que contém o léxico que será utilizado. Cada linha deve corresponder a uma palavra e um caractere de tabulação seguida dos possíveis pares de etiquetas/formas canônicas. As etiquetas e formas canônicas são separadas por espaços em branco. Sendo que não é obrigatório o uso da forma canônica, para tanto basta ter um hifen "-" onde estaria a forma canônica. Como mostrado no exemplo:

a ART PREP PPOA a

ou

a ART PREP PPOA -

menina $N \quad A D J$ - 
classes abertas é o arquivo que contém as etiquetas de classes abertas que poderão ser utilizadas pelo etiquetador, isto é possíveis etiquetas para palavras desconhecidas. Este arquivo deve conter apenas as etiquetas separadas por um espaço em branco. Por exemplo:

VTD VTI VINT VBI VAUX VLIG ADV N NP

arquivo de treinamento é o arquivo que contém os dados que serāo utilizados no treinamento e também deve conter apenas uma palavra/símbolo de pontuação por linha seguidos por um coractere de tabulação e a etiqueta. Como mostro o exemplo abaixo:

A ART

menina $\quad N$

é VLIG

bonita $A D J$

arquivo modelo é o arquivo onde o TreeTagger armazenará o modelo gerado por ele neste treinamento.

Existem também alguns parâmetros adicionais que podem ser utilizados no treinamento:

-st <etiqueta sent>: serve para indicar quais säo as etiquetas utilizadas para pontuações que indiquem final de período - ... ? ! para os casos em que näo é utilizada a etiqueta SENT que é a etiqueta default de pontuações que indicam final de período do TreeTagger.

- $d$ <tamanho do contexto>: indica o número de palovras anteriores que seräo utilizadas como contexto. 0 valor default do TreeTagger para este parâmetro é $2.1 / 1$ que corresponde a um
unigrama.

- dtg <ganho mínimo da árvore de decisão > : indica um limiar para o qual o último nó da árvore de decisão deve ser deletado caso o ganho de informação seja menor. 0 valor default é 0,7 .

- atg <ganho da árvore de afixo>: indica um limiar para o qual o último nó da árvore de afixo deve ser deletado caso o gonho de informaçáo seja menor. O valor default é 0,15 .

Feito isto, pora etiquetar um texto, deve-se utilizar o comando:

\section{tree-tagger [-token] [-lemma] [-sgml] [-proto] [-base] <arquivo de parâmetro> <arquivo de entrada> <arquivo de saída>}

Em que:

arquivo de parâmetro é o arquivo onde está o modelo criado no treinamento, é o arquivo de saída do treinamento.

arquivo de entrada é o arquivo que deverá ser etiquetado. Deve conter openas uma palavra/símbolo de pontuação por linha. Um arquivo válido, estaria no seguinte formato:

Ele

moro

em 
arquivo de saída é o arquivo onde o etiquetador deverá armazenar o texto etiquetado.

Existem cinco parâmetros adicionais que podem ser utilizados na etiquetagem:

-token : faz com que o arquivo onde é armazenado o resultado da etiquetagem, apresente além das etiquetas suas palavras correspondentes.

-lemma : além da palavra caracter de tabulação etiqueta o arquivo canterá também a forma canônica de cada palavra.

-sgml : no caso do texto submetido ao etiquetador conter etiquetas SGML esta opçäo ignoratudo que aparecer entre '<' e '>'.

-proto : com esta opção o etiquetador gera também um arquivo chamado "lexicon-protocol.txt" que contém informaçóes sobre o grau de ambigüidade e outras possíveis etiquetas de cada palavra.

-base : esta opção faz com que o etiquetador utilize apenas as informaçōes lexicais na etiquetagem.

A Figura 31 mostra o fluxo dos dados no treinamento e na etiquetagem, as ferramentas que estão em laranja fazem parte do módulo $X$ e são explicadas no Apêndice $D$.

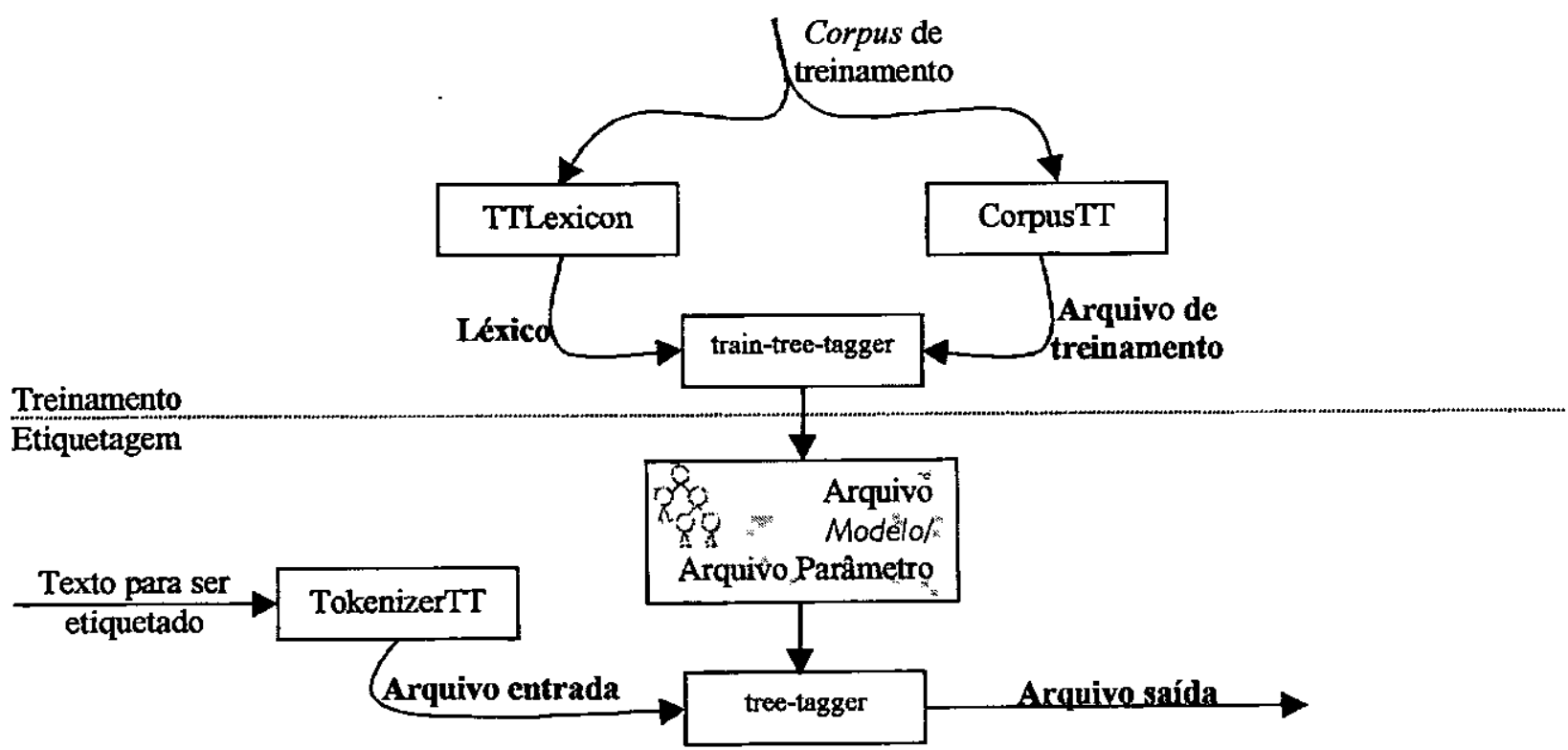

Figura 38 - Fluxo de dados no treinamento e etiquetagem com o etiquetador TreeTagger 


\section{B2 - TBL}

$O$ treinamento com o etiquetodor TBL consiste de duas etapas: aprender regras para etiquetagem de palovros desconhecidas e aprender regras contextuais.

No treinamento para aprendizado de regras para palovras desconhecidas utiliza-se 0 comondo:

unknown-lexical-leam.prl BIGWORDLIST SMALLWORDTAGLIST BIGBIGRAMUIST $n$ LEXRULEOUTFILE Em que:

BIGWORDLIST é um arquivo com todas as palavras/símbolos que estäo presentes no corpus em ordem decrescente de freqüência.
de
$a$
que
do

0

e

SMALLWORDTAGLIST é Um arquivo no formato - palavro etiqueto frequência - que listo o número de vezes que uma palovra aparece com uma doda etiqueta no corpus.

., 3093

. . 1787

de PREP 1411

O ART 909

e CONJCOORD 879

a ART 806

BIGBIGRAMLIST é um arquivo com as bigramas que aparecem no corpus de treinamento.
- Porto
permite que
único,
das freqüentes
dar ordens
as concorrências
preocupaçōes afostoram

n é um número que indica que deverāo ser utilizados apenas os bigramas onde pelo menos uma das palovras é uma das n mais frequentes no corpus.

LEXRULEOUTFILE é o arquiva onde seräo armazenadas as regras aprendidas. 
No treinamento para aprendizado de regras contextuais utilizo-se o comando:

\section{contextual-rule-learn TAGGED-CORPUS DUMMY-TAGGED-CORPUS $\mid$ CONTEXT-RULEFILE} TRAINING.LEXICON

Em que:

TAGGED-CORPUS é o arquivo que contém o texto etiquetado manualmente, "tokenizodo" e no formato de um periodo por linha

DUMMY-TAGGED-CORPUS é o arquivo formado pelo mesmo texto do arquivo TAGGED-CORPUS só que etiqueado pelo etiquetador inicial.

CONIEXTRULEFILE é o arquivo on de serão armazenadas as regras contextuais.

IRAININGLEXICON é o arquivo do léxico, que é formado pelas palavras e as possiveis etiquetas para cada palavra que tenham aparecido no corpus de treinamento.

rosto $N$

(Disponivel em http://www. folha.com.br/istoe RES

vassouro-de-bruxa $N$

ortesanal $A D J$

troca N LPREP

amarrada VTD ADJ

escrito ADJ N VINT VTD

Depois ADV LPREP LCONJ

Embora ADV CONJCOORD

O etiquetador TBL tem ferramentas ouxiliares para gerar estes arquivos que são utilizados na treinamento e estäo descritos no arquivo readme que acompanho o etiquetador.

Na etiquetagem é utilizado o comando:

\section{tagger TRAININGLEXICON CORPUS BIGBIGRAMLISTS LEXICALRULEOUTFILE CONTEXTUALRULEFILE [opç̄es]}

Em que:

CORPUS é o nome do arquivo que será etiquetado.

Depois do nome de todos os arquivos, podem ser colocadas opçöes (Tabela 34). 
Tabela 34 - Opções do comando tagger

\begin{tabular}{|ll|}
\hline -h & Help \\
-w wordlist & Provê um conjunto extra de palavras além das que estão no léxico \\
-i filename & Escreve o resultado intermediário do estado inicial em um arquivo \\
-s number & Para saber o número de linhas etiquetadas por tempo \\
-S & Usa apenas o etiquetador inicial \\
-F & Usa apenas o etiquetador final, ou seja o corpus tem de estar etiquetado \\
\hline
\end{tabular}

O etiquetador TBL provê ainda a possibilidade de aumentar-se a lista de bigramas e 0 léxico. Há também a possibilidade de se alterar manualmente as regras.

O fluxo de dados no treinamento do etiquetador TBL é mostrado na Figura 39.

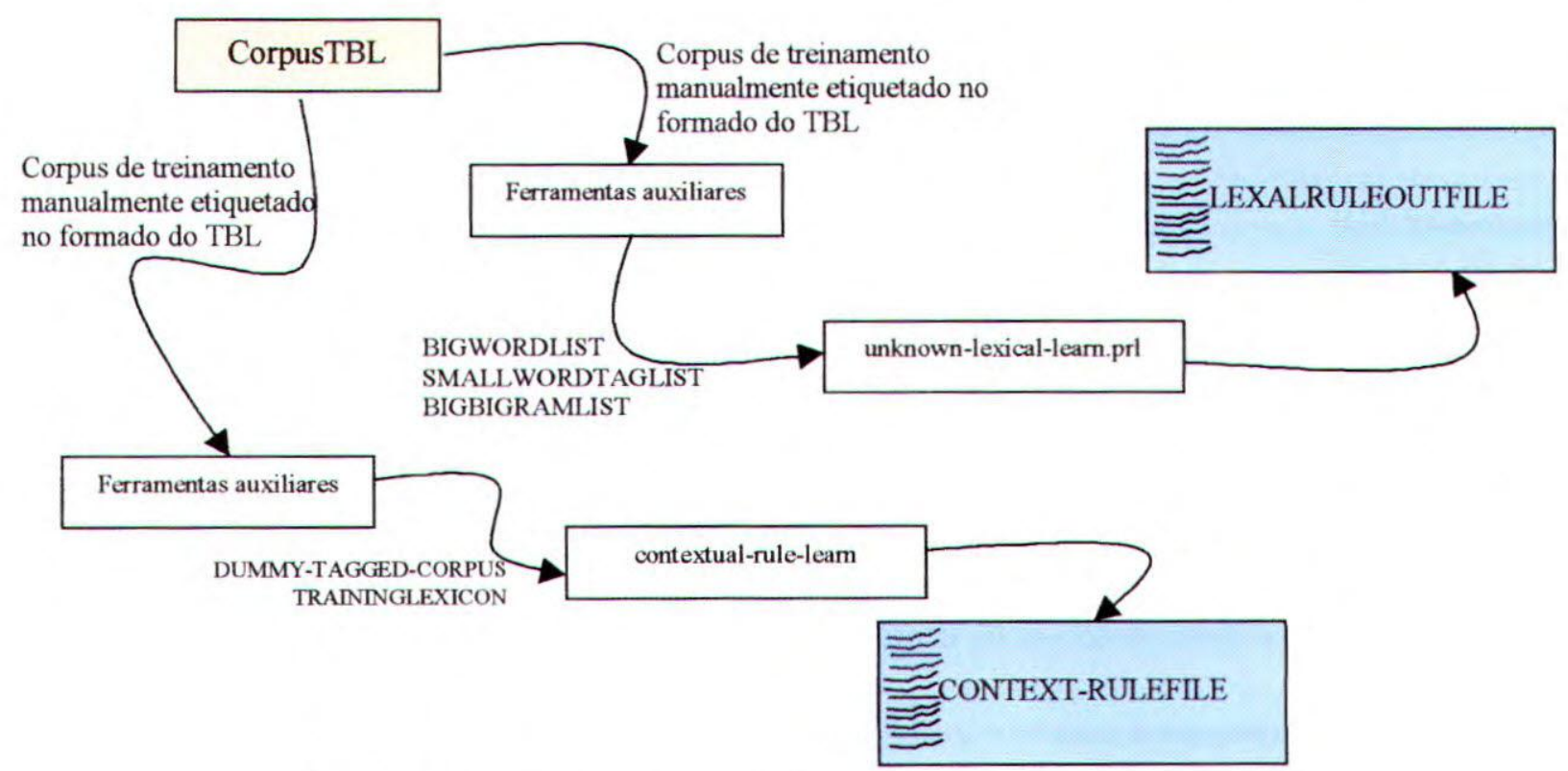

Figura 39 - Fluxo de dados no treinamento com o etiquetador TBL

\section{B3 - MXPOST}

O treinamento com o etiquetador MXPOST é feito através do comando:

$$
\text { trainmxpost }<\text { diretório }><\text { corpus de treinamento }>
$$

Em que:

diretório: é o nome dado ao diretório onde estaräo os arquivos do modelo gerado pelo etiquetador 
corpus de treinamento: é o corpus de treinamento no formato palavra_etiqueta, com um período por linha

A etiquetagem do etiquetador MXPOST é feita através do comando:

$$
\text { mxpost diretório }<\text { texto }>\text { textosaída }
$$

Em que:

diretório é o nome do diretório onde está o modelo do etiquetador texto é o texto que será etiquetado e que deve estar no formato: um período por linha textosaída é o texto etiquetado pelo MXPOST

A Figura 34 mostra o fluxo de dados no treinamento e na etiquetagem do etiquetador MXPOST

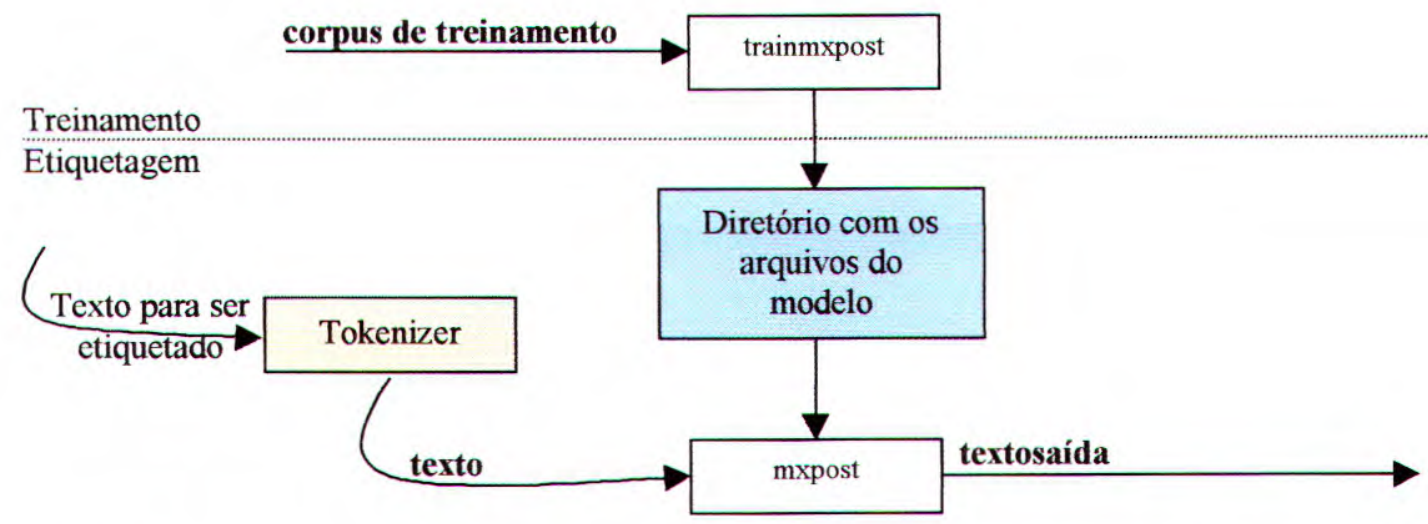

Figura 40 - Fluxo de dados no treinamento e etiquetagem com o etiquetador MXPOST

\section{B4 - PoSiTagger}

A treinamento com o etiquetador PoSiTagger é feita através do comando:

simbolico $<$ texto $><$ textosaída $>$

Em que:

texto é o texto a ser etiquetado com um período por linha.

textosaída é o texto etiquetado no formato palavra_etiqueta com um período por linha.

A Figura 41 mostra o fluxo de dados no etiquetador PoSiTagger.

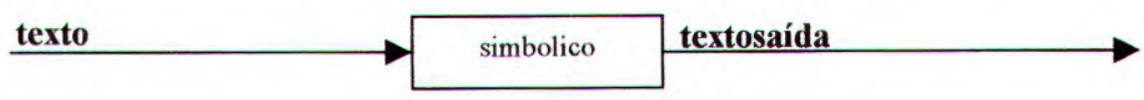

Figura 41 - Fluxo de dados no PoSiTagger 



\section{APÊNDICE C - REGRAS PARA DESAMBIGÜIZAÇÃO GRAMATICAL}

\section{C1 - Regras para etiquetagem morfossintática do REGRA ${ }^{28}$}

Regras Nãa-Lexicalizadas
Mude Etiqueta $=$ ADJ para Etiqueta $=$ ADV se EtiquetaA $=$ VBI
Mude Etiqueta $=$ ADJ para Etiqueta $=$ ADV se EtiquetaA $=$ VESTAR
Mude Etiqueta $=$ ADJ para Etiqueta $=$ ADV se EtiquetaA $=$ VHAVER
Mude Etiqueta $=$ ADJ para Etiqueta $=$ ADV se EtiquetaA $=$ VINT
Mude Etiqueta $=$ ADJ para Etiqueta $=$ ADV se EtiquetaA $=$ VIR
Mude Etiqueta $=$ ADJ para Etiqueta $=$ ADV se EtiquetaA $=$ VSER
Mude Etiqueta $=$ ADJ para Etiqueta $=$ ADV se EtiquetaA $=$ VTD
Mude Etiqueta $=$ ADJ para Etiqueta $=$ ADV se EtiquetaA $=$ VTER
Mude Etiqueta $=$ ADJ para Etiqueta $=$ ADV se EtiquetaA $=$ VTI
Mude Etiqueta $=$ ADJ para Etiqueta $=$ ADV se EtiquetaP $=$ ADJ
Mude Etiqueta $=$ ADJ para Etiqueta $=$ ADV se EtiquetaP $=$ ADV
Mude Etiqueta $=$ ADJ para Etiqueta $=\mathrm{N}$ se EtiquetaA $=$, e EtiquetaP $=$, e Etiqueta2A $=\mathrm{N}$
Mude Etiqueta $=$ ADJ para Etiqueta $=$ N se EtiquetaA $=$, e EtiquetaP $=$ PREP e Etiqueta2A $=\mathrm{N}$
Mude Etiqueta $=$ ADJ para Etiqueta $=\mathrm{N}$ se EtiquetaA $=$, e EtiquetaP $=$ PREP e Etiqueta2A $=$ NP
Mude Etiqueta $=$ ADJ para Etiqueta $=$ N se EtiquetaA $=$ PREP e EtiquetaP $=$ ADJ
Mude Etiqueta $=$ ADJ para Etiqueta $=\mathrm{N}$ se EtiquetaA $=$ PREP e EtiquetaP $=$ PREP

${ }^{28}$ Esta lista de regras foi obtida em julho de 1999. 


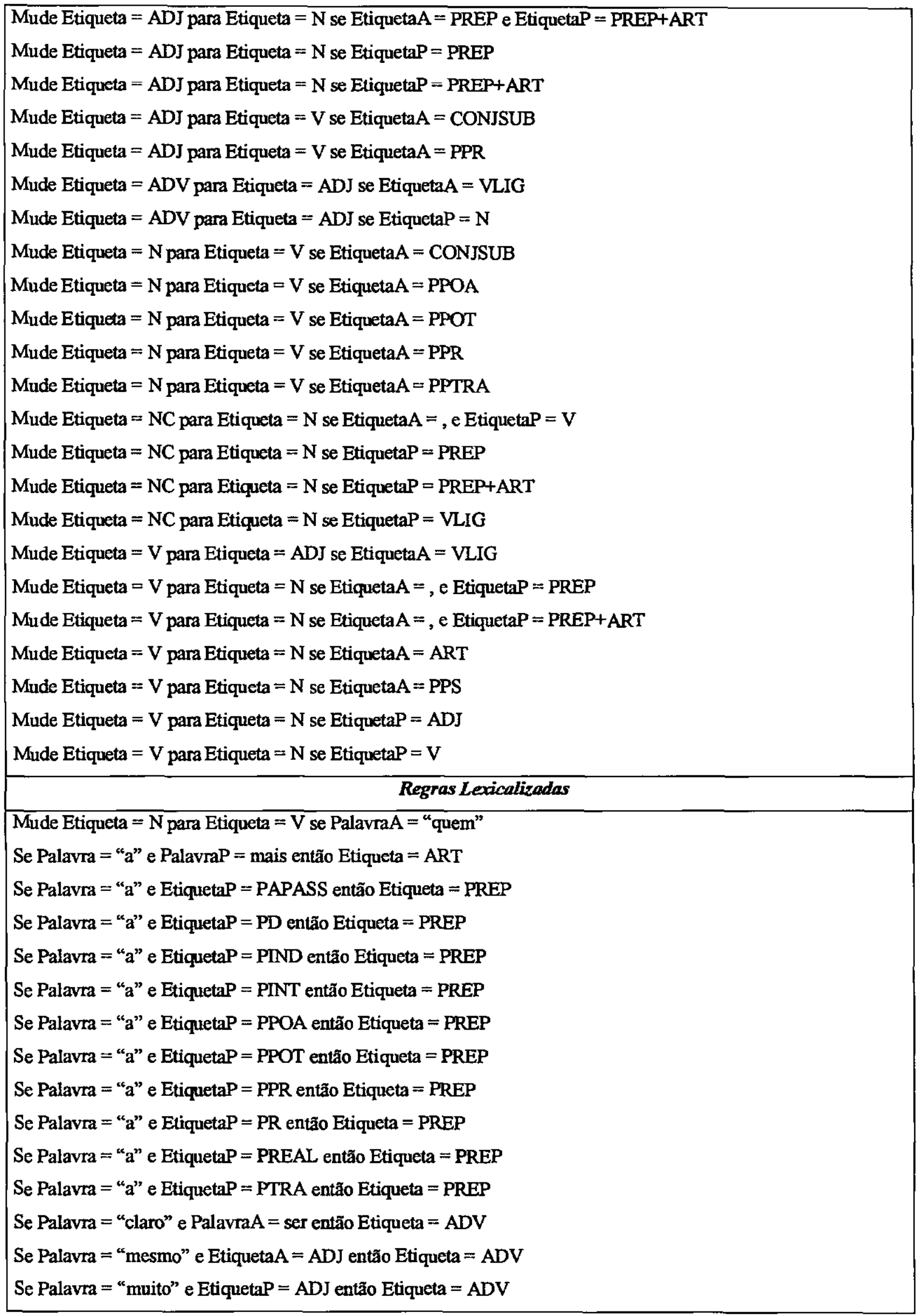




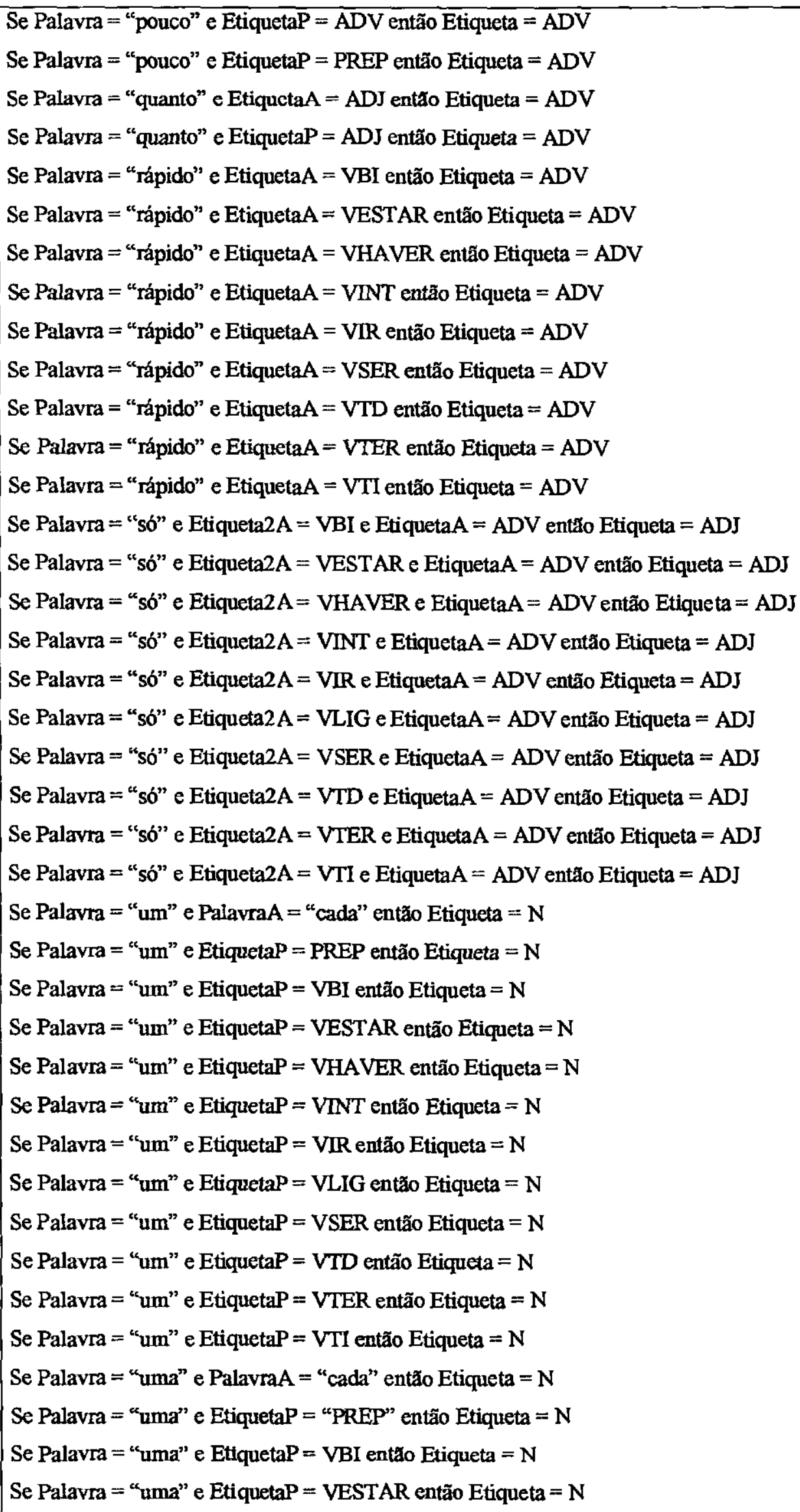




\begin{tabular}{|c|}
\hline Se Palavra = "uma" e EtiquetaP = VHAVER então Etiqueta $=\mathrm{N}$ \\
\hline Se Palavra = "uma" e EtiquetaP $=$ VINT então Etiqueta $=\mathrm{N}$ \\
\hline Sc Palavra = "uma" c EtiquetaP = VIR então Etiqueta $=\mathrm{N}$ \\
\hline Se Palavra $=$ "uma" e EtiquetaP $=$ VLIG então Etiqueta $=\mathrm{N}$ \\
\hline Se Palavra = "uma" e EtiquetaP = VSER então Etiqueta $=\mathrm{N}$ \\
\hline Se Palavra $=$ "uma" e EtiquetaP $=$ VTD então Etiqueta $=\mathrm{N}$ \\
\hline Se Palavra = "uma" e EtiquetaP $=$ VTER então Etiqueta $=\mathrm{N}$ \\
\hline Se Palavra $=$ "uma" e EtiquetaP $=$ VTI então Etiqueta $=\mathrm{N}$ \\
\hline Se Palavra = "uns" e PalavraP = "de" então Etiqueta = PIND \\
\hline Se Palavra = "uns" e PalavraP = "dentre" então Etiqueta = PIND \\
\hline Obs.: Etiqueta = Etiqueta da palavra que está sendo etiquetada; \\
\hline EtiquetaA = Etiqueta da palavra anterior a que está sendo etiquetada; \\
\hline Etiqueta2A = Etiqueta da palavra que está duas posições antes da que está sendo etiquetada; \\
\hline EtiquetaP = Etiqueta da palavra seguinte a que está sendo etiquetada; \\
\hline Etiqueta2P = Etiqueta da palavra que está duas posições depois da que está sendo etiquetada; \\
\hline Palavra = Palavra que está sendo etiquetada; \\
\hline PalavraA = Palavra anterior a que está sendo etiquetada; \\
\hline PalavraP = Palavra que vem em seguida a que está sendo etiquetada; \\
\hline Palavra2A = Palavra que está duas posições antes da que está sendo etiquetada; \\
\hline Palavra2P = Palavra que está duas posições depois da que está sendo etiquetada. \\
\hline
\end{tabular}

\section{C2 - Regras do etiquetador TBL}

As regras apresentadas aqui são resultado do treinamento do etiquetador TBL com $80 \%$ do corpus de treinamento - 376 regras para palavras desconhecidas e 271 regras contextuais -, e estão representadas da mesma forma com que estão no etiquetador. $O$ número que aparece em cada regra é a pontuação de cada regra dada pelo etiquetador. Os seis exemplos abaixo são exemplos de regras para palavras desconhecidas para o inglês, para que fique claro o formato utilizado pelo etiquetador TBL.

\section{1) NN s thassuf 1 NNS 3022.2549507603848724}

É o mesmo que dizer: Mude a etiqueta de NN para NNS sẹ a palavra tiver o sufixo s

2) Ed hassuf 2 VBN 1203.543544204078895

É o mesmo que dizer: Mude a etiqueta para VBN se o sufixo é "ed"

3) Ly addsuf 2 JJ 578.41553589321256368

É o mesmo que dizer: Mude a etiqueta para $\mathrm{JJ}$ se adicionando o sufixo "ly" o resultado é uma palavra 


\section{4) - char JJ 425.28095238095232844}

É o mesmo que dizer: Mude a etiqueta para JJ se o caracter "-" aparecer na palavra

5) NN to fgoodright VB 224.95212906910632

É o mesmo que dizer: Mude a etiqueta de NN para VB se a palavra vier sempre a direita da palavra "to"

\section{6) Un deletepref $2 \mathrm{JJ} 67.245614035087726279$}

É o mesmo que dizer: Mude a etiqueta para JJ se deletando o prefixo "un" resultar em uma palavra.

\section{C21 Regras para palavras desconhecidas}

No fgoodleft VTD 192.510261367627

u hassuf I VTD 132.94880952381

- char VTD+PPOA 130.733333333333

$\mathrm{N}$ ar fhassuf 2 VTD 128.921153846154

$\mathrm{N}$ do thassuf 2 VTD 126.31829004329

$\mathrm{N} m$ thassuf I VTD 111.126984126984

ente hassuf 4 ADV 99.3333333333333

N 1 fhassuf 1 ADJ 79.968426018426

mais goodright ADJ 67.1399168651192

1 char NC 66

VTD o fgoodright N 58.822095104017

$m$ addsuf 1 VTD 50.4225188604499

ada hassuf 3 ADJ 42.6333333333333

$\mathrm{N}$ ica fhassuf 3 ADJ 37.7619047619048

ava hassuf 3 VTD 37.5

anos goodleft NC 35.4494172494173

$\mathrm{N}$ ais fhassuf 3 ADJ 34.6818181818182

$\mathrm{N}$ adas thassuf 4 ADJ 33.3095238095238

$\mathrm{N}$ ico fhassuf 3 ADJ 27.36666666666667

dos hassuf 3 ADJ 25.6380952380952

ADJ de fgoodright N 35.8223208971185

uma goodright $\mathrm{N} 25.4985514485514$

N não fgoodright VTD 22.5646207723231

0 char NC 22

um goodright $\mathrm{N} 21.059188034188$

muito goodright ADJ 20.7765656565657

N oso fhassuf 3 ADJ 20

$\mathrm{N}$ icos fhassuf 4 ADJ 19.06666666666667

$\mathrm{N}$ ir thassuf 2 VTD 18.3888888888889

osa hassuf 3 ADJ 18

se goodright VTD 17.1666666666667

ei hassuf 2 VTD 16.33333333333333

icas hassuf 4 ADJ 14

VTD da fgoodleft VTI 13.36666666666667

me goodright VTD 14.1397058823529

$\mathrm{N}$ ana fhassuf 3 ADJ 13

2 char NC 13

ida hassuf 3 ADJ 12.9444444444444

mos hassuf 3 VTD 12.5

tão goodright ADJ 12

VTD do fgoodright $N 11.8333333333333$

$\mathrm{N}$ ante fhassuf 4 ADJ 11.3333333333333 


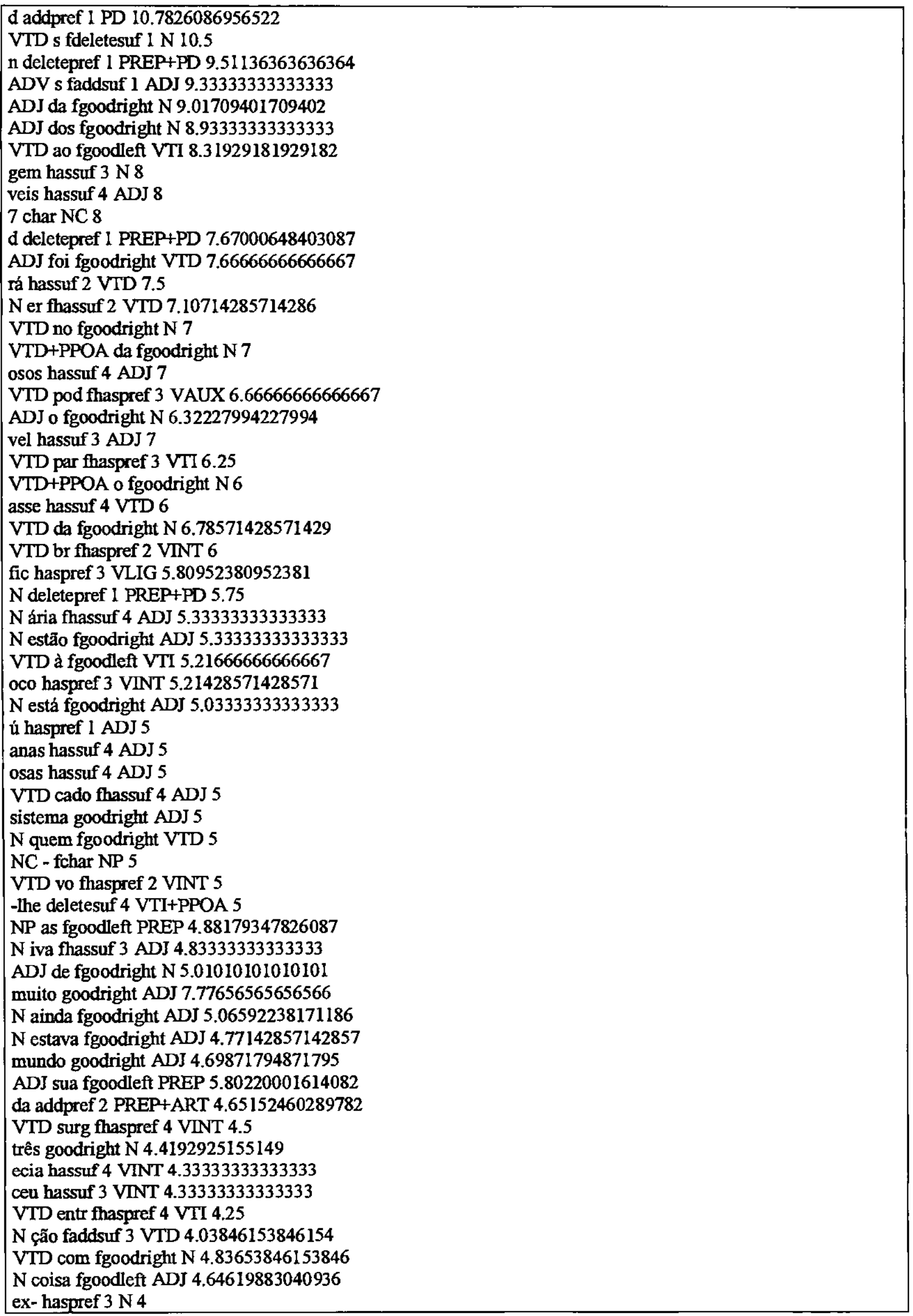


- goodleft $\mathrm{N} 4$

ADJ aos fgoodright $N 4$

VTD do fgoodright $\mathrm{N} 4$

$\mathrm{N}$ imo thassuf 3 ADJ 4

peq haspref $3 \mathrm{ADJ} 4$

$\mathrm{N}$ ext fhaspref 3 ADJ 4

pado hassuf $4 \mathrm{ADJ} 4$

verm haspref 4 ADJ 4

$\mathrm{N}$ forma fgoodright ADJ 4

tara hassuf 4 VTD 4

VTD dor thaspref 3 VINT 4

VTD mor thaspref 3 VINT 4

VTD cho thaspref 3 VINT 4

VTD go fhaspref 2 VTI 4

VTD lu thaspref 2 VTI 4

8 char NC 4

VTD obr thaspref 3 VBI 4

VTD+PPOA do fgoodleft VBI+PPOA 4

NC $h$ fchar RES 4

PREP+PD $\mathrm{m}$ fchar PREP+ART 4

nos haspref 3 PPS 4

guém hassuf 4 PIND 4

possivel goodleft VLIG 3.93955611441657

aqu addpref 3 PPR 3.9162363740677

alg addpref 3 ART 3.78288274832467

$\mathrm{N}$ ano fhassuf 3 ADJ 3.66666666666667

N Não fgoodright VTD 3.66666666666667

VTI mas fgoodright ADV 3.50128101269158

$\mathrm{N}$ eu fgoodright VTD 3.5

VID+PPOA para fgoodleft VBI+PPOA 3.5

mili haspref 4 ADJ 3.33333333333333

VTD can thaspref 3 VINT 3.33333333333333

$\mathrm{N}$ tempo fgoodleft ADJ 3.28571428571429

Out haspref 3 ADJ 3.16666666666667

ADJ ã fchar N 3

VTD um thassuf $2 \mathrm{~N} 3$

téc haspref $3 \mathrm{~N} 3$

VTD+PPOA Na fgoodright $\mathrm{N} 3$

ADV nte fdeletesuf 3 ADJ 3

Alg deletepref 3 ADJ 3

VTI ado thassuf 3 ADJ 3

$\mathrm{N}$ nse fhassuf 3 ADJ 3

pró haspref $3 \mathrm{ADJ} 3$

diá haspref 3 ADJ 3

fem haspref $3 \mathrm{ADJ} 3$

$\mathrm{N}$ ime fhaspref $3 \mathrm{ADJ} 3$

ersa hassuf $4 \mathrm{ADJ} 3$

aída hassuf $4 \mathrm{ADJ} 3$

sivo hassuf $4 \mathrm{ADJ} 3$

ânea hassuf 4 ADJ 3

VTD gado thassuf 4 ADJ 3

VTD hado fhassuf 4 ADJ 3

paul haspref 4 ADJ 3

VTD ficou fgoodright ADJ 3

$\mathrm{N}$ ministro fgoodright ADJ 3

$\mathrm{N}$ vezes fgoodright $A D J 3$

$\mathrm{N}$ seres fgoodright ADJ 3

$\mathrm{N}$ mão fgoodright ADJ 3

NP am fhassuf 2 VTD 3 


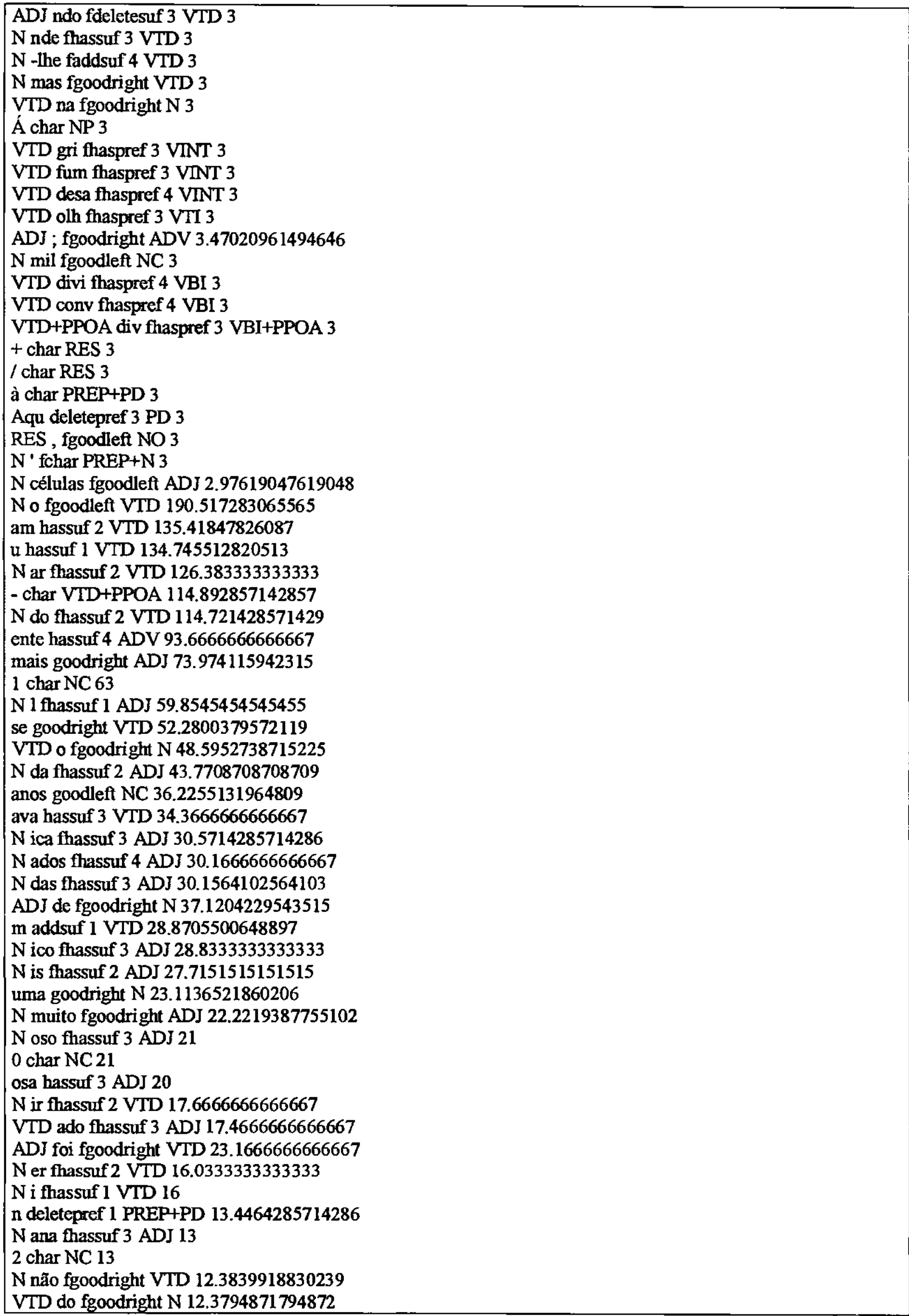


tão goodright ADJ 12

icas hassuf 4 ADJ 11.7142857142857

ção addsuf 3 VTD 11.4107142857143

VTD da fgoodleft VTI 11.3214285714286

d addpref I PD 11.2528985507246

um goodright $\mathrm{N} 10.9404761904762$

ADJ da fgoodright $N$ 12.721645021645

$\mathrm{N}$ ante fhassuf 4 ADJ 10.7333333333333

VTD à fgoodleft VTI 10.4188453159041

amos hassuf 4 VTD 10

ADV $s$ faddsuf 1 ADJ 9.83333333333333

ADJ do fgoodright $N$ 9.31020408163265

ADJ dos fgoodright $\mathrm{N} 9.11818181818182$

icos hassuf 4 ADJ 9.01428571428571

osas hassuf 4 ADJ 9

rá hassuf 2 VTD 9

VTD+PPOA he fhassuf 2 VBI+PPOA 9

N deletepref 1 PREP+PD 8.5

VTD do fgoodleft VII 8.44223602484472

me goodright VTD 8.28535353535354

ex- haspref $3 \mathrm{~N} 8$

osos hassuf 4 ADJ 8

N rem fhassuf 3 VINT 8

8 char NC 8

Na goodright $N 7.42857142857143$

VTD par fhaspref 3 VTI 7.18333333333333

VTD ao fgoodleft VTI 7

sem hassuf 3 VTD 7

N sse fhassuf 3 VTD 7

ceu hassuf 3 VINT 7

ADJ pela fgoodleft VTD 6.43333333333333

ADJ havia fgoodright VTD 6.33333333333333

VTI s faddsuf $1 \mathrm{~N} 6.325$

d deletepref 1 PREP+PD 6.03921356421356

emos hassuf 4 VTD 6

VTD+PPOA de fgoodleft VBI+PPOA 6

3 char NC 5.7

NC $h$ fchar RES 6

$\mathrm{N}$ ária thassuf 4 ADJ 5.666666666666667

$\mathrm{N}$ está fgoodright ADJ 5.66666666666667

$\mathrm{N}$ ivo fhassuf 3 ADJ 5.66666666666667

VTD da fgoodright N 5.61904761904762

ADJ no fgoodright $N 5.6$

fazer goodleft VAUX 5.42029686094904

$\mathrm{N}$ estava fgoodright ADJ 5.34883720930233

ADJ são fgoodright VTD 5.14166666666667

VTD ; fgoodleft VINT 5.03888888888889

coisa goodleft ADJ 5.1213468013468

VTD+PPOA ã fchar N 5

nea hassuf 3 ADJ 5

vel hassuf 3 ADJ 5

/ char RES 5

VTD+PPOA tor thaspref 3 VLIG+PPOA 5

$\mathrm{N}$ ainda fgoodright ADJ 4.90681272509004

pró haspref $3 \mathrm{ADJ}$ 4.85714285714286

ADJ os fgoodright N 4.85714285714286

sala goodleft PREP+ART 4.75108225108225

surg haspref 4 VINT 4.666666666666667

ADJ das fgoodright $N 4.625$ 
foram goodright VID 4.5

$\mathrm{N}$ fin fhaspref 3 ADJ 4.45454545454546

lhe goodright VID 4.38611111111111

VID ent fhaspref 3 VTI 4.76666666666667

duas goodright $\mathrm{N} 4.35$

outras goodleft PREP 4.29241968516852

possível goodleft VLIG 4.21339808339808

$\mathrm{N}$ mulheres fgoodright ADJ 4.10164835164835

VTD+PPOA to thassuf $2 \mathrm{~N} 4$

hos hassuf $3 \mathrm{~N} 4$

ú haspref $1 \mathrm{ADJ} 4$

bru haspref 3 ADJ 4

peq haspref $3 \mathrm{ADJ} 4$

osto hassuf 4 ADJ 4

ivas hassuf 4 ADJ 4

siva hassuf 4 ADJ 4

em deletesuf 2 VID 4

$\mathrm{N}$ quem fgoodright VTD 4

Á char NP 4

NC - fchar NP 4

VID resp fhaspref 4 VINT 4

VID pass fhaspref 4 VTI 4.3051282051282

$\mathrm{N}$ m fäeletesuf 1 VTI 4

VTD go fhaspref 2 VTI 4

VTD mor fhaspref 3 VTI 4

VID dep fhaspref $3 \mathrm{VBI} 4$

VTD+PPOA para fgoodleft VBI+PPOA 4

+ char RES 4

PREP+PD $m$ fchar PREP+ART 4

guém hassuf 4 PIND 4

nos haspref 3 PPS 4

aqu addpref 3 PPR 3.97872340425532

$\mathrm{N}$ ele fgoodright VINT 3.95

-lhe addsuf 4 VTD 3.9

ADJ pelas fgoodleft VTD 3.83333333333333

lon haspref 3 ADJ 3.79166666666667

alg addpref 3 ART 3.77646777597516

NP as fgoodleft PREP 3.76704545454545

VID tão fgoodleft VLIG 3.76189338883392

VTI mas fgoodright ADV 3.75919732441472

VID contra fgoodleft VTI 3.71666666666667

fica haspref 4 VLIG 3.58333333333333

N cromossomos fgoodright ADJ 3.5

VID va thaspref 2 VINT 3.5

VID exis fhaspref 4 VINT 3.5

VLIG . fgoodleft ADV 3.48133005556714

óide hassuf 4 ADJ 3.4

ADJ pelos fgoodleft VTD 3.33333333333333

ADJ sem fgoodright N 3.33333333333333

acab haspref 4 VTI 3.26666666666667

VID trab fhaspref 4 VTI 3.26666666666667

PREP o fhassuf 1 CONJSUB 3.23214285714286

VTD oco thaspref 3 VINT 3.21428571428571

sendo goodleft VLIG 3.1965591879385

VID eram fgoodright ADV 3.17690058479532

NP : fgoodleft N 3.07142857142857

NP um fgoodleft VID 4

pap haspref $3 \mathrm{~N} 3$

ADJ dia thaspref $3 \mathrm{~N} 3$ 
ex-addpref $3 \mathrm{~N} 3$

VTD no fgoodright $\mathrm{N} 3$

VTD+PPOA do thassuf 2 ADJ 3

ADV nte fdeletesuf 3 ADJ 3

VTI lar fhassuf 3 ADJ 3

abe haspref 3 ADJ 3

pio haspref $3 \mathrm{ADJ} 3$

gro haspref $3 \mathrm{ADJ} 3$

diá haspref $3 \mathrm{ADJ} 3$

fem haspref $3 \mathrm{ADJ} 3$

Out haspref $3 \mathrm{ADJ} 3$

cido hassuf $4 \mathrm{ADJ} 3$

mili haspref 4 ADJ 3

paul haspref 4 ADJ 3

bran haspref $4 \mathrm{ADJ} 3$

$\mathrm{N}$ ministro fgoodright ADJ 3

$\mathrm{N}$ vezes fgoodright $\mathrm{ADJ} 3$

$\mathrm{N}$ ar fgoodright $\mathrm{ADJ} 3$

$\mathrm{N}$ forma fgoodright ADJ 3

$\mathrm{N}$ mundo fgoodright ADJ 3

zado hassuf 4 VTD 3

tara hassuf 4 VTD 3

N sse faddsuf 3 VTD 3

VTD au fhassuf 2 NP 3

VTD $S$ fchar VINT 3

rol haspref 3 VINT 3

VTD gri fhaspref 3 VINT 3

dava hassuf 4 VINT 3

viaj haspref 4 VINT 3

reag haspref 4 VINT 3

VTD apar fhaspref 4 VINT 3

NP ei fhassuf 2 VTI 3

VTD pene fhaspref 4 VTI 3

VTD corr fhaspref 4 VTI 3

7 char NC 3

VTD obr fhaspref 3 VBI 3

$\mathrm{N} d$ fhassuf 1 RES 3

$\mathrm{NC}$ m fhassuf $1 \mathrm{NO} 3$

VAUX as fgoodleft PREP 2.96741874349236

C22 Regras contextuais

N ADJ PREVT AG N

PR CONJSUB PREVTAG VTD

PIND ADI NEXT1OR2TAG N

ART PREP NEXT1OR2TAG ART

VLIG VAUX NEXTTAG VTD

PREP LPREP PREVTAG LPREP

ADJ N PREVTAG PREP

$N$ ADJ NEXTTAG $N$

ART PREP WDNEXTTAG a VTD

VAUX VLIG NEXTTAG ART

PREP+ART LPREP PREVTAG LPREP

ART LP NEXTTAG PR

PR LP PREVWD O

$N$ VTD PREVWD que

ART PREP WDNEXTTAG a NC

VINT VTD NEXTIOR2OR3TAG ART

ADV LPREP NEXTWD de

PREP LPREP PREVTAG LPREP 


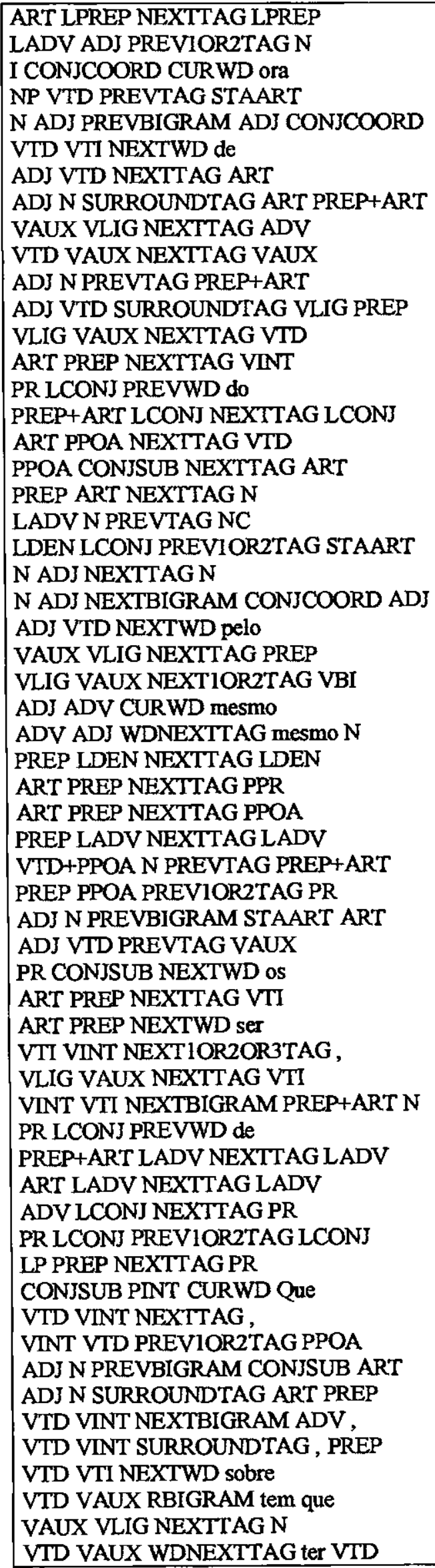




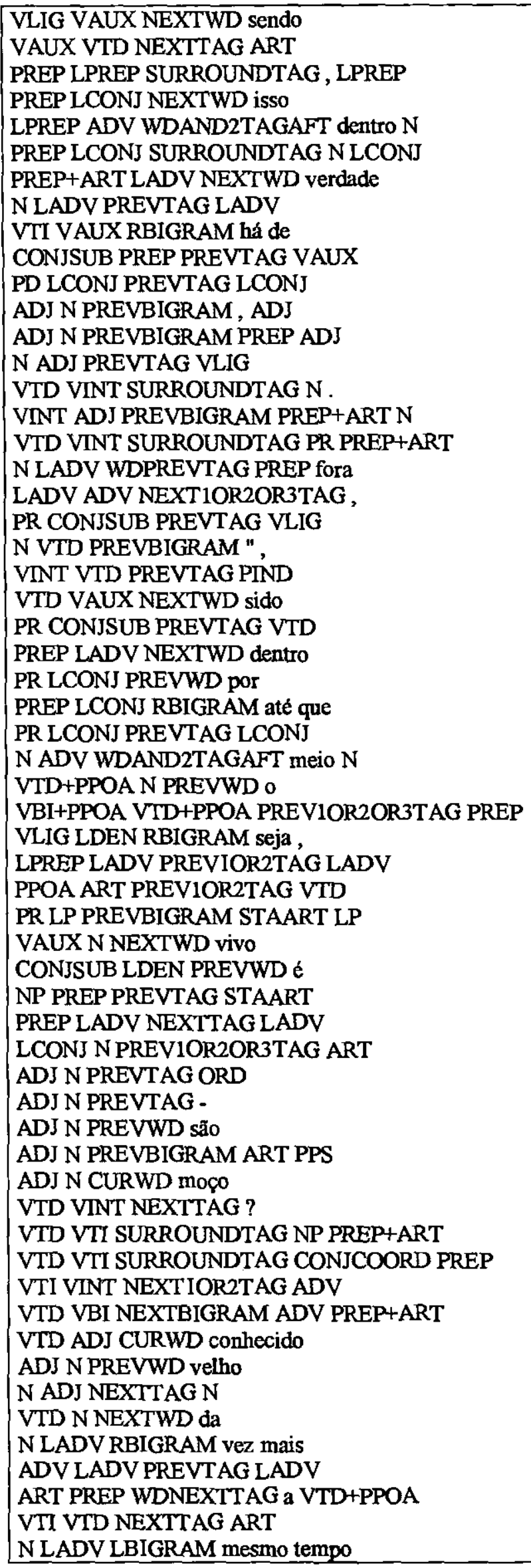




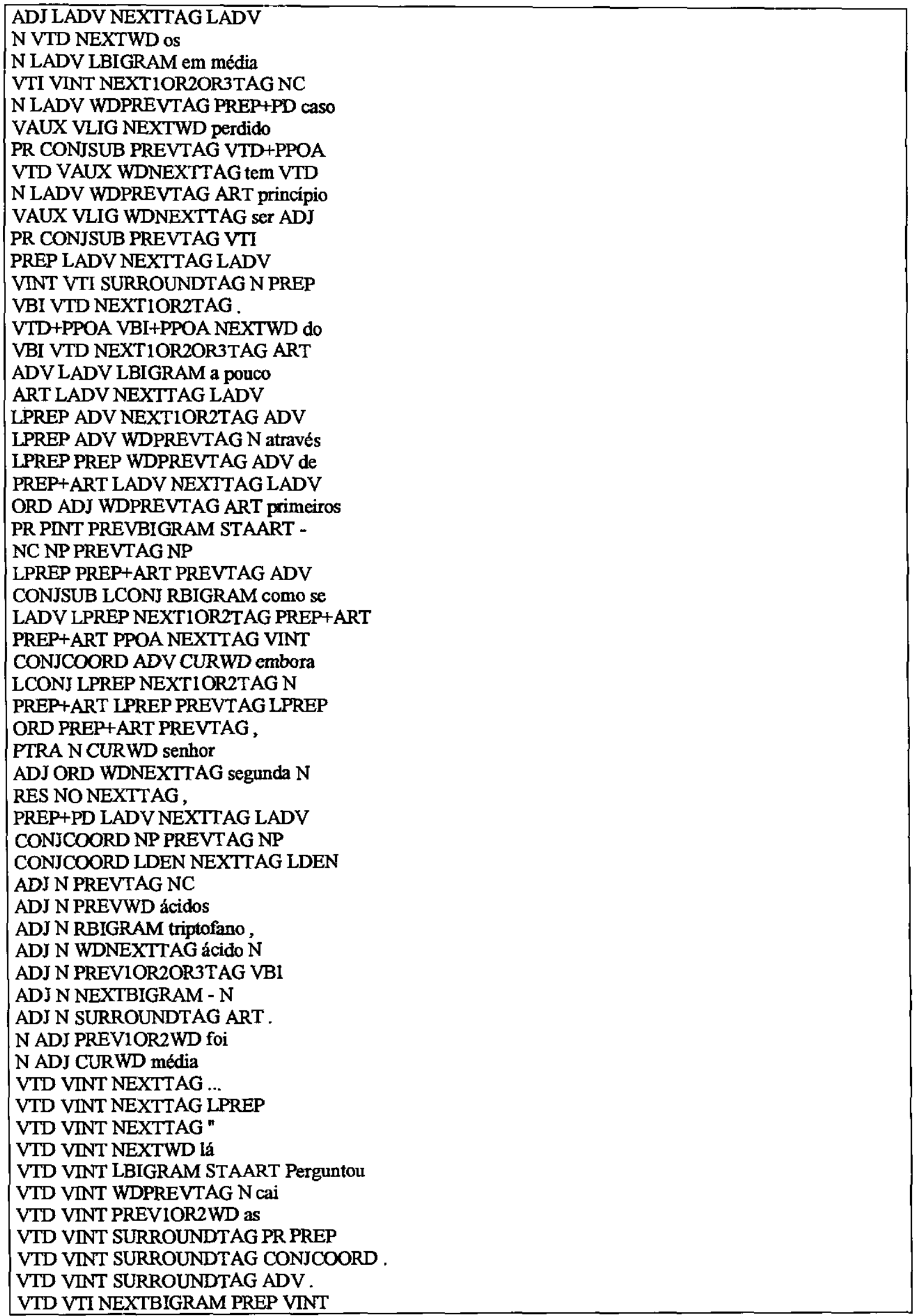




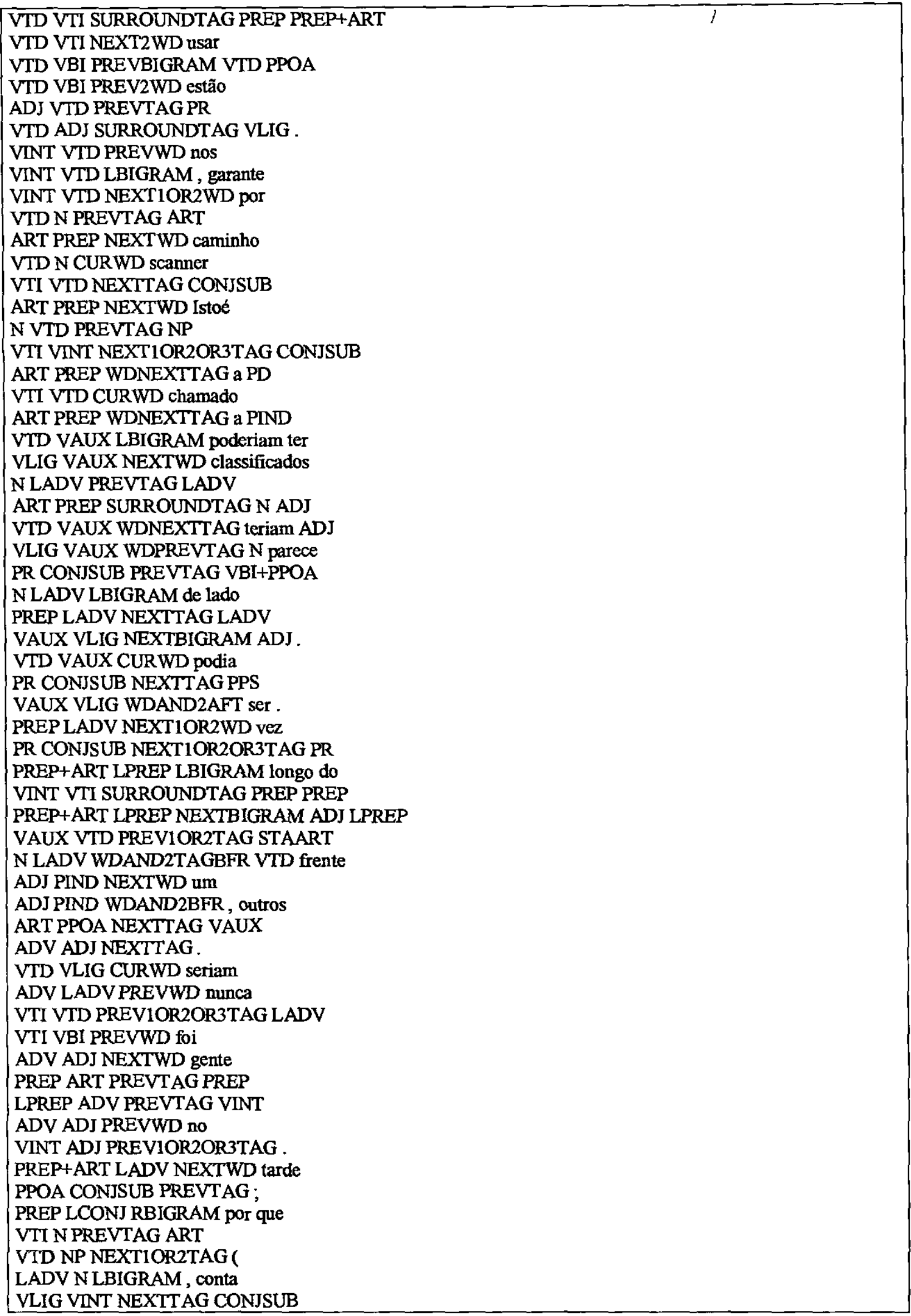




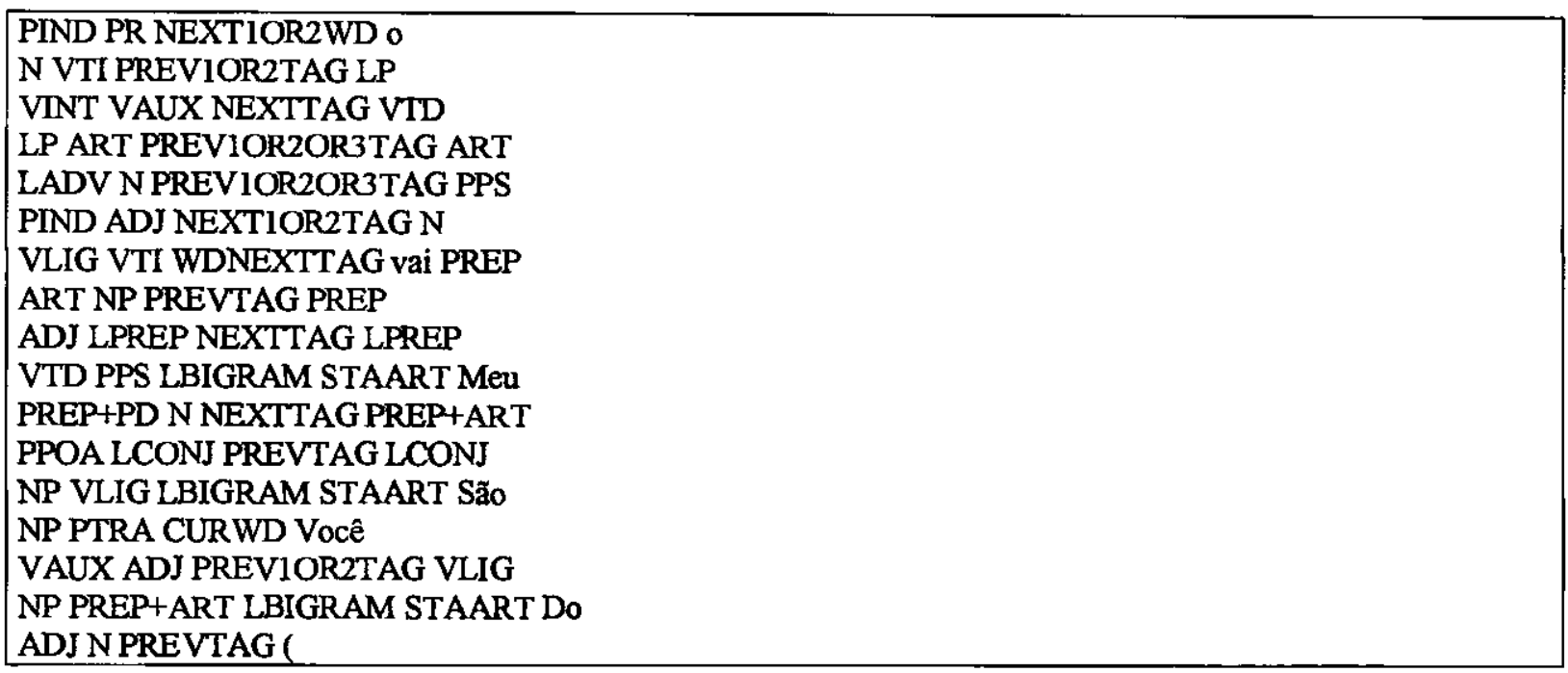

\section{C3 Regras do etiquetador $X$}

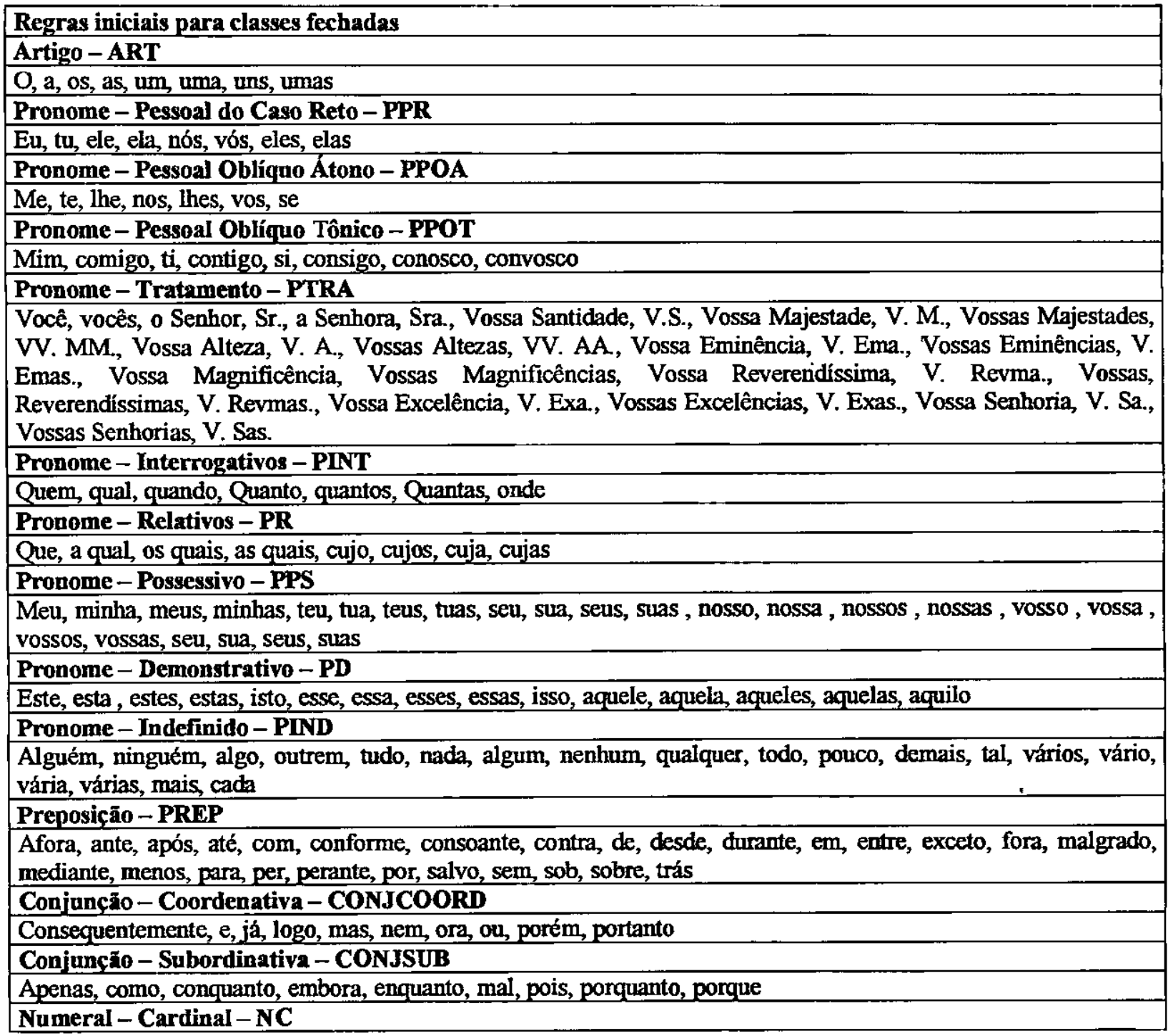


Bilhão, bilhões, catorze, cem, cento, cinco, cinqüenta, dez, dezenove, dezesseis, dezessete, dezoito, dois, doze, duas, duzentas, duzentos, mil, milhão, milhões, nove, novecentas, novecentos, noventa, oitenta, oito, oitocentas, oitocentos, onze, Quarenta, quatorze, quatro, quatrocentas, Quatrocentos, quinhentas, quinhentos, Quinze, seis, seiscentas, seiscentos, sessenta, sete, setecentas, seteccntos, setenta, três, treze, trezentas, trezentos, trilhão, trilhões, trinta, vinte, zero

\section{Numeral - Ordinal - ORD}

As palavras em azul podem ser numeral ordinal ou fracionário - serão fracionários quando vierem com outro número antes.

Duodécimo, duodécimos, enésima, enésimas, enésimo, enésimos, nongentésimo, nongentésimos, primeira, primeiras, primeiro, primeiros, segunda, segundas, segundo, segundos, setuagésima, setuagésimas, setuagésimo, setuagésimos, terceira, terceiras, terceiro, Terceiros, undécimo, undécimos, bilionésima. bilionésimas, bilionésimo, bilionésimos, centésima, centésimas, centésimo, centésimos, décima, décimas, décimo. décimos. ducentésima, ducentésimas, ducentésimo, ducentésimos, milésima, milésimas, milésimo, milésimos, milionésima, milionésimas, milionésimo, milionésimos, nona, nonagésima, nonagésimas, nonagésimo, nonagésimos, nonas, noningentésima, noningentésimas, noningentésimo, noningentésimos, nono, nonos. octingentésima, octingentésimas, octingentésimo. octingentésimos, octogésima, octogésimas, octogésimo, octogésimos, oitava, oitavas, oitavo, oitavos. quadragésima. Quadragésimas. quadragésimo. quadragésimos. quadringentésima. quadringentésimas, quadringentésimo. quadringentésimos, quarta, quartas, quarto, quartos, qüingentésima, qüingentésimas, qüingentésimo, qüingentésimos, qüinquagésima. qüinquagésimas, qüinquagésimo, qüinquagésimos, Quinta, quintas, quinto, quintos, septuagésima, septuagésimas, septuagésimo, septuagésimos, sétima, sétimas, sétimo, sétimos, setingentésima, setingentésimas, setingentésimo, setingentésimos, sexagésima, sexagésimas, sexagésimo, sexagésimos, sexcentésima, sexcentésimas, sexcentésimo, sexcentésimos, sexta, sextas, sexto, sextos, trecentésima, trecentésimas, trecentésimo, trecentésimos, trigésima, trigésimas, trigésimo, trigésimos, vigésima. vigésimas, vigésimo, vigésimos

\section{Numeral - Outros Números - NO}

Ambos, cêntuplo, décuplo, duodécuplo, dupla, duplas, dúplex, dúplice, dúplices, duplo, duplos, meia, meias, meio, meios, nônuplo, óctuplo, quádruplo, quíntuplo, sétuplo, sêxtuplo, terça, terças, terço, Terços, triplo, undécuplo

\section{Interjeição - I}

Estas exepressões são interjeição quando aparecem exatamente desta forma seguidas de exclamação.

Ah, Ai De Mim, Ai, Alô, Alto Lá, Alto, Apoiado, Arreda, Atenção, Avante, Ave, Basta, Bico, Bis, Boa, Bravo, Calma, Céus, Chi, Chi, Coragem, Cuidado, Deus, Devagar, Diabo, Eh, Eia, Fora, Francamente, Hem, Hum, Hurra , Ih, Jesus(I), Meu Deus, Morra(I), Muito Bem, Ó, Ô, Oba, Oh, Olá, Olha Lá, Opa, Ora Bolas, Oxalá, Psit, Psiu, Puxa, Que Nada, Quê, Salve, Silêncio, Socorro, Ué, Uh, Ui, Upa, Valha-Me, Vamos, Viva

\begin{tabular}{|c|c|}
\hline \multicolumn{2}{|l|}{ Regras iniciais para classes abertas } \\
\hline \multicolumn{2}{|c|}{ Advérbio - ADV } \\
\hline \multicolumn{2}{|c|}{$\begin{array}{l}\text { não, muito, alto, baixo, rápido, fundo, súbito, bem, depressa, devagar, ainda, agora, acima, abaixo, ligeiro, ligeira, } \\
\text { sobremaneira, lá, acolá, amanhã, amiúde, longe, hoje, sempre, semelhante, diante, bastante, avante, doravante, } \\
\text { defronte, distante, forte, leve, idem, ibidem, ontem, anteontem, também, além, aquém, sim, tão, então, adrede, } \\
\text { talvez, grátis, depois, bis, jamais, ademais, antes, dantes, entrementes, algures, nenhures, alhures, aliás, deveras, } \\
\text { arredor, derredor, porventura, sequer, assim, enfim, donde, mesmo, debaixo, assaz, tanto, quase, dentro, adentro, } \\
\text { aí, acaso, afinal, meio, permeio, ali, aonde, aqui, cá, sobremodo, cedo, cedinho, debalde, decerto, detrás, } \\
\text { tampouco, inda, quão }\end{array}$} \\
\hline mente, inda & $\begin{array}{l}\text { ADV - as palavras que terminam como os sufixos da lista a } \\
\text { esquerda }\end{array}$ \\
\hline \multicolumn{2}{|l|}{ Substantivo - Comum - N } \\
\hline $\begin{array}{l}\text { mento, dor, dora, ança, ada, anda, fobia, cia, dia, } \\
\text { grafia, fia, gia, lia, mia, nia, pia, tria, sai, tia, quia, } \\
\text { xia, zia, ela, ola, ula, ama, oma, ura, eza, ice, dade, } \\
\text { ase, ese , ise, ose, sse, ite, ol, gem, im, men, ção, } \\
\text { ções, grafo, ifo, lho, eio, cópio, ismo, metro, } \\
\text { mento, dez }\end{array}$ & $\begin{array}{l}\mathrm{N} \text { - as palavras que terminam com os sufixos da lista a } \\
\text { esquerda. }\end{array}$ \\
\hline \multicolumn{2}{|l|}{ Adjetivo - N } \\
\hline $\begin{array}{l}\text { ivo, iva, ente, ais, ido, idos, forme, al, ável, ível, } \\
\text { úvel, ico, esco, diço, ceo, neo, reo, seo, teo, veo, } \\
\text { fero, gero, voro, oso, lento, íssimo, érrimo }\end{array}$ & $\begin{array}{l}\text { ADJ - as palavras que terminam com os sufixos da lista a } \\
\text { esquerda. }\end{array}$ \\
\hline
\end{tabular}




\section{Outras Regras iniciais}

\section{Paravra}

Etiqueta

Ítem de Lista $=\mathbf{~} \mathbf{L}$

Sạ̃o considerados índices as letras e números que vem seguidos de ) ou -. Note que sempre há espaço depois de ),

Exemplos:

a)

1)

$1-$

ii)

Palavra Denotativa - PDEN

Eis, só, somente, exclusive, senão, inclusive, sobretudo

Locuções Adverbiais - LADV 
à baila, à bala, a bandeiras despregadas, a bem dizer, a bordo, a cada passo, a capucha, a carga cerrada, a cavalinhas, a cavaleiro, a cavalo, a certa altura, a chucha calada, a chucha caladinha, a colação, a compita, a contento, a desora, a deus e a ventura, a deus misericórdia, à direita, à distância, a domicílio, a duras penas, a eito, à entrada, a escala vista, a escuta, a esmo, à espera, a espora fita, à esquerda, a facadas, a falsa fé, a farta, a fio, a fito, a flux, à francesa, à frente, a frio, a fundo, a furtapasso, a furta-passo, a furto, a galope, a gosto, a granel, ainda assim, ainda bem, ainda por cima, a lanço, a lápis, alguma vez, algumas vezes, a limpo, a lufa-lufa, a maior parte das vezes, a maioria da vezes, a mais, a mal, a mancheias, amanhã de manhã, amanhãde tarde, à mão, a mão tenente, a martelo, a máquina, a mata cavalos, a medo, a menos, à minha custa, à minha disposição, à minha espera, à minha vista, à minha volta, a monte, a nado, à noite, à noitinha, à nossa custa, à nossa disposição, à nossa espera, à nossa vista, à nossa volta, à nossa vontade, antes de ontem, antes pelo contrário, ao acaso, ao atar das feridas, ao certo, ao contrário, ao desbarato, ao deus dará, ao fim e ao cabo, ao fundo, ao invés, ao lado, ao largo, ao léu, a olhos vistos, ao longe, ao longo, ao menos, ao mesmo tempo, ao meu lado, ao nosso lado, ao pé, ao pôrdo-sol, ao redor, ao revés, aos poucos, ao seu lado, ao singelo, ao teu lado, ao todo, ao viés, ao vivo, a ouro e fio, à parte, a pau, a paulada, a pauladas, a pé, a pé quedo, a pelo, a picareta, a pique, a pleno, a pontapés, a postos, a pouco e pouco, a pressa, à primeira vista, a princípio, a proposito, a própria, a recado, a rédea solta, a regalada, a reio, a revelia, a revezes, a rigor, a risca, a rodo, a sabendas, a sabor, à saida, às apalpadelas, às avemarias, às avemarias, às avessas, às bandeiras despregadas, às cavaleiras, às cegas, às claras, às costas, às direitas, a seco, a sério, às escondidas, às escuras, às fincas, às furtadas, a meu talante, a seu talante, as mais das vezes, as mais vezes, às mancheias, às mãos ambas, às mãos lavadas, a socapa, a solapa, a sorrelfa, a sós, às pauladas, às pressas, às rebatinhas, às singelas, assim assim, assim como, assim como assim, à sua đisposiçâo, à sua espera, à sua vista, à sua volta, à sua vontade, a súbitas, a surdina, às vezes, às tontas, à tarde, à tardinha, até certo ponto, a tempo, a tempo e a hora, a tempo e a horas, a tempo e hora, até pelo contrário, a tinta, à toa, à toda, a toda a hora, a toda hora, a todo o pano, a todo o pulso, à tona, a torto e a direito, a trecheio, a trecho, a tripa forra, a trouxe-mouxe, à tua custa, à tua disposição, à tua espera, à tua vista, à tua volta, à tua vontade, à uma, à uma hora, a unha de cavalo, a unhas de cavalo, a vau, à vela, a ventura, a vezes, à vista, a voga arrancada, à volta, à vontade, a vozes, bastante devagar, bem assim, bem longe da cidade, bem tarde, cada vez mais, cada vez menos, certas vezes, com amor, com calma, com certeza, com desconfiança, com desgosto, com exatidão, com gosto, com jeito, com medo, com muito jeito, com pressa, como tal, daqui a bocado, daqui a pouco, daqui a um bocadinho, daqui a um bocado, de acordo, de afogadilho, de alguma forma, de alto a baixo, de assento, de beijado, de bom grado, de cabo a rabo, de cada vez, de caso pensado, de cara, de certa maneira, de certo, de certo modo, de chapa, de chofre, de cima, de cima a baixo, de cima em baixo, de cor, de costas, de cotio, de dentro, de dia, de enviés, de esguelha, de espaço, de estudo, de fato, de fio a pavio, de fora, de fora parte, de forma alguma, de forma nenhuma, de frente, de golpe, de gosto, de graça, de improviso, de indústria, de jeito algum, de jeito nenhum, de joelhos, de lado, de largo, de leve, de longe, de longe a longe, de longe em longe, de má vontade, de maneira alguma, de maneira nenhuma, de manhã de mansinho, de mão beijada, de mão em mão, de menos, de modo algum, de modo geral, de modo nenhum, de molde, de momento a momento, de muito, de nenhum modo, de noite, de norte a sul, de novo, dentro em breve, dentro em pouco, de oitiva, de onde em onde, de ouvida, de palanques, de parte a parte, de passagem, de perto, de pé, de pé atrás, depois de amanhã, de ponto em branco, de pouco, de preferência, de presente, de presto, de primeiro, de propósito, de qualquer jeito, de qualquer forma, de qualquer maneira, de qualquer modo, de quando em quando, de quando em vez, de raiz, de regra, de relance, de repelão, de repente, de resto, de revés, de rojo, de roldão, de rota batida, de salto, desde já, de segunda mão, de sobre, de sobreaviso, de sobrerrolda, de sobre-rolda, de sobressalto, de soslaio, de súbito, de tarde, de tempos a tempos, de tempos em tempos, de toda a parte, de toda forma, de toda maneira, de toda parte, de todo, de trás, de través, de tropel, de uma maneira geral, de uma vez, de um golpe, de um tiro, de verdade, de vereda, de vez, de vez em quando, de vez em vez, de vista, de viva voz, de volta, dia a dia, dia-a-dia, diversas vezes, do mesmo modo, do meu lado, do nosso lado, do seu lado, dos pés à cabeça, do teu lado, dum modo geral, duma maneira geral, duma vez, eis senão quando, em absoluto, em barda, em breve, em caixa, em caminho, em certa medida, em cheio, em cima, em conjunto, em conta, em contacto, em demasia, em especial, em excesso, em frente, em geral, em hipótese alguma, em mão, em média, em meu lugar, em nosso lugar, em parte, em particular, em pé, em ponto, em primeira mão, em princípio, em público, em que pé, em que pé que, em redor, em regra, em revés, em roda, em seguida, em segunda mão, em seu lugar, em série, em silêncio, em som de guerra, em suma, em surdina, em tempo, em termos, em teu lugar, em toda a parte, em toda a volta, em través, em vão, em verdade, em via de regra, em vista, em volta, entre a cruzz e a caldeirinha, entre lusco e fusco, fora de mão, fora parte, frente a frente, graças a deus, grosso modo, gota a gota, hoje de noite, hoje em dia, inda agora, inda bem, inda por cima, inda assim, inúmeras vezes, lá dentro, lado a lado, lá em cima, lá embaixo, lá fora, mais cedo ou mais tarde, mais e mais, mais ou menos, menos mal, mercê de deus, muita vez, muitas das vezes, muitas vezes, muito cedo, muito rapidamente, muito tarde da noite, na certa, na medida do possivel, na mesma, não raro, nas imediações, na verdade, nem mais nem menos, nem por isso, nem sempre, nem tanto, nenhuma vez, nesse caso, nesse comenos, nesse entremeio, nesse meio tempo, no conjunto, no fim, no fundo, no gênero, no geral, noite e dia, num átimo, nunca mais, nunca por nunca, o mais das vezes, outra vez, outras vezes, outro dia, outro tanto, p-a-pá santa justa, para a frente, para a semana, para baixo, para cima, para cima e para baixo, para dentro, para diante, para fora, para frente, para já, para lá, para menos, para o ano, para o lado, para o nosso lado, para o seu lado, para o teu lado, para onde, para todo o sempre, para trás, parte fora, passo a passo, pela frente, pela manhã, pela rama, pelo contrário, pelo meio, por acaso, por agora, por ali, por aqui, por artes de berlinques e berloques, por atacado, por baixo, por bem, por certo, por cima, por completo, por conta, por dá cá aquela palha, por dentro, por detrás, por enquanto, por fora, por força, por fim, por gosto, por hoje, porr] 
a fim de que, agora que, ainda que, além de que, além disso, à medida que, a menos que, a não ser que, antes que, ao mesmo tempo, ao mesmo tempo que, ao passo que, apesar de que, à proporção que, assim como, assim que, até que, bem como, bem que, cada vez que, com tal que, como que, como quer que, como se, contanto que, dado que, daí que, da mesma maneira que, de cada vez que, de forma que, de jeito que, de maneira que, de modo que, de molde que, depois que, de que, desde a hora que, desde o momento que, desde que, de sorte que, dessa forma, de tal modo que, de tal sorte que, do mesmo modo que, do que, eis que, eis senão que, em vista disso, enquanto que, entretanto que, exceto se, inda que, já que, logo que, mas ainda, mas também, mesmo que, muito embora, nada obstante, na medida em que, não apenas, não obstante, não só, não somente, nem que, no caso que, no entanto, para que, pois que, por conseguinte, por conseqüência, por isso, por isso que, por mais que, por maior que, por melhor que, por menor que, por menos que, por muito que, por outro lado, por pior que, por pouco que, por que, por sua vez, posto que, primeiro que, quanto maior, quanto mais...mais, quanto mais...menos, quanto melhor, quanto menor, quanto menos...mais, quanto menos...menos, quanto pior, que nem, salvo se, se bem que, sem que, sempre que, senão ainda, suposto que, tal como, tal qual, tanto assim que, tanto como, tanto mais, tanto menos, tanto quanto, tanto que, tăo logo que, todas as vezes que, uma vez que, visto como, visto que

\section{Locucões Denotativas - LDEN}

afinal de contas, além disso, além do que, a saber, com efeito, de mais a mais, diante disso, em conclusão, em resumo, em todo caso, em todo o caso, em virtude disso, em vista disso, espera aí, espera lá, mesmo assim, na verdade, não só, nesse ínterim, neste comenos, no fim das contas, ora bem, ou antes, ou seja, ou melhor, pelo contrário, pelo visto, pois bem, pois claro, por exemplo, por fim, por outro lado, por um lado, quer dizer, salvo erro Locuçöes Prepositivas - LPREP

abaixo de, à borda de, à busca de, a caminho de, a cargo de, acerca de, acima de, a coberto de, à conta de, à custa de, a despeito de, adiante de, à direita de, à disposição de, à đistância de, à espera de, à esquerda de, à exceção de, a favor de, a fim de, à flor de, à força de, à frente de, além de, a mandado de, a mando de, à maneira de, à margem de, à mercê de, a nível de, antes de, ao abrigo de, ao através de, ao cabo de, ao contrário de, ao encontro de, ao fim de, ao invés de, ao lado de, ao largo de, ao longo de, ao mandado de, ao mando de, ao modo de, ao nível de, ao par de, ao pé de, ao peso de, ao redor de, ao sabor de, aos cuidados de, ao termo de, a par de, a partir de, apesar de, a peso de, a poder de, a ponto de, à procura de, a propósito de, aquém de, a respeito de, à roda de, às custas de, às escondidas de, à sombra de, até a, à tona de, atrás de, através de, a ver com, à vista de, à volta com, à volta de, cerca de, com a intenção de, com base em, com o intuito de, com o propósito de, com relação a, com respeito a, com risco de, com vista a, com vistas a, da parte de, de acordo com, debaixo de, de conformidade com, de cima de, de dentro de, de encontro a, de fora de, de forma a, defronte de, de jeito a, de maneira a, de mistura com, de modo a, de molde a, dentro de, dentro em, de par com, depois de, de trás de, devido a, diante de, do gênero de, do lado de, em apoio a, em apoio de, em atenção a, embaixo de, em benefício de, em busca de, em caso de, em cima de, em comparação com, em conformidade com, em contraste com, em decorrência de, em face a, em face de, em favor de, em forma de, em frente a, em frente de, em função de, em lugar de, em meio a, em meio de, em oposição a, em prol de, em que pese a, em redor de, em relação a, em roda de, em termos de, em tomo a, em tomo de, em troca de, em vez de, em via de, em vias de, em virtude de, em vista de, em volta de, face a, fora de, graças a, junto a, junto com, junto de, longe de, mercê de, na base de, na conformidade de, na conta de, não obstante, no alto de, no caso de, no centro de', no fim de, no fundo de, no gênero de, no interior de, no meio de, nos arredores de, no sentido de, para além de, para baixo de, para cima de, para cá de, para cima de, para com, para debaixo de, para dentro de, para fora de, para lá de, para o lado de, para trás de, pelo meio de, perto de, por baixo de, por causa de, por cima de, por conselho de, por conta de, por culpa de, por debaixo de, por dentro de, por detrás de, por diante de, por entre, por fora de, por força de, por mandado de, por mando de, por meio de, por menos de, por motivo de, por ocasião de, por trás de, por via de, por volta de, por vontade de, quanto a, relativamente a, respeito a, sem embargo de, sob pena de, um bocadinho de

Locuções Pronominais- LP

a gente, alguma coisa, aquele outro, cada qual, cada um, cada uma, comigo mesma, comigo mesmo, comigo própria, comigo próprio, conosco mesmas, conosco mesmos, consigo mesma, consigo mesmas, consigo mesmos, contigo mesma, contigo mesmo, ela mesma, elas mesmas, ela própria, elas próprias, ele mesmo, eles mesmos, ele próprio, eles próprios, eu mesma, eu mesmo, eu própria, eu próprio, fosse o que fosse, fossem quais fossem, fosse qual fosse, fosse quem fosse, mim mesma, mim mesmo, mim própria, mim próprio, nós mesmas, nós mesmos, nós próprias, nós próprios, o mais, o meu, o qual, o que, o que quer que, o que quer que seja, os quais, onde quer que, quaisquer que sejam, qualquer um, qualquer que fosse, qualquer que seja, quando quer que, quanto quer que, quem quer, quem quer que, quem quer que seja, seja de que maneira for, seja onde for, seja o que for, seja qual for, seja quem for, sejam quais forem, si mesma, si mesmas, si mesmo, si mesmos, si própria, si próprias, si próprio, si próprios, tal e qual, tal e tal, ti mesma, ti mesmo, ti própria, ti próprio, todo aquele, todo aquele que, tu mesma, tu mesmo, tu própria, tu próprio, um ou outro, você mesma, você mesmo, vocês mesmas, vocês mesmos, você própria, vocês próprias, você próprio, vocês próprios 
Residual - RES

Todas as palavras que não tiverem sido etiquetadas até agora serão etiquetadas de acordo com a etiqueta que estiver associada a ela no léxico. Caso a palavra não conste no léxico serão utilizados os léxicos de sufixos e o de prefixos, na tentativa de formar uma palavra que faça parte do léxico. Se ainda assim a palavra for uma palavra desconhecida - em caso de iniciar com letra minúscula será etiquetada como RES e em caso de iniciar com letra maiúscula será etiquetada como NP.

\begin{tabular}{|c|c|c|}
\hline \multicolumn{3}{|l|}{ Lista de regras contextuais } \\
\hline Mude a etiqueta de $X$ para $Y$ & Se a palavra atual é $W$ & E a condição $Z$ acontece \\
\hline ART - PPOA & $\mathrm{O}, \mathrm{a}, \mathrm{os}$, as & Se a etiqueta+1/etiqueta-1 é $\mathrm{V}^{*}$ \\
\hline ART - PD & $\mathrm{O}, \mathrm{a}, \mathrm{os}$, as & Se a palavratl é que \\
\hline ART $-\mathbf{N}$ & $\mathrm{O}, \mathrm{a}, \mathrm{os}$, as, um & Se a etiqueta-1 for ART ou PPS \\
\hline ART - PREP & & Se a etiqueta-1 for VTI \\
\hline ART - PIND & Um, uma, uns, umas & $\begin{array}{l}\text { Se a palavra+l ou palavra }+2 \text { é que. Ou se } \\
\text { etiqueta }+1 \text { é ... ou . ou ! ou ?. }\end{array}$ \\
\hline & Um, uma, uns, umas & Ou se a etiqueta+1 é $V^{*}$ \\
\hline & Uns, umas & Ou se a palavra +1 é quaisquer. \\
\hline ART - NC & Um, uma & $\begin{array}{l}\text { Se a palavra+1 é e ou a palavrat } 1 \text { é mais } \\
\text { ou a palavra+l é só ou a palavra+l é menos } \\
\text { ou a palavra+1 é vezes. Ou se palavra+1 é } \\
\text { dividido e a palavra+ } 2 \text { é por. }\end{array}$ \\
\hline PPOA - PAPASS & $\mathrm{Se}$ & $\begin{array}{l}\text { Se a etiqueta+1 ou a etiqueta-1 é VTD ou } \\
\text { VBI }\end{array}$ \\
\hline PPOA - CONISUB & $\mathrm{Se}$ & $\begin{array}{l}\text { Se a etiqueta-1 era ... ou . ou ! ou ? ou } \\
\text { (início de período). }\end{array}$ \\
\hline PINT - PR & Quem & $\begin{array}{l}\text { Se a etiqueta-1 é pronome pessoal ou PREP } \\
\text { ou } \mathrm{V}^{*}\end{array}$ \\
\hline & & 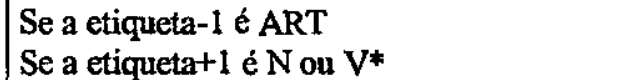 \\
\hline & Quanto & $\begin{array}{l}\text { Se a palavra-1 é tudo ou toda ou toda ou } \\
\text { todos ou todas. }\end{array}$ \\
\hline & Onde & Se a etiqueta-1 é $N$ ou PREP \\
\hline PINT - PIND & $\begin{array}{l}\text { Qual } \\
\text { Quanto }\end{array}$ & $\begin{array}{l}\text { Se a etiqueta+l é VAUX ou VTD ou VTI } \\
\text { ou VBI ou VINT e a frase termina com ?. } \\
\text { Se a palavra+l é mais ou se a palavra+1 é } \\
\text { menos. Ou se etiqueta-1 é } V^{*} \text { e a } \\
\text { etiqueta+l é } V^{*} \text {. }\end{array}$ \\
\hline PINT - CONJSUB & Qual & $\begin{array}{l}\text { Se a etiquetat } 1 \text { é } \mathrm{N} \text { e a etiqueta- } 1 \text { é, e a } \\
\text { etiqueta+ } 2 \text { ou etiqueta+ } 3 \text { é, (faz parte de } \\
\text { um aposto) }\end{array}$ \\
\hline & Quando & $\begin{array}{l}\text { Se a etiqueta-1 era ... ou . ou ! ou ? (início } \\
\text { de período) ou , (início de oração } \\
\text { subordinada) }\end{array}$ \\
\hline PINT - ADJ & Qual & $\begin{array}{l}\text { Se a etiqueta+l é N e o última palavra do } \\
\text { periodo não é uma? (frases declarativas) }\end{array}$ \\
\hline PINT - ADV & Quanto & $\begin{array}{l}\text { Quando o periodo termina com ! (períodos } \\
\text { exclamativas). } \\
\text { Ou se a palavra+1 é custa }\end{array}$ \\
\hline PR-PINT & Que & $\begin{array}{l}\text { Se é a primeira palavra da frase e a frase } \\
\text { termina com? }\end{array}$ \\
\hline PR - PIND & Que & $\begin{array}{l}\text { Se a etiqueta+l é } \mathrm{N} \text { e a frase termina com. } \\
\text { ou! }\end{array}$ \\
\hline PR - CONJCOORD & Que & $\begin{array}{l}\text { Se a palavra-1 é uma das conjungaçóes dos } \\
\text { verbos dizer falar afirmar declarar iurar }\end{array}$ \\
\hline $\begin{array}{l}\text { PR - CONJSUB } \\
\text { PPS - ADJ }\end{array}$ & $\begin{array}{l}\text { Que } \\
\text { Meu, minha, meus, minhas, teu } \\
\text { tua, teus, tuas, seu, sua, seus, }\end{array}$ & $\begin{array}{l}\text { Se a etiqueta-1 é, } \\
\text { Se a etiqueta+1 é N }\end{array}$ \\
\hline
\end{tabular}




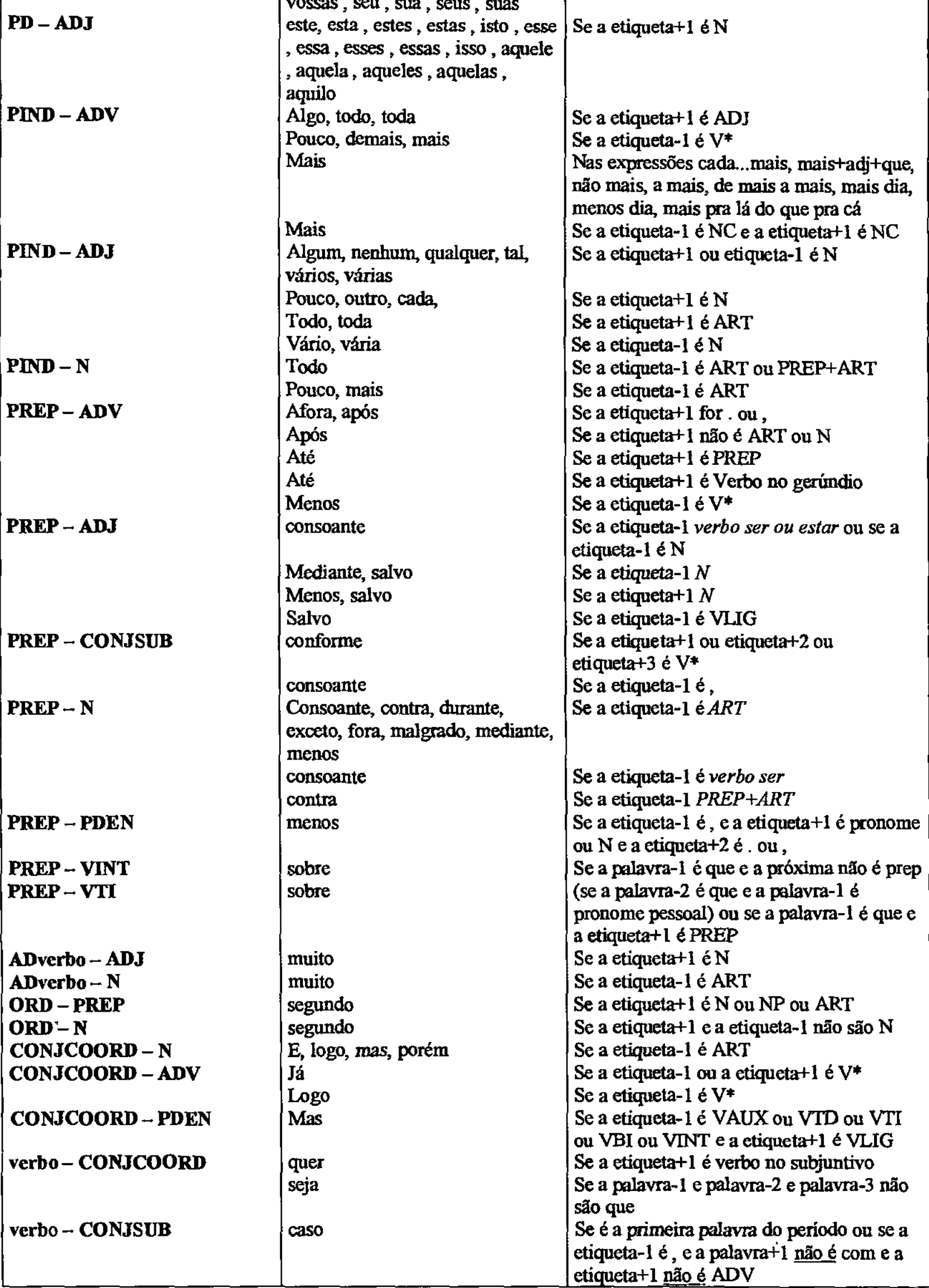




\begin{tabular}{|c|c|c|}
\hline $\begin{array}{l}\text { CONJSUB - PREP } \\
\text { CONJSUB - CONJCOORD }\end{array}$ & $\begin{array}{l}\text { caso } \\
\text { mal } \\
\text { como } \\
\text { como } \\
\text { como }\end{array}$ & $\begin{array}{l}\text { Se a etiqueta-1 é ART } \\
\text { Se a etiqueta-1 é ART } \\
\text { Se a palavra-1 é eu. Ou se não nenhuma } \\
\text { outra palavra do periodo está etiquetada } \\
\text { como verbo. } \\
\text { Se o periodo termina com ? ou ! } \\
\text { Se a palavra-1 é uma das conjugacões de: } \\
\text { Conte, diga, descreva, fale (interrogação } \\
\text { indireta) } \\
\text { Se a etiqueta+1 é ART e a etiqueta+2 é N } \\
\text { Se a etiqueta-1 é e a etiqueta+l é,. Ou se } \\
\text { a etiqueta-1 é; }\end{array}$ \\
\hline \multirow[t]{5}{*}{$\mathbf{N}-\mathbf{A} \mathbf{D J}$} & Qualquer que seja a palavra & Se a palavra-1 é muito ou tão ou bem. \\
\hline & & $\begin{array}{l}\text { Se a palavra-1 é mais e a palavra a ser } \\
\text { etiquetada estiver no singular. }\end{array}$ \\
\hline & & Se a etiqueta+1 ou se a etiqueta- 1 é $\mathrm{N}$. \\
\hline & & $\begin{array}{l}\text { Se as etiqueta+l é VLIG e a etiqueta+2 é } \\
\text { ART. (Doce é a pera) }\end{array}$ \\
\hline & & $\begin{array}{l}\text { Se a etiqueta-1 é VTD+PPOA ou PPOA ou } \\
\text { VTD ou VTI + PPOA. }\end{array}$ \\
\hline \multirow[t]{3}{*}{$\mathbf{N}-\mathbf{V T D}$} & $\begin{array}{l}\text { Palavras que apresentam os } \\
\text { sufixos de verbo }{ }^{29} \text { - a, ado, ais, } \\
\text { am, amos, ando, ar, ara, aram, } \\
\text { áramos, aras, ardes, ardes, áreis, } \\
\text { arem, ares, armos, as, asse, ásseis, } \\
\text { assem, ássemos, asses, aste, astes, } \\
\text { ava, avam, ávamos, avas, áveis, e, } \\
\text { ei, em, emos, endo, er, era, eram, } \\
\text { éramos, eras, erdes, ereis, erem, } \\
\text { eres, ermos, es, esse, ésseis, } \\
\text { essem, éssemos, esses, este, estes, } \\
\text { i, ia, iam, íamos, ias, ido, ieis, } \\
\text { ieis, imos, imos, indo, ir, ira, } \\
\text { iram, iramos, iras, irdes, ireis, } \\
\text { irem, ires, irmos, is, isse, isseis, } \\
\text { issem, issemos, isses, iste, istes, } \\
\text { iu, o, ou, rá, ram, rão, rás, rei, } \\
\text { reis, remos, ria, riam, riamos, } \\
\text { rias, rieis }\end{array}$ & Se a etiqueta-1 ou a etiqueta+l é PPOA. \\
\hline & * & Se a etiqueta+1 é ART e a etiqueta+ 2 é $N$. \\
\hline & $\begin{array}{l}\text { Palavras que apresentam os } \\
\text { sufixos de verbo: } \\
\text { ado, ido }\end{array}$ & Se a etiqueta-1 é VAUX (voz passiva) \\
\hline \multirow[t]{2}{*}{$\mathbf{N}-\mathbf{V L I G}$} & $*$ & Se a etiqueta+1 é ADJ \\
\hline & $*$ & Se a etiqueta+1 é PREP \\
\hline $\mathbf{N}$-VAUX & * & $\begin{array}{l}\text { Se a etiqueta+1 é V e a palavra+1 tem os } \\
\text { sufixos:ando, endo, indo, ado, ido }\end{array}$ \\
\hline $\mathbf{N}-\mathbf{V T I}$ & * & $\begin{array}{l}\text { Se a etiqueta }+1 \text { ou etiqueta }+2 \text { é PREP ou } \\
\text { PREP+ART }\end{array}$ \\
\hline N-VINT & * & Se a etiqueta+ I é ADV \\
\hline \multirow[t]{3}{*}{$\mathbf{N}-\mathbf{V B I}$} & & $\begin{array}{l}\text { verbos dar, devolver, entregar, mostrar, } \\
\text { oferecer, pedir,enviar }\end{array}$ \\
\hline & $*$ & $\begin{array}{l}\text { se o verbo for seguido de PPOA e a } \\
\text { etiqueta+1 é PREP (absolvê-lo de...) }\end{array}$ \\
\hline & $*$ & $\begin{array}{l}\text { Se a etiqueta+1 é N ou PREP ou } \\
\text { PREP+ART (acertou Pedro no braço) }\end{array}$ \\
\hline
\end{tabular}

${ }^{29} \mathrm{O}$ símbolo * será utilizado a partir deste ponto para indicar as palavras que terminem com este mesmo sufixo 



\section{APÊNDICE D - INCORPORA}

O InCorpora é um software que intregra 27 ferramentas - implementadas em ANSI C responsáveis por preparar corpus e textos para treinamento e etiquetagem, gerar estatísticas e listas de dados que auxiliem na avaliação dos métodos de etiquetagem, combinar as saídas dos etiquetadores utilizando os métodos descritos no Capítulo 5 e avaliar os resultados da combinaçāo. O módulo incorpora nōo possui ainda uma interface gráfica fazendo com que 0 acesso às ferramentos se dê através de linhos de comando. Cada uma das ferramentas é detalhada abaixo.

\section{D1 CorpusTT}

Entrada: corpus etiquetado no formato palavra_etiqueta com um periodo por linha Saida: corpus etiquetado no formato palavraTABBetiqueta com uma palavra por linha Finalidade: colocar um corpus de treinamento no formato pedido pelo etiquetador TreeTagger Linha de comando: CorpusTT <corpus1 ><corpus2> Onde:

$T A B$ é tabulação corpus 1 é o arquivo de entrada corpus 2 é o arquivo de saída

\section{D2 CorpusTBL}

Entrada: corpus etiquetado no formato palavra_etiqueta com um período por linha Saida: corpus etiquetado no formato palavra/etiqueta com um periodo por linha Finalidade: colocar um corpus de treinamento no formato pedido pelo etiquetador TBL Linha de comando: CorpusTBL < corpus $1><$ corpus $2>$ 
Onde:

corpus 1 é o arquivo de entrada

corpus 2 é o arquivo de saída

\section{D3 Lexify}

Entrada: corpus etiquetado no formato palavra etiqueta com um período por linha

Saída: corpus etiquetado no formato palavra@etiqueta/outraet $t_{1} / . /$ outraet $_{n}$ com um período por linha finalizado por //

Finalidade: colocar um corpus de treinamento no formato pedido pelo etiquetador neural elástico

\section{Linha de comando: Lexify <corpus 1><corpus $2>$}

Onde:

Outraet $_{i} \operatorname{com} \mathrm{i}=1 \ldots \mathrm{n}$ são as n outras etiquetas possíveis para aquela palavra segundo um léxico corpusI é o arquivo de entrada

corpus 2 é o arquivo de saída

\section{D4 Lexicon}

Entrada: corpus etiquetado no formato palavra etiqueta com um período por linha

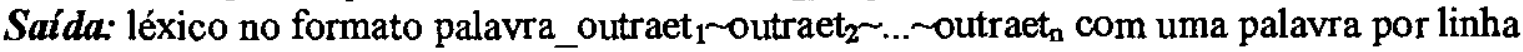

Finalidade: gerar um léxico a partir do corpus de treinamento para ser utilizado pela ferramenta Lexify e pelo PoSiTagger

Linha de comando: Lexicon <corpus1><léxico>

Onde:

outraet $_{i} \operatorname{com} \mathrm{i}=1$...n são as $\mathrm{n}$ etiquetas possíveis para uma dada palavra

corpus 1 é o arquivo de entrada

léxico é o arquivo de saída

\section{D5 TTLexicon}

Entrada: corpus etiquetado no formato palavra etiqueta com um periodo por linha

Saida: léxico no formato palavraTABoutraet $t_{1}$ TAB-TABoutraet ${ }_{2}$ TAB-...TABoutraet ${ }_{n}$

Finalidade: gerar um léxico a partir do corpus de treinamento para ser utilizado no treinamento do etiquetador TreeTagger

Linha de comando: TTLexicon <corpus 1> <léxico>

Onde:

$T A B$ é tabulação

outraet $_{i} \operatorname{com} \mathrm{i}=1$...n são as-n etiquetas possiveis para uma dada palavra

corpus1 é o arquivo de entrada

léxico é o arquivo de saída

\section{D6 TokenizerTT}

Entrada: texto não etiquetado

Saída: texto não etiquetado com uma palavra/símbolo por linha

Finalidade: colocar um texto a ser etiquetado no formato exigido pelo etiquetador TreeTagger

Linha de comando: TokenizerTT <textol $><$ texto $2>$

Onde:

textol é o arquivo de entrada

texto 2 é o arquivo de saida 


\section{D7 Tokenizer}

Entrada: texto não etiquetado

Saída: texto não etiquetado com as palavras separadas dos símbolos por espaço em branco, no formato um periodo por linha

Finalidade: colocar um texto a ser etiquetado no formato exigido pelo etiquetador TBL e MXPOST

Linha de comando: Tokenizer $<$ texto1 $><$ texto2>

Onde:

textol é o arquivo de entrada

texto2 é o arquivo de saída

\section{D8 Ambiguous}

Entrada: texto não etiquetado no formato um período por linha

Saida: apresenta na tela o número de palavras ambíguas

Finalidade: calcular o número de palavras ambíguas presentes em um texto

Linha de comando: ambiguous $\langle$ léxico $>\langle$ texto $>$

Onde:

texto é o texto para o qual deve ser calculado o número de palavras ambíguas

léxico é o léxico que servirá de base para que o programa decida se uma palavra é ou não ambigua

\section{D9 Diff}

\section{Entrada:}

1) corpus de treinamento etiquetado no formato palavra_etiqueta com um período por linha

2) texto etiquetado no formato palavra etiqueta com um período por linha

Saída: arquivo com o número de palavras desconhecidas e a lista destas palavras

Finalidade: verificar o número de palavras desconhecidas presentes em um texto

Linha de comando: diff <corpustrain $><$ texto $><$ arquivosaída $>$

Onde:

corpustrain é o corpus de treinamento que será tomado como base para saber se uma palavra é desconhecida, ou por não ter aparecido no treinamento ou por não ter aparecido no treinamento com uma determinada etiqueta

texto é o texto para o qual deve ser calculado o número de desconhecidas

arquivosaída é o arquivo com o número de palavras desconhecidas e uma lista de quais são elas

\section{D10 Comp}

\section{Entrada:}

1) texto etiquetado pelo TreeTagger, ou TBL, ou MXPOST, ou PoSiTagger, ou Neural Elástico

2) texto manualmente etiquetado no formato palavra etiqueta

Saída: arquivo com a avaliação do etiquetador contendo: número de palavras, múmero de erros, precisão geral, precisão por etiqueta, precisão por gnupo

Finalidade: avaliar os resultados dos etiquetadores

Linha de comando: Comp $<$ texto1 $><$ texto $2><$ avaliação $>$

Onde:

texto1 é o texto etiquetado automaticamente

texto2 é o texto etiquetado manualmente 
avaliaçäo é o arquivo de saída que contém o número de palavras do texto, o número de erros, a precisão geral e as precisões por etiquetas

\section{D11 Lista}

Entrada: arquivo com a lista dos arquivos de configuração de cada um dos etiquetadores que serão comparados

Saída: arquivo com a lista dos erros cometidos da mesma forma por todos os etiquetadores

Finalidade: gerar uma lista com os erros cometidos da mesma forma por todos os etiquetadores com a etiqueta correta para aquele caso

Linha de comando: lista <listaconfig > <listaerros>

Onde:

listaconfig é o arquivo de entrada com a lista dos arquivos de configuração dos etiquetadores no formato:

etiquetador 1.txt

etiquetadidor $2 . t x t$

...

etiquetadorn.txt

Onde:

etiquetadorn.txt é o arquivo de configuração do etiquetador $\mathrm{n}$ no formato:

@tagger configuration@v1.0@

[NomeEtiquetador]

log_file=arquivolog

tagged_file=arquivoetiquetador

train_file-arquivomanual

tagset_file=conjuntoetiquetas

Onde:

arquivolog é o arquivo gerado por este programa que contém os dados da avaliação do etiquetador - - precisão geral e precisão por etiquetas

arquivoetiquetador é o arquivo etiquetado pelo etiquetador no formato palavra_etiqueta

arquivomanual é o arquivo etiquetado manualmente no formato palavra_etiqueta

conjuntoetiquetas é o conjunto de etiquetas.

listaerros é o arquivo de saída no formato: palavra etiqueta1 etiqueta2 ... etiquetan etiquetacorreta. Onde etiqueta 1 é a etiqueta de saída do etiquetador 1 , etiqueta2 é a etiqueta de saida do etiquetador2, etiquetan é a etiqueta de saída do etiquetadorn e etiquetacorreta é a etiqueta do texto manualmente etiquetado.

\section{D12 Lista2}

Entrada: arquivo com a lista dos arquivos de configuração de cada um dos etiquetadores que serão comparados

Saída: arquivo com a lista dos casos em que todos os etiquetadores erraram

Finalidade: gerar uma lista com os em que todos os etiquetadores erraram

Linha de comando: lista $2<$ listaconfig $><$ listaerros $>^{30}$

\section{D13 Bootstraping}

Entrada: Corpus manualmente etiquetado no formato palavra_etiqueta

\footnotetext{
30 Para a ferramento Lista2 os arquivos listoconfig e listaerros säo como os da ferramenta Listal
} 
Saida: $\mathrm{n}$ pares de corpus de treinamento (.bs) e teste (.bst) no formato palavra_etiqueta

Finalidade: gerar uma aproximação da precisão geral verdadeira utilizando o método $e 0$ bootstraping descrito na Seção 4.1.3.1

Linha de comando: bootstrap $<$ corpus $><n>$

Onde:

corpus é o corpus a partir do qual o programa irá gerar n corpus de treinamento e teste

$n$ é o número de duplas corpus de treinamento/corpus de teste que deverá ser gerado

\section{D14 Combin}

Entrada: arquivos etiquetados por dois etiquetadores

Saída: a taxa de complementaridade dos etiquetadores

Finalidade: verificar qual é a taxa de complementaridade entre dois etiquetadores

Linha de comando: combin <texto1 ><texto2>

Onde:

Texto1: é o texto etiquetado pelo etiquetador 1

Texto2: é o texto etiquetado pelo etiquetador 2

\section{D15 Random}

Entrada: arquivos etiquetados pelos etiquetadores que serão combinados

\section{Saida:}

1) arquivo com o resultado da combinação no formato palavra_etiqueta

2) arquivo com a avaliação da combinação com o número de palavras, número de palavras que todos os etiquetadores etiquetaram corretamente, número de palavras que todos os etiquetadores etiquetaram errado, número de vezes em que a maioria dos etiquetadores etiqueta corretamente, número de vezes em que a minoria dos etiquetadores etiqueta corretamente, número de vezes que pelo menos um dos etiquetadores etiqueta corretamente, precisão geral obtida pelo método de combinação, precisão geral que poderia ter sido alcançada, precisão geral de cada etiquetador individual, precisão por etiquetas do método e dos etiquetadores.

Finalidade: combinar as saidas de vários etiquetadores aleatoriamente e avaliar os resultados desta combinação

Linha de comando: random <listataggers $><$ textocombinado $><$ avalcombinacao $>$ Onde:

listataggesr lista com os arquivos de configuração dos etiquetadores no formato:

etiquetador 1. txt

etiquetador $2 . \mathrm{txt}$

etiquetadorn.txt

Onde:

etiquetadorn.txt é o arquivo de configuração do etiquetador $\mathrm{n}$ no formato:

@tagger configuration@v1.0@

[NomeEtiquetador]

log_file=arquivolog

tagged file=arquivoetiquetador

train_file-arquivomanual

tagset_file=conjuntoetiquetas 
Onde:

arquivolog é o arquivo gerado por este programa que contém os dados da avaliação do etiquetador — precisão geral e precisão por etiquetas

arquivoetiquetador é o arquivo etiquetado pelo etiquetador no formato palavra_etiqueta

arquivomanual é o arquivo etiquetado manualmente no formato palavra_etiqueta

conjuntoetiquetas é o conjunto de etiquetas.

textocombinado é o arquivo com o texto etiquetado através da combinação aleatória das saidas

dos etiquetadores

avalcombinação é o arquivo que contém a avaliação do método de combinação

\section{D16 Majority ${ }^{31}$}

Finalidade: combinar as saídas de vários etiquetadores utilizando o método Majorityl descrito no Capitulo 5

Linha de comando: majority <listataggers $><$ textocombinado $><$ avalcombinacao $>$

\section{D17 Simplev}

Finalidade: combinar as saídas de vários etiquetadores utilizando o método Majority2 descrito no Capitulo 5

Linha de comando: simplev <listataggers ><textocombinado><avalcombinacao >

\section{D18 Major}

Finalidade: combinar'as saídas de vários etiquetadores utilizando o método Majority3 descrito no Capítulo 5

Linha de comando: major <listataggers><textocombinado><avalcombinacao >

\section{D19 Totprec}

Entrada: arquivos etiquetados pelos etiquetadores que serão combinados e corpus de calibração

\section{Saida:}

1) arquivo com o resultado da combinação no formato palavra_etiqueta

2) arquivo com a avaliação da combinação com o número de palavras, número de palavras que todos os etiquetadores etiquetaram corretamente, número de palavras que todos os etiquetadores etiquetaram errado, número de vezes em que a maioria dos etiquetadores etiqueta corretamente, número de vezes em que a minoria dos etiquetadores etiqueta corretamente, número de vezes que pelo menos um dos etiquetadores etiqueta corretamente, precisão geral obtida pelo método de combinação, precisão geral que poderia ter sido alcançada, precisão geral de cada etiquetador individual, precisão por etiquetas do método e dos etiquetadores.

Finalidade: combinar as saidas de vários etiquetadores utilizando o método TotPrecision descrito no Capítulo 5

Linha de comando: totprec <listataggers><textocombinado><avalcombinacao> Onde:

\footnotetext{
${ }^{31}$ As definiçóes de entrada, saida, listatagger, textocombinada e avalcombinaçäo sāo as mesmas da ferramenta DI5 e também valem para os ferramentas 017 e 018 .
} 
listataggers lista com os arquivos de configuração dos etiquetadores no formato:

etiquetadorl.txt

etiquetador $2 . t x t$

etiquetadorn.txt

Onde:

etiquetadorn.txt é o arquivo de configuração do etiquetador $\mathrm{n}$ no formato:

@tagger configuration@v1.0@

[NomeEtiquetador]

log_file=arquivolog

tagged_file=arquivoetiquetador

train_file=arquivomanual

tune_man_file $=$ calibraman

tune train_file $=$ calibraet

tagset_file $=$ conjuntoetiquetas

[

Onde:

arquivolog é o arquivo gerado por este programa que contém os dados da avaliação do etiquetador — precisão geral e precisão por etiquetas

arquivoetiquetador é o arquivo etiquetado pelo etiquetador no formato palavra_etiqueta

arquivomanual é o arquivo etiquetado manualmente no formato palavra_etiqueta

calibraman é o corpus de calibração no formato palavra_etiqueta

calibraet é o corpus de calibração etiquetado pelo etiquetador no formato palavra_etiqueta

conjuntoetiquetas é o conjunto de etiquetas.

textocombinado é o arquivo com o texto etiquetado através da combinação aleatória das saídas dos etiquetadores

avalcombinação é o arquivo que contém a avaliação do método de cọmbinação

\section{D20 Tagprec T2 $^{32}$}

Finalidade: combinar as saídas de vários etiquetadores utilizando o método TagPrecision descrito no Capítulo 5

Linha de comando: tagprec <listataggers><textocombinado><avalcombinacao>

\section{D21 Precall}

Finalidade: combinar as saídas de vários etiquetadores utilizando o método Precision-Recall descrito no Capítulo 5

Linha de comando: precall <listataggers $><$ textocombinado><avalcombinacao $>$

\section{D22 Pairwise}

Finalidade: combinar as saídas de vários etiquetadores utilizando o método TagPair descrito no Capítulo 5

Linha de comando: pairwise $<$ listataggers > <textocombinado><avalcombinacao > 


\section{D23 Stack pair}

Finalidade: combinar as saídas de vários etiquetadores utilizando o método Tags descrito no Capitulo 5

Linha de comando: stack_pair <listataggers $><$ textocombinado $><a v a l c o m b i n a c a o>$

\section{D24 Stack_pair_word}

Finalidade: combinar as saidas de vários etiquetadores utilizando o método Tags ${ }^{+}$word descrito no Capitulo 5

Linha de comando: stack_pair_word <listataggers><textocombinado><avalcombinacao $>$

\section{D25 Picktag}

Finalidade: combinar as saídas de vários etiquetadores utilizando o método Pick tag descrito no Capitulo 5

Linha de comando: picktag <listataggers><textocombinado><avalcombinacao>

\section{D26 Picktagger}

Finalidade: combinar as saídas de vários etiquetadores utilizando o método Pick tagger descrito no Capitulo 5

Linha de comando: picktagger<listataggers $><$ textocombinado $><$ avalcombinacao $>$

\section{D27 Bagging}

Entrada: Corpus de treinamento manualmente etiquetado no formato palavra_etiqueta

Saída: $\mathrm{n}$ corpus de treinamento

Finalidade: gerar aleatoriamente n corpus de treinamento a partir do corpus original e com o mesmo tamanho do corpus original para serem utilizados no método de combinação bagging descrito no capítulo 5

Linha de comando: bagging <corpustrein $><n>$

Onde:

corpustrein é o corpus de treinamento a partir do qual o programa irá gerar os $\mathbf{n}$ corpus de treinamento

$n$ é o número de corpus de treinamento que deverá ser gerado

\footnotetext{
${ }^{32}$ As definiçōes de entrada, saída, listotagger, textocombinado e avalcombinaçāo săo as mesmas da ferramenta D/9 e também valem para as ferramentas D21, D22, D23, D24, D25 e D26.
} 


\section{GLOSSÁRIO}

\section{Algoritmo back-propagation}

É um algoritmo supervisionado, em que as instâncias de treinamento (entrada, saída desejada) são utilizadas por um mecanismo de correçāo de erros cuja peculiaridade é o aprendizado dos pesos da rede em duas fases - chamadas de fase forward e fase backward. A fase forward é utilizada para definir a saída para um dado padräo de entrada (Braga et al., 1998). Dada uma rede com n camadas, o algoritmo seria como o mostrado abaixo.

\section{$\underline{\text { Repita }}$}

Para cada instância de treinamento propague as entradas pela rede

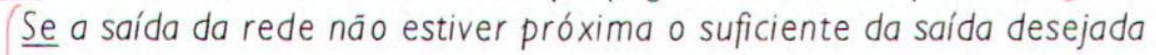
então

Para cada camada da rede, começando na camada n até a camada I Backward $\frac{\text { Para cada nó nesta camada }}{\text { Ajuste os pesos do nó }}$

Até que a saída esteja próxima o suficiente da saída desejada para cada instância

\section{Algoritmo da Freqüência Relativa}

Faz a estimativa dos parâmetros de um HMM, baseando-se nas freqüências dos padrôes que ocorrem em um dado corpus etiquetado. Calcula-se a freqüência com que uma palavra $p$, ocorre com a etiqueta tagi (freqüência lexical) e o número de vezes de que uma etiqueta tag é precedida pelas etiquetas $\operatorname{tag}_{i-2}$ e $\operatorname{tag}_{i-1}$ (freqüência contextual). 


\section{Algoritmo de Viterbi}

É uma maneira simples e otimizada de fazer o cálculo do caminho mais provável (sequência de estados percorridos para gerar um período). Analisa um símbolo da seqüência a cada espaço de tempo, começando pelo símbolo inicial. Para o símbolo que está sendo analisado o algoritmo calcula o caminho mais provável para chegar a cada um dos estados existentes ou seja, é feito o cálculo do melhor caminho resultante em cada um dos estados (Viterbi, 1967).

\section{Algoritmo Forward-Backward}

É utilizado para fazer o treinamento de HMMs. Utiliza probabilidades forward e backward para ajustar os parâmetros do HMM, de modo que seja atribuída a maior probabilidade possivel a seqüência de treinamento analisada. Calcula recursivamente dois conjuntos de probabilidades: a forward e a backward. A probabilidade forward é a probabilidade de em um dado instante de tempo $(t)$, dada uma sequência de símbolos $\left\{p_{1}, p_{2}, \ldots, p_{t-1}\right\}$ o HMM estar em um estado $S_{1}$. já a probabilidade backward é a probabilidade de estando em um estado $S_{i}$, no tempo t, se ter a sequência $\left\{p_{t}, \ldots, p_{n}\right\}$.

\section{Classes abertas}

Todas as classes de palavras que podem produzir palavras novas. Por exemplo: substantivo, verbo e adjetivo.

\section{Classes de ambigüidade}

Classes de ambiguidade são pares, triplas,...,n-ênuplas formados pelas etiquetas que possam ser associadas às palavras com mesma forma. Por exemplo, a palavra "casa", pode ser a palavra "casa" verbo ou a palavra "casa" substantivo, o mesmo vale para a palavra "mata". A classe de ambigüidade da qual forão parte estas palavras é a classe SUBSTANTIVO-VERBO, do qual também fazem parte outras palavras que têm sua ambigüidade na decisão de se são substantivo, ou verbo. 


\section{Classificadores}

Säo ferramentas de aprendizado de máquina que classificam exemplos conhecidos e novos, utilizondo-se paro isto de um modelo que é gerado do extraçäo de conhecimento de um conjunto de dados - escolha e adaptação de parâmetros do representação do modelo, através do paradigma escolhido (tais como simbólico, estatístico, e outros). 0 etiquetador morfossintático é um classificador que gera um modelo a partir de um corpus de treinamento (conjunto de dodos) paro etiquetor novos textos (novos exemplos) que podem conter palavros e contextos conhecidos e/ou desconhecidos.

\section{Corpora}

É o plural de corpus.

\section{Corpus}

A princípio qualquer coleção de mais de um texto pode ser chamada de corpus. Mas quando este termo é utilizado em lingǘrtica moderno tende a ser utilizado com mais freqüencia como uma coleçāo (conjunto) de textos representativos da língua, que tem tomanho finito, estó disponíbilizada em formato eletrônico e é um podrōo de referência.

\section{Counstraint Grammar}

Uma coleção de regras de ação-padrão, sendo apenas uma regra para cada forma ambígua de etiqueta. Cada regra especifica um ou mais padröes de contexto ou "restrições", em que a etiqueta näo é válida. Se algum destes contextos for satisfeito durante a desambigüização, a etiqueta é apagada. Estes padrões de contexto podem ser locais ou globais, e podem se referir a análises ambíguas ou näo.

\section{Dicionário Aberto}

É constituído por todas as palavras do corpus de treinamento e por suas respectivas classes de ambigüidade. 


\section{Dicionário Fechado}

É constituído por todas as palavras do corpus de treinamento e de teste e por suas respectivas classes de ambigüidade.

\section{Hidden Markov Model (HMM)}

É uma máquina de estado finito que é uma generalização da cadeia de Markav, em que assumese que as transições de estado não foram observadas. No entanta. funciona como um gerador de sequências de abservação aleatórias, conhecendo assim quais sảo as possíveis sequências.

\section{Information Gain}

Considera cada atributo isoladamente avaliando o quanto à informaçäo fornecida por este atributa contribui para se saber qual é a classificaçāo carreta - ganho de informaçāo. O ganho de infarmação que um dado atributa pode gerar é dado pela diferença de incerteza (por exemplo, entrapia) entre situoçóes sem e cam conhecimento do valor deste atributo.

\section{Máxima Entropia}

Entropia é uma medida matemática de ignarância, é inversamente proporcional à informaçāo, isto é, quando o número de informaçōes diminui a entropia aumenta (alta entropia é sinônimo de alta ignorância). O conceito de entropia começou a ser utilizada no século 19 por J. Willard Gibbs para inferir propriedades termodinâmicas de sistemas físicos de seus valares de energia.

De acordo com a segunda lei da termodinâmica, entropia em um sistema fechado tende ao máximo (total desordem), de forma que a informaçāo se dissipa mas näo é alcançada. Uma situaçāo bem estruturada e arganizada que tenha baixa entropia precisa de menas informaçäo para ser descrita, mas pode ser também resultado da adição de mais informaçäo ao sistema. Máxima entropia pressupóe que todas as probabilidades säo iguais e independentes umas das outras. Mínima entropia existe quando se esperar encontrar uma única possibilidade.

\section{Modelo de Markov}

É um processo estocóstica com instantes discretas em que dada uma sequência aleatória de 
varióveis $X=\left(X_{1}, \ldots, X_{T}\right)$ que assumem valores de algum conjunto finito $S=\left\{s_{1}, \ldots, s_{N}\right\}$, vale a seguinte propriedade:

1) $P\left(X_{t+1}=s_{k} \mid X_{1}, \ldots X\right)=P\left(X_{t+1}=s_{k} \mid X\right)$

$=P\left(X_{2}=s_{k} \mid X_{1}\right)$

Chama-se $X$ de cadeia de Markov ou diz-se que $X$ tem as propriedades de Markov.

Ou seja, neste modelo uma variável depende somente da variável anterior e influencia somente a variável seguinte.

\section{Modelo de n-gramas}

Torna possivel analisar a "vizinhança" de uma palavra, o contexto. Define que, para cada palavra, deverão ser analisadas as ' $n-1$ ' vizinhas. Os mais utilizados são o bigrama (Church \& Gale, 1991) (é analisada apenas a palavra anterior) e trigrama (são analisadas as duas palavras anteriores).

\section{Período}

O termo sentence do inglês refere-se a período apesar de costumar ser traduzido equivocadamente como sentença. Um período é composto por um ou mais oraçōes e/ou frases e tem como características:

- apresentação de um sentido ou significado completo;

- encerrar-se por meio de certos símbolos de pontuação.

\section{Redes MLP (Multilayer Perceptron)}

Redes MLP são redes perceptron multi-camadas utilizadas para resolver problemas nāo linearmente separáveis (Braga et al., 1998). 